UNIVERSIDADE DE SÃO PAULO

ESCOLA DE ENGENHARIA DE SÃO CARLOS

DEPARTAMENTO DE TRANSPORTES

\title{
AVALIAÇÃO DA EFICIÊNCIA DE MÉTODOS DE COORDENAÇÃO SEMAFÓRICA EM VIAS ARTERIAIS
}

\section{CRISTIANE BIAZZONO DUTRA}

\author{
Dissertação apresentada à Escola de \\ Engenharia de São Carlos, da Universidade \\ de São Paulo, como parte dos requisitos para \\ obtenção do título de Mestre em Engenharia \\ Civil com ênfase em Transportes.
}

Orientador: Prof. Dr. Sergio Henrique Demarchi

São Carlos

2005 


\section{AGRADECIMENTOS}

Agradeço ao bom Deus e à querida mãe Maria, que me abençoam com saúde e disposição para viver e aprender ...

Minha sincera gratidão à família amada, Salvador, Marilda, Sérgio e Luciane - os “Ceneviva-Biazzono”, que desde sempre são meu suporte, estímulo e apoio incondicional. Amo vocês.

Ao meu marido Rogério Dutra, companheiro e amante, que em todos estes anos me apoiou e me cuidou, com amor, paciência e compreensão.

Ao Prof. Dr. Sergio Henrique Demarchi, pela orientação incansável desta dissertação, por sua dedicação e criatividade. Agradeço pelo incentivo e inspiração, regados de refinado bom humor, independente de hora (altas da madrugada pela Internet) e local (Londrina, Maringá, São Carlos, São Paulo ou Brasília), sempre esteve me presenteando com seu conhecimento e me impulsionando através de novas idéias e sugestões.

Ao Prof. Dr. José Reynaldo A. Setti, pela colaboração e pelas oportunidades que me ofereceu nesta caminhada, desde a época da Especialização até o cuidado da escolha certeira de minha orientação.

Agradeço à Prof. Dra. Maria Alice Prudêncio Jacques, ao Prof. Dr. Antonio Clóvis Pinto Ferraz (Coca) e ao Prof. Dr. Carlos Felipe Grangeiro Loureiro, pela atenção e generosidade nas sugestões para melhoria do conteúdo desta dissertação.

Sou grata aos professores, funcionários e alunos do Departamento de Transportes da Escola de Engenharia de São Carlos / USP, onde encontrei pessoas realmente comprometidas com a pesquisa, em um lugar privilegiado pelo encanto do conhecimento e de inesquecíveis amizades.

Ao IPPUL - Instituto de Pesquisa e Planejamento Urbano de Londrina, pelo apoio na realização do programa de mestrado, e em especial, diretores e colegas de trabalho, que souberam compreender a importância desta pesquisa também para nossa cidade.

A todos que consciente ou inconscientemente participaram e colaboraram com este trabalho. 


\section{SUMÁRIO}

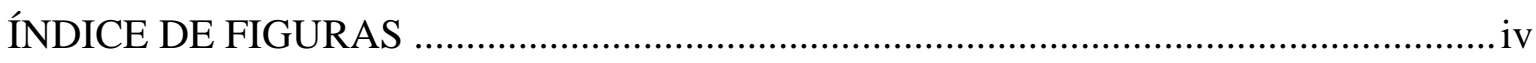

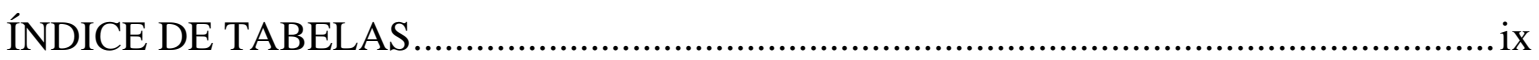

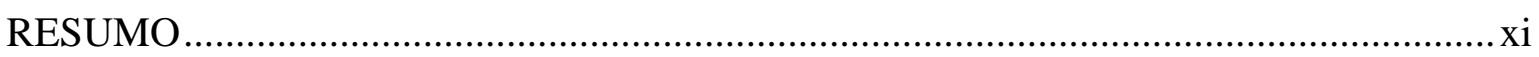

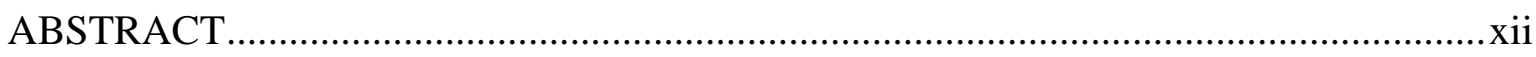

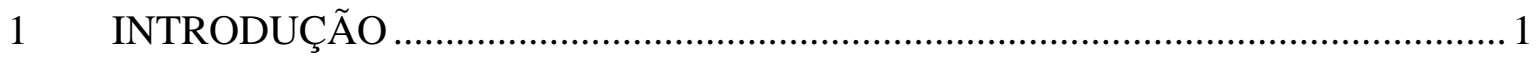

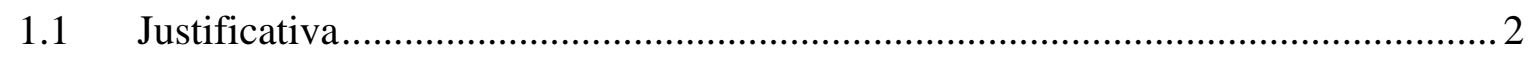

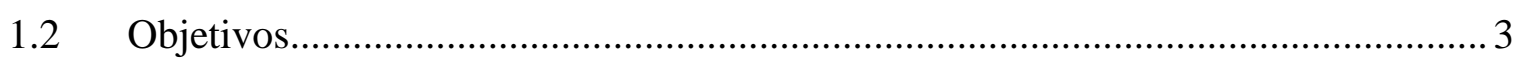

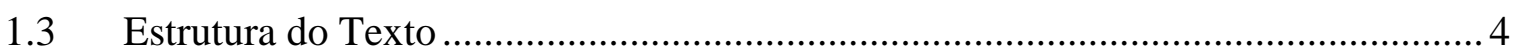

2 COORDENAÇÃO SEMAFÓRICA EM CIDADES BRASILEIRAS ......................... 6

2.1 Coordenação Semafórica nas Capitais Brasileiras ........................................................ 9

2.2 Coordenação Semafórica nas Cidades Brasileiras de Médio Porte...........................11

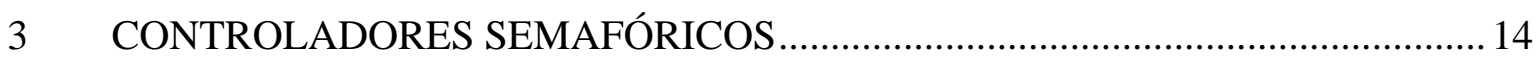

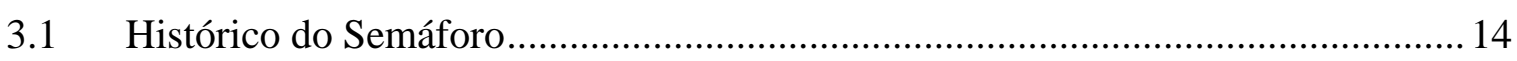

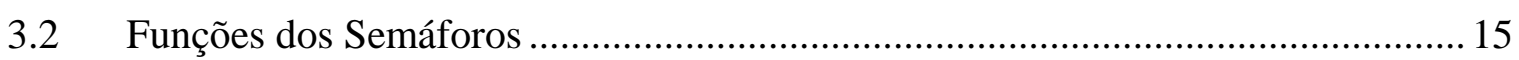

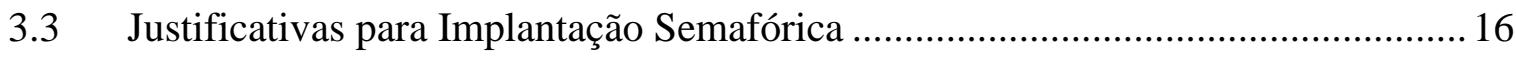

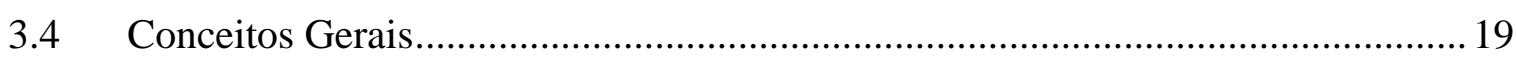

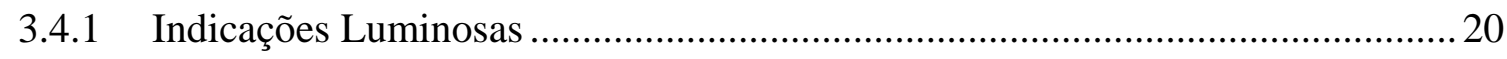

3.4.2 Diagrama de Estágios e de Tempos ................................................................ 21

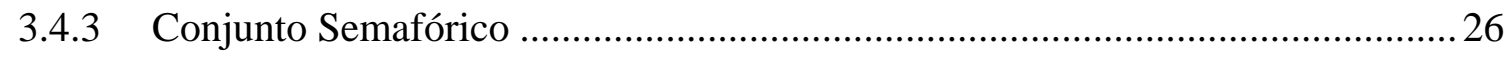

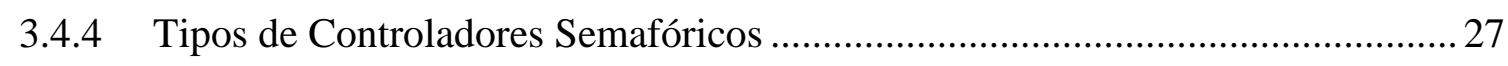

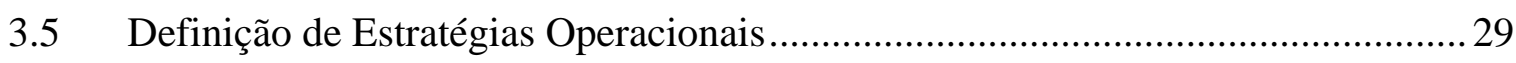

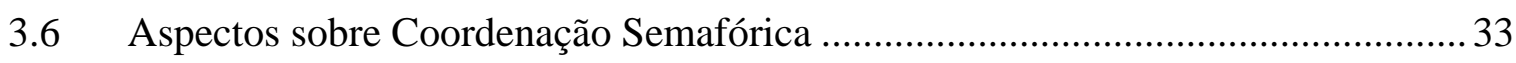

3.6.1 Benefícios da Coordenação Semafórica.................................................................. 34

4 MÉTODOS DE COORDENAÇÃO SEMAFÓRICA ……………………………......36

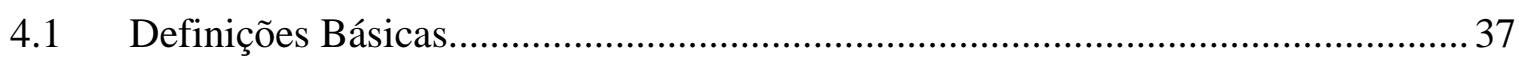

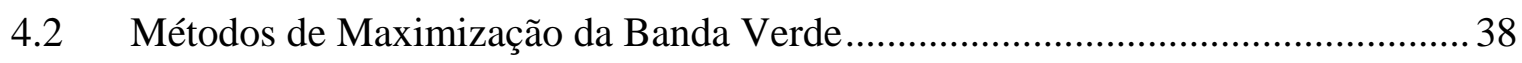

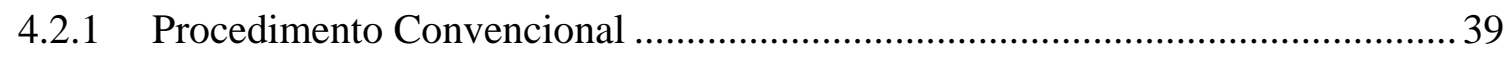

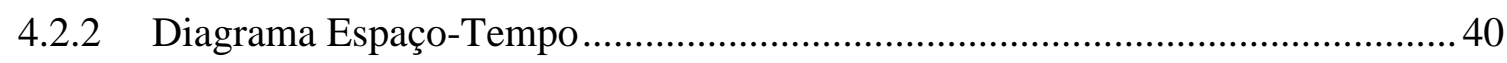

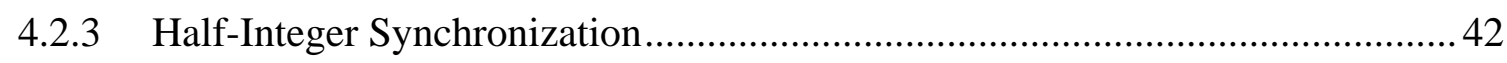

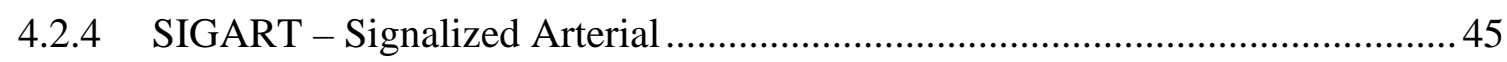

4.2.5 Interferência de Brooks / Bleyl ......................................................................... 46

4.2.6 MILP - Mixed-Integer Linear Programming.................................................... 46 
4.2.7 PASSER - Progression Analysis and Signal System Evaluation Routine .......... 50

4.2.8 MAXBAND - Maximal Bandwidth Program ................................................... 52

4.2.9 BANDTOP - Bandwidth of Timing Optimization Program ............................... 53

4.2.10 MULTIBAND - Variable-Bandwidth Arterial Progression Scheme ............... 55

4.2.11 U-BAND / V-BAND - Uniform and Variable Bandwidth Arterial Progression. 57

4.2.12 MULTIBAND-96 - Variable-Bandwith Progression Optimization of

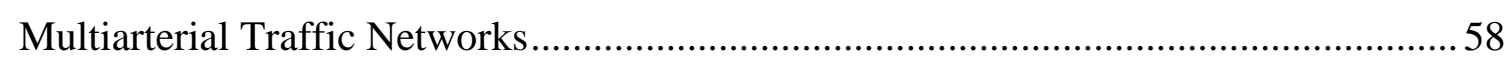

4.3 Métodos de Minimização de Atrasos e Paradas ..................................................... 58

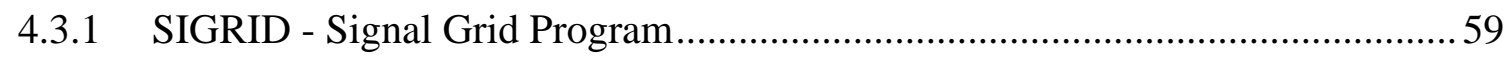

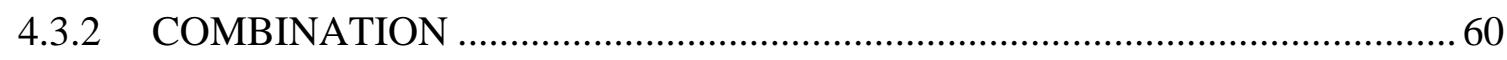

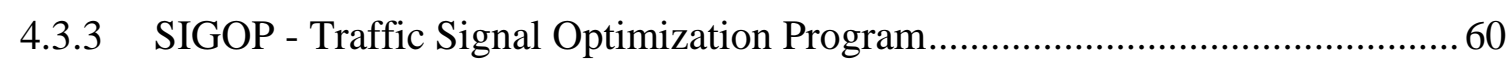

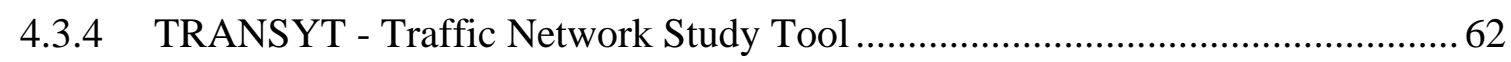

4.3.5 MITROP - Mixed-Integer Traffic Optimization Program ...................................66

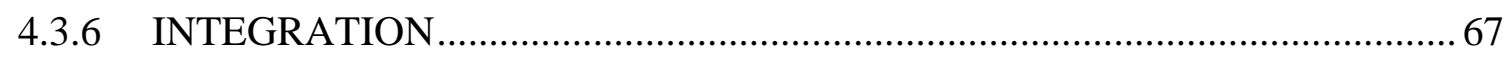

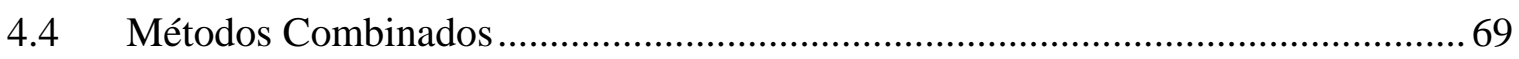

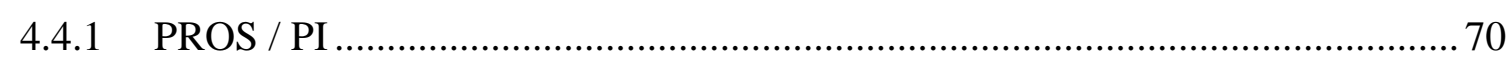

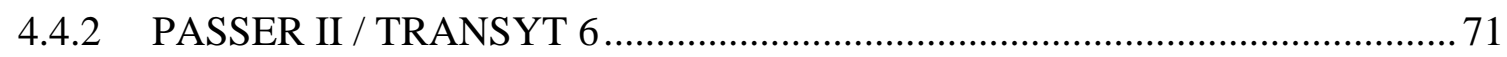

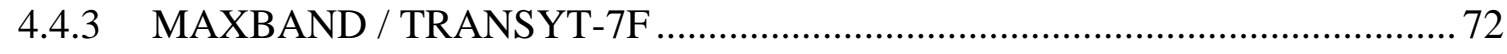

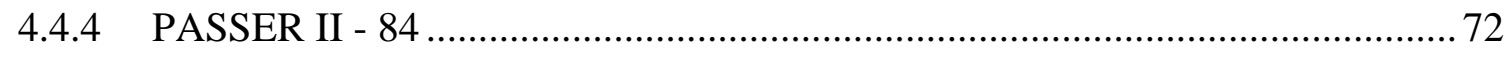

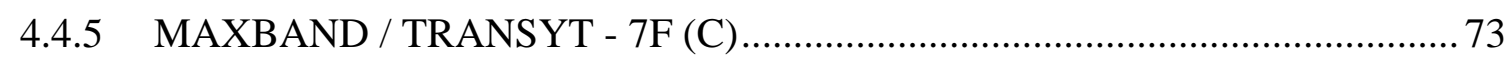

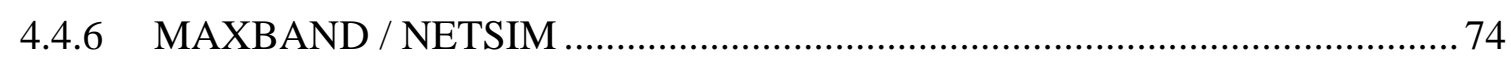

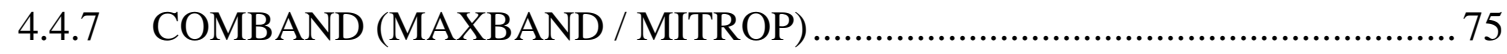

4.5 Esquema Geral dos Métodos Computacionais de Coordenação Semafórica.......... 76

5 SBAND: UM APLICATIVO PARA MAXIMIZAÇÃO DA BANDA VERDE EM CORREDORES SEMAFORIZADOS................................................................. 78

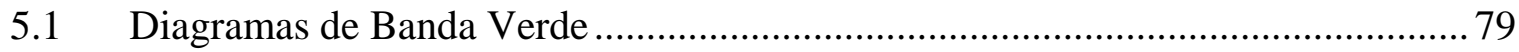

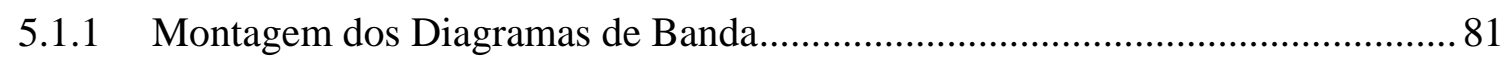

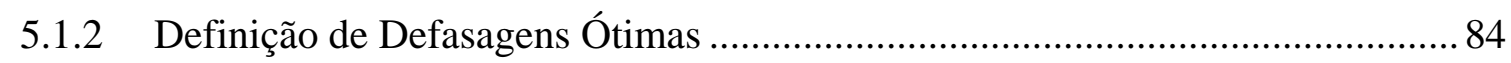

5.1.3 Determinação das Defasagens para Bandas Iguais ............................................ 84

5.2 Determinação da Banda Máxima para Mais de Dois Semáforos ............................. 84

5.2.1 Determinação de Bandas Iguais para Ambos os Sentidos .................................. 86

5.2.2 Determinação da Posição das Trajetórias que Definem a Banda Verde.............. 89

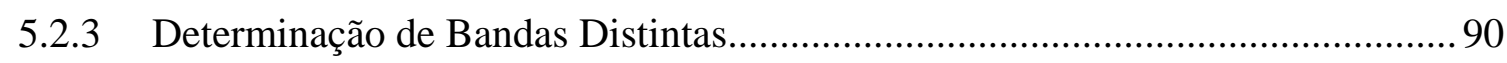

5.2.4 Montagem do Diagrama Espaço-Tempo …...................................................... 92

5.3 Considerações Finais do Capítulo .......................................................................... 92 
6 CENÁRIOS SIMULADOS PARA AVALIAÇÃO DOS MÉTODOS DE

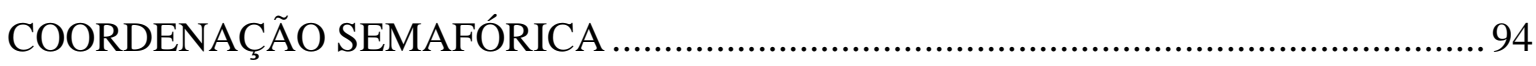

6.1 Caracterização dos Corredores Arteriais Analisados ............................................. 95

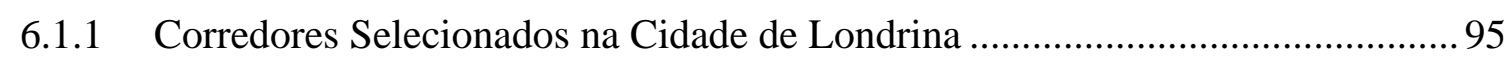

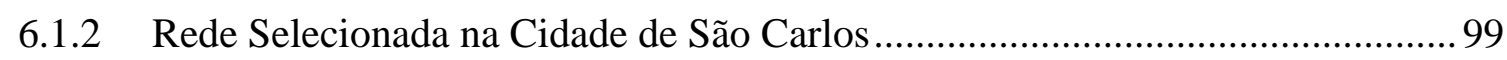

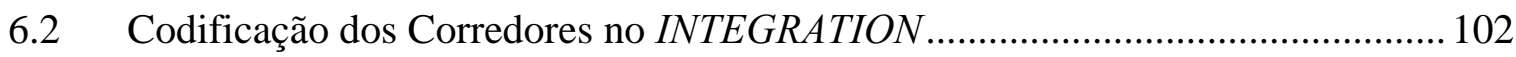

6.3 Calibração e Validação do Simulador INTEGRATION ......................................... 103

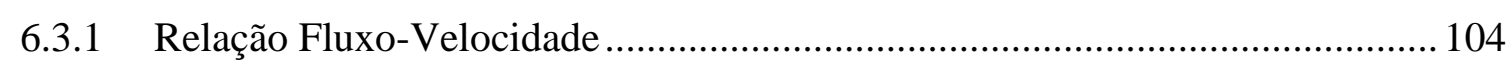

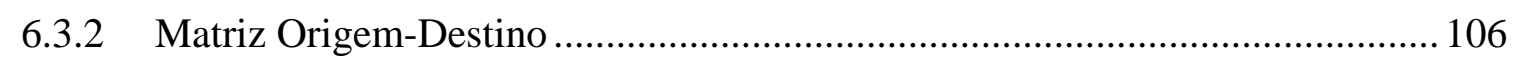

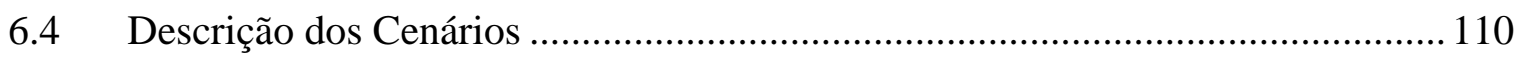

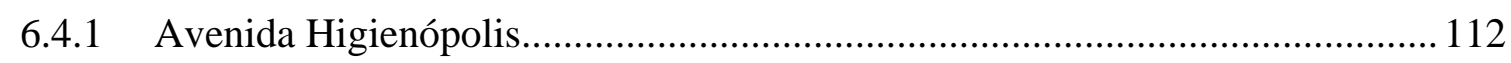

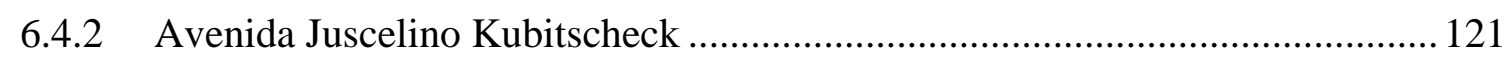

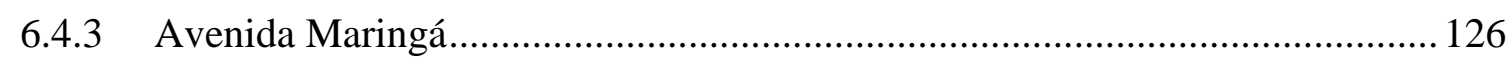

6.4.4 Rede da Cidade de São Carlos ..................................................................... 129

7 ANÁLISE DOS RESULTADOS OBTIDOS NAS SIMULAÇÕES....................... 137

7.1 Simulações dos Cenários com Demanda Real .................................................. 138

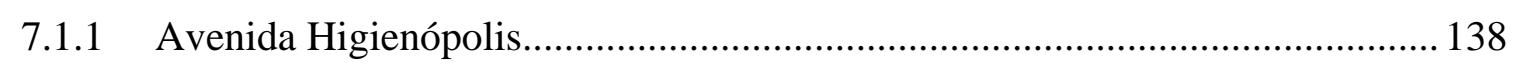

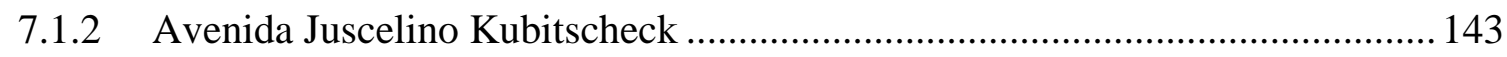

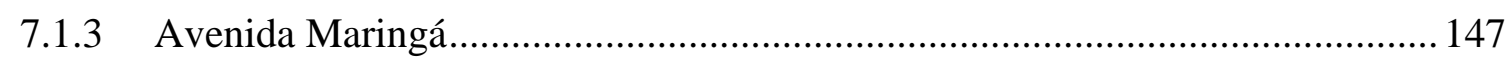

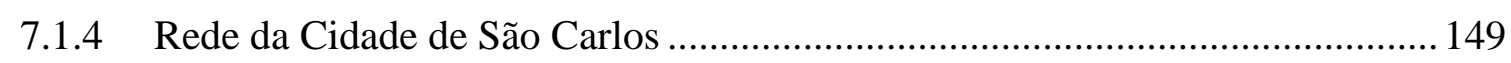

7.2 Simulações dos Cenários com Demandas Reduzidas ......................................... 154

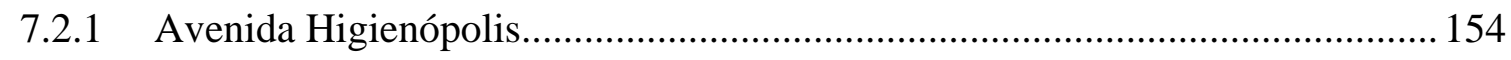

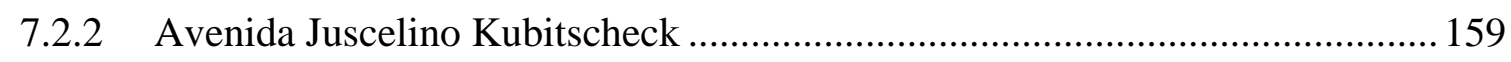

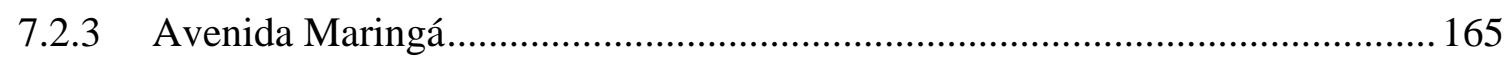

7.3 Simulações dos Cenários com Diferentes Espaçamentos entre Semáforos .......... 170

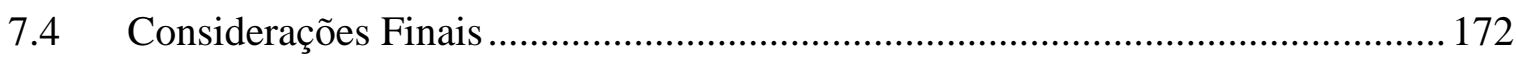

8 CONCLUSÕES E RECOMENDAÇÕES ...................................................... 177

8.1 Métodos e Programas de Coordenação Utilizados pelas Prefeituras Brasileiras .178

8.2 Revisão Bibliográfica dos Métodos de Coordenação Semafórica ........................ 179

8.3 Desenvolvimento de um Aplicativo Computacional de Coordenação

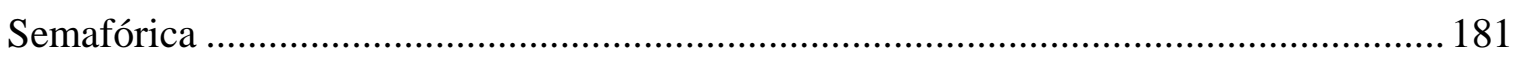

8.4 Avaliação da Eficiência dos Programas SBAND e INTEGRATION .................... 181

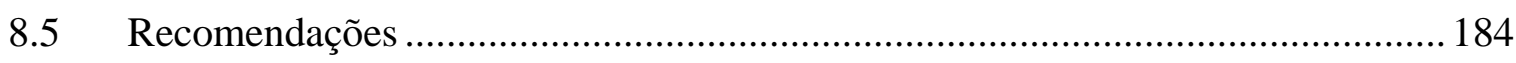

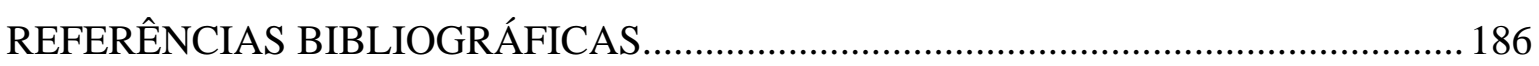




\section{ÍNDICE DE FIGURAS}

Figura 2-1: Densidade demográfica em diferentes regiões do Brasil ........................... 6

Figura 2-2: Central de controle de tráfego de Fortaleza .............................................. 11

Figura 3-1: Fotos de semáforo veicular e de pedestres.............................................. 20

Figura 3-2: Legenda dos componentes semafóricos .................................................... 22

Figura 3-3: Esquema de operação semafórica para vias de sentido único de circulação22

Figura 3-4: Esquema de operação semafórica para vias de sentido único de circulação, com fase exclusiva para pedestres ....................................................................... 23

Figura 3-5: Esquema de operação semafórica com fase exclusiva para conversão à esquerda com verde adiantado ....................................................................... 23

Figura 3-6: Esquema de operação semafórica com fase exclusiva para conversão à esquerda com verde atrasado ........................................................................... 24

Figura 3-7: Esquemas de operação semafórica alternativos ......................................... 25

Figura 3-8: Esquema de operação semafórica para vias de sentido duplo de circulação25

Figura 3-9: Esquema de operação semafórica alternativo para vias de sentido duplo de

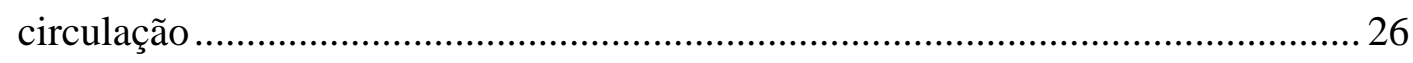

Figura 3-10: Elementos de um conjunto semafórico ................................................ 27

Figura 4-1: Variáveis utilizadas no método de maximização da banda verde ................ 38

Figura 4-2: Diagrama Espaço-Tempo para um corredor viário hipotético..................... 41

Figura 4-3: Possíveis posições dos centros dos vermelhos .......................................... 42

Figura 4-4: Diagramas espaço-tempo obtidos com Half-Integer Synchronization, para

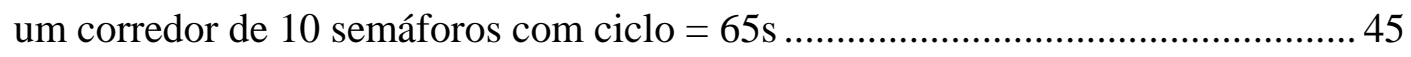

Figura 4-5: Variáveis do método Mixed-Integer Linear Programming ......................... 47

Figura 4-6: Árvore de solução do método branch-and-bound ...................................... 49

Figura 4-7: Diagrama espaço-tempo obtido com Mixed-Integer Linear Programming,

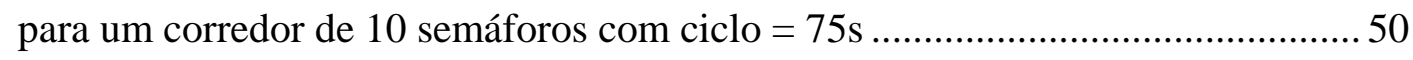

Figura 4-8: Quatro padrões para fases de conversão à esquerda ................................... 51

Figura 4-9: Diagramas espaço-tempo obtidos com programa $M A X B A N D$, para um 
corredor de 9 semáforos de duas ou múltiplas fases com ciclo $=70 \mathrm{~s}$ 53

Figura 4-10: Oito padrões para fases de conversão à esquerda 54

Figura 4-11: Diagrama espaço-tempo obtido com programa BANDTOP, para um corredor de 4 semáforos com ciclo $=80 \mathrm{~s}$

Figura 4-12: Diagramas espaço-tempo obtidos com programa MULTIBAND, para um corredor de 9 semáforos de duas ou múltiplas fases com ciclo $=70 \mathrm{~s}$. 56

Figura 4-13: Diagrama espaço-tempo obtido com o método PROS/PI, para o exemplo de 8 semáforos com ciclo $=90 \mathrm{~s}$ 71

Figura 5-1: Variáveis utilizadas no método de maximização da banda verde 79

Figura 5-2: Diagrama de banda verde $b_{i j}$ e $b_{j i}$ em função da defasagem $\theta_{i j}$ 80

Figura 5-3: Diagramas de bandas típicos para os sentidos $i-j$ e $j-i$. .81

Figura 5-4: Montagem dos diagramas de banda para os sentidos $i-j$ e $j-i$ 82

Figura 5-5: Obtenção dos diagramas de banda a partir do diagrama padrão. 83

Figura 5-6: Exemplo de interferência da posição do vermelho na definição da largura da banda . 85

Figura 5-7: Montagem da planilha para determinação da banda máxima global..... 86

Figura 5-8: Árvore de busca da banda máxima para o sistema de 10 semáforos ..... 89

Figura 5-9: Coordenação de uma rede composta por 10 interseções semaforizadas com ciclo $=65 \mathrm{~s}, b^{i-j}=23,1 \mathrm{~s}, b^{j-i}=7,5 \mathrm{~s}$ 91

Figura 5-10: Dados de entrada e resultados gerados pelo programa SBAND 92

Figura 6-1: Vista da cidade de Londrina .95

Figura 6-2: Corredores selecionados na cidade de Londrina, Paraná. 96

Figura 6-3: Características da Avenida Higienópolis. 97

Figura 6-4: Características da Avenida Juscelino Kubitscheck .98

Figura 6-5: Características da Avenida Maringá 99

Figura 6-6: Vista da cidade de São Carlos. 99

Figura 6-7: Corredores da rede selecionada na cidade de São Carlos, São Paulo......... 100

Figura 6-8: Características da rede de São Carlos 101

Figura 6-9: Relação fluxo-velocidade e densidade-velocidade obtida 104 
Figura 6-10: Diagrama Espaço-Tempo simultâneo da Av. Higienópolis. 113

Figura 6-11: Diagrama Espaço-Tempo vigente da Av. Higienópolis 113

Figura 6-12: Diagramas Espaço-Tempo gerados pelo SBAND com bandas iguais para a Av. Higienópolis. 114

Figura 6-13: Diagramas Espaço-Tempo gerados pelo SBAND com bandas diferentes para a Av. Higienópolis 114

Figura 6-14: Diagramas Espaço-Tempo gerados pelo SBAND em duas etapas para a Av. Higienópolis 115

Figura 6-15: Diagrama Espaço-Tempo gerado pelo INTEGRATION para a Av. Higienópolis. 116

Figura 6-16: Diagramas Espaço-Tempo simultâneo e gerado pelo SBAND com bandas iguais para a Av. Higienópolis supondo distância de 220 metros entre semáforos 116

Figura 6-17: Diagramas Espaço-Tempo simultâneo e gerado pelo SBAND com bandas iguais para a Av. Higienópolis supondo distância de 320 metros entre semáforos 117

Figura 6-18: Diagramas Espaço-Tempo simultâneo e gerado pelo SBAND com bandas iguais para a Av. Higienópolis supondo distância de 420 metros entre semáforos 118

Figura 6-19: Diagramas Espaço-Tempo simultâneo, gerado pelo SBAND com bandas iguais e pelo INTEGRATION respectivamente, para a Av. Higienópolis supondo distância de 520 metros entre semáforos

Figura 6-20: Diagrama Espaço-Tempo simultâneo da Av. Juscelino Kubitscheck ..... 121

Figura 6-21: Diagrama Espaço-Tempo vigente da Av. Juscelino Kubitscheck 122

Figura 6-22: Diagramas Espaço-Tempo gerados pelo SBAND com bandas iguais para a Av. Juscelino Kubitscheck 123

Figura 6-23: Diagramas Espaço-Tempo gerados pelo SBAND com bandas diferentes para a Av. Juscelino Kubitscheck 123

Figura 6-24: Diagramas Espaço-Tempo gerados pelo SBAND em duas etapas para a Av. Juscelino Kubitscheck. 124

Figura 6-25: Diagrama Espaço-Tempo gerado pelo INTEGRATION para a Av. Juscelino Kubitscheck 124 
Figura 6-26: Diagrama Espaço-Tempo simultâneo da Avenida Maringá 126

Figura 6-27: Diagrama Espaço-Tempo vigente da Avenida Maringá.. 127

Figura 6-28: Diagramas Espaço-Tempo gerados pelo SBAND com bandas iguais para a Avenida Maringá

Figura 6-29: Diagramas Espaço-Tempo gerados pelo SBAND com bandas diferentes para a Avenida Maringá. 128

Figura 6-30: Diagramas Espaço-Tempo gerados pelo SBAND em duas etapas para a Avenida Maringá 128

Figura 6-31: Diagrama Espaço-Tempo gerados pelo INTEGRATION para a Avenida Maringá. 129

Figura 6-32: Diagramas Espaço-Tempo simultâneos da rede de São Carlos 131

Figura 6-33: Diagramas Espaço-Tempo vigentes da rede de São Carlos 132

Figura 6-34: Diagramas Espaço-Tempo gerados pelo SBAND para a rede de São Carlos, com velocidades de 40-50-50 km/h. 133

Figura 6-35: Diagramas Espaço-Tempo gerados pelo SBAND para a rede de São Carlos, com velocidades de 30-40-40 km/h. 134

Figura 6-36: Diagramas Espaço-Tempo gerados pelo INTEGRATION para a rede de São Carlos 135

Figura 7-1: Médias das medidas de desempenho para a Avenida Higienópolis 139

Figura 7-2: Medidas operacionais de eficiência por tramo da Avenida Higienópolis . 142 Figura 7-3: Médias das medidas de desempenho para a Avenida Juscelino Kubitscheck 144

Figura 7-4: Medidas operacionais de eficiência por tramo da Avenida Juscelino Kubitscheck 146

Figura 7-5: Médias das medidas de desempenho para a Avenida Maringá 147

Figura 7-6: Medidas operacionais de eficiência por tramo da Avenida Maringá. 150

Figura 7-7: Médias das medidas de desempenho para a rede de São Carlos 151

Figura 7-8: Medidas operacionais de eficiência por tramo da rede de São Carlos 153

Figura 7-9: Valores de tempo médio de percurso obtidos para cada porcentagem de viagens na Avenida Higienópolis 154 
Figura 7-10: Valores de atraso médio obtidos para cada porcentagem de viagens na Avenida Higienópolis 156

Figura 7-11: Valores de número de paradas obtidos para cada porcentagem de viagens na Avenida Higienópolis . 158

Figura 7-12: Valores de tempo médio de percurso obtidos para cada porcentagem de viagens na Avenida Juscelino Kubitscheck.... 160

Figura 7-13: Valores de atraso médio obtidos para cada porcentagem de viagens na Avenida Juscelino Kubitscheck.

Figura 7-14: Valores de número de paradas obtidos para cada porcentagem de viagens na Avenida Juscelino Kubitscheck 164

Figura 7-15: Valores de tempo médio de percurso obtidos para cada porcentagem de viagens na Avenida Maringá 165

Figura 7-16: Valores de atraso médio obtidos para cada porcentagem de viagens na Avenida Maringá 167

Figura 7-17: Valores de número de paradas obtidos para cada porcentagem de viagens na Avenida Maringá. 169 
Tabela 2-1: Frota de veículos por Estado em junho de 2003 .7

Tabela 2-2: Municípios brasileiros das regiões Sul e Sudeste com frota superior a 30.000 veículos em junho de 2003

Tabela 2-3: Informações sobre o sistema de controle semafórico em capitais brasileiras9

Tabela 2-4: Informações relativas ao sistema semafórico em cidades de médio porte .. 12

Tabela 3-1: Parâmetros para definição do Índice de Interdependência.......................... 31

Tabela 3-2: Parâmetros para definição do Índice de União............................................ 32

Tabela 4-1: Síntese dos métodos computacionais de coordenação semafórica............... 76

Tabela 5-1: Características da rede semaforizada exemplo......................................... 85

Tabela 5-2: Busca da solução ótima para a rede de 10 semáforos ................................ 89

Tabela 6-1: Resumo de características dos corredores arteriais de Londrina................. 97

Tabela 6-2: Resumo de características da rede de São Carlos..................................... 101

Tabela 6-3: Fluxos de saturação na cidade de Londrina.............................................. 105

Tabela 6-4: Fluxos de saturação na cidade de São Carlos............................................ 106

Tabela 6-5: Densidades de congestionamento na cidade de São Carlos ....................... 106

Tabela 6-6: Fatores de equivalência veicular utilizados no município de Londrina .... 108

Tabela 6-7: Matrizes origem-destino dos corredores de Londrina ............................... 109

Tabela 6-8: Matriz origem-destino da rede de São Carlos ........................................... 110

Tabela 6-9: Cenários simulados para a Avenida Higienópolis..................................... 120

Tabela 6-10: Cenários simulados para a Avenida Juscelino Kubitscheck ................... 125

Tabela 6-11: Cenários simulados para a Avenida Maringá......................................... 130

Tabela 6-12: Cenários simulados para a rede de São Carlos ........................................ 136

Tabela 7-1: Quadro comparativo entre as medidas de desempenho para a Avenida Higienópolis............................................................................................. 140

Tabela 7-2: Quadro comparativo entre as medidas de desempenho para a Avenida Juscelino Kubitscheck ......................................................................................... 144 
Tabela 7-3: Quadro comparativo entre as medidas de desempenho para a Avenida Maringá..... 148

Tabela 7-4: Quadro comparativo entre as medidas de desempenho para a rede da cidade de São Carlos 152

Tabela 7-5: Percentuais de redução ou acréscimo nos tempos médios de percurso obtidos na Avenida Higienópolis. 155

Tabela 7-6: Percentuais de redução ou acréscimo nos atrasos médios obtidos na Avenida Higienópolis 157

Tabela 7-7: Percentuais de redução ou acréscimo nos números médios de paradas obtidos na Avenida Higienópolis 159

Tabela 7-8: Percentuais de redução ou acréscimo nos tempos médios de percurso obtidos na Avenida Juscelino Kubitscheck 161

Tabela 7-9: Percentuais de redução ou acréscimo nos atrasos médios obtidos na Avenida Juscelino Kubitscheck.

Tabela 7-10: Percentuais de redução ou acréscimo nos números médios de paradas obtidos na Avenida Juscelino Kubitscheck 164

Tabela 7-11: Percentuais de redução ou acréscimo nos tempos médios de percurso obtidos na Avenida Maringá..... 166

Tabela 7-12: Percentuais de redução ou acréscimo nos atrasos médios obtidos na Avenida Maringá 168

Tabela 7-13: Percentuais de redução ou acréscimo nos números médios de paradas obtidos na Avenida Maringá. 170

Tabela 7-14: Quadro comparativo entre as medidas de desempenho para diferentes espaçamentos entre semáforos. 171

Tabela 7-15: Características das redes simuladas em Londrina e São Carlos 173

Tabela 7-16: Resumo dos percentuais de redução ou acréscimo nas medidas de desempenho para as demandas reais. 173

Tabela 7-17: Resumo dos percentuais de redução ou acréscimo nas medidas de desempenho para demandas reduzidas 175

Tabela 8-1: Programa de coordenação recomendado de acordo com as características das vias..... 183 


\section{RESUMO}

Dutra, C. B. Avaliação da Eficiência de Métodos de Coordenação Semafórica em Vias Arteriais. São Carlos, 2005. 189 p. Dissertação (Mestrado) - Escola de Engenharia de São Carlos, Universidade de São Paulo.

Os planos de coordenação semafórica são reconhecidamente eficientes para promover a fluidez das correntes de tráfego e melhorar a qualidade operacional do sistema viário. Portanto, os técnicos responsáveis pela gestão do tráfego deveriam, sempre que possível, adotar métodos para a definição adequada das defasagens, utilizando ferramentas que auxiliem na decisão das operações. Porém, uma pesquisa realizada em cidades das regiões Sul e Sudeste sobre as estratégias de coordenação empregadas, demonstrou especialmente para municípios de porte médio que somente 13\% utilizam ferramentas computacionais para prover planos de coordenação nos semáforos monitorados por centrais. Para os demais corredores semaforizados, cerca de $27 \%$ utilizam o Diagrama Espaço-Tempo, 36\% realizam ajustes locais através da observação do tráfego, 14\% utilizam veículo-teste e 23\% não adotam esquemas de coordenação.

O objetivo desta dissertação é avaliar a eficiência de dois programas de coordenação semafórica que poderiam ser utilizados em cidades que não dispõem de técnicas mais eficientes para definir os planos semafóricos. Uma revisão bibliográfica sobre os métodos mais conhecidos foi realizada, identificando que os programas disponíveis seguem três critérios distintos: a maximização da largura da banda verde; a minimização dos atrasos e paradas; e a combinação das vantagens de ambos os critérios.

O primeiro programa, cujo nome é SBAND, consiste em uma implementação computacional do critério de maximização de banda baseada no método Half-integer Synchronization, proposto por Morgan e Little. O segundo programa é o simulador INTEGRATION, que coordena semáforos baseado no critério de minimização de atrasos e paradas. Com esses programas, foram gerados planos semafóricos para diversas condições de tráfego em vias arteriais de Londrina e São Carlos, simuladas com o INTEGRATION. A análise das medidas de desempenho - tempo de percurso, atraso médio e número médio de paradas - indica que é possível planos semafóricos melhores do que aqueles em vigência nos corredores analisados, com redução dos valores médios destas medidas. A análise sugere que o programa INTEGRATION é mais recomendado para os casos em que o fluxo de veículos é elevado e semelhante na via principal e nas transversais, enquanto o programa SBAND é recomendado quando a via principal apresenta volume de tráfego leve ou moderado, maior do que nas vias secundárias.

Palavras-chave: coordenação semafórica, defasagem, banda verde, atraso, paradas 
ABSTRACT

Dutra, C. B. Performance Analysis of Traffic Signal Synchronization Methods for Arterial Streets. São Carlos, 2005. 189 p. Dissertação (Mestrado) - Escola de Engenharia de São Carlos, Universidade de São Paulo.

Traffic signal synchronization strategies are useful to improve traffic flow mobility and level of service of arterial streets. Therefore, technicians in charge of management of the traffic system operation should take advantage of the benefits of these tools, as always as possible, in order to define the most adequate traffic signal offsets. However, interviews carried on mid-size cities of Southern and Southwestern regions of Brazil indicated that only $13 \%$ of these cities define plans for traffic signal networks, controlled by a central control room, based on any type of traffic signal coordination software. For non-controlled streets, $27 \%$ of the cities define offsets using the traditional space-time diagram, 36\% make local adjustments in a trial and error basis, $14 \%$ use a test vehicle and the remaining $23 \%$ do not use any strategy for synchronization.

Based on these findings, the objective of this master thesis is to assess the performance of two traffic signal synchronization tools that might be used in cities which do not make use of more efficient techniques to define signal plans. Literature review indicates that the available softwares are developed according to three distinct approaches: bandwidth maximization, minimization of delays and stops and combination of both previous methods.

The first software tested, named SBAND, is based on the Morgan and Little Half-Integer Synchronization algorithm, which maximizes bandwidth of signalized arterial streets. The second software is the INTEGRATION traffic simulation tool, which synchronizes traffic signals minimizing delays and stops. Different signal plans were defined by means of these two softwares, for several traffic conditions in arterial streets of Londrina and São Carlos, and simulated with INTEGRATION. The analysis of measures of effectiveness generated on the simulations - travel time, average delay and average number of stops - indicate that is possible to obtain better traffic signal plans, with reduction on the measures of effectiveness for the plans currently adopted for these arterials. The results also suggest that INTEGRATION is more recommended for scenarios when traffic flow on principal arterials is heavy and similar to the traffic on secondary streets, while SBAND is recommended for light to moderate traffic flow on main street, with through trips predominating and lighter traffic on secondary streets. Keywords: traffic signal synchronization, offsets, bandwidth, delay, number of stops 


\section{INTRODUÇÃO}

Atrasos e congestionamentos de tráfego ocorrem diariamente na maioria das cidades brasileiras de médio e grande porte, notadamente nas regiões metropolitanas, mas também nas cidades menores, causando impacto na distribuição do tráfego, na freqüência das viagens, no comportamento dos motoristas, na segurança, no uso do solo e na economia, implicando em prejuízos significativos à sociedade.

Os semáforos são implantados nas interseções entre ruas ou avenidas do sistema viário de uma cidade como forma de controle dos movimentos conflitantes e de definição do direito de passagem para os fluxos concorrentes entre veículos e também pedestres, reduzindo a probabilidade de ocorrência de acidentes e promovendo a fluidez do tráfego nestes pontos críticos e vitais das redes de transporte.

Apesar de promover a segurança e disciplinar o movimento das correntes de tráfego, os semáforos podem ocasionar desconforto aos motoristas, com o aumento no número de paradas dos veículos, no tempo de percurso, no consumo de combustível e na emissão de poluentes, além da formação de filas e da redução da velocidade média nas vias. Webster e Cobbe (1966) estimaram que os atrasos gerados pelos semáforos da Grã-Bretanha (Inglaterra, Escócia, País de Gales e Irlanda do Norte) representavam mais de um terço do tempo total das viagens, acumulando aproximadamente 100 milhões de horas de veículos em fila por ano. Para as grandes cidades do Brasil, o DENATRAN (1984) estimou que 50\% dos tempos de viagem e 30\% do consumo de combustível são gastos em paradas nos cruzamentos semaforizados.

Tais fatores podem ser ainda agravados no caso de redes compostas por diversas interseções semaforizadas relativamente próximas umas das outras. As estratégias de coordenação semafórica são, dessa maneira, importantes e reconhecidamente eficientes na promoção de fluidez das correntes de tráfego e na manutenção da qualidade operacional do sistema viário, reduzindo atrasos e paradas excessivas (Wallace e Courage, 1982). Para isso, é necessário utilizar métodos ou ferramentas apropriadas para a definição dos tempos de ciclo e das defasagens adequados à operação do sistema. 


\subsection{Justificativa}

A coordenação semafórica é considerada como uma das principais ferramentas para garantir a fluidez do tráfego nas áreas centrais de cidades de médio e grande porte, sendo que diferentes técnicas de obtenção de planos coordenados foram desenvolvidas e implementadas em programas computacionais.

Apesar de vários destes programas terem sido desenvolvidos nos últimos 40 ou 50 anos e estarem disponíveis no mercado, uma pesquisa realizada com municípios brasileiros de médio e grande porte para diagnosticar a forma de utilização dos métodos de coordenação semafórica existentes constatou que várias cidades brasileiras que já vivenciam problemas de circulação, atrasos, filas e congestionamentos, praticamente não fazem uso dessas ferramentas, seja porque não possuem os programas específicos para esse fim ou pela falta de conhecimento mais aprofundado sobre sua utilização. A partir dos resultados desta pesquisa, apresentados no Capítulo 2 desta dissertação, pôdese perceber que a maioria das cidades não conta com um profissional disponível somente para a avaliação das questões semafóricas, como a análise da implantação dos equipamentos, os dimensionamentos semafóricos e as possíveis programações, e raramente dispõe de qualquer tipo de software que promova planos de otimização ou coordenação semafórica.

A literatura apresenta diversos métodos analíticos de coordenação semafórica, que são praticamente uma extensão do método gráfico amplamente conhecido e que formam a base dos modelos computacionais (Tsay e Lin, 1988). Alguns destes programas já consideram inclusive as características do tráfego e a interdependência entre semáforos e fluxos de veículos ao longo dos corredores ou através de redes semaforizadas, podendo ser altamente sensíveis e responsivos às variações do volume de tráfego (Gartner et al., 1990; Abu-Lebdeh e Benekohal, 1997).

No entanto, programas computacionais como o TRANSYT são encontrados principalmente em prefeituras de grandes cidades, e ainda com utilização restrita por parte do corpo técnico municipal, que muitas vezes não dispõe dos dados de campo atualizados para a realização de novas simulações. Em algumas cidades de médio porte, uma consultoria contratada gera com o programa TRANSYT um plano off-line inicial de coordenação para o cenário de tráfego vigente no momento, mas que dificilmente será novamente revisto e aplicado com segurança pelos técnicos do local, que desconhecem detalhes do método utilizado, dificultando também uma avaliação da eficácia do plano estabelecido. 
Nas cidades de pequeno e médio porte, os métodos mais usados ainda são os procedimentos de tentativa e erro do Diagrama Espaço-Tempo ou de ajustes promovidos in loco, que permitem a coordenação de redes simples, mas sua utilização para avenidas com dois sentidos de tráfego e redes complexas é muito trabalhosa, exigindo que o analista teste de forma exaustiva uma série de alternativas dentre as possíveis. Em muitos casos, a experiência de alguns técnicos do serviço público de manutenção dos equipamentos semafóricos constitui a única alternativa para promover a coordenação semafórica dos corredores principais, através de tentativa e erro e em função da observação do fluxo e suas variações.

Essa lacuna entre a literatura e a efetiva aplicação dos métodos na prática constitui a principal motivação para a realização da dissertação de mestrado.

\subsection{Objetivos}

O objetivo geral desta pesquisa é avaliar a eficiência de métodos de coordenação semafórica para aplicação em vias arteriais de cidades de médio porte. Para isso, a dissertação está baseada na divisão desta meta em 3 objetivos específicos:

- Elaborar a revisão sobre os métodos existentes - os métodos mais conhecidos e citados na bibliografia são descritos em uma revisão bibliográfica cronológica detalhada, útil para identificar os conceitos básicos das primeiras técnicas de coordenação desenvolvidas, que possam servir de subsídio na elaboração de um modelo próprio de coordenação em vias semaforizadas de áreas urbanas;

- Apresentar o desenvolvimento e avaliar a eficiência de um aplicativo computacional denominado SBAND, cujo princípio de coordenação baseia-se no critério de maximização da banda verde;

- Avaliar o método de coordenação incorporado ao simulador INTEGRATION, que promove a coordenação semafórica tomando como base o critério de minimização de atrasos e paradas. Este simulador também será utilizado para gerar as medidas de desempenho para avaliação do programa SBAND.

Pretende-se utilizar ambos os programas mencionados na definição das estratégias de controle off-line para operação coordenada de interseções semaforizadas em cenários reais, assim como avaliar sua facilidade de utilização, as situações recomendadas de aplicação e a eficiência dos resultados obtidos, com o intuito principal de gerar uma forma alternativa para obtenção de coordenação para as prefeituras brasileiras. 


\subsection{Estrutura do Texto}

O texto desta dissertação está dividido em 8 capítulos, dentre os quais esta seção introdutória, que apresenta a justificativa e os objetivos da pesquisa.

No Capítulo 2 são apresentados os resultados de uma pesquisa realizada em cidades brasileiras de médio e grande porte sobre as formas de operação semafórica e os métodos de coordenação adotados pelos técnicos dos poderes públicos municipais. A pesquisa tem o intuito de diagnosticar a situação atual das cidades no uso de métodos de coordenação semafórica, e mostra que boa parte das prefeituras não avalia estratégias de coordenação baseadas em softwares, a não ser a adoção de progressões pela utilização em alguns casos de Diagramas Espaço-Tempo, por ajustes locais ou veículos-teste.

O terceiro capítulo apresenta um histórico sobre os controladores semafóricos, relaciona suas principais funções, vantagens e desvantagens, citando os parâmetros de justificativa para a implantação dos semáforos e os tipos de equipamentos disponíveis. Também aborda critérios para definição do melhor tipo de estratégia a ser adotada na operação de sistemas de semáforos, assim como os conceitos básicos e os benefícios da coordenação semafórica.

O Capítulo 4 apresenta em uma revisão cronológica os aspectos importantes dos principais métodos e programas de coordenação semafórica desenvolvidos nos últimos 40 anos, desde os antigos esquemas manuais e de cálculo até os softwares atuais, e que servirão de base para definição de um método simplificado, aplicável à realidade de cidades de porte médio.

O Capítulo 5 descreve em etapas a metodologia utilizada no desenvolvimento do modelo alternativo de coordenação SBAND para a maximização da banda verde em corredores semaforizados, desde o relato do conceito original para definição dos diagramas de banda, da determinação das defasagens, até a montagem do diagrama Espaço-Tempo.

As simulações realizadas em diversos cenários e com demandas diferentes para testar a eficiência do método de coordenação proposto são apresentadas no Capítulo 6, utilizando o programa INTEGRATION como ferramenta para a comparação das medidas de eficiência e também como alvo de avaliação do desempenho de sua estratégia de coordenação semafórica, baseada na minimização de atrasos e paradas.

Por fim, as análises dos resultados obtidos nas simulações são relatadas no 
Capítulo 7, e servem de subsídio para as conclusões da pesquisa e as considerações finais descritas no Capítulo 8. Todas as referências bibliográficas consultadas e citadas são relacionadas na última seção da dissertação. 


\section{COORDENAÇÃO SEMAFÓRICA EM CIDADES BRASILEIRAS}

Cerca de 85\% da população brasileira, de aproximadamente 180 milhões de habitantes, encontra-se atualmente nas regiões Nordeste, Sudeste e Sul do país, conforme ilustram os mapas da Figura 2-1. Somente as regiões Sul e Sudeste englobam quase $60 \%$ da população brasileira, e ainda contam com cinco das dez mais populosas cidades do Brasil. A frota registrada no país, que já ultrapassava 35 milhões de veículos em junho de 2003, concentra $77 \%$ deste total nos sete estados das regiões Sul e Sudeste, de acordo com a Tabela 2-1.

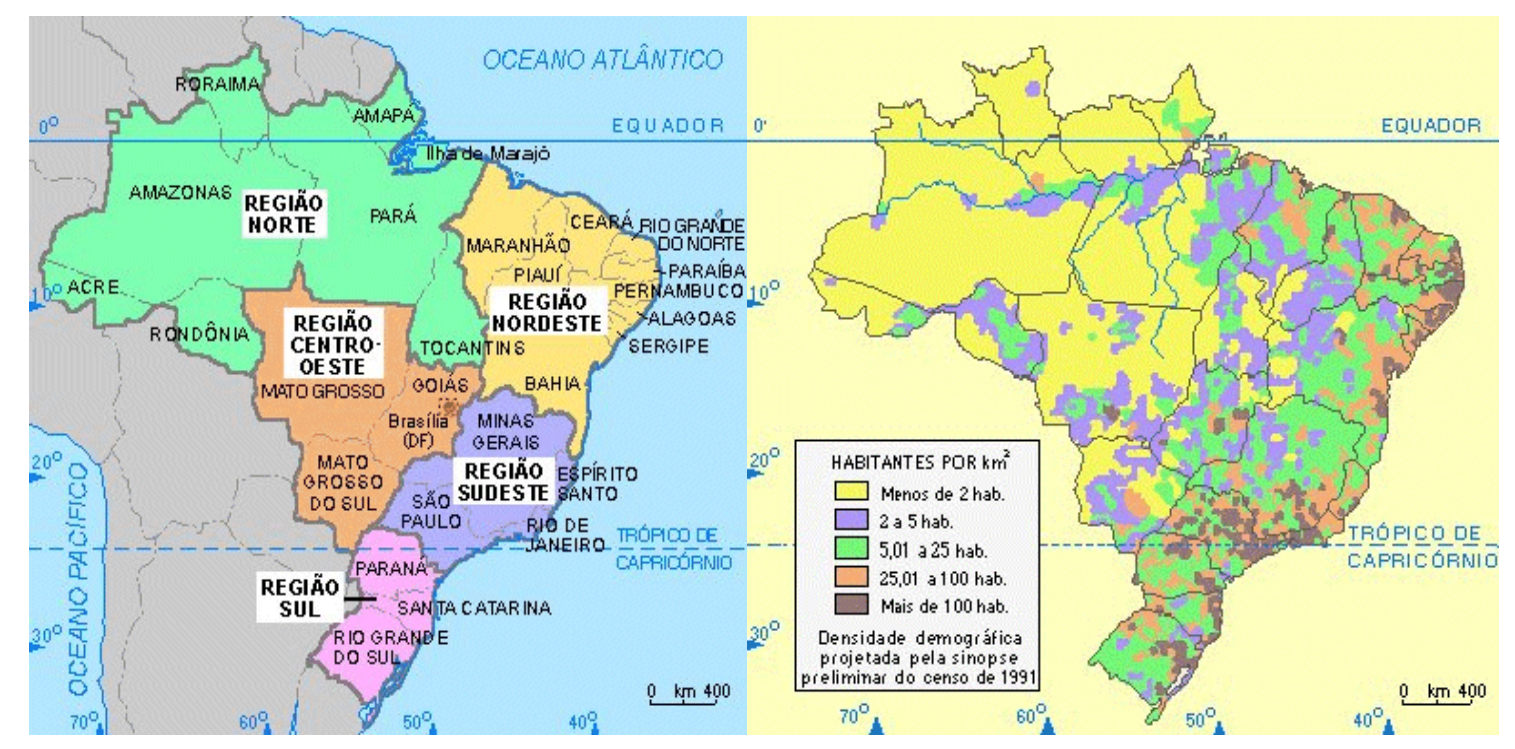

Figura 2-1: Densidade demográfica em diferentes regiões do Brasil (PlanetaGeo, 2003)

Considerando esta concentração, uma pesquisa foi realizada a respeito dos métodos mais comuns de coordenação semafórica empregados em municípios dos sete estados das regiões Sul e Sudeste: Espírito Santo, Minas Gerais, Paraná, Rio de Janeiro, Rio Grande do Sul, Santa Catarina e São Paulo. Para escolher as cidades representativas, no contexto de locais que sofrem grande impacto do nível de motorização, a seleção não foi feita em função do tamanho da população, mas sim em função da frota de veículos registrados nos municípios, através da análise dos dados do mês de junho de 2003, obtidos no site oficial do Departamento Nacional de Trânsito DENATRAN (2003). 
Tabela 2-1: Frota de veículos por Estado em junho de 2003 (DENATRAN, 2003)

\begin{tabular}{cccc}
\hline ESTADO & FROTA & ESTADO & FROTA \\
\hline Acre & 55.704 & Paraíba & 311.484 \\
Alagoas & 209.992 & Paraná & $\mathbf{2 . 8 4 5 . 9 8 4}$ \\
Amapá & 40.673 & Pernambuco & 892.591 \\
Amazonas & 234.851 & Piauí & 223.862 \\
Bahia & 1.025 .445 & Rio de Janeiro & $\mathbf{2 . 8 2 6 . 0 4 5}$ \\
Brasília - DF & 709.056 & Rio Grande do Norte & 325.628 \\
Ceará & 799.381 & Rio Grande do Sul & $\mathbf{2 . 9 6 8 . 6 2 9}$ \\
Espírito Santo & $\mathbf{6 1 5 . 3 5 1}$ & Rondônia & 223.047 \\
Goiás & 1.174 .365 & Roraima & 51.101 \\
Maranhão & 267.546 & Santa Catarina & $\mathbf{1 . 8 0 0 . 2 7 1}$ \\
Mato Grosso & 503.612 & São Paulo & $\mathbf{1 2 . 3 2 2 . 6 2 1}$ \\
Mato Grosso do Sul & 497.821 & Sergipe & 205.110 \\
Minas Gerais & $\mathbf{3 . 7 5 2 . 4 3 3}$ & Tocantins & 138.350 \\
Pará & 370.286 & \multicolumn{2}{c}{$\mathbf{3 5 . 3 9 1 . 2 3 9}$} \\
\hline \multicolumn{2}{c}{ TOTAL GERAL } & \multicolumn{2}{c}{}
\end{tabular}

Dessa maneira, foram selecionados nas regiões Sul e Sudeste alguns dos municípios com frota superior a 30.000 veículos, dentre as possibilidades demonstradas na Tabela 2-2, sempre incluindo nas entrevistas a capital do estado e pelo menos uma cidade de médio ou pequeno porte. A identificação dos setores ou órgãos de trânsito dos municípios foi feita através de pesquisa dos sites na Internet, e as entrevistas foram feitas por telefone entre os meses de agosto de 2003 a janeiro de 2004.

Nestas cidades, foram levantadas informações junto a cada engenheiro de tráfego ou técnico responsável pelo Setor de Trânsito do município, a respeito da quantidade e tipos de equipamentos semafóricos em funcionamento, número de centrais computadorizadas de tráfego em operação e respectivas quantidades de cruzamentos controlados, datas de início de funcionamento das centrais, grau de controle e eventuais estratégias de gerenciamento do tráfego empregadas, tais como a otimização ou a coordenação semafórica, tanto nas centrais (quando existentes) quanto nos principais corredores de tráfego.

Além disso, também foram registradas as peculiaridades de cada município, tais como contratações de consultorias para estabelecer os planos semafóricos de operação ou terceirizações para coleta de dados sobre capacidade e contagens volumétricas nas interseções semaforizadas. Os responsáveis pelo gerenciamento do trânsito foram questionados sobre a utilização de planos fixos ou atuados pelos veículos de acordo com dados coletados por laços detectores. 
Tabela 2-2: Municípios brasileiros das regiões Sul e Sudeste com frota superior a 30.000 veículos em junho de 2003 (DENATRAN, 2003)

\begin{tabular}{|c|c|c|c|}
\hline $\begin{array}{c}\text { ESTADO } \\
\text { (REGIÃO) }\end{array}$ & $\begin{array}{l}\text { FROTA } \\
\text { TOTAL }\end{array}$ & MUNICÍPIOS & FROTA \\
\hline \multirow{5}{*}{$\begin{array}{c}\text { Espírito Santo } \\
\text { (Sudeste) }\end{array}$} & \multirow{5}{*}{615.351} & Cachoeira de Itapemirim & 44.197 \\
\hline & & \begin{tabular}{|l|l} 
Cariacica \\
\end{tabular} & 49.892 \\
\hline & & Serra & 51.407 \\
\hline & & Vila Velha & 83.791 \\
\hline & & Vitória & 99.566 \\
\hline \multirow{14}{*}{$\begin{array}{l}\text { Minas Gerais } \\
\text { (Sudeste) }\end{array}$} & \multirow{14}{*}{3.752 .433} & Belo Horizonte & 757.161 \\
\hline & & Betim & 50.646 \\
\hline & & Contagem & 126.452 \\
\hline & & Divinópolis & 54.310 \\
\hline & & Governador Valadares & 55.390 \\
\hline & & Ipatinga & 59.926 \\
\hline & & Juiz de Fora & 111.281 \\
\hline & & Montes Claros & 70.232 \\
\hline & & Patos de Minas & 38.439 \\
\hline & & Poços de Caldas & 47.418 \\
\hline & & Pouso Alegre & 32.087 \\
\hline & & Sete Lagoas & 41.799 \\
\hline & & Uberaba & 91.328 \\
\hline & & Uberlândia & 174.711 \\
\hline
\end{tabular}

\begin{tabular}{|c|c|c|c|}
\hline \multirow{13}{*}{$\begin{array}{c}\text { Paraná } \\
\text { (Sul) }\end{array}$} & \multirow{13}{*}{2.845 .984} & Apucarana & 31.983 \\
\hline & & Arapongas & 32.449 \\
\hline & & Cascavel & 86.380 \\
\hline & & \begin{tabular}{|c|} 
Colombo \\
\end{tabular} & 35.743 \\
\hline & & \begin{tabular}{|l|} 
Curitiba \\
\end{tabular} & 786.167 \\
\hline & & Foz do Iguaçu & 71.578 \\
\hline & & \begin{tabular}{|l} 
Guarapuava \\
\end{tabular} & 36.882 \\
\hline & & Londrina & 180.964 \\
\hline & & Maringá & 136.264 \\
\hline & & Ponta Grossa & 77.589 \\
\hline & & São José dos Pinhais & 57.637 \\
\hline & & Toledo & 35.514 \\
\hline & & Umuarama & 31.384 \\
\hline
\end{tabular}

\begin{tabular}{|c|c|l|c|}
\hline & Campos de Goytacazes & 80.546 \\
\cline { 3 - 3 } & Duque de Caxias & 92.187 \\
\cline { 3 - 4 } $\begin{array}{c}\text { Rio de Janeiro } \\
\text { (Sudeste) }\end{array}$ & Macaé & 34.951 \\
\cline { 3 - 4 } & Niterói & 150.311 \\
\cline { 3 - 4 } & Nova Friburgo & 59.825 \\
\cline { 3 - 4 } & Nova Iguaçu & 85.135 \\
\cline { 3 - 4 } & Petrópolis & 78.991 \\
\cline { 3 - 4 } & Rio de Janeiro & 1.492 .158 \\
\cline { 3 - 4 } & São Gonçalo & 93.527 \\
\hline & São João de Meriti & 49.504 \\
\hline & Teresópolis & 35.353 \\
\hline & Volta Redonda & 57.351 \\
\hline
\end{tabular}

\begin{tabular}{|c|c|c|c|}
\hline $\begin{array}{l}\text { ESTADO } \\
\text { (REGIÃO) }\end{array}$ & $\begin{array}{l}\text { FROTA } \\
\text { TOTAL }\end{array}$ & MUNICÍPIOS & FROTA \\
\hline \multirow{11}{*}{$\begin{array}{c}\text { Santa Catarina } \\
\text { (Sul) }\end{array}$} & \multirow{11}{*}{1.800 .271} & Blumenau & 115.253 \\
\hline & & Brusque & 42.168 \\
\hline & & Chapecó & 51.310 \\
\hline & & Criciúma & 64.993 \\
\hline & & Florianópolis & 158.715 \\
\hline & & Itajai & 57.238 \\
\hline & & Jaguará do Sul & 47.727 \\
\hline & & \begin{tabular}{|l|} 
Joinville \\
\end{tabular} & 153.700 \\
\hline & & \begin{tabular}{|l|} 
Lages \\
\end{tabular} & 43.716 \\
\hline & & \begin{tabular}{|l} 
São José \\
\end{tabular} & 59.268 \\
\hline & & Tubarão & 40.070 \\
\hline
\end{tabular}

\begin{tabular}{|c|c|c|c|}
\hline \multirow{60}{*}{$\begin{array}{l}\text { São Paulo } \\
\text { (Sudeste) }\end{array}$} & \multirow{30}{*}{12.322 .621} & Americana & 79.190 \\
\hline & & Araçatuba & 74.396 \\
\hline & & Araraquara & 77.052 \\
\hline & & Araras & 42.252 \\
\hline & & Assis & 33.852 \\
\hline & & Atibaia & 39.541 \\
\hline & & Barretos & 36.256 \\
\hline & & Barueri & 57.099 \\
\hline & & Bauru & 123.804 \\
\hline & & Birigui & 39.105 \\
\hline & & Botucatu & 42.836 \\
\hline & & Bragança Paulista & 47.405 \\
\hline & & Campinas & 424.603 \\
\hline & & Carapicuiba & 55.319 \\
\hline & & Catanduva & 49.530 \\
\hline & & Cotia & 38.141 \\
\hline & & Diadema & 67.468 \\
\hline & & Franca & 107.142 \\
\hline & & Guaratinguetá & 30.451 \\
\hline & & Guarujá & 46.615 \\
\hline & & Guarulhos & 237.168 \\
\hline & & Indaiatuba & 60.656 \\
\hline & & Itapetininga & 37.471 \\
\hline & & Itatiba & 31.926 \\
\hline & & Itu & 49.534 \\
\hline & & Jacarei & 57.551 \\
\hline & & \begin{tabular}{|l|l} 
Jau \\
\end{tabular} & 44.860 \\
\hline & & Jundiai & 150.675 \\
\hline & & Limeira & 90.830 \\
\hline & & Marília & 69.463 \\
\hline & 12.022 .021 & Mauá & 80.805 \\
\hline & & Mogi das Cruzes & 89.456 \\
\hline & & Mogi -Guaçu & 43.221 \\
\hline & & Mogi-Mirim & 32.430 \\
\hline & & Osasco & 163.284 \\
\hline & & Pindamonhangaba & 31.964 \\
\hline & & \begin{tabular}{|l|} 
Piracicaba \\
\end{tabular} & 136.180 \\
\hline & & Praia Grande & 32.011 \\
\hline & & \begin{tabular}{|l|} 
Presidente Prudente \\
\end{tabular} & 70.967 \\
\hline & & Ribeirão Preto & 229.104 \\
\hline & & Rio Claro & 76.200 \\
\hline & & Santa Barbara D'oeste & 61.698 \\
\hline & & Santo André & 279.525 \\
\hline & & Santos & 163.485 \\
\hline & & \begin{tabular}{|l|} 
São Bernardo do Campo \\
\end{tabular} & 288.383 \\
\hline & & \begin{tabular}{|l|} 
São Caetano do Sul \\
\end{tabular} & 87.194 \\
\hline & & \begin{tabular}{|l|} 
São Carlos \\
\end{tabular} & 75.875 \\
\hline & & São José do Rio Preto & 166.001 \\
\hline & & \begin{tabular}{|l} 
São José dos Campos \\
\end{tabular} & 184.645 \\
\hline & & São Paulo & 4.295 .160 \\
\hline & & São Vicente & 46.378 \\
\hline & & Sertãozinho & 37.096 \\
\hline & & Sorocaba & 185.004 \\
\hline & & Sumaré & 54.110 \\
\hline & & Suzano & 44.574 \\
\hline & & Taboão da Serra & 34.509 \\
\hline & & Tatui & 31.224 \\
\hline & & Taubaté & 87.907 \\
\hline & & Valinhos & 40.837 \\
\hline & & $\mid \begin{array}{l}\text { Votuporanga } \\
\end{array}$ & 34.347 \\
\hline
\end{tabular}

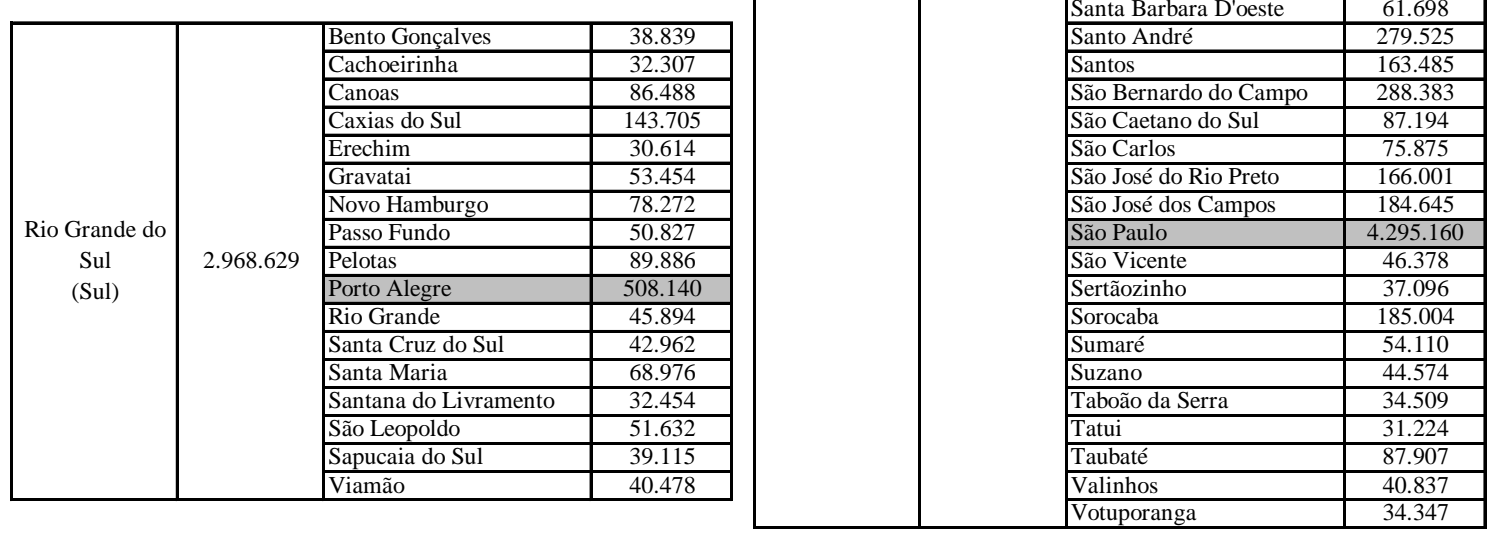


Devido à dificuldade em contatar os profissionais de todos esses municípios e ainda a ocorrência de situações onde o poder público não mantinha a atualização destes dados, foi possível contabilizar 30 prefeituras entrevistadas que efetivamente disponibilizaram as informações solicitadas, permitindo compilar os dados de forma a traçar um panorama dos esquemas de coordenação utilizados nas capitais e nas cidades de médio porte brasileiras. Os resultados das entrevistas realizadas nas capitais estão descritos no item 2.1, e em seguida as conclusões obtidas para as cidades de médio porte são apresentadas no item 2.2.

\subsection{Coordenação Semafórica nas Capitais Brasileiras}

De uma maneira geral, as capitais dispõem de centrais computadorizadas de controle de tráfego em área (CTA), onde praticamente todas utilizaram o programa TRANSYT pelo menos para a implantação da programação inicial de seus sistemas, e mantêm equipe técnica que realiza ajustes através de novas simulações ou principalmente por observação das condições do tráfego. Porém nem todas as equipes dispõem de dados de contagem atualizados para realizar simulações mais próximas à realidade, deixando de fazer uso de todo o potencial disponível do software adquirido.

Praticamente 50 a $60 \%$ dos cruzamentos semaforizados destas capitais são controlados por uma ou mais centrais, e ainda outros corredores semaforizados recebem coordenação por progressão principalmente através da análise do Diagrama EspaçoTempo. A Tabela 2-3 apresenta resumidamente os dados obtidos sobre a forma de controle semafórico adotada nas capitais brasileiras das regiões Sul e Sudeste, além de Fortaleza, sendo que cada um dos métodos e programas de coordenação mais utilizados serão descritos no Capítulo 4 deste trabalho.

Tabela 2-3: Informações sobre o sistema de controle semafórico em capitais brasileiras

\begin{tabular}{|c|c|c|c|c|c|c|c|}
\hline \multirow{2}{*}{ Cidade } & \multirow{2}{*}{ Estado } & \multirow{2}{*}{$\begin{array}{l}\text { Frota de } \\
\text { veículos }\end{array}$} & \multirow{2}{*}{$\begin{array}{l}\text { Cruzamentos } \\
\text { semaforizados }\end{array}$} & \multirow{2}{*}{$\begin{array}{c}\text { Centrais } \\
\text { de } \\
\text { tráfego }\end{array}$} & \multirow{2}{*}{$\begin{array}{c}\text { Cruzamentos } \\
\text { controlados } \\
\text { pelas centrais }\end{array}$} & \multicolumn{2}{|c|}{$\begin{array}{l}\text { Método ou programa de } \\
\text { coordenação utilizado }\end{array}$} \\
\hline & & & & & & Central & Corredores \\
\hline Belo Horizonte & MG & 757.161 & 567 & 2 & $357 *$ & TRA & TRA \\
\hline Curitiba & PR & 786.167 & 885 & 3 & 534 & TRA & DET \\
\hline Florianópolis & SC & 158.715 & 130 & 1 & 81 & TRA / RAM & $\mathrm{DET} / \mathrm{PAL}$ \\
\hline Fortaleza & $\mathrm{CE}$ & 416.061 & $400 *$ & 1 & 189 & SCO & DET \\
\hline Porto Alegre & RS & 508.140 & 955 & 1 & $570 *$ & TRA & PAL \\
\hline Rio de Janeiro & $\mathrm{RJ}$ & 1.492 .158 & $2.000 *$ & 8 & $1.000 *$ & TRA & DET \\
\hline São Paulo & SP & 4.295 .160 & $4.600 *$ & 5 & $1.200 *$ & TRA / SCO & TRA / PAL \\
\hline Vitória & ES & 99.566 & 176 & 2 & 175 & DET & DET \\
\hline \multicolumn{8}{|c|}{ PAL: PROGRESSÃO POR AJUSTES LOCAIS } \\
\hline \multicolumn{8}{|c|}{ DET: DIAGRAMA ESPAÇO-TEMPO } \\
\hline
\end{tabular}


Os técnicos da cidade de Florianópolis rodaram em 2003 o programa TRANSYT para prover os planos semafóricos, e com laços detectores de veículos instalados nos 81 cruzamentos da central computadorizada, utilizam o programa francês $R A M S E ́ S$ para a escolha automática dos planos fixos pré-estabelecidos, de acordo com a demanda de tráfego identificada. Por sua vez, a prefeitura de Belo Horizonte, que em 1999 firmou convênio com a Universidade Federal de Minas Gerais para realizar pesquisas de volume e capacidade e rodar o programa TRANSYT para estabelecer os planos semafóricos de operação, está substituindo o sistema de suas duas centrais para alterações dos planos em tempo real, baseadas nos dados coletados por laços detectores. Parte das centrais de Curitiba e São Paulo funciona com laços detectores em alguns cruzamentos estratégicos da rede, a fim de gerar dados para promover ajustes instantâneos das programações semafóricas.

Em Porto Alegre, o engenheiro responsável pela operação da central de controle recebeu na Inglaterra treinamento específico para manipulação do programa TRANSYT, mas esta ferramenta não é utilizada há três anos por falta de novas contagens volumétricas de tráfego, obrigando os técnicos a realizarem ajustes locais baseados na observação do tráfego. A cidade de Vitória adquiriu recentemente o TRANSYT, mas ainda não elaborou programação baseada neste programa devido à inexistência de contagens volumétricas mais atuais.

Vale ressaltar que, apesar de não ter sido alvo das capitais selecionadas para as entrevistas, Fortaleza apresenta no Brasil uma situação privilegiada de controle de tráfego, pois 189 de seus cruzamentos semaforizados funcionam desde 2000 com laços detectores que coletam e enviam informações sobre a demanda de veículos, ligados a um sistema centralizado adaptativo em tempo real, conforme ilustra a foto da Figura 2-2 (site da Prefeitura de Fortaleza, 2004 e Loureiro et al., 2003a). O programa SCOOT Split Cycle Offset Optimization Technique é utilizado para analisar esses dados e otimizar a programação dos semáforos a cada ciclo, ajustando os tempos de verde, as defasagens e a duração do ciclo, de forma a atender o volume de tráfego atual e acompanhar as variações instantâneas de médio e longo prazo. Além da operação automatizada, o sistema permite a intervenção de técnicos e operadores na modificação dos parâmetros e na implementação de planos fixos para situações atípicas ou fora dos horários de pico (Loureiro et al., 2003b). 


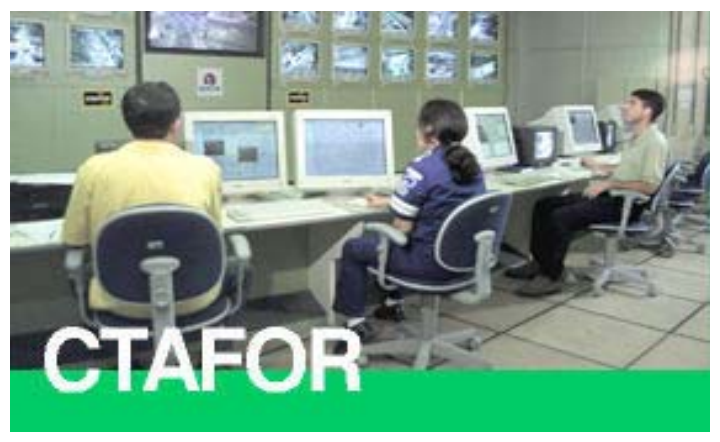

Figura 2-2: Central de controle de tráfego de Fortaleza (Prefeitura de Fortaleza, 2004)

\subsection{Coordenação Semafórica nas Cidades Brasileiras de Médio Porte}

Poucas cidades de médio porte que não as capitais possuem uma central de tráfego que controla a programação semafórica de uma quantidade significativa de interseções, conforme dados apresentados na Tabela 2-4.

Juiz de Fora é o único exemplo de cidade de médio porte entrevistada que utilizou o programa TRANSYT de otimização de defasagens para gerar a programação inicial da central computadorizada, e mantém o programa RAMSÉS para escolher entre os planos fixos pré-estabelecidos de acordo com dados coletados em laços detectores de veículos. Consultorias contratadas em 1998 e 1999 estabeleceram respectivamente, através do programa TRANSYT, as programações iniciais para as centrais de Cascavel e Maringá, além das coordenações semafóricas para as vias não monitoradas pela central, determinadas pelos técnicos municipais com a elaboração do Diagrama Espaço-Tempo e ajustadas em campo.

Em Joinville e Londrina, os planos de operação introduzidos na central e as progressões estabelecidas e mantidas por relógio em outros corredores semafóricos foram determinados através do Diagrama Espaço-Tempo. Em Araraquara, apesar de ainda não existir na época da entrevista uma central de controle, cinco dos principais corredores da cidade recebem progressão com defasagens definidas através de um veículo-teste, assim como Petrópolis, Presidente Prudente e São Leopoldo, onde os técnicos realizam coordenação entre semáforos em alguns corredores através de tentativa e erro, baseando-se na observação do tráfego local.

Outra parcela dos municípios não adota esquemas de coordenação, como o exemplo de Ponta Grossa, onde uma central controla 70\% dos semáforos da cidade, mas nenhum método é utilizado para prover coordenação entre as interseções da rede, e de Uberaba que não adota formas de coordenação, mesmo com 30\% dos semáforos ligados 
a uma central. Embora a cidade de Arapongas conte com treze de seus dezesseis cruzamentos semaforizados funcionando com equipamentos eletrônicos, o poder público não provê coordenação nem na avenida principal, que reúne seis semáforos eqüidistantes em duplo sentido de circulação. Situação semelhante ocorre na principal avenida da cidade de São Carlos, onde apesar de haver sentido único de circulação, a prefeitura adota somente a abertura simultânea dos semáforos.

Tabela 2-4: Informações relativas ao sistema de controle semafórico em cidades de médio porte

\begin{tabular}{|c|c|c|c|c|c|c|c|}
\hline \multirow{2}{*}{ Cidade } & \multirow{2}{*}{ Estado } & \multirow{2}{*}{$\begin{array}{l}\text { Frota de } \\
\text { veículos }\end{array}$} & \multirow{2}{*}{$\begin{array}{l}\text { Cruzamentos } \\
\text { semaforizados }\end{array}$} & \multirow{2}{*}{$\begin{array}{l}\text { Centrais } \\
\text { de } \\
\text { tráfego }\end{array}$} & \multirow{2}{*}{$\begin{array}{c}\text { Cruzamentos } \\
\text { controlados } \\
\text { pelas centrais }\end{array}$} & \multicolumn{2}{|c|}{$\begin{array}{l}\text { Método ou programa de } \\
\text { coordenação utilizado }\end{array}$} \\
\hline & & & & & & Central & Corredores \\
\hline Araçatuba & $\mathrm{SP}$ & 74.396 & 65 & 0 & 0 & - & DET \\
\hline Arapongas & PR & 32.449 & 16 & 0 & 0 & - & - \\
\hline Araraquara & SP & 77.052 & 98 & 0 & 0 & - & PVT \\
\hline $\begin{array}{l}\text { Bento } \\
\text { Gonçalves }\end{array}$ & RS & 38.839 & 17 & 0 & 0 & - & $\mathrm{DET} / \mathrm{PAL}$ \\
\hline Canoas & RS & 86.488 & $55^{*}$ & 0 & 0 & - & - \\
\hline Cascavel & PR & 86.380 & 96 & 1 & 56 & TRA & PAL \\
\hline Chapecó & SC & 51.310 & 17 & 0 & 0 & - & - \\
\hline Joinville & SC & 153.700 & 118 & 1 & $60 *$ & DET & DET \\
\hline Juiz de Fora & MG & 111.281 & 91 & 1 & 81 & TRA / RAM & - \\
\hline Londrina & PR & 180.964 & 192 & 1 & 38 & DET & PAL \\
\hline Maringá & PR & 136.264 & 121 & 1 & 56 & TRA / DET & $\mathrm{DET} / \mathrm{PAL}$ \\
\hline Petrópolis & $\mathrm{RJ}$ & 78.991 & $26 *$ & 0 & 0 & - & PAL \\
\hline $\begin{array}{l}\text { Poços de } \\
\text { Caldas }\end{array}$ & MG & 47.418 & 72 & 1 & 7 & PAL & PAL \\
\hline Ponta Grossa & PR & 77.589 & $62 *$ & 1 & $44^{*}$ & - & - \\
\hline $\begin{array}{l}\text { Presidente } \\
\text { Prudente }\end{array}$ & SP & 70.967 & $44^{*}$ & 0 & 0 & - & PAL \\
\hline $\begin{array}{l}\text { Ribeirão } \\
\text { Preto }\end{array}$ & SP & 229.104 & $390 *$ & 1 & 275 & $\mathrm{PA} / \mathrm{PS}$ & PAL \\
\hline Santa Maria & RS & 68.976 & 52 & 0 & 0 & - & DET / PAL \\
\hline São Carlos & SP & 75.875 & 36 & 0 & 0 & - & PS \\
\hline São Leopoldo & RS & 51.632 & 32 & 0 & 0 & - & PAL \\
\hline Serra & ES & 51.407 & 13 & 0 & 0 & - & - \\
\hline Uberaba & MG & 91.328 & $100 *$ & 1 & 30 & - & PVT \\
\hline $\begin{array}{l}\text { Volta } \\
\text { Redonda }\end{array}$ & $\mathrm{RJ}$ & 57.351 & 53 & 0 & 0 & - & $\mathrm{DET} / \mathrm{PVT}$ \\
\hline \multicolumn{3}{|c|}{ PS: PROGRESSÃO SIMULTÂNEA } & \multicolumn{3}{|c|}{ PAL: PROGRESSÃO POR AJUSTES LOCAIS } & \multicolumn{2}{|c|}{ RAM: PROGRAMA RAMSES } \\
\hline \multicolumn{3}{|c|}{ PA: PROGRESSÃO ALTERNADA } & DET: DIAGRAMA & SPAÇO-TEN & & \multicolumn{2}{|c|}{ SCO: PROGRAMA SCOOT } \\
\hline \multicolumn{3}{|c|}{ PVT: PROGRESSÃO POR VEÍCULO TESTE } & TRA: PROGRAMA & TRANSYT & & \multicolumn{2}{|c|}{ * valores aproximados } \\
\hline
\end{tabular}


Embora praticamente $40 \%$ das cidades brasileiras de médio porte tenham central semafórica computadorizada, somente 30\% destas utilizam software de coordenação, ou seja, 13\% dos municípios médios entrevistados. Para os demais corredores semaforizados não monitorados por central, a análise das informações relativas às estratégias semafóricas adotadas demonstra ainda que $27 \%$ dos municípios de porte médio entrevistados utilizam o procedimento manual do Diagrama EspaçoTempo para definição dos planos de coordenação, 36\% realizam repetidos ajustes locais em observação ao tráfego vigente, $14 \%$ utilizam veículos-teste na busca do melhor esquema de operação, enquanto que o restante das cidades entrevistadas (23\%) não adota esquemas de coordenação, nem mesmo nas principais vias semaforizadas em que o sistema de “onda-verde” poderia representar uma significativa melhoria na operação do sistema.

O fato de que os programas computacionais de coordenação semafórica não são utilizados em grande parte das cidades de médio porte pode se explicado, talvez, por dois fatores: a falta de pessoal capacitado para trabalhar com tais programas ou ainda a falta de aplicativos mais acessíveis, que possam auxiliar na definição dos esquemas de coordenação de uma forma mais simples e eficiente. Sendo assim, o Capítulo 5 deste trabalho enfoca o desenvolvimento de um procedimento computacional que exija relativamente poucos dados de entrada para definir esquemas de coordenação, voltado principalmente para municípios de médio porte.

Simulações testam a viabilidade prática de utilização deste método como uma possível alternativa aos repetitivos ajustes locais ou métodos manuais de coordenação amplamente utilizados nas cidades brasileiras, sendo apresentadas no Capítulo 6 e avaliadas no Capítulo 7 desta dissertação. O programa INTEGRATION é utilizado nestas simulações, para comparação de cenários vigentes aos planos gerados pelo método proposto e pelo próprio simulador, sendo também avaliado quanto à sua eficiência e facilidade de aplicação. 


\section{CONTROLADORES SEMAFÓRICOS}

De forma geral, pode-se dizer que o local mais complexo em qualquer rua ou sistema de vias é a interseção, pois os fluxos de veículos e pedestres de diferentes aproximações utilizam um mesmo espaço físico para circulação. Em nenhum outro local das vias há tantos conflitos em potencial, portanto é necessário estabelecer normas de controle para atribuir o direito de passagem, reduzindo os riscos de acidentes e melhorando as condições de fluidez.

A definição da prioridade de movimentos através das placas "Parada Obrigatória” ou "Dê a Preferência” podem gerar elevado tempo de espera, formação de filas e situações inseguras em interseções de vias com significativo volume de tráfego. Já o semáforo garante uma ordenação seqüencial e cíclica de passagem no cruzamento, dando a determinada corrente de tráfego um período específico de tempo, sem que haja simultaneamente a permissão de movimentos conflitantes.

Porém, segundo Roess et al. (1998) a avaliação para instalação semafórica dever ser bastante criteriosa, pois seu custo é relativamente alto e o impacto negativo de sua aplicação equivocada é maior do que em outros tipos de sinais, chegando a ponto de se avaliar a remoção de semáforos já existentes que não apresentem mais as justificativas para sua permanência.

O semáforo é o tipo mais comum de controle em interseções com tráfego pesado em áreas urbanas. De acordo com Homburger et al. (1992), os equipamentos semafóricos são displays operados por energia, utilizados para regular o tráfego, controlando interseções rodoviárias ou ferroviárias, faixas exclusivas e pedestres.

\subsection{Histórico do Semáforo}

A instalação do primeiro semáforo ocorreu em Westminster - Inglaterra em 1868, com utilização de um dispositivo de braço com lâmpadas a gás vermelha e verde para uso noturno, porém Webster e Cobbe (1966) relatam a ocorrência de uma explosão no equipamento, culminando na estagnação de experimentos desta natureza por meio século.

O semáforo elétrico foi inventado por James Hoge em 1913, sendo instalado em 1914, em Cleveland / Ohio. O funcionamento dos primeiros semáforos nos Estados 
Unidos em sistema interconectado em rede ocorreu em 1917 e no sistema coordenado progressivo em 1922 (Homburger et al., 1992; Roess et al., 1998).

No início da década de 30 houve uma primeira tentativa nos Estados Unidos de controle semafórico atuado por veículos, através de microfones instalados ao lado da rua onde os motoristas deveriam buzinar. Objeções foram feitas contra este esquema, e outro método usando contatos elétricos no trajeto dos veículos foi experimentado, utilizando tubos pneumáticos onde a passagem dos veículos promovia o deslocamento do ar pelo tubo e acionava um contato elétrico situado em um compartimento ao lado da rua.

Segundo Webster e Cobbe (1966), o primeiro semáforo atuado por veículos da Grã-Bretanha foi instalado em Londres - Inglaterra em 1932, e após 3 anos funcionaria a primeira rede totalmente constituída de semáforos atuados por veículos em Londres e também em Glasgow na Escócia.

\subsection{Funções dos Semáforos}

Conforme o Manual de Semáforos do DENATRAN (1984), o controlador semafórico é um dispositivo que envia aos grupos focais dos semáforos, comandos através de pulsos elétricos para as mudanças de cores das indicações luminosas, autorizando a movimentação dos veículos de acordo com os planos semafóricos estabelecidos.

Os principais benefícios dos equipamentos semafóricos foram citados por vários autores, tais como Homburger et al. (1992) e Roess et al. (1998):

- permitir que correntes de tráfego conflitantes usem a mesma interseção, por meio de separação destas correntes em intervalos de tempo específicos;

- alternar o direito de uso da via entre os fluxos de tráfego, ordenando os movimentos e minimizando atrasos médios para todos os veículos e pedestres;

- reduzir o estresse da dificuldade de realização de manobras em interseções operando próximas da capacidade;

- eliminar ou reduzir conflitos de fluxo de tráfego que possam produzir acidentes;

- reduzir a freqüência de alguns tipos de acidentes, principalmente colisão lateral e atropelamento de pedestres;

- aumentar a capacidade de tráfego da interseção, onde o arranjo físico e as medidas de controle são apropriados; 
- permitir economia através da redução de fiscalização por agentes de trânsito;

- dividir as correntes de tráfego em pelotões, permitindo que pedestres cruzem as pistas com maior facilidade e segurança;

- interromper o fluxo elevado de tráfego para permitir outro tráfego cruzar (veicular ou de pedestres);

- prover movimento contínuo e ordenado do fluxo de tráfego na velocidade definida ao longo de uma rota, através da operação coordenada;

- em sistemas de controle por área de tráfego, oferecer a possibilidade de aumentar a capacidade global do sistema viário central das cidades.

Algumas possíveis desvantagens são ressaltadas, e poderão ser observadas especialmente em casos de semáforos instalados e/ou programados inadequadamente:

- aumentar o atraso na interseção e o consumo de combustível, principalmente em horário-pico;

- induzir ao uso de rotas alternativas menos adequadas;

- aumentar a freqüência de certos tipos de acidentes, tais como colisão traseira;

- causar atraso desnecessário e encorajar o desrespeito;

- causar atraso excessivo, aumentando a irritação dos motoristas.

De maneira geral, em interseções com baixo volume de tráfego, o equipamento semafórico gera atraso total maior do que se não houvesse o semáforo. Já para volumes altos, o atraso total é menor e a capacidade aumenta com a adequada utilização do semáforo. Desde 1956, estudos de acidentes antes e depois de intervenções semafóricas já revelavam $40 \%$ de redução de colisões laterais quando o semáforo substituiu nenhum tipo de controle ou placas de parada (Webster e Cobbe, 1966).

\subsection{Justificativas para Implantação Semafórica}

Cada país utiliza parâmetros específicos para avaliar a necessidade da implantação semafórica. Em 1966, Webster e Cobbe elencaram os parâmetros mínimos para implantação de semáforos, definidos pelo Ministério de Transportes na Grã-Bretanha: fluxo médio de 300 veículos por hora, acima de 16 horas por dia, onde pelo menos 100 veículos por hora estejam na via secundária, e com volume mínimo na hora pico de 500 veículos entrando no cruzamento. 
Nos Estados Unidos, os parâmetros regulamentados a serem avaliados são (Roess et al., 1998):

- $\quad$ volume veicular mínimo (8 horas);

- interrupção do tráfego contínuo (8 horas);

- $\quad$ volume mínimo de pedestres (8 horas);

- área escolar;

- movimento progressivo (formação de pelotões);

- índice de acidentes;

- combinação das justificativas;

- $\quad$ volume veicular de 4 horas;

- atraso da hora-pico e volume da hora pico.

Os autores apresentam ainda um estudo de alteração na regulamentação, visando suprimir os dois primeiros parâmetros e basear a análise somente nos estudos em campo de aceitação de brechas (gaps) e/ou atraso individual por veículo na aproximação secundária. O limiar sugerido é 25 seg/veículo como atraso médio na aproximação secundária, em cada uma das 4 horas-pico do dia. $\mathrm{O}$ estudo dos gaps na via principal determina quantos veículos da aproximação podem passar, sendo que os gaps são categorizados por seu comprimento, em segundos.

No Brasil, o Departamento Nacional de Trânsito (DENATRAN, 1984) estabelece nove critérios que justificam a implantação semafórica, bastante semelhantes aos já consagrados parâmetros norte-americanos:

1. Volumes veiculares mínimos em todas as aproximações da interseção: definido em função do volume bidirecional da via principal e unidirecional da via secundária, a serem observados em pelo menos 8 horas consecutivas ou não do dia, de acordo com tabela fornecida no Manual de Semáforos do DENATRAN;

2. Interrupção de tráfego contínuo: baseado na tentativa de minimizar atrasos excessivos, este critério é utilizado quando veículos da via secundária apresentam grande dificuldade em cruzar ou entrar no fluxo da via principal, com volumes mínimos de oito horas também estabelecidos no Manual de Semáforos;

3. Volumes conflitantes em interseções de cinco ou mais aproximações: inicialmente deve-se buscar a alteração da interseção para outra equivalente a quatro 
aproximações, através da restrição de sentido e circulação. Caso não seja possível, recomenda-se a implantação do semáforo se for verificado volume equivalente total de no mínimo 800 veículos por hora;

4. Volumes mínimos de pedestres que cruzam a via principal: a instalação semafórica é justificada quando há pelo menos 250 pedestres por hora em ambos os sentidos da travessia, associado a 600 veíc/h nos dois sentidos da via sem canteiro ou 1.000 veíc/h nos dois sentidos da avenida com canteiro central de pelo menos 1 metro;

5. Índice de acidentes e os diagramas de colisão: critério voltado para casos em que o semáforo é capaz de corrigir os acidentes registrados, e que sejam no mínimo 5 acidentes com ferido por ano;

6. Melhoria de sistema progressivo: a implantação de um novo semáforo em um sistema coordenado é justificada se contribuir para o ajuste da velocidade de progressão e manutenção do pelotão, comprovada através do Diagrama EspaçoTempo;

7. Controle de áreas congestionadas: áreas que já apresentam congestionamentos constantes e inevitáveis por outras intervenções de engenharia de tráfego;

8. Combinação de critérios: para situações em que $80 \%$ de dois valores dos critérios 1 a 5 forem observados ou $70 \%$ de três valores destes mesmos critérios;

9. Situações locais específicas: a experiência profissional de técnicos poderá justificar a instalação semafórica em situações especiais como, por exemplo, para locais em que a distância mínima de visibilidade não é mantida, gerando situação potencial de risco.

Como a prática brasileira enfoca a análise principal nos volumes mínimos veiculares, o próprio Manual de Semáforos do DENATRAN sugere que se o volume de tráfego do local somente atinge valores representativos que justifiquem a implantação em períodos de pico, e o município disponha de controlador que possibilite diferentes programações ao longo do dia, que a instalação possa acontecer com a operação funcionando nos horários de pico e com sinalização amarela piscante de advertência nos intervalos de baixo volume.

O atraso causado pelo semáforo aos veículos e seus ocupantes e também seu custo de implantação e manutenção requer justificativas criteriosas para a decisão de sua instalação, baseada em detalhada coleta dos dados em campo, que segundo o Manual de Semáforos do DENATRAN (1984) devem incluir: 
- croqui de identificação dos elementos geométricos e do mobiliário urbano;

- volume de tráfego em 16 horas consecutivas de um dia típico, dividida a cada 15 minutos e classificada por tipo de veículo, onde os volumes veiculares devem ser obtidos pela equivalência com veículos leves, sendo o fator de ajuste para ônibus e caminhões igual a 2, motocicletas igual a 0,5 e bicicletas igual a 0,2 ;

- contagem de pedestres num raio de 30 metros, por 4 horas de maior movimento, podendo ser dividida em 3 classes de idade: menor que 13 anos, entre 13 e 60, e maior que 60 anos;

- velocidade do $85^{\circ}$ percentil dos veículos nas aproximações da interseção, dentro de 50 metros;

- diagrama de acidentes com tipo, localização, severidade, hora do dia e dia da semana, de 3 anos ou de pelo menos 1 ano;

- tempo de atraso para cada aproximação;

- número e distribuição das brechas.

\subsection{Conceitos Gerais}

O semáforo é um dispositivo de controle de tráfego que, através de indicações luminosas transmitidas para motoristas e pedestres, promove a ordenação seqüencial e cíclica, alternando o direito de passagem de veículos e/ou pedestres em interseções de duas ou mais vias. O Manual de Semáforos do Departamento Nacional de Trânsito (DENATRAN, 1984) apresenta conceitos básicos para o dimensionamento semafórico:

- Movimentos: caracterizam a origem e o destino dos veículos e/ou pedestres na interseção, podendo ser conflitantes quando se cruzam numa interseção, convergentes quando têm origens diferentes e mesmo destino ou divergentes quando têm a mesma origem e destinos diferentes. Também podem ser permitidos quando são realizados junto com outro fluxo conflitante, onde o motorista deverá selecionar o intervalo apropriado para executar a manobra, ou protegidos quando ocorrem em um intervalo separado, sem que haja fluxo conflitante;

- Ciclo: tempo em segundos para uma seqüência completa de todas as indicações luminosas oferecidas aos vários grupos focais $[c]$;

- Fase: seqüência de cores (indicações luminosas) aplicada a uma ou mais faixas de tráfego (movimento), durante o ciclo, recebendo simultaneamente indicações idênticas do semáforo. As diferentes configurações dentro de uma mesma fase 
constituem as subfases, que coincidem com os estágios;

- Estágio: período de tempo em que as indicações luminosas não mudam de aspecto, para um ou mais movimentos:

- Intervalo verde: indicação verde para um ou mais movimentos [ $G$ ];

- Intervalo vermelho: indicação vermelha para um ou mais movimentos [ $R$ ];

- Intervalo de mudança: indicação amarela entre o verde e o vermelho, para evitar zona de dilema $[A]$;

- Período entreverdes [ $I=A+R t$ ]: tempo entre o final do verde da fase que está perdendo o direito de passagem, para o início do verde da fase que está ganhando, usualmente 3 a 5 segundos (amarelo: 3 segundos + vermelho total: 2 segundos). No Brasil, normalmente, o período entreverdes é igual ao tempo de amarelo, e em locais com excesso de velocidade, presença elevada de pedestres ou com necessidade de maior segurança na limpeza de veículos do cruzamento, utiliza-se o tempo de amarelo mais o tempo de vermelho total.

\subsubsection{Indicações Luminosas}

Conforme estabelece a Lei Federal n 9.503/97 - Código de Trânsito Brasileiro, são dois os tipos de semáforos: veicular e para pedestres. As fotos da Figura 3-1 ilustram alguns dos diferentes projetos de semáforos em funcionamento no Brasil.
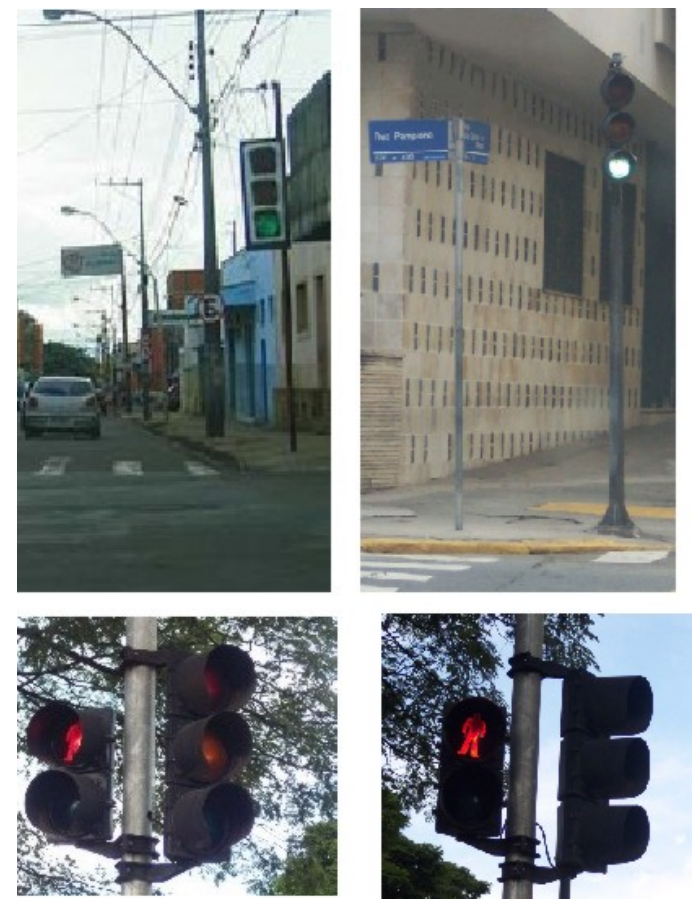
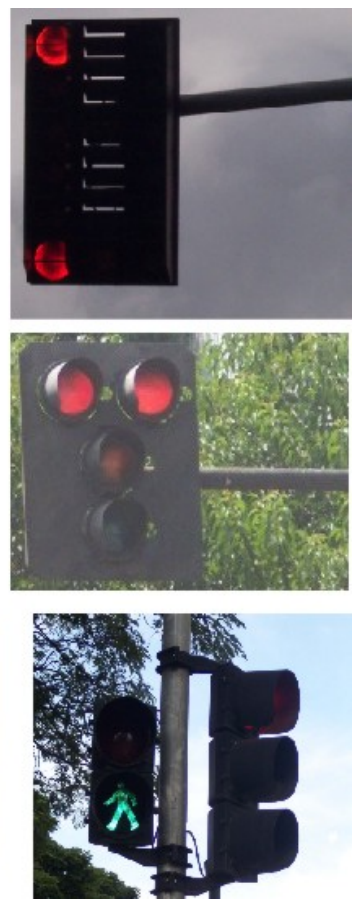

Figura 3-1: Fotos de semáforo veicular e de pedestres 
- Semáforo veicular: este dispositivo geralmente é composto por três focos de luz com seção circular, com diâmetro de 200 ou 300 milímetros, nas cores vermelho, amarelo e verde, obrigatoriamente dispostas da esquerda para a direita e/ou de cima para baixo, autorizando ou proibindo o movimento dos veículos em uma determinada corrente de tráfego. Suas indicações luminosas transmitem através das cores, diferentes mensagens aos motoristas: o vermelho ("Pare”) é a indicação para permanecer parado antes da faixa de retenção até receber a indicação luminosa verde; o amarelo (“Atenção”) adverte que a indicação vermelha será imediatamente exibida, devendo parar o veículo antes de entrar na interseção ou concluir a passagem caso já tenha iniciado; o verde (“Siga”) indica a permissão de seguir em frente ou realizar os movimentos permitidos. Estas indicações que apresentam os estágios aos veículos são circulares e fixas, porém podem ser circulares e intermitentes para indicar aos veículos a necessidade de realizar os movimentos com cautela em períodos do dia em que haja baixo fluxo; com setas e fixas, para apresentar aos veículos somente os estágios indicados pelas setas; ou também com setas e intermitentes, para indicar aos veículos a necessidade de realizar os movimentos indicados pelas setas com cautela.

- Semáforo para pedestre: dispositivo composto por dois focos de luz com seção quadrada ou retangular, com lado de 200 a 300 milímetros e indicações feitas através de máscaras fixadas na parte interna da lente dos focos, representando legendas ou bonecos humanos, para indicar as condições de movimento e espera. $\mathrm{O}$ boneco verde fixo, em posição de caminhada, indica a permissão de travessia dos pedestres; o boneco vermelho intermitente, em posição estática, indica que a permissão de travessia para os pedestres está acabando; e o boneco vermelho fixo estabelece a parada dos pedestres para aguardar a próxima indicação verde.

\subsubsection{Diagrama de Estágios e de Tempos}

As representações gráficas dos movimentos veiculares e de pedestres e das indicações luminosas possibilitam a visualização facilitada da operação em um cruzamento semaforizado. Relacionando a tabela dos movimentos com os estágios, identificam-se os grupos focais necessários, e cada grupo focal estará associado a uma fase.

- Diagrama de estágios: representação esquemática da seqüência de movimentos permitidos e proibidos para cada intervalo do ciclo.

- Diagrama de tempos: associa os instantes de mudança dos estágios com a seqüência de cores e duração das fases, mostrando o comportamento das indicações luminosas 
nos vários grupos focais ao longo do ciclo.

Segundo Ferraz et al. (1999), a escolha do plano de operação em uma interseção semaforizada deverá buscar o esquema mais simples e seguro possível, com o menor número de estágios - o ideal seria no máximo 3 estágios - e o maior número de movimentos não conflitantes por estágio. Observando a legenda apresentada na Figura 3-2, são demonstradas algumas possibilidades de operação semafórica, de acordo com a circulação de veículos e pedestres, e os movimentos permitidos desejáveis em cada caso.

\begin{tabular}{|c|c|c|c|}
\hline \multicolumn{4}{|c|}{ LEGENDA } \\
\hline$\vec{v}$ & Grupo focal para veículos & G & Indicação verde (green) \\
\hline$\vec{P}$ & Grupo focal para pedestres & $\mathrm{R}$ & Indicação vermelha (red) \\
\hline$\longrightarrow$ & Movimentos de veículos & A & Indicação amarela (ambar) \\
\hline$--\rightarrow$ & Movimentos de pedestres & 1 & Entreverdes $(\mathrm{I}=\mathrm{A}+\mathrm{Rt})$ \\
\hline
\end{tabular}

Figura 3-2: Legenda dos componentes semafóricos

Um cruzamento de duas vias de sentido único de circulação terá a operação semafórica esquematizada na Figura 3-3:
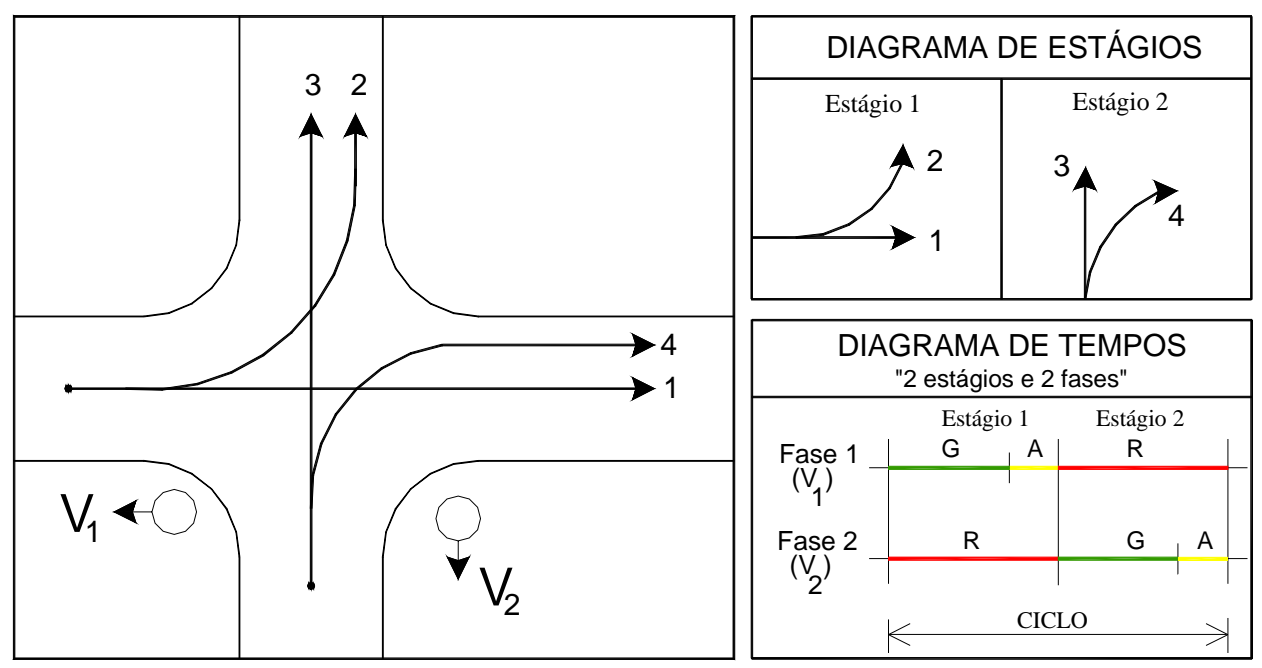

Figura 3-3: Esquema de operação semafórica para vias de sentido único de circulação

O esquema para operação em duas vias de sentido único de circulação também poderá incluir uma fase exclusiva para travessia protegida de pedestres, com a utilização de vermelho total para os veículos, conforme ilustra a Figura 3-4. 

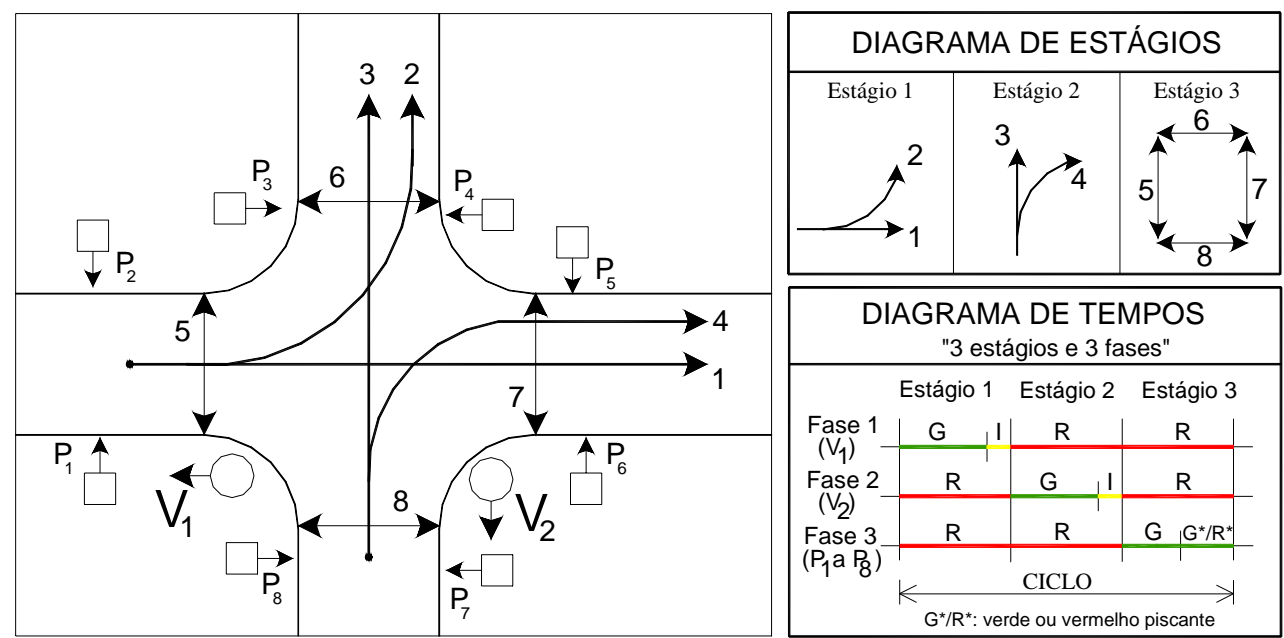

Figura 3-4: Esquema de operação semafórica para vias de sentido único de circulação, com fase exclusiva para pedestres

Em cruzamentos semaforizados de uma via de sentido único com uma via de sentido duplo, a operação poderá ter diferentes aspectos, dependendo das condições locais. No Brasil não é comum a utilização de movimentos veiculares permitidos porém não protegidos. Além disso, a operação em cruzamentos de via de sentido único com via de sentido duplo eventualmente segrega uma fase para conversão à esquerda, assim como uma faixa de rolamento exclusiva para acomodar os veículos deste movimento, para evitar que causem prejuízos aos demais fluxos. O movimento de conversão à esquerda pode ser liberado preferencialmente antes do movimento em sentido oposto, chamado de verde “adiantado" e ilustrado na Figura 3-5.
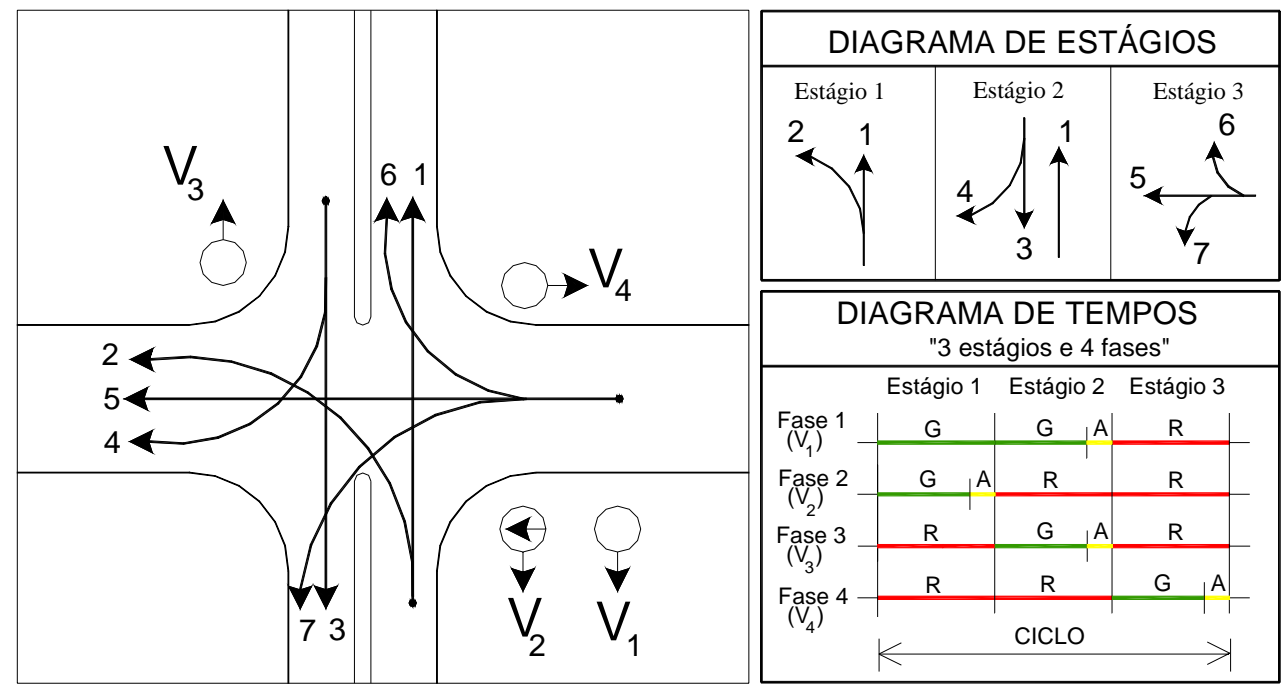

Figura 3-5: Esquema de operação semafórica com fase exclusiva para conversão à esquerda com verde adiantado 
Outra opção menos utilizada para liberação do movimento de conversão à esquerda é depois do movimento do fluxo oposto, denominado verde "atrasado", conforme representado na Figura 3-6.

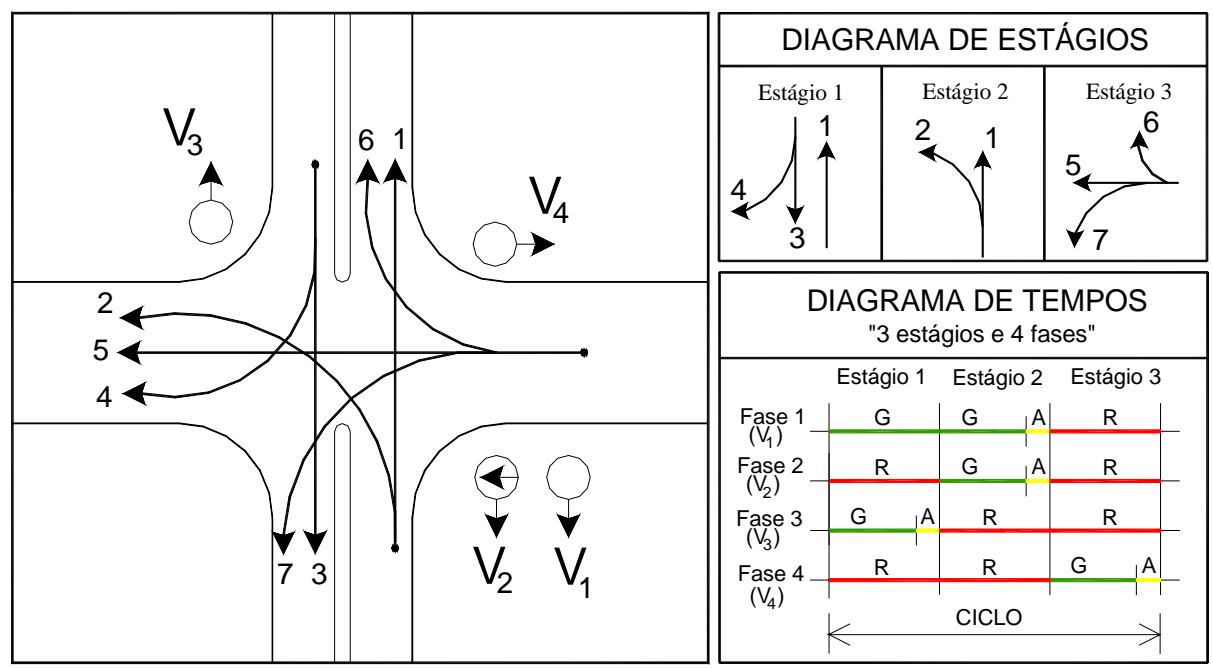

Figura 3-6: Esquema de operação semafórica com fase exclusiva para conversão à esquerda com verde atrasado

Caso haja algum movimento com maior volume que os demais, este poderá ser privilegiado através de uma operação mais eficiente que o inclua em mais de um estágio, conforme apresentado nos dois exemplos de operação alternativos representados na Figura 3-7, em que o volume de tráfego que realiza o movimento 6 é maior do que o volume do movimento 1. Em alguns casos de corredores de tráfego importantes e com alto fluxo de passagem, a conversão à esquerda pode ser proibida, e esta movimentação deverá ser realizada através do contorno ao redor da quadra. Para isto, é recomendável que as vias ao redor da quadra tenham sentido único de circulação, a fim de reduzir movimentos conflitantes.

A operação semafórica de duas vias de sentido duplo de circulação deve ser evitada para situações em que todos os movimentos são permitidos, conforme esquematizado na Figura 3-8, pois desta forma é necessário utilizar mais do que três estágios, o que resulta em elevado tempo perdido total no ciclo, redução da capacidade da interseção e grandes períodos de espera, incentivando inclusive o desrespeito ao semáforo. 

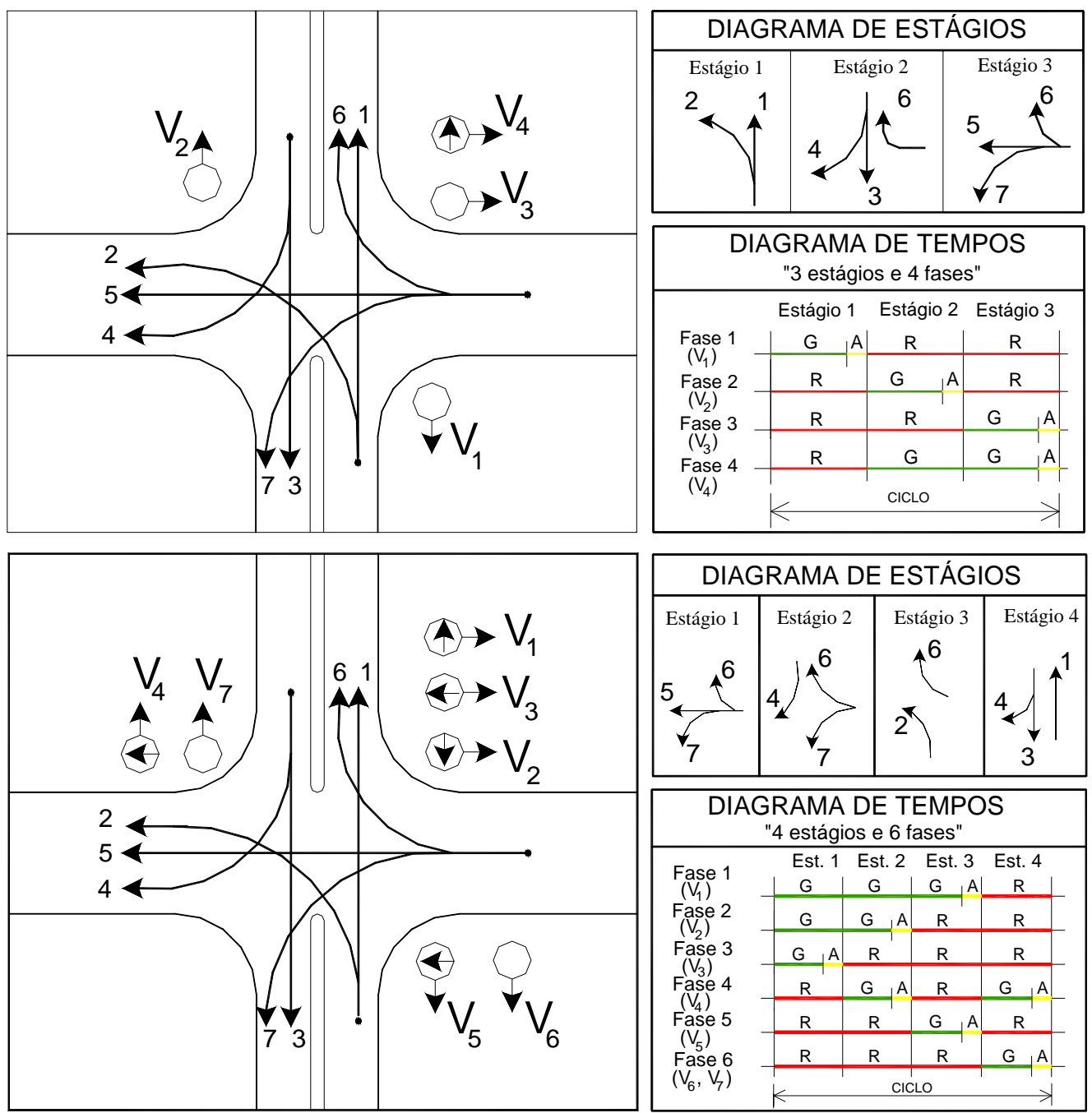

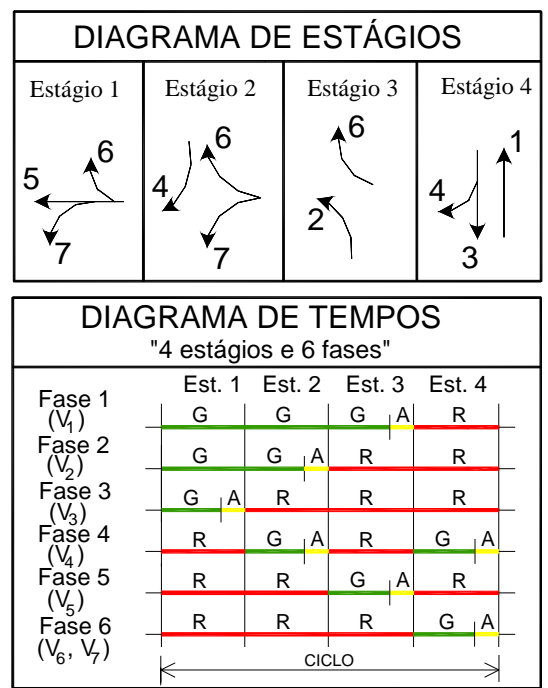

Figura 3-7: Esquemas de operação semafórica alternativos
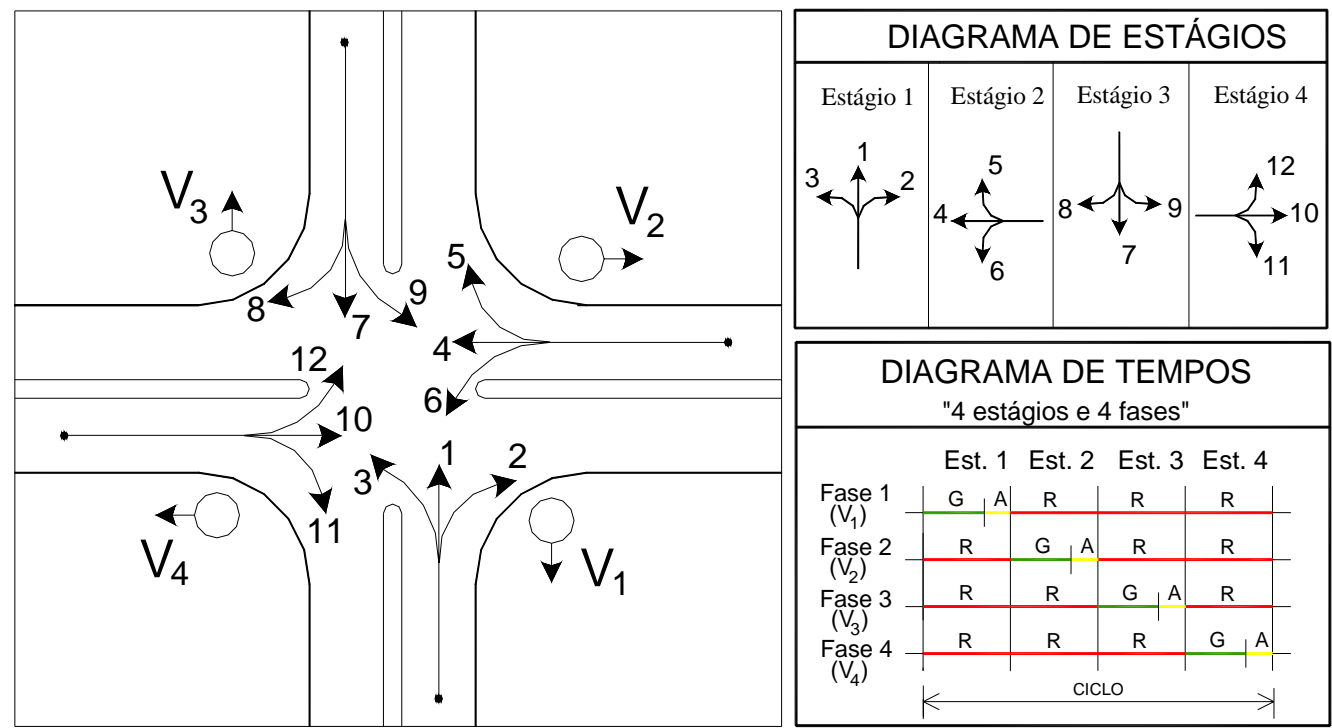

Figura 3-8: Esquema de operação semafórica para vias de sentido duplo de circulação 
Uma solução alternativa é avaliar os volumes de cada movimento da interseção, para restringir as conversões à esquerda em uma das vias com menor demanda deste movimento, de acordo com a Figura 3-9, onde o movimento de conversão à esquerda de uma via foi suprimido.

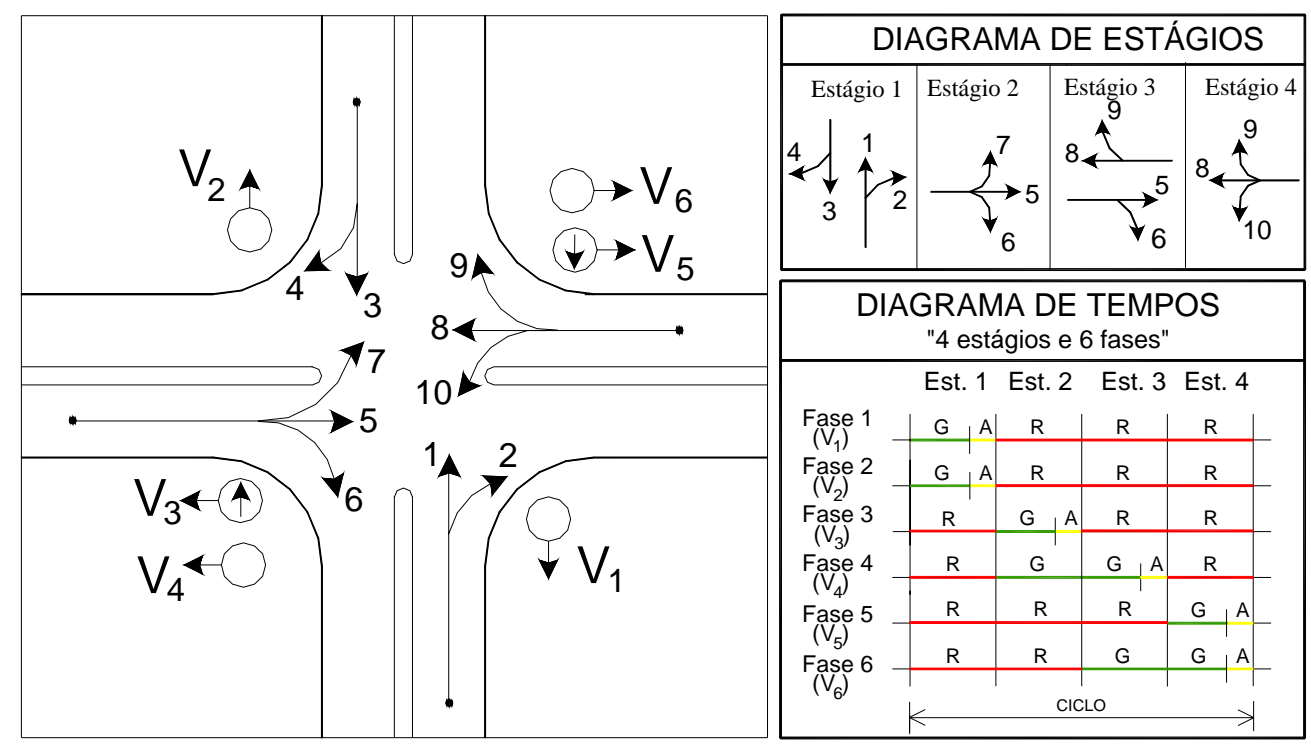

Figura 3-9: Esquema de operação semafórica alternativo para vias de sentido duplo de circulação

\subsubsection{Conjunto Semafórico}

Os porta-focos (displays) informam os motoristas do plano de controle vigente do semáforo (Roess et al., 1998), e pode ser montado de três formas:

- Postes: geralmente mais baratos, porém podem ser inadequados para serem instalados em áreas comerciais, onde possivelmente o porta-foco ficaria obstruído ou confundido pelos letreiros das lojas ou por propagandas;

- Mastros: levam o porta-foco até dentro da interseção, permitindo que fique no eixo da via de aproximação. Podem receber mais de um porta-foco para enfatizar a permissão de determinado movimento ou aumentar a visibilidade do grupo focal;

- Cabos: mais usados em interseções amplas, permitindo a instalação de vários portafocos, um para cada faixa específica de tráfego.

Um exemplo de conjunto semafórico bastante comum no Brasil está ilustrado na Figura 3-10, e é composto pela coluna de sustentação, o braço de projeção do portafoco sobre a via, o anteparo de proteção das lâmpadas e o controlador dos grupos focais. 


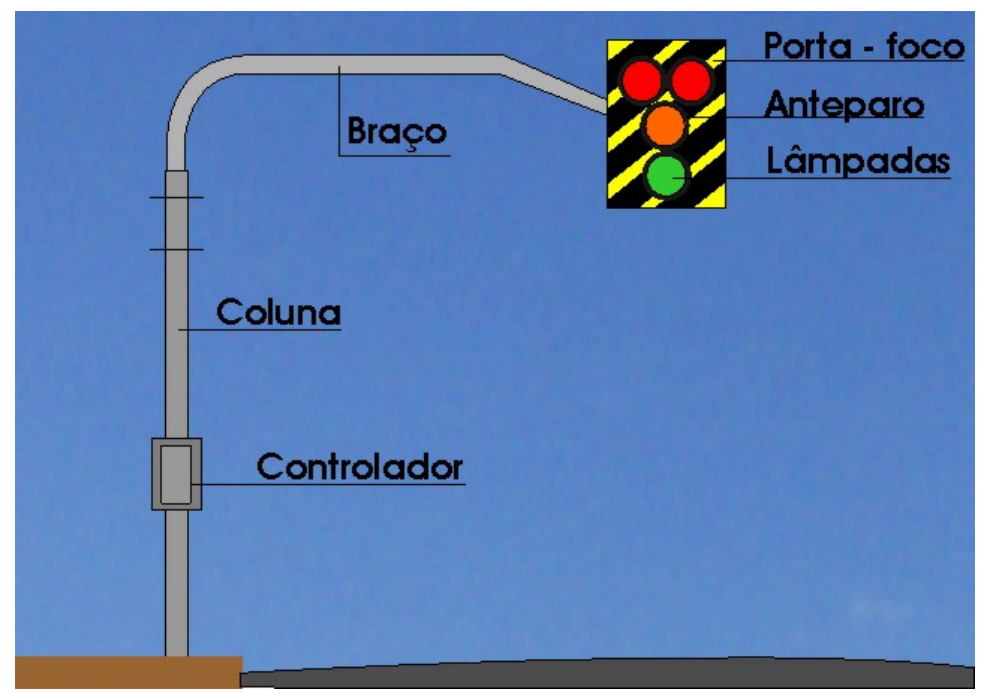

Figura 3-10: Elementos de um conjunto semafórico

As instalações dos focos semafóricos seguem dois modelos. O europeu, com os focos posicionados antes da interseção, e o americano, onde os focos são instalados depois da interseção. A maioria das cidades brasileiras adota o modelo americano, considerando que inexiste normatização em nossa legislação, utilizando postes instalados na parte posterior do cruzamento, após a área de conflito.

\subsubsection{Tipos de Controladores Semafóricos}

Atualmente, os controladores semafóricos são constituídos por equipamentos eletrônicos modernos que utilizam circuitos integrados e contatos digitais, permitindo maior flexibilidade nos ciclos e diversidade nos planos. Porém, muitas cidades brasileiras ainda utilizam equipamentos eletro-mecânicos dotados de engrenagens com diversos tamanhos para diferentes comprimentos de ciclo, acionadas por motor elétrico, onde a volta completa da engrenagem determina um ciclo e a colocação de pinos em posições apropriadas divide o ciclo em fases.

De forma geral, existem três categorias de controle dos semáforos, conforme classificação citada por Webster e Cobbe (1966) e Roess et al. (1998), a serem utilizados de acordo com estudos de engenharia, das condições do local e da tecnologia do controlador:

- Controladores de tempo-fixo: o comprimento do ciclo, as fases e os intervalos são fixos, podendo ter programações fixas diferenciadas ao longo do dia, a fim de atender diferentes condições de volume de tráfego em períodos pré-determinados. Estes controladores são simples e relativamente baratos, e são aconselhados para 
interseções que operam próximo da capacidade ou para uso em sistemas coordenados;

- Controladores atuados por veículos: os períodos de verde são relacionados às flutuações no volume de tráfego, usando detectores nas aproximações, que transmitem as informações ao controlador. Podem variar o ciclo e os tempos de verde em resposta aos dados dos detectores, alterar a ordem e a seqüência das fases, assim como pular ou omitir fases que eventualmente não sejam necessárias em determinados ciclos. São recomendados para interseções com grandes flutuações de volume durante o dia ou para interseções relativamente isoladas com grande número de aproximações ou maior quantidade de fases, operando perto da saturação em todas as aproximações. Estes controladores são inadequados para uso em sistemas semafóricos coordenados, onde se pretenda operar todos os semáforos com único comprimento de ciclo para manter a defasagem e os padrões de progressão;

- Controladores semi-atuados por veículos: os detectores são instalados somente nas aproximações das vias secundárias onde as correntes têm menor fluxo de tráfego. O direito de passagem é dado para a via principal, sendo transferido para a via secundária quando um veículo passa pelo detector, ativando-o e indicando sua presença à espera do serviço.

Os controladores atuados ou semi-atuados por veículos realizam os ajustes para as condições do tráfego, porém limitados por valores mínimos e máximos estabelecidos previamente:

- Período mínimo: menor período de direito de passagem dado para uma fase, variando preferencialmente entre 7 e 15 segundos, suficiente para a passagem dos veículos acumulados entre o detector e a linha de retenção;

- Extensão do período pelos veículos: o período de verde pode ser estendido do mínimo, pelos veículos que passam nos detectores. Para cada veículo que cruza o detector, o período de verde é aumentado de uma quantidade chamada "extensão do período pelos veículos”. Quando o intervalo entre os veículos que cruzam o detector fica maior que a extensão do período de verde, o direito de passagem é transferido para a outra fase, se necessário;

- Período máximo: estabelecido para prevenir que os veículos esperem indefinidamente pelo direito de passagem;

- Período máximo variável: permite que o período máximo seja estendido automaticamente se a taxa média de fluxo de tráfego no final do período máximo 
exceder um valor crítico pré-determinado;

- Período entreverdes variável: tempo de limpeza extra pode ser necessário para proteger a passagem do tráfego;

- Seqüência de estágios: as fases se dão de forma cíclica, e se não há tráfego em uma fase particular, ela é omitida;

- Corte prematuro: para facilitar o movimento de uma quantidade elevada de conversões à esquerda em uma aproximação, o tempo de verde da aproximação oposta pode ser cortado alguns segundos antes.

\subsection{Definição de Estratégias Operacionais}

As áreas da malha viária que já apresentam grande incidência de equipamentos semafóricos, principalmente nas regiões centrais, são ambientes que despertam maior cautela na escolha do tipo de controle a ser implementado. Uma das primeiras questões que o engenheiro de tráfego ou o responsável pela implantação e gerenciamento do controle de tráfego deve se defrontar refere-se ao tipo de estratégia operacional da rede semafórica a ser utilizado. Segundo o Manual de Semáforos do DENATRAN (1984), existem pelo menos três formas distintas que podem ser adotadas para a operação de um sistema semafórico de tempo fixo, considerando semáforos isolados ou então operando de forma coordenada entre si:

- Controle isolado do cruzamento: restringe a operação somente à interseção em questão, sem prever interferências oriundas de interseções adjacentes, sendo recomendado para interseções afastadas fisicamente do conjunto dos demais semáforos em aproximadamente 500 metros ou que apresentem características de fluxo muito distintas das demais;

- Controle arterial de cruzamentos (rede aberta): trata corredores semaforizados no intuito de garantir e privilegiar a progressão para o fluxo de passagem ao longo da via arterial, de forma a manter pelotões de veículos com continuidade de movimento entre as interseções adjacentes. As vias de sentido único são especialmente atrativas, pois facilitam a progressão semafórica ao longo do corredor;

- Controle de cruzamentos em área (rede fechada): utilizado em regiões que concentram maior volume de tráfego ou mesmo congestionamentos, o controle em rede busca realizar simultaneamente a coordenação de todos os cruzamentos semaforizados da área, quer seja para minimizar atrasos e paradas globais ou para maximizar a progressão. Normalmente é realizado através de uma central onde o computador envia os comandos para controlar os semáforos, podendo usar dados de 
campo e estudos de técnicos e engenheiros.

A central computadorizada oferece a possibilidade de alteração das programações, modificação do ciclo, da duração das fases e das defasagens, economizando tempo das equipes técnica e de manutenção, pois também provê informações e emite relatórios sobre falhas nos equipamentos. Detectores no campo podem alimentar com informações a central, servindo como coletores de dados para ajustes, permitindo o desenvolvimento de planos diferenciados e mais eficientes para os movimentos dos veículos no conjunto de vias muito carregadas, através da comparação entre o padrão do tráfego atual estimado dos dados em campo e o esperado.

O sistema de controle de tráfego em área por central computadorizada oferece várias vantagens e facilidades (Webster e Cobbe, 1966):

- provê programações coordenadas de acordo com as condições do tráfego;

- redireciona o fluxo de rotas congestionadas para vias alternativas com capacidade disponível;

- seleciona períodos para funcionamento de faixas ou vias reversíveis;

- restringe movimentos quando há formação de filas nos semáforos subseqüentes;

- prioriza movimentos para limpeza de filas;

- adequa programações de emergência em condições de bloqueio por acidentes, obras, eventos especiais, clima.

Alguns esforços foram direcionados no sentido de indicar o tipo de operação mais adequado para cada condição de tráfego. O Manual de Semáforos do Departamento Nacional de Trânsito apresenta um critério para auxiliar na decisão do técnico na adoção da estratégia entre semáforos adjacentes, realizando previamente a análise do Índice de Interdependência conforme a Equação (3-1) (DENATRAN, 1984):

$$
I I=\frac{0,5}{1+t}\left(\frac{n \cdot q_{\text {máx }}}{q_{1}+q_{2}+\ldots+q_{n}}-1\right)
$$

em que II: Índice de Interdependência;

$t$ : tempo de percurso entre ambos os semáforos, em minutos (comprimento do trecho dividido pela velocidade média dos veículos);

$n$ : número de faixas de tráfego que escoam os veículos procedentes do cruzamento anterior; 
$q_{\text {máx }}:$ fluxo direto procedente do trecho anterior;

$q_{1}+q_{2}+\ldots+q_{n}$ : fluxo total que chega na interseção.

Os intervalos descritos na Tabela 3-1 sugerem o tipo de operação mais adequada a ser adotada em cada trecho:

Tabela 3-1: Parâmetros para definição do Índice de Interdependência

\begin{tabular}{cc}
\hline Índice de Interdependência & Estratégia de operação \\
\hline $0<I I \leq 0,35$ & operação isolada \\
$0,35<I I \leq 0,43$ & operação isolada ou coordenada \\
$0,43<I I \leq 1,00$ & operação coordenada \\
\hline
\end{tabular}

Skabardonis et al. (1998) também propuseram um critério para seleção do tipo de controle mais apropriado, demonstrando através de vários estudos em campo que a estratégia escolhida pode melhorar o desempenho de uma interseção ou de todo o sistema. Os fatores a serem considerados na seleção são:

- Características de tráfego na interseção: grau de saturação, proporção do fluxo direto conflitante, movimentos de conversão, número e seqüência das fases, atividade de pedestres;

- Características físicas da interseção: geometria e leiaute, distância entre interseções, localização no sistema;

- Características do sistema: comprimento da via arterial, configuração da rede, variação dos volumes da via arterial, qualidade da progressão.

Inicialmente a análise é realizada separadamente para arteriais e redes, avaliando a relação entre volume e capacidade nas interseções, associada aos movimentos de conversão e ao número de fases, respectivamente. Desta forma, obtémse uma indicação para o tipo de controle a ser adotado (fixo, atuado ou semi-atuado). Em seguida, o Índice de União deve ser calculado para cada um dos tramos da via arterial ou da rede, através da Equação (3-2):

$$
I U=\frac{V}{d}
$$

em que $I U$ : Índice de União;

$V$ : volume bidirecional da hora pico [veíc/h];

$d$ : distância entre os semáforos [ft]; 
Todo o valor de $I U$ que seja maior que 0,5 sugere a progressão semafórica, na forma recomendada na Tabela 3-2 apresentada abaixo:

Tabela 3-2: Parâmetros para definição do Índice de União

\begin{tabular}{cc}
\hline Índice de União & Estratégia de operação \\
\hline$I U \leq 0,5$ para todas as direções & operação isolada \\
$I U>0,5$ somente na via principal & operação coordenada na arterial \\
$I U>0,5$ na via principal e pelo & operação coordenada nestas duas vias \\
menos em uma via secundária & operação coordenada na rede \\
$I U>0,5$ em todas as vias &
\end{tabular}

Considerando, por exemplo, a situação do quadrilátero central da cidade de Londrina - Paraná, onde o espaçamento entre os cruzamentos semaforizados é de aproximadamente $125 \mathrm{~m}$ (410ft) e o volume horário em cada aproximação varia entre 500 e 1200 veículos na hora pico, o Índice de União apresenta valores entre 1,20 e 2,90, todos maiores que 0,5 sugerindo que as interseções fazem parte de uma densa rede que deve operar com estratégias de coordenação entre os semáforos adjacentes.

Após a definição da estratégia de operação dos semáforos, é necessário definir a programação mais adequada da estratégia indicada. No caso da operação ser isolada, aplica-se o método de Webster para definição do ciclo ótimo para o qual o atraso total numa interseção é mínimo. Após a realização de diversas pesquisas através da TRRL Transportation and Road Research Laboratory da Inglaterra, Webster e Cobbe (1966) apresentaram a metodologia para definição do ciclo ótimo e da duração das fases, conforme Equações (3-3) e (3-4). Esta técnica foi amplamente utilizada e adotada como padrão para regulagem de semáforos no Brasil, por se tratar de um método completo e detalhado, que aborda praticamente todos os fatores que interferem no valor da capacidade.

$$
C o=\frac{1,5 L+5}{1-\sum_{i} Y_{c}^{i}}
$$

em que Co: duração do ciclo ótimo [s];

$L:$ tempo total perdido no ciclo [s];

$Y c^{i}$ : taxa de ocupação crítica na fase $i$.

A duração do verde de cada fase busca minimizar o tempo médio de espera dos veículos na interseção, dividindo o ciclo disponível de forma proporcional à razão entre 
a taxa de chegadas e o fluxo de saturação da aproximação.

$$
G e_{i}=\frac{Y_{c}^{i}}{\sum_{i} Y_{c}^{i}} \times G e
$$

em que $G e_{i}$ : verde efetivo da fase $i[\mathrm{~s}]$;

$G e$ : verde efetivo total do ciclo [s], sendo $G e=C o-L$.

Para a estratégia de operação coordenada, os ciclos ótimos são calculados para as interseções mais críticas de tráfego, a fim de escolher o maior valor que será selecionado como o ciclo comum a ser utilizado para a rede ou corredor. Além da definição do ciclo e da duração das fases é necessário definir as defasagens entre semáforos de interseções próximas, ou seja, coordenar os semáforos de forma a garantir a fluidez da corrente de tráfego.

\subsection{Aspectos sobre Coordenação Semafórica}

A coordenação de semáforos em um corredor ou rede viária consiste, basicamente, em determinar as diferenças entre os instantes de início dos tempos de verde de cada um dos semáforos (defasagens), de tal forma a garantir que o maior número de veículos consiga circular pela rede sem a necessidade de parar nos semáforos fechados. Historicamente, segundo Roess et al. (1998), a maioria dos sistemas de coordenação envolve controladores de tempo fixo, uma vez que a utilização do comprimento do ciclo igual ou múltiplo para todas as interseções é um pré-requisito do controle coordenado.

Para manter um sistema de semáforos em coordenação ao longo de uma única arterial ou mesmo em uma rede, os controladores das interseções individuais devem ser interconectados. Um controlador mestre é usado para enviar pulsos de coordenação a todos os controladores das interseções, e deve ter um relógio que irá selecionar o plano a ser implementado dependendo da hora do dia e da semana.

De acordo com Roess et al. (1998), os sistemas mais sofisticados incluem semáforos atuados que buscam manter a coordenação, assegurando que o tempo de verde da via principal não seja interrompido a não ser que haja quantidade significante de veículos à espera nas vias transversais. Outros sistemas de ajuste de tráfego utilizam detectores ao longo de uma arterial para medir os níveis de tráfego, computar o fluxo em cada direção como uma porcentagem do carregamento da hora pico esperado e usar esta informação para determinar o plano a ser selecionado que melhor sirva o tráfego 
observado. Posteriormente, este sistema de resposta de tráfego passou a usar detectores de ocupação para fazer a seleção do plano. Ultimamente, para redes mais complexas, o uso de sistemas computacionais expandiu de maneira significativa o número de semáforos que podem ser coordenados.

\subsubsection{Benefícios da Coordenação Semafórica}

A coordenação semafórica facilita a circulação do tráfego, promovendo sua movimentação suave ao longo da rede, em velocidades eficientes, através da formação de pelotões que atravessam sucessivas interseções com menor espaçamento entre os veículos (Sripathi et al., 1995), prevenindo a formação de filas, evitando paradas, atraso e desgaste aos veículos. Esta é também uma maneira efetiva de reduzir o consumo excessivo de combustível e preservar o meio ambiente através da mínima poluição atmosférica (Wallace e Courage, 1982).

Portanto, a coordenação semafórica torna-se muitas vezes mais importante do que algumas intervenções físicas, pois sua qualidade pode melhorar até dois níveis no serviço oferecido na via (Roess et al., 1998), sem a necessidade de grandes investimentos. O Manual de Semáforos do DENATRAN (1984) atribuiu ao ajuste adequado das defasagens entre semáforos, reduções na ordem de 10 a 30\% no atraso sofrido pelos veículos.

De acordo com Green e Robertson (1974) os benefícios ao tráfego e o custo em equipamentos na operação com coordenação semafórica dependem principalmente da distância entre as interseções, pois com o aumento da distância os benefícios tendem a diminuir como efeito da dispersão do pelotão, e os custos com equipamentos convencionais tendem a aumentar devido à necessidade de conexões por cabo. Quanto maior a dispersão do pelotão viajando através de um corredor, maior será a proporção de paradas nos semáforos, e menores os benefícios obtidos com a coordenação.

Veículos oriundos de um semáforo freqüentemente mantêm-se agrupados por aproximadamente 300 metros, portanto a coordenação é normalmente utilizada para semáforos distanciados em até 800 metros. Em alguns casos, dois semáforos estão tão próximos que deveriam ser considerados como sendo um único e outros estão tão afastados que poderiam ser considerados independentes (Roess et al., 1998).

Outros fatores podem reduzir sensivelmente os benefícios da coordenação, como a existência de estacionamento ou fila dupla, interseções complicadas que incluem controladores com múltiplas fases, grande variações nas velocidades do 
tráfego, espaçamento muito pequeno entre semáforos e alto volume de conversões.

Existem diversos métodos de coordenação flexível descritos na literatura, sendo que aqueles mais citados serão detalhadamente abordados no próximo capítulo. 


\section{MÉTODOS DE COORDENAÇÃO SEMAFÓRICA}

Quando duas ou mais interseções semaforizadas estão próximas umas das outras, dispostas ao longo de um corredor de tráfego ou integrantes de uma rede, torna-se necessária alguma forma de coordenação entre os semáforos para reduzir atrasos e prevenir repetidas paradas (Webster e Cobbe, 1966). Os esquemas de coordenação semafórica existem na Inglaterra e nos Estados Unidos desde 1926, e os métodos gráficos de obtenção das bandas de progressão são conhecidos desde o início da década de 1930 (Bavarez e Newell, 1967).

Assim que os computadores ficaram mais acessíveis, as soluções computacionais aceleraram entre as décadas de 1960 e 1970 (Roess et al., 1998), e os pesquisadores concentraram-se no desenvolvimento de técnicas computacionais de coordenação semafórica.

De acordo com as condições de tráfego, Webster e Cobbe (1966), o Manual de Semáforos do DENATRAN (1984) e Roess et al. (1998) sugerem a utilização de diferentes formas de coordenação, tais como:

- Sistema Simultâneo: o esquema de coordenação simultânea pressupõe que todos os semáforos ao longo da via controlada deverão ter o mesmo aspecto para as mesmas correntes de tráfego ao mesmo tempo, ou seja, abrir simultaneamente. Este sistema pode encorajar o aumento da velocidade quando os motoristas tentam passar a maior quantidade de interseções possíveis antes do semáforo fechar, portanto somente deve ser utilizado quando o espaçamento entre semáforos é pequeno;

- Sistema Alternado: os semáforos consecutivos ao longo da via controlada deverão apresentar indicações contrárias, para que os veículos viajem uma quadra na metade do tempo do ciclo, e caso os motoristas excedam na velocidade, irão parar em cada semáforo. Este sistema não é adequado para ruas onde a distância entre interseções varia muito, mas sim para quadras que apresentem praticamente o mesmo comprimento;

- Sistema Reverso: em algumas circunstâncias, as filas formadas nas quadras são tão longas que a defasagem ideal deve ser negativa. O semáforo a jusante deve ficar verde antes do semáforo a montante, para permitir tempo suficiente para a fila começar a se mover antes da chegada do pelotão; 
- Sistema Flexível: este esquema requer a definição da cada defasagem entre pares de semáforos da via arterial ou da rede, podendo buscar a melhor estratégia de coordenação segundo três abordagens distintas: 1) maximização da largura da banda verde de progressão, que consiste em definir as defasagens entre os instantes de abertura de semáforos consecutivos de forma que os motoristas que percorrem a via encontrem os semáforos abertos, criando assim um efeito de “onda verde”; 2) minimização dos atrasos e paradas, que consiste em definir os instantes de abertura dos semáforos de forma a minimizar uma combinação entre os atrasos sofridos por cada veículo e o número de paradas nas interseções; ou 3) uma forma combinada que reúne de maneira seqüencial ou simultânea, as vantagens de ambos os métodos mencionados anteriormente.

A seguir, as técnicas de obtenção das defasagens para sistemas de coordenação flexível são descritas, enfocando principalmente a evolução dos métodos computacionais off-line de coordenação utilizados em operações semaforizadas de tempo fixo. Antes, a fim de facilitar a compreensão dos métodos, algumas definições úteis são apresentadas.

\subsection{Definições Básicas}

No caso de modelos analíticos de coordenação baseados na maximização da banda verde, o diagrama espaço-tempo também é usado como base para a definição das variáveis mostradas na Figura 4-1 e definidas a seguir:

$c$ : duração do ciclo [s];

$r_{i}, r_{j}$ : duração dos vermelhos dos semáforos $i$ e $j$ para a via analisada [s];

$x_{i}, x_{j}$ : instantes referentes aos centros dos vermelhos dos semáforos $i$ e $j[\mathrm{~s}]$;

$y_{i}, y_{j}$ : posições dos centros das interseções semaforizadas $i$ e $j$ em relação à origem do diagrama espaço-tempo [m];

$v_{i j}, v_{j i}$ : velocidades médias de percurso entre semáforos $i$ e $j$ e entre semáforos $j$ e $i[\mathrm{~km} / \mathrm{h}]$;

$b_{i j}, b_{j i}$ : largura das bandas verdes nos sentidos $i-j$ e $j-i[\mathrm{~s}]$;

$t_{i j}, t_{j i}:$ tempos de viagem nos segmentos $i-j$ e $j-i[\mathrm{~s}]$;

$\theta_{i j}, \theta_{j i}$ : defasagens entre semáforos nos sentidos $i-j$ e $j-i[\mathrm{~s}]$. 


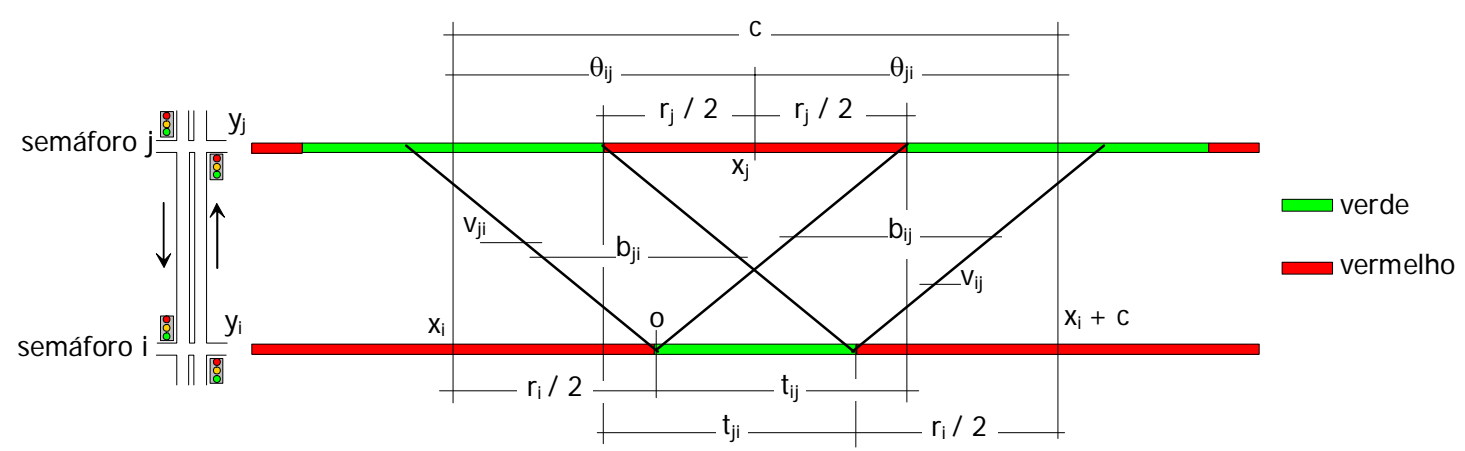

Figura 4-1: Variáveis utilizadas no método de maximização da banda verde

As defasagens $\theta_{i j}$ e $\theta_{j i}$ entre semáforos nos sentidos $i-j$ e $j-i$ são as diferenças entre os pontos (ou instantes) centrais dos vermelhos dos semáforos $i-j$ e $j-i$, respectivamente:

$$
\begin{gathered}
\theta_{i j}=x_{j}-x_{i} \\
\theta_{j i}=x_{i}+c-x_{j}
\end{gathered}
$$

Substituindo (4-1) em (4-2) é possível observar que:

$$
c=\theta_{i j}+\theta_{j i}
$$

sendo $0 \leq \theta_{i j} \leq c$ e $0 \leq \theta_{j i} \leq c$.

\subsection{Métodos de Maximização da Banda Verde}

O método mais freqüente de coordenação flexível é a maximização da banda verde, que objetiva a passagem da quantidade máxima de veículos sem paradas obrigatórias, permitindo um fluxo de tráfego priorizado e contínuo, principalmente em corredores arteriais. Idealmente os tempos de verde devem aparecer progressivamente ao longo da rota, através de defasagens adequadas entre os inícios dos verdes entre semáforos consecutivos, para corresponder à dispersão dos pelotões de tráfego e facilitar o movimento preferencial para o fluxo com maior volume em cada período projetado.

As defasagens deste esquema de coordenação flexível, necessárias para a criação do efeito "onda verde”, podem ser definidas pelo procedimento convencional com cálculos numéricos, pelo processo de tentativa e erro através da manipulação gráfica do Diagrama Espaço-Tempo ou por procedimentos computacionais, descritos a seguir. 


\subsubsection{Procedimento Convencional}

De acordo com Magalhães (1981), o método convencional de progressão flexível considera as defasagens em vias de mão única como sendo o tempo de viagem realizado por veículos entre semáforos adjacentes, e são calculadas conhecendo-se a velocidade média dos pelotões de tráfego e as distâncias que separam os pares de semáforos, conforme a Equação (4-4):

$$
\theta_{i j}=3,6 \frac{d_{i j}}{v_{i j}}
$$

em que $\theta_{i j}$ : defasagem entre os semáforos $i$ e $j[\mathrm{~s}]$;

$d_{i j}$ : distância entre os semáforos $i$ e $j[\mathrm{~m}]$;

$v_{i j}$ : velocidade média do pelotão de veículos entre os semáforos $i$ e $j[\mathrm{~km} / \mathrm{h}]$.

Caso haja fila formada no semáforo $j$ devido a veículos que não conseguiram atravessar a interseção no ciclo anterior, a Equação (4-5) deverá ser utilizada:

$$
\theta_{i j}=3,6 \frac{d_{i j}}{v_{i j}}-\left(\frac{Q I_{j}}{S_{j}}+T P I_{j}\right)
$$

em que $Q I_{j}$ : fila média inicial no semáforo $j$ [veículos];

$S_{j} \quad$ : taxa de liberação da fila no semáforo $j$ [veíc/s];

$T P I_{j}$ : tempo perdido no semáforo $j$, devido ao começo de movimento da fila inicial [s].

Em vias de duplo sentido de circulação, $\theta_{i j}$ é calculado como demonstrado na Equação 4-5, e a defasagem $\theta_{j i}$ para o outro sentido é dada pela Equação (4-6):

$$
\theta_{j i}=3,6 \frac{d_{j i}}{v_{j i}}-\left(\frac{Q I_{i}}{S_{i}}+T P I_{i}\right)
$$

Neste caso, é necessário considerar ainda a Equação (4-3), mencionada no item 4.1 das definições básicas, como condição do tamanho do ciclo $c$.

Porém, na maioria dos casos esta condição não pode ser encontrada, portanto é comum na prática o favorecimento de uma direção de viagem com maior volume de tráfego, em detrimento à direção de menor volume, tornando o método convencional de progressão bastante limitado para ajustes em corredores de sentido duplo de tráfego. 


\subsubsection{Diagrama Espaço-Tempo}

A técnica manual de progressão flexível mais conhecida e freqüentemente adotada em cidades brasileiras para coordenar semáforos é o Diagrama Espaço-Tempo. Nesse caso, utiliza-se um procedimento gráfico de tentativa e erro, que foi desenvolvido entre as décadas de 1930 e 1940, para definir as bandas verdes e as defasagens semafóricas do sistema de progressão. Este método de coordenação permite que o engenheiro de tráfego visualize previamente a largura da banda verde disponível, sendo que a progressão também é facilmente percebida pelos motoristas. No entanto, o procedimento mostra-se bastante trabalhoso para a coordenação de várias interseções, especialmente em vias de duplo sentido ou redes mais complexas.

Webster e Cobbe (1966) apresentaram no Road Research Technical Paper $n^{\circ}$ 56 um apêndice sobre Sistemas de Coordenação Semafórica, com a descrição detalhada da preparação manual do Diagrama Espaço-Tempo, produzido pelo Ministério de Transporte e baseado no trabalho originalmente preparado pelo Vehicle Actuated Road Signal Development Association em Fevereiro de 1965. O procedimento é iniciado com o cálculo dos ciclos ótimos de cada interseção, visando identificar o maior ciclo que será estabelecido para todo o sistema, sendo posteriormente definidas as divisões dos tempos de verde e vermelho em cada interseção e a defasagem entre interseções sucessivas ao longo da rota.

Os dados necessários para a preparação do Diagrama Espaço-Tempo são:

- a velocidade de progressão desejada da rota;

- contagens volumétricas em cada interseção para decidir inicialmente quantas interseções serão incluídas no esquema, o que pode ter que ser modificado posteriormente, dependendo dos resultados das bandas obtidas pelo diagrama. As contagens devem ser divididas por hora, durante o período de 16 horas, anotando para cada aproximação o volume de fluxo direto, conversão à esquerda e à direita;

- o ciclo ótimo para condições do período de pico para cada interseção, além do número de fases, comprimento do vermelho total, fluxo de saturação e tempo perdido. A interseção que tiver o tráfego mais intenso e portanto necessitar do tempo de ciclo mais longo é designada "mestre”, e este ciclo deverá ser adotado para as interseções restantes ao longo do trecho. Uma interseção "mestre” diferente pode ser escolhida (e também ciclo diferente) para cada uma das situações de tráfego que ocorram durante a semana, fora de pico e finais de semana. 
A preparação do Diagrama Espaço-Tempo é essencialmente uma questão de buscar a cada tentativa uma solução de progressão bidirecional melhor do que a antecedente. Inicialmente, uma linha da velocidade de progressão é proposta na direção do maior fluxo, e desenhada a partir da origem do diagrama. Linhas horizontais são desenhadas através do diagrama para identificar a posição de cada interseção em relação à origem, e então os períodos de verde e vermelho para a rota principal são alocados, preferencialmente em tiras separadas de papel que possam ser movimentadas e ajustadas a fim de formar a banda nesta direção. A banda de progressão ao longo da rota principal estará então definida na velocidade desejada, e os períodos de verde e vermelho para a direção oposta devem ser examinados para ver se são adequados para seu volume de tráfego, conforme ilustrado na Figura 4-2. Deve ser observado que na prática a produção manual do diagrama fica muito trabalhosa se o número de interseções controladas ao longo da rota exceder seis (Webster e Cobbe, 1966).

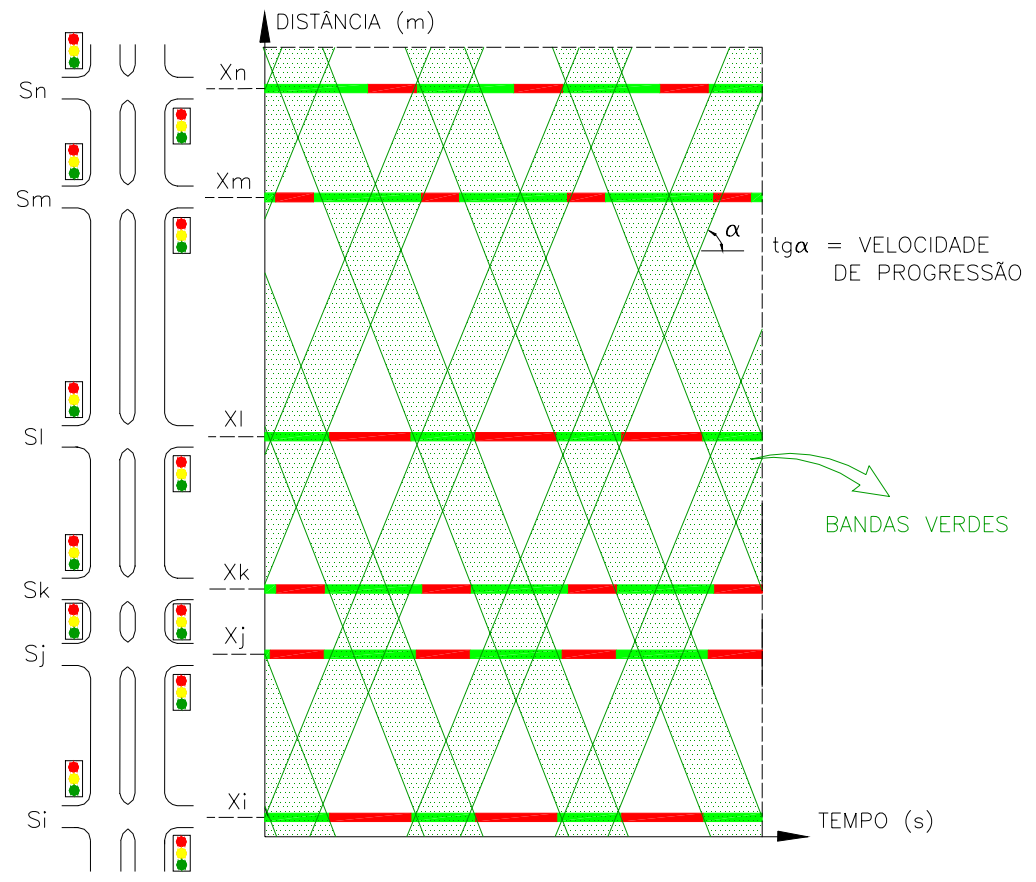

Figura 4-2: Diagrama Espaço-Tempo para um corredor viário hipotético

Uma pesquisa deve revelar se a velocidade constante é apropriada, pois características físicas da via (gradientes e curvas) ou volumes de tráfego podem sugerir que diferentes velocidades são mais adequadas para diferentes seções da rota. Para alcançar uma progressão aceitável nas duas direções, pode-se mudar a ordem cíclica das fases das interseções, além de cuidados especiais que devem ser tomados para certificar que importantes vias transversais não sejam bloqueadas pelo tráfego armazenado na via principal. 


\subsubsection{Half-Integer Synchronization}

Os métodos computacionais de coordenação flexível através da maximização da banda verde são uma extensão dos métodos manuais em que o diagrama espaço-tempo é utilizado para definir, através de tentativa e erro, as defasagens que fornecem a maior largura de banda possível. Os métodos analíticos de maximização da banda verde mais conhecidos foram desenvolvidos por John D. C. Little, do MIT - Massachusetts Institute of Technology. O primeiro método, descrito nos artigos de Morgan e Little (1964) e Little et al. (1966), é denominado Half-Integer Synchronization, e consiste em determinar as melhores posições dos centros dos vermelhos dos vários semáforos de duas fases ao longo de uma via, de tal forma a conseguir a maior largura de banda verde possível nos dois sentidos de tráfego e, se desejado, modificar tais valores para aumentar a banda no sentido de maior volume de tráfego (Demarchi e Dutra, 2004a).

O nome do método diz respeito ao tipo de solução obtida, pois as defasagens ótimas correspondem a 0 ou $1 / 2$ do valor do ciclo semafórico $c$ (isto é, $0 . c / 2$ ou $1 . c / 2$ ), conforme ilustra a Figura 4-3, quando a velocidade de progressão é igual em ambas as direções da via. Existem somente duas opções possíveis de coordenação para cada par de semáforos ao longo da via arterial, portanto este tipo de problema em que é necessário escolher um dentre dois possíveis valores de uma variável representa um problema de programação inteira. Segundo Magalhães (1981), o método de Morgan e Little demonstra que os semáforos ao longo da arterial estarão coordenados para a máxima largura total da banda em ambas as direções, selecionando uma destas duas possibilidades.

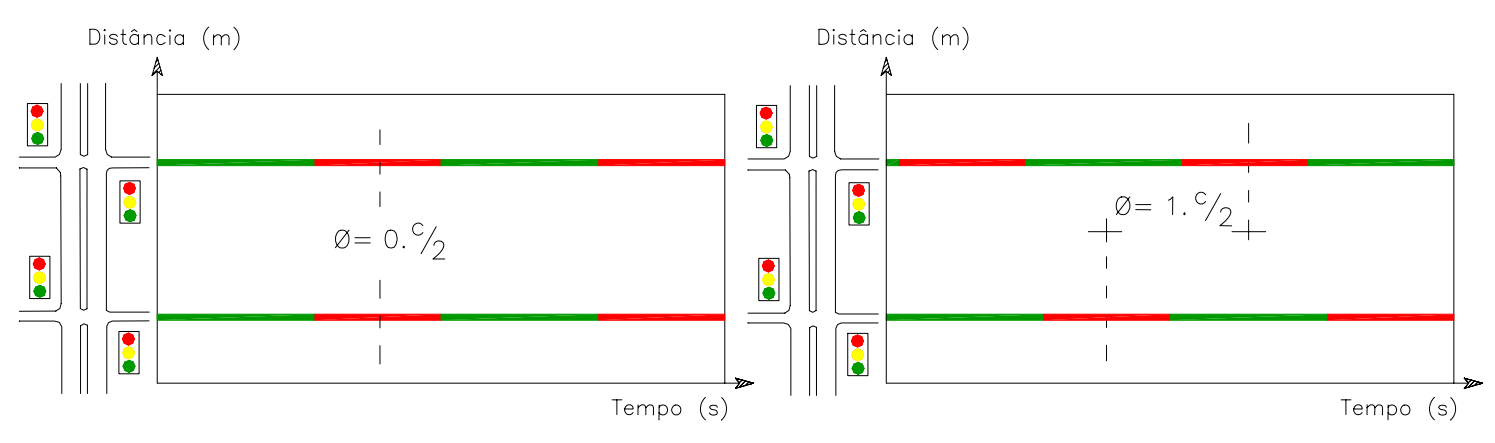

Figura 4-3: Possíveis posições dos centros dos vermelhos

O algoritmo computacional utilizado no método Half-Integer Synchronization requer como dados de entrada o número de semáforos, os espaçamentos entre eles, um ciclo comum, a duração do verde e do vermelho de cada semáforo e os tempos de viagem entre semáforos adjacentes em cada direção. 
O método consiste inicialmente, na definição da maior largura de banda possível para pares de semáforos com duas fases. Para isso, Morgan e Little (1964) definem que em qualquer rede de semáforos existe pelo menos um semáforo crítico, identificado como sendo aquele em que a trajetória frontal da banda de um dos sentidos $(i-j$ ou $j-i)$ toca um dos lados do vermelho do semáforo crítico, enquanto que a trajetória traseira da banda do sentido contrário toca o outro lado do vermelho. Morgan e Little (1964) consideram ainda que os semáforos críticos podem ser classificados em 2 grupos:

- Grupo 1: a trajetória frontal da banda no sentido $i-j$ toca o vermelho do semáforo crítico, enquanto que a trajetória traseira no sentido $j-i$ toca o outro lado do vermelho; e

- Grupo 2: a trajetória traseira da banda no sentido $i-j$ toca o vermelho do semáforo crítico, ao mesmo tempo em que a trajetória frontal no sentido $j-i$ toca o outro lado do vermelho.

Na Figura 4-1, o semáforo $j$ enquadra-se no grupo 1, enquanto que o semáforo $i$ pode ser classificado como pertencendo tanto ao grupo 1 como ao grupo 2 . A partir da situação ilustrada na Figura 4-1, as seguintes expressões podem ser definidas:

$$
\begin{aligned}
& \frac{r_{i}}{2}+t_{i j}=\theta_{i j}+\frac{r_{j}}{2} \\
& \frac{r_{i}}{2}+t_{j i}=\theta_{j i}+\frac{r_{j}}{2}
\end{aligned}
$$

Subtraindo (4-8) de (4-7) e lembrando que $\theta_{j i}=c-\theta_{i j}$, é obtido o valor da defasagem entre os vermelhos dos semáforos $i$ e $j$ que fornece bandas iguais nos sentidos $i-j$ e $j-i$ :

$$
\theta_{i j}=\frac{c}{2}+\frac{t_{i j}-t_{j i}}{2}
$$

Além disso, existe outra defasagem para a qual as bandas são iguais, obtida através da Equação (4-10), considerando que num sistema cíclico $c \bmod (c)=0$, ou seja:

$$
\theta_{i j}=\frac{t_{i j}-t_{j i}}{2}
$$

De uma forma geral, as expressões (4-9) e (4-10) podem ser representadas por: 


$$
\theta_{i j}=\left(\pi_{i j} \cdot \frac{c}{2}+\frac{t_{i j}-t_{j i}}{2}\right) \bmod (c)
$$

sendo $\pi_{i j}=0$ ou $\pi_{i j}=1$, e $a$ mod (c) o resto da divisão de $a$ por $c$. Para determinar a banda ótima, é considerado somente um sentido de tráfego (por exemplo, $i-j$ ), pois o valor da banda é igual nos dois sentidos. A banda máxima é definida a partir de suas trajetórias frontal e traseira, sendo que a trajetória frontal $u_{i j}$ é obtida a partir de relações algébricas entre variáveis da Figura 4-1, tomando como origem do sistema o ponto $o$ :

$$
u_{i j}=-\frac{r_{i}}{2}+\theta_{i j}+\frac{r_{j}}{2}-t_{i j}
$$

Morgan e Little (1964) consideram que a expressão (4-12) é equivalente à expressão (4-13), para fazer com que $u_{i j}$ seja igual a $c$ sempre que (4-12) for igual a 0 :

$$
u_{i j}=c-\left(\frac{r_{i}}{2}-\theta_{i j}-\frac{r_{j}}{2}+t_{i j}\right) \bmod (c)
$$

Substituindo (4-11) em (4-13) e fazendo $u_{i j}$ ser dependente de $\pi_{i j}$, é obtida:

$$
u_{i j}\left(\pi_{i j}\right)=c-\left(\frac{r_{i}-r_{j}}{2}+\frac{t_{i j}+t_{j i}}{2}-\pi_{i j} \cdot \frac{c}{2}\right) \bmod (c)
$$

Conseqüentemente, a trajetória que toca o lado esquerdo do vermelho do semáforo $j$ passa pelo semáforo $i$ em $u_{i j}-r_{j}$, o que corresponde à largura a banda verde considerando o semáforo $j$. Neste caso, a maior banda seria obtida a partir de:

$$
\max u_{i j}\left(\pi_{i j}\right)-r_{j}
$$

Considerando diferentes pares de semáforos e $\pi_{i j}=\{0,1\}$, a banda verde máxima e igual para ambas direções é dada por:

$$
b=\max \min \max \left[u_{i j}\left(\pi_{i j}\right)-r_{j}\right]
$$

Como os comprimentos dos pelotões são geralmente diferentes nas duas direções, posteriormente o método utiliza os volumes horários em cada direção e o headway entre os veículos, a fim de ajustar as defasagens para aumentar uma das bandas e favorecer o sentido de maior volume de tráfego, mantendo a outra mais larga possível, de forma a dividir a largura total da banda em proporção aos volumes 
direcionais da via.

Os diagramas obtidos para as situações de bandas bidirecionais máximas iguais e bandas proporcionais aos volumes em cada sentido, descritos como exemplo no artigo de Morgan e Little (1964), estão ilustrados na Figura 4-4.
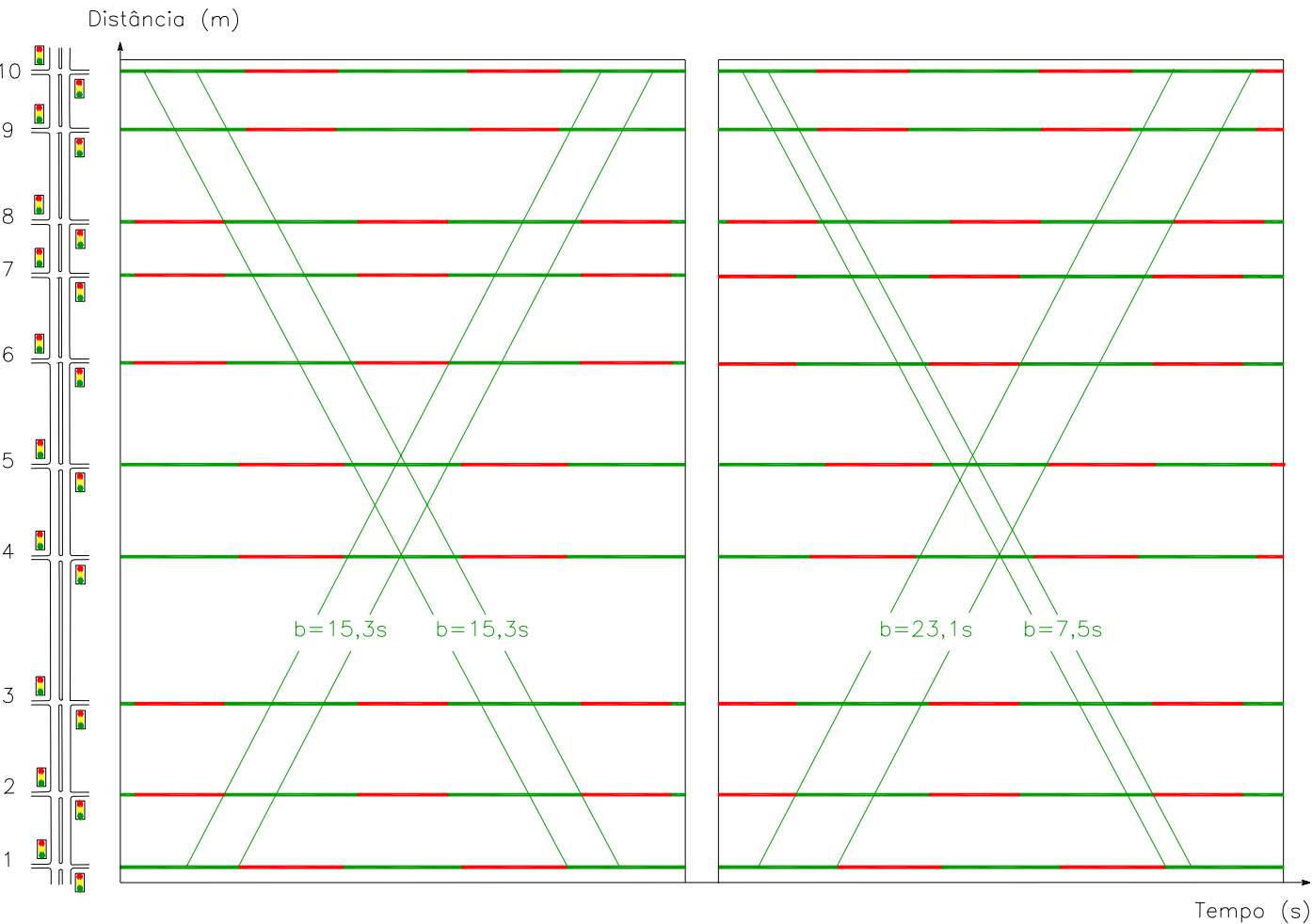

Figura 4-4: Diagramas espaço-tempo obtidos com Half-Integer Synchronization, para um corredor de 10 semáforos com ciclo $=65 \mathrm{~s}$

\subsubsection{SIGART - Signalized Arterial}

Em 1965, o programa SIGART - Signalized Arterial, criado no Metropolitan Toronto Traffic Control System, produzia defasagens entre semáforos convencionais de duas fases, baseado no ciclo, nas velocidades livres e no espaçamento entre os semáforos, que maximizavam as larguras das bandas para a via arterial, podendo favorecer uma direção sobre a outra, dependendo da demanda direcional por hora do dia (Wallace e Courage, 1982).

Embora este programa seja citado por alguns autores em artigos sobre coordenação flexível, não foi possível obter informações sobre sua forma de implementação ou linguagem de programação, nem tampouco identificar se o algoritmo proposto por Morgan e Little (1964) foi adotado como base do programa SIGART. 


\subsubsection{Interferência de Brooks / Bleyl}

Entre 1966 e 1967 Brooks e Bleyl adaptaram o programa Half-Integer Synchronization de Morgan e Little para coordenação entre semáforos de duas fases, através da elaboração de um método computacional para construção de diagramas bidirecionais, convertendo as unidades de velocidade e distância em unidade de tempo de viagem em ambos os eixos, de forma a considerar elementos variáveis (como diferentes velocidades a cada segmento de via) e simplificar os cálculos (Bleyl, 1967). Desenvolvido para a linguagem de programação computacional FORTRAN IV, o método necessita da quantidade de semáforos, suas distâncias, as porcentagens das divisões das fases, os comprimentos de ciclo mínimos e máximos a serem considerados aceitáveis, a proporção desejada das bandas em cada direção em função dos volumes de tráfego direcionais, as velocidades de progressão direcionais desejadas e o limite máximo de tolerância das velocidades sugeridas.

O método toma como origem a interseção com largura de banda mínima, ou seja, com menor tempo de verde na via principal, e determina as larguras máximas das duas bandas. Posteriormente avalia as progressões que minimizam a interferência (ou seja, a quantidade de verde não utilizada nas bandas) no valor total das bandas bidirecionais para um grupo de defasagens, ciclos e velocidades nos segmentos da via, possibilitando também o ajuste das defasagens para favorecer a largura da banda na direção desejada.

\subsubsection{MILP - Mixed-Integer Linear Programming}

A maioria dos programas de coordenação que buscam a maximização das bandas bidirecionais foram desenvolvidos com base no algoritmo de Morgan e Little (1964). Um segundo algoritmo foi desenvolvido por Little (Little, 1966) como uma adaptação do primeiro, aprimorando o método Half-Integer Synchronization de forma a obter a estratégia ótima de coordenação considerando, além da definição das defasagens em uma rede de semáforos, a possibilidade de variação da velocidade de progressão da corrente de tráfego entre interseções e da duração do ciclo dentro de limites mínimos e máximos pré-estabelecidos.

O programa Mixed-Integer Synchronization de otimização de redes semafóricas consiste basicamente em combinar o método Half-Integer Synchronization de vias arteriais individuais e adicionar restrições de conexão entre estas vias para a formação de um sistema fechado. Seu desenvolvimento é baseado no diagrama espaçotempo da Figura 4-5, do qual a maioria das variáveis foi definida no item 4.1, com 
exceção das seguintes variáveis:

$w_{i j}^{i}, w_{i j}^{j}$ : parcelas de verde dos semáforos $i$ e $j$, respectivamente, que estão à esquerda da banda verde no sentido $i-j[\mathrm{~s}]$;

$w_{j i}^{i}, w_{j i}^{j}$ : parcelas de verde dos semáforos $i$ e $j$, respectivamente, que estão à direita da banda verde no sentido $j-i$ [s].

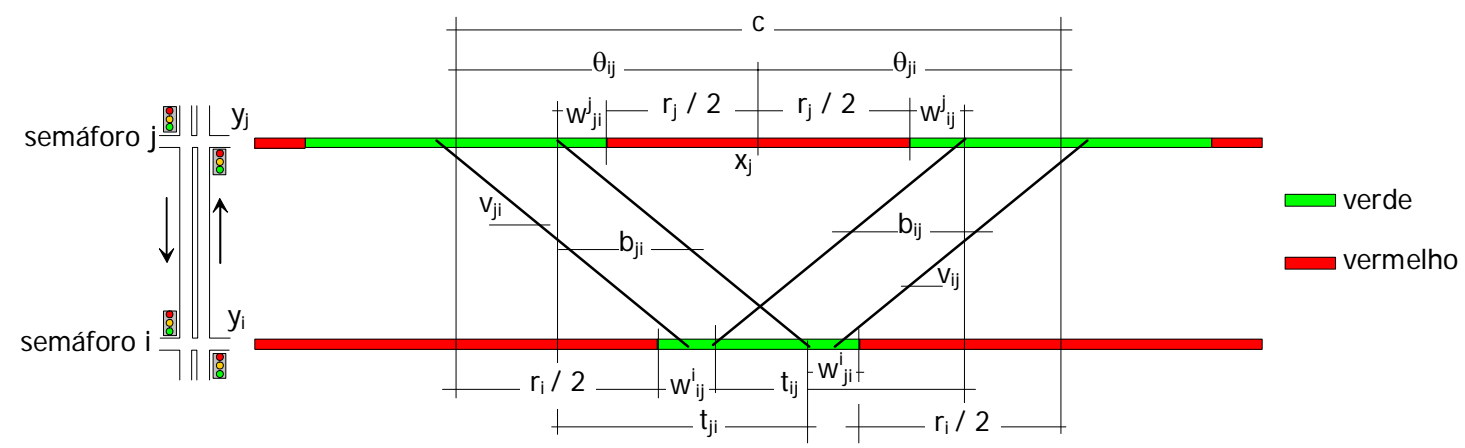

Figura 4-5: Variáveis do método Mixed-Integer Linear Programming

Com o objetivo principal de alocar a largura da banda nas ruas e direções da rede, dois artifícios são utilizados no método Mixed-Integer Synchronization: a limitação da largura da banda para ser maior do que o tamanho necessário para passar o fluxo conhecido, restringindo a progressão à exigência da fração de verde/vermelho associada à demanda de fluxo; e a limitação da progressão à exigência física do laço fechado das quadras da rede.

Da Figura 4-5 é possível identificar as seguintes igualdades:

$$
\begin{aligned}
& \frac{r_{i}}{2}+w_{i j}^{i}+t_{i j}-w_{i j}^{j}-\frac{r_{j}}{2}=\theta_{i j} \\
& \frac{r_{i}}{2}+w_{j i}^{i}+t_{j i}-w_{j i}^{j}-\frac{r_{j}}{2}=\theta_{j i}
\end{aligned}
$$

Na interseção de duas arteriais, o semáforo pode ser crítico para apenas uma delas, portanto uma troca de verde de uma rua para outra pode aumentar a largura da banda em uma arterial sem reduzi-la na outra via. Somando (4-17) com (4-18), a seguinte expressão é obtida:

$$
\left(w_{i j}^{i}+w_{j i}^{i}\right)-\left(w_{i j}^{j}+w_{j i}^{j}\right)+\left(t_{i j}+t_{j i}\right)+\left(r_{i}-r_{j}\right)=\theta_{i j}+\theta_{j i}
$$

As restrições são necessárias para que as bandas verdes nas duas direções 
nutram a cada semáforo uma relação entre si, pois os tempos de verde e de vermelho ocorrem a cada intervalo cíclico. Portanto, a limitação estará também na soma dos tempos entre o centro dos vermelhos, que equivale a um número inteiro $m_{i j}$ de ciclos:

$$
m_{i j} \times c=\theta_{i j}+\theta_{j i}
$$

A expressão (4-20), por sua vez, nada mais é que uma generalização da Equação (4-3), apresentada anteriormente. Dessa maneira:

$$
\left(w_{i j}^{i}+w_{j i}^{i}\right)-\left(w_{i j}^{j}+w_{j i}^{j}\right)+\left(t_{i j}+t_{j i}\right)+\left(r_{i}-r_{j}\right)=m_{i j} \times c
$$

Deve ser observado que a Equação (4-21) é válida para qualquer um dos pares consecutivos de semáforos $i-j$ e, para quaisquer outros pares de semáforos (por exemplo, $i$ e $k$ ), o valor de $m_{i k}$ é obtido pela combinação linear de $m_{i j}$ e $m_{j k}$, ou seja:

$$
m_{i k}=m_{i j}+m_{j k}
$$

Além disso, é possível observar que, para qualquer um dos semáforos de uma rede, existem as seguintes restrições:

$$
\begin{aligned}
& w_{i j}^{i}+b_{i j} \leq c-r_{i} \\
& w_{j i}^{i}+b_{j i} \leq c-r_{i}
\end{aligned}
$$

Tomando como base as expressões anteriores, Little (1966) define que a largura máxima da banda verde para o sistema de semáforos consiste em um problema de programação linear. Considerando, por exemplo, que $b_{i j}=b_{j i}=b$, o problema pode ser expresso da seguinte maneira: determine $b, w_{i j}^{i}$, $w_{j i}^{i}, m_{i j}$, considerando todos os pares $i$-j de semáforos, de forma a maximizar $b$, sujeito às restrições impostas pelas Equações (4-19), (4-23) e (4-24), lembrando que os $m_{i j}$ devem ser variáveis inteiras e que $b, w_{i j}^{i}$ e $w_{j i}^{i}, \geq 0$. Para esse tipo de problema, existem $3 n-1$ restrições e $3 n$ incógnitas para uma rede formada por $n$ semáforos.

Este tipo de problema é apenas um dos apresentados por Little (1966). Outros problemas são extensões do problema aqui apresentado, nos quais são incluídas as determinações das velocidades ótimas de progressão nos trechos entre pares de semáforos, bem como a duração do ciclo do sistema, restritas a uma faixa de variação definida pelo usuário. Também é possível determinar larguras distintas de banda para cada um dos sentidos de tráfego.

Como todos os problemas mencionados consistem em problemas de 
otimização de variáveis contínuas e inteiras, o método recebeu o nome de MILP Mixed-Integer Linear Programming, e utiliza na busca da solução o procedimento branch-and-bound de decisão, que divide o problema em sub-problemas menores, cada um deles com número menor de variáveis. As possíveis soluções das subseções são representadas como nós de uma árvore e o processo de separação delas é representado como galhos, criando uma árvore de decisão para a seleção da melhor solução, conforme demonstrado por Little (1966) e reproduzido na Figura 4-6. De acordo com Little (1966), a eficiência computacional do processo é dependente do método utilizado para realizar as divisões e calcular seus limites.

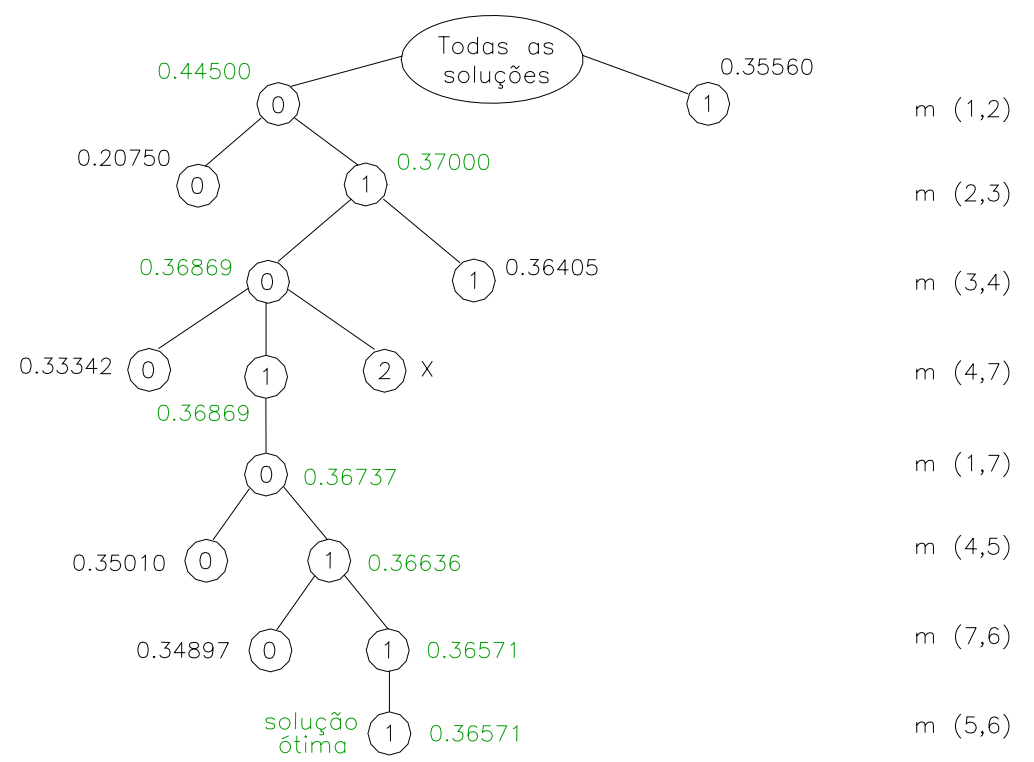

Figura 4-6: Árvore de solução do método branch-and-bound (baseada em Little, 1966)

No procedimento branch-and-bound, os dois primeiros semáforos são avaliados inicialmente, com a definição de suas equações para o problema de programação linear e a determinação da melhor solução, indicada no nó da árvore de decisão. Em seguida, os demais semáforos são adicionados ao problema, até que todos tenham sido avaliados.

A partir das características geométricas da rede, das divisões de cada semáforo, dos limites mínimo e máximo para o ciclo e das velocidades entre semáforos, o método Mixed-Integer Linear Programming gera o ciclo, as divisões, as velocidades e as defasagens entre semáforos que maximizam a soma da largura das bandas nas duas direções das vias da rede, sendo que a largura da banda em uma direção poderá ser uma proporção da outra direção. O diagrama obtido para a situação de bandas bidirecionais máximas iguais, com limite de velocidade mínimo de 48,3 km/h e máximo de 64,4 
km/h, descrito como exemplo no artigo de Little (1966), está ilustrado na Figura 4-7.

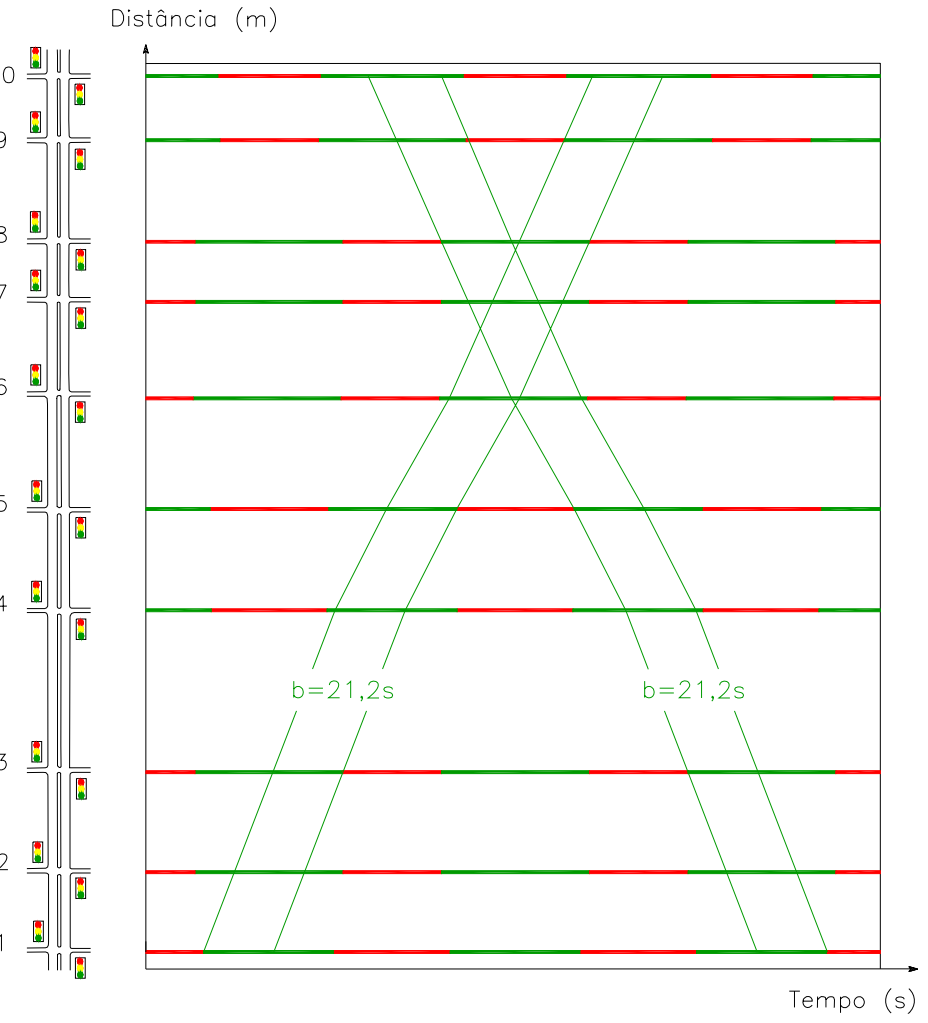

Figura 4-7: Diagrama espaço-tempo obtido com Mixed-Integer Linear Programming, para um corredor de 10 semáforos com ciclo $=75 \mathrm{~s}$

\subsubsection{PASSER - Progression Analysis and Signal System Evaluation Routine}

Os programas anteriores a 1973, que determinavam defasagens para prover a melhor progressão, operavam com semáforos de duas fases, e não se aplicavam em operações semafóricas com múltiplas fases onde os verdes de progressão em cada direção geralmente têm comprimentos desiguais e são defasados entre si. Messer et al. (1973) desenvolveram o modelo macroscópico PASSER - Progression Analysis and Signal System Evaluation Routine, baseado no algoritmo Half-Integer Synchronization de maximização da largura da banda criado por Morgan e Little e no algoritmo de interferência de Brooks e Bleyl, incluindo rotinas para otimização da seqüência de múltiplas fases ao longo de vias arteriais.

Esta rotina de otimização é caracterizada também por um problema de programação inteira, na busca da seleção entre os quatro padrões possíveis para fases de conversão à esquerda, conforme representação da Figura 4-8, determinando a seqüência das fases e as defasagens em cada interseção que maximizam a progressão. O programa PASSER foi avaliado em um estudo piloto na cidade de Dallas - Texas, e utiliza como 
dados de entrada as distâncias entre interseções, velocidade média nos segmentos da via, movimentos de conversão, fluxos de saturação, intervalos para limpeza da fila e tempos de verde mínimos.

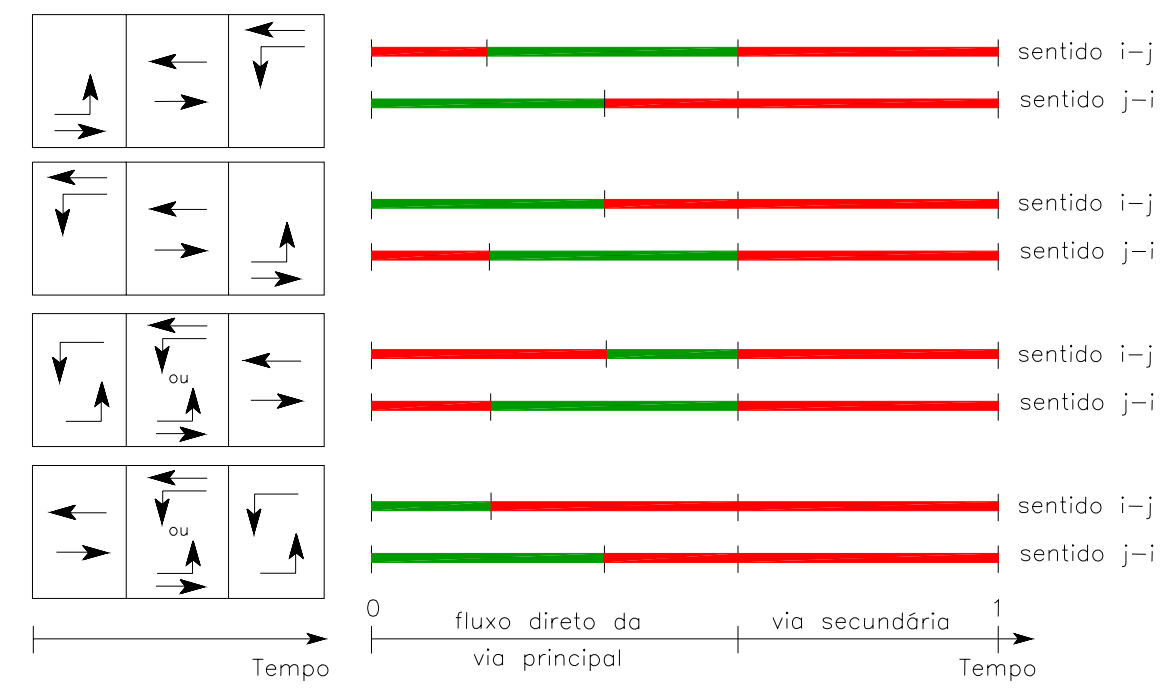

Figura 4-8: Quatro padrões para fases de conversão à esquerda (Little et al., 1981)

O programa determina as divisões das fases baseado nas proporções de volume-capacidade segundo o método de Webster e Cobbe (1966), e seleciona o ciclo que maximiza a porcentagem de eficiência da banda de progressão para a escolha da solução de progressão ótima, semelhante ao procedimento de duas fases descrito por Bleyl. Uma medida de ganho (attainability) é utilizada para avaliar o quão boa é a solução de progressão para determinada condição de tráfego e proporção de verde, mensurando a habilidade de determinada estratégia de progressão em utilizar as progressões verdes disponíveis das interseções da rede. Esta medida de ganho seria igual a $100 \%$ caso as larguras das bandas bidirecionais fossem iguais à menor duração dos verdes em cada direção.

Com o objetivo de garantir que pelotões de veículos atravessem o sistema semaforizado sem realizar paradas durante o tempo de verde, em função de filas formadas por movimentos de conversão vindos das vias secundárias ou por manobras de estacionamento, o programa PASSER avalia um tempo adicional na banda de passagem para permitir a limpeza da fila antes que o pelotão chegue a uma determinada interseção, calculado a partir o número médio de veículos na fila no início do verde, do momento do início da fila e da capacidade do fluxo do movimento em questão. 


\subsubsection{MAXBAND - Maximal Bandwidth Program}

Em 1980, adequações no método Mixed-Integer Linear Programming foram realizadas para o desenvolvimento do programa MAXBAND - Maximal Bandwidth Program (Little et al., 1981) de coordenação entre semáforos com múltiplas fases em arteriais ou em sistemas compostos por até três vias conectadas (redes de formato triangular). A limitação física do laço ao redor da rede é utilizada como restrição, considerando que esta soma de tempo deve ser um número inteiro de ciclos (conforme demonstra a Equação 4-20), assim como generalizações sobre os quatro padrões de conversão à esquerda permitem que o otimizador decida sobre sua posição (quando a conversão à esquerda existe) em relação ao fluxo direto, como já ilustrado na Figura 4-8.

O programa computacional consiste de uma rotina principal que controla a chamada de outras sub-rotinas, destinadas à entrada de dados, de conversão dos dados de entrada na forma de um problema de programação mista, busca da solução através da técnica branch-and-bound e análise dos resultados. Os tempos de verde podem ser fornecidos como dados de entrada, ou alternativamente, os volumes de tráfego e as capacidades das aproximações podem ser inseridos para o cálculo automático da alocação das fases a partir do método de Webster.

O programa $M A X B A N D$ seleciona o melhor padrão para a fase de conversão à esquerda, podendo ser adiantado (quando o tempo de verde para o movimento de conversão à esquerda começa antes do movimento reto do sentido oposto) ou atrasado (quando a conversão à esquerda é liberada depois do verde para o movimento reto do fluxo oposto). Permite tempo de limpeza de fila para o fluxo secundário acumulado durante o tempo de vermelho e aceita pesos atribuídos pelo usuário para bandas verdes em cada direção. Alguns aspectos especiais deste programa incluem a escolha automática do ciclo entre limites pré-estabelecidos, permitindo que a velocidade de projeto também varie entre dadas tolerâncias, para produzir a seqüência das fases e as defasagens para maximizar a largura da banda na obtenção da solução ótima global.

Em 1986, o programa foi adaptado também para ser utilizado para coordenação de redes semafóricas constituídas por várias vias arteriais, gerando a versão $M A X B A N D$-86, que resulta em progressões com bandas de largura uniforme, conforme ilustra a Figura 4-9, buscando atender o tráfego nas vias principais sem deteriorar o desempenho das vias secundárias (Stamatiadis e Gartner, 1996). 

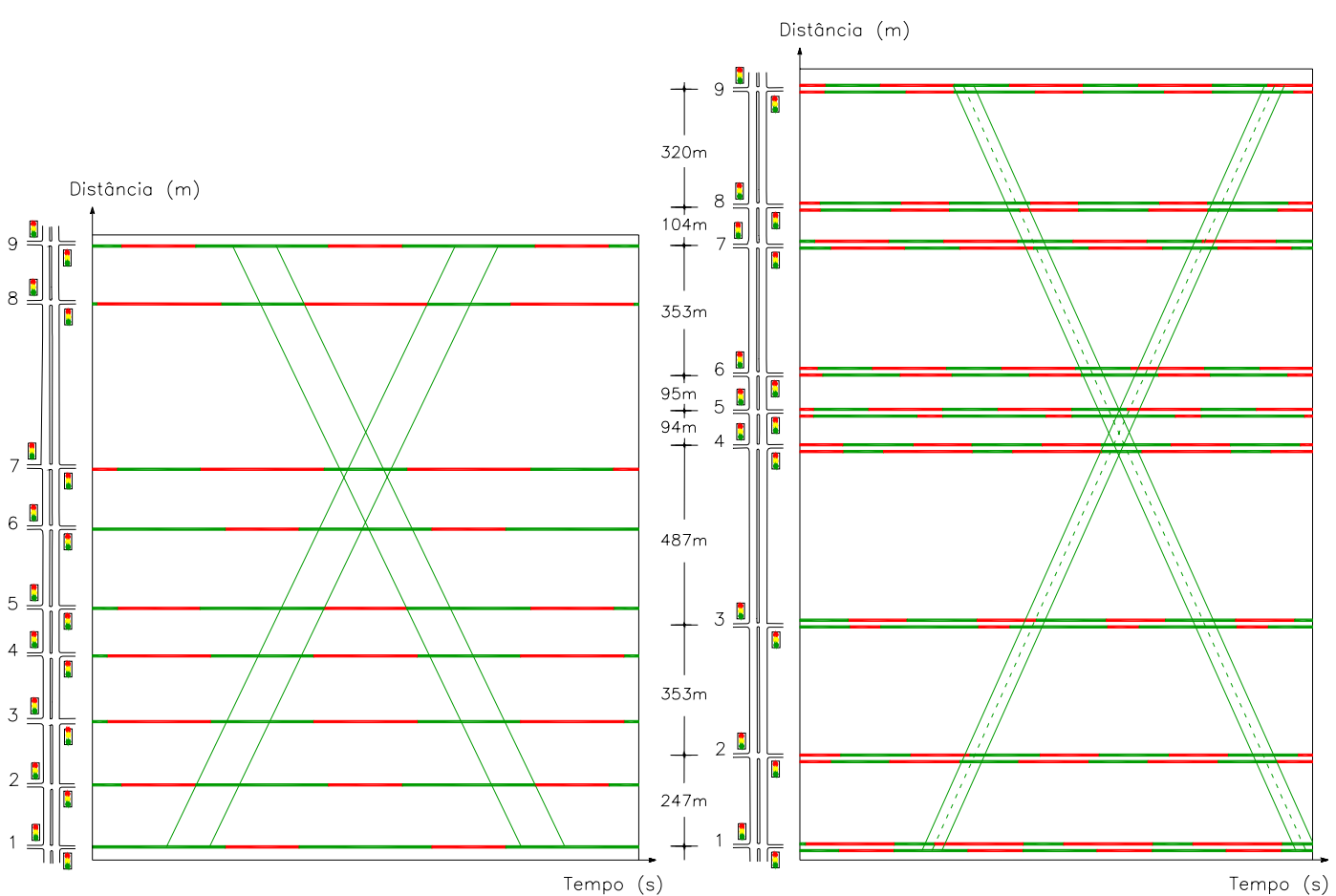

Figura 4-9: Diagramas espaço-tempo obtidos com programa $M A X B A N D$, para um corredor de 9 semáforos de duas ou múltiplas fases com ciclo $=70 \mathrm{~s}$

\subsubsection{BANDTOP - Bandwidth of Timing Optimization Program}

A limitação dos programas baseados na maximização da largura da banda é que seu critério de projeto para progressão considera o volume de tráfego direcional total da arterial, sendo insensível à variação dos fluxos em cada segmento da via. Somente a largura da banda total obtida para a via pode ser distribuída proporcionalmente aos volumes nas duas direções. Porém, devido ao fluxo de entrada e saída de veículos nas interseções com as vias secundárias, os volumes de tráfego ao longo dos segmentos das vias podem variar bastante. Uma vez que o tamanho do pelotão não é constante, a largura da banda verde pode ser desperdiçada nas interseções com fluxo direto abaixo da média e ser insuficiente nas interseções com fluxo direto acima da média. Sendo assim, os métodos baseados na maximização da banda evoluíram para também incorporar critérios de dependência do volume de tráfego nos segmentos das vias.

O programa BANDTOP - Bandwidth of Timing Optimization Program foi desenvolvido por Tsay e Lin (1988) a partir da formulação inicial de programação linear inteira mista do $M A X B A N D$, propondo encontrar a largura máxima de banda verde em ambas as direções, mas considerando simultaneamente as oportunidades de progressão parcial nos segmentos da via arterial. Esta técnica garante que nenhum veículo na banda de progressão precisará parar nos semáforos consecutivos, e os 
veículos fora da banda precisarão parar no máximo uma vez para atravessar a seção da via arterial.

O tempo de limpeza das interseções passa a ser calculado através do cômputo dos movimentos dos fluxos e comprimentos das filas em cada interseção (e não um valor fixo pré-especificado pelo usuário como na formulação do programa $M A X B A N D$ ), para permitir a limpeza da fila de veículos antes da chegada do novo pelotão, considerando além do tempo de limpeza da fila que se forma no vermelho, mas também o tempo de percurso do fluxo que chega da interseção adjacente.

O programa BANDTOP necessita dos dados sobre a ordem e distância dos semáforos, os fluxos de saturação e as capacidades, os limites mínimos e máximos de velocidade e ciclo, os volumes de tráfego e as proporções das bandas desejáveis em cada direção. Adicionando um limite que garante o uso total da banda pelos veículos sem incorrer em paradas, e um tempo mínimo de verde para as vias secundárias, o algoritmo determina a melhor seleção dentre os oito padrões possíveis para fases de conversão à esquerda representados na Figura 4-10, e encontra o tempo mínimo de ciclo.

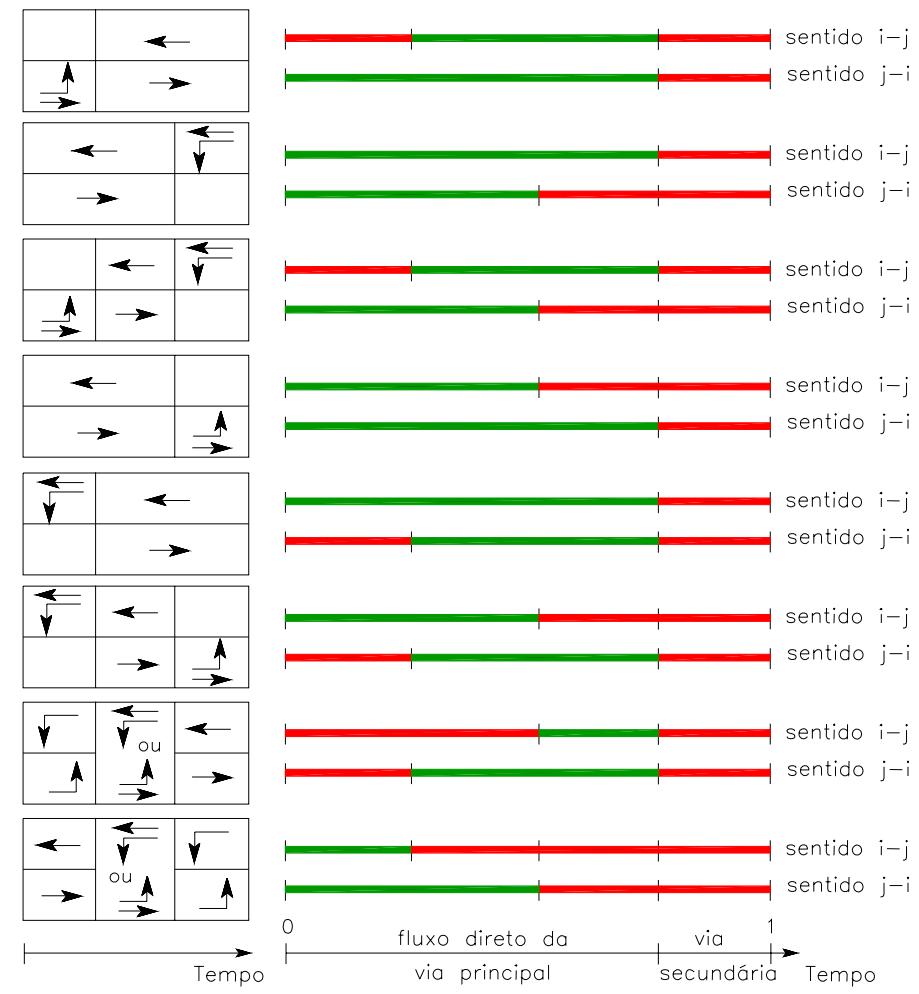

Figura 4-10: Oito padrões para fases de conversão à esquerda (Tsay e Lin, 1988)

O formato final da banda de progressão não é paralelo e uniforme, mas sim do 
tipo “dente-de-serrote" nas duas direções, conforme ilustra a Figura 4-11. Caso nenhuma solução seja obtida por este algoritmo, isto significa que nestas condições não é possível viabilizar uma banda de progressão real na via arterial, portanto o usuário deverá alterar o número de interseções a serem consideradas no sistema ou a forma da programação semafórica. Conforme comentários de Stamatiadis e Gartner (1996), a banda gerada pelo programa BANDTOP tem aplicação limitada, pois nem sempre o modelo é capaz de adequar a banda às variações do fluxo de veículos, uma vez que a progressão do tipo “dente-de-serrote” (também chamada de “funil-invertido”) possibilita o aumento da largura a cada segmento de via somente no sentido de circulação do tráfego.

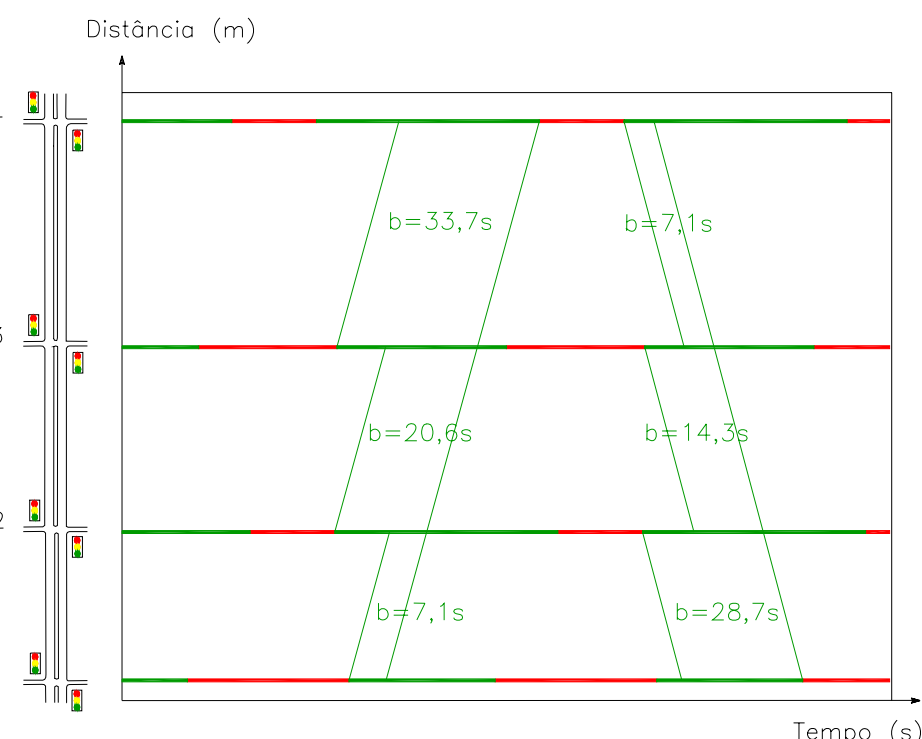

Figura 4-11: Diagrama espaço-tempo obtido com programa $B A N D T O P$, para um corredor de 4 semáforos com ciclo $=80 \mathrm{~s}$

Testes comparativos entre BANDTOP, MAXBAND e PASSER II, avaliados pelos programas TRANSYT-7F e NETSIM, demonstraram progressões obtidas pelo programa $B A N D T O P$ mais confiáveis e satisfatórias, pois geram menor atraso e número de paradas, utilizando menor tempo de computação.

\subsubsection{MULTIBAND - Variable-Bandwidth Arterial Progression Scheme}

Gartner et al. (1990) desenvolveram em 1989 o método MULTIBAND - VariableBandwidth Arterial Progression Scheme como uma extensão do programa MAXBAND, realizando a otimização através da programação linear inteira mista e incorporando no procedimento de cálculo um critério sistemático de dependência do volume de tráfego. Pesos diferentes são atribuídos para cada segmento da arterial, proporcionais às respectivas taxas de fluxo e capacidade dos segmentos, além de uma série de variáveis 
de decisão e de restrição, para obtenção simultânea das progressões proporcionais aos volumes nos segmentos e da menor quantidade de paradas e atraso, gerando uma nova função objetivo para o cálculo da banda (B), conforme demonstra a Equação (4-25).

$$
\operatorname{maximiza} B=\frac{1}{n-1} \sum_{i=1}^{n-1}\left(a_{i j} b_{i j}+a_{j i} b_{j i}\right)
$$

em que $n$ : variáveis de restrição;

$a_{i j}\left(a_{j i}\right)$ : pesos direcionais dos segmentos de via (volume / fluxo de saturação);

$b_{i j}\left(b_{j i}\right)$ : largura da banda em cada segmento de via e direção.

O ciclo e a velocidade em cada segmento tornam-se variáveis a serem otimizadas dentro de limites mínimos e máximos, dando flexibilidade ao cálculo da melhor progressão. Este método determina a solução ótima, calculando o ciclo, defasagens, velocidades de progressão e seqüências das fases para maximizar a combinação das bandas individualmente atribuídas a cada seção direcional da arterial, de acordo com a ilustração da Figura 4-12, mantendo a progressão do pelotão e resultando em bandas contínuas com larguras variáveis a cada tramo.
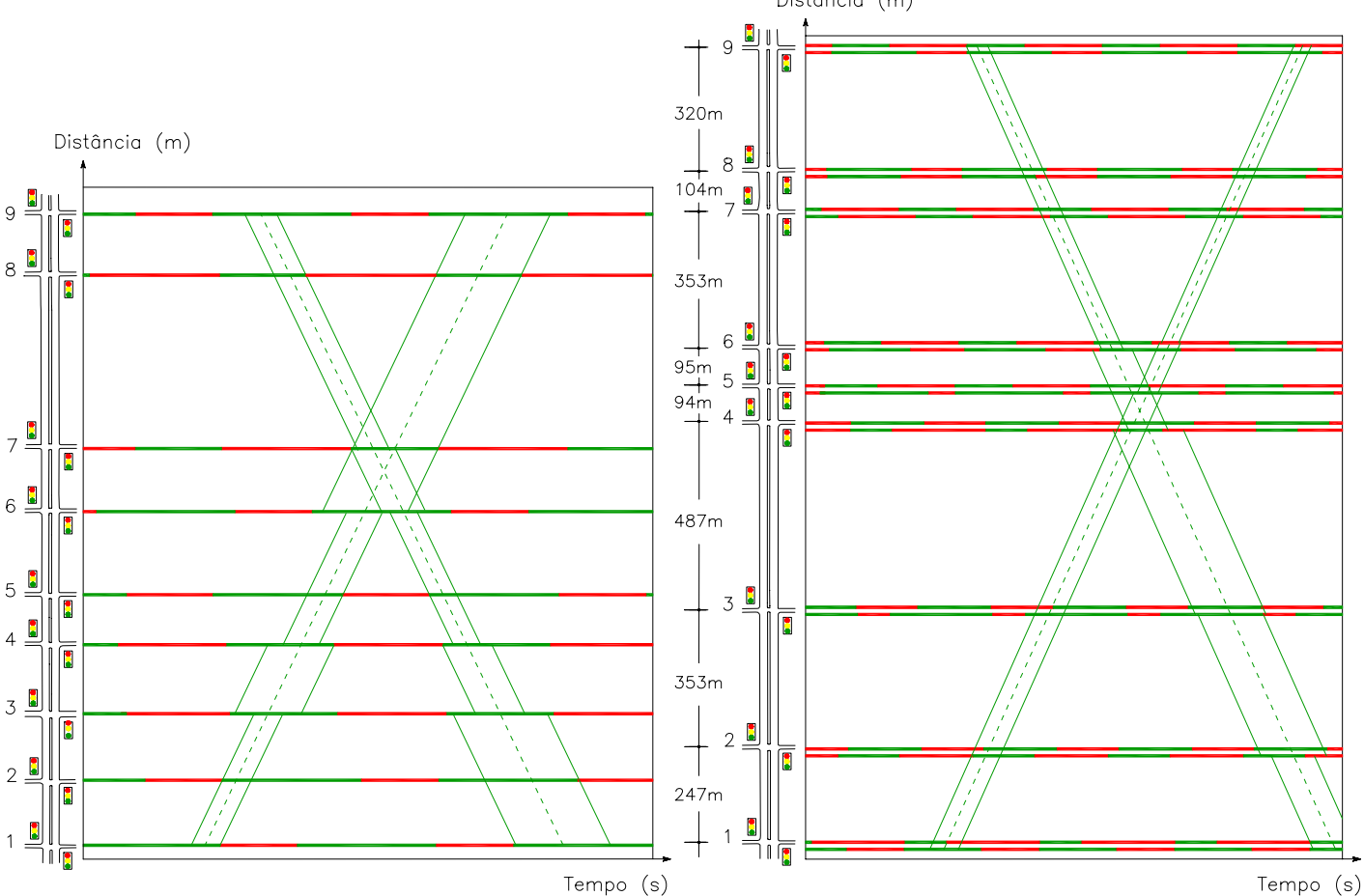

Figura 4-12: Diagramas espaço-tempo obtidos com programa MULTIBAND, para um corredor de 9 semáforos de duas ou múltiplas fases com ciclo $=70 \mathrm{~s}$

Diferentes cenários foram avaliados com as programações geradas pelos 
programas MAXBAND e MULTIBAND e simulados pelo programa NETSIM, a fim de comparar o desempenho de cada modelo. Os resultados indicaram em todos os casos as vantagens de desempenho do MULTIBAND, com significativa redução no atraso, paradas, tempos de viagem e consumo de combustível.

\subsubsection{U-BAND / V-BAND - Uniform and Variable Bandwidth Arterial Progression}

As programações matemáticas utilizadas como ferramenta na otimização da progressão, assim como os procedimentos que usavam a técnica branch-and-bound, demandavam considerável tempo na busca da solução ótima, sob pena de não convergirem no cálculo. Sripathi et al. (1995) desenvolveram procedimentos seqüenciais simplificados para otimização das larguras das bandas uniforme e variável em vias arteriais, gerando os modelos U-BAND e $V$-BAND - Uniform and Variable Bandwidth Arterial Progression Schemes, ao invés de utilizarem pacotes de programações matemáticas existentes.

Inicialmente o modelo $U$-BAND maximiza as bandas de largura uniforme em ambas as direções da via arterial, através do procedimento Half-Integer Synchronization desenvolvido por Morgan e Little (1964). A largura total da banda é dividida em proporção aos volumes direcionais da via arterial e a defasagem para os semáforos de duas fases é calculada. Posteriormente, $U-B A N D$ combina estes dados com um procedimento de otimização da seqüência de múltiplas fases, avaliando as quatro possíveis combinações das fases em cada interseção (já representadas na Figura 4-8), e repete a otimização para diferentes comprimentos de ciclo dentro de limites estabelecidos e diferentes velocidades de viagem que resultem na maior banda possível.

Obtida a banda máxima uniforme por direção através do modelo $U-B A N D$, pesos direcionais dependentes dos volumes de tráfego nos tramos são atribuídos no modelo $V$-BAND, e as defasagens são ajustadas em cada semáforo pela técnica hillclimbing, que busca sistematicamente a programação que maximiza a oportunidade do tráfego transpor cada interseção sem paradas, gerando bandas com largura variável em cada tramo.

Algumas avaliações foram realizadas com os modelos $M A X B A N D$, MULTIBAND, $U$-BAND e $V$-BAND, para verificar a consistência dos dados das progressões variáveis obtidos de forma simplificada através das progressões uniformes. Aspectos relevantes foram levantados, tais como: o programa MAXBAND otimiza a velocidade de cada tramo independentemente e o ciclo é tratado como uma variável 
contínua, já o modelo $U$-BAND não apresenta estas disponibilidades; os resultados obtidos pelos modelos $V$-BAND e MULTIBAND foram melhores que dos modelos $U$ $B A N D$ e $M A X B A N D$, com redução de $10 \%$ no atraso médio e de $13 \%$ no atraso parado, indicando também que o modelo $V$-BAND simplificado é similar ao modelo sofisticado MULTIBAND; o procedimento dos modelos $U-B A N D$ e $V-B A N D$, onde a largura da banda total disponível em cada tramo é distribuída de acordo com uma função de utilidade, apresenta melhoras significativas se comparadas aos modelos de banda uniforme, mas este procedimento não garante a solução de otimização global.

\subsubsection{MULTIBAND-96 - Variable-Bandwith Progression Optimization of Multiarterial Traffic Networks}

Stamatiadis e Gartner (1996) realizaram modificações no programa de maximização da largura da banda MULTIBAND, que já considerava o critério de dependência do tráfego para obtenção simultânea das progressões proporcionais aos volumes nos segmentos de vias arteriais, e produziram o modelo MULTIBAND-96 - Variable-Bandwidth Progression Optimization of Multiarterial Traffic Networks, para produzir progressões de largura variável ao longo de cada arterial da rede, e simultaneamente otimizar as variáveis semafóricas (ciclo, defasagens, divisões e seqüência de fases). Portanto o programa MULTIBAND que era utilizado para aplicação em vias arteriais, passou a possibilitar na versão MULTIBAND-96 a coordenação de redes.

A formulação do MULTIBAND-96 consiste em diversos blocos de restrições que unem as várias vias arteriais individuais, e asseguram que as bandas contínuas são formadas através da interseção das arteriais da rede, utilizando um pacote matemático denominado MINOS - para resolver o problema da programação linear inteira mista.

Uma rede composta de 14 interseções semaforizadas em oito vias arteriais, sendo somente uma com sentido único de circulação, serviu de cenário para a comparação dos programas $M U L T I B A N D-96$ e $M A X B A N D$-86, através de simulações realizadas com o programa NETSIM. Os resultados da pesquisa elaborada por Stamatiadis e Gartner (1996) demonstraram que o atraso médio obtido através da otimização de progressão variável sob medida produzida pelo programa MULTIBAND96 foi $11 \%$ menor do que a solução de progressão com banda uniforme gerada pelo programa $M A X B A N D-86$, as paradas 5,8\% menores e a velocidade média 5,7\% maior.

\subsection{Métodos de Minimização de Atrasos e Paradas}

Uma das críticas aos métodos de maximização de banda verde é que a largura de banda 
é uma quantidade geométrica que não necessariamente é apropriada às condições de tráfego de determinada via, uma vez que em situações em que existe um elevado número de semáforos ou combinações adversas de comprimentos de quadra e de velocidades, pode ser impraticável prover uma banda de progressão (Gartner et al., 1975) ou mesmo as bandas geradas podem não ser efetivamente aproveitadas nos casos de formação de filas e bloqueios de quadra. Desta forma, como alternativa aos métodos de maximização de banda foram desenvolvidos métodos de coordenação que buscam minimizar uma função combinada de atrasos e paradas para rede de semáforos, expressa da seguinte forma:

$$
\min P I=\Sigma_{(i, j)}\left(\alpha . D_{i j}+\beta . S_{i j}\right)
$$

em que $P I$ : Índice de Performance, avaliado como medida de ineficiência do sistema;

$\alpha$ e $\beta$ : constantes atribuídas pelo usuário como qualquer número não negativo, permitindo o balanceamento da priorização entre atraso e paradas;

$D$ : atraso médio por veículo [s];

$S:$ paradas sofridas pelos veículos.

Além de considerar os efeitos determinísticos de diferentes possibilidades de ciclo, proporções de verde e defasagens nos segmentos das vias, e os efeitos estocásticos causados pelas filas que ocorrem entre um ciclo e outro, os métodos de minimização de atrasos e paradas também consideram restrições de conexão entre as vias que compõem a rede em função da duração do ciclo, ou seja, à soma algébrica das defasagens ao redor de uma quadra da rede como um número inteiro múltiplo do ciclo, conforme citado no item 4.2.6 e demonstrado na Equação (4-20).

A seguir serão descritos alguns dos programas que tomam como base o critério de minimização de atrasos e paradas.

\subsubsection{SIGRID - Signal Grid Program}

O programa SIGRID - Signal Grid Program foi desenvolvido pela Traffic Research Corporation / Canadá em 1964, e recebendo dados dos segmentos das vias, ciclo, proporções de verde e defasagens ideais ou desejadas, utiliza um procedimento de seleção destas defasagens que minimizam a soma das medidas de atraso e paradas para cada um dos segmentos da rede (Gartner et al, 1975). Contudo, os resultados obtidos podem não garantir uma otimização global, pois o programa não leva em consideração a dispersão do pelotão e o tráfego das vias transversais, utilizando para o cálculo dos 
tempos médios de espera suposições simplificadas que não refletem necessariamente as características reais dos atrasos.

Embora o programa SIGRID tenha sido considerado como um programa revolucionário no campo de otimização para redes semaforizadas da época, relativamente simples de usar e que necessitava de pouco esforço computacional no processo (ITE, 1992), ele somente solucionava parte do problema de coordenação, uma vez que avaliava as soluções de defasagem que geram menor atraso em cada interseção dentre os valores de proporções de verde e defasagens previamente fornecidos pelo usuário, definidos através de outro método ou por experiência.

\subsubsection{COMBINATION}

O programa COMBINATION foi desenvolvido no TRRL - Transport and Road Research Laboratory e apresentado por Hillier em 1965, como um processo sistemático para o cálculo das defasagens entre semáforos de uma via arterial ou rede, pelo qual se procura a minimização de uma função de atrasos e paradas, supondo inicialmente que o atraso veicular ao longo de um segmento de via depende dos padrões de chegada e de partida de veículos nos cruzamentos (Magalhães, 1981). Em uma versão mais atualizada, um modelo de dispersão de pelotões, semelhante ao utilizado no programa TRANSYT, foi incorporado ao programa.

A aproximação da interseção crítica é escolhida para determinar o ciclo da rede, e o método COMBINATION calcula as proporções de verde em cada interseção localmente. De acordo com Magalhães (1981), o procedimento de otimização do programa é o cálculo, para cada segmento de via da rede, de uma relação entre o atraso sofrido pelo tráfego e a defasagem dos dois semáforos localizados nas extremidades do segmento. Posteriormente, baseando-se na hipótese simplificada que cada segmento de via pode ser considerado independentemente, pares de segmentos são combinados, e a relação atraso/defasagem resultante para cada par é calculada, repetindo o processo até que a rede inteira seja reduzida a um único segmento. A defasagem que produz o mínimo atraso para este único segmento é o resultado da combinação pela qual as defasagens ótimas de todos os semáforos podem ser obtidas.

\subsubsection{SIGOP - Traffic Signal Optimization Program}

O otimizador de rede semafórica SIGOP - Traffic Signal Optimization Program foi desenvolvido pela Traffic Research Corporation / EUA em 1966, para determinar os tempos de verde e as defasagens para diversos valores de ciclo pré-estabelecidos pelo 
usuário. Manipulando as variáveis que afetam o desempenho dos semáforos (ciclo, proporções de verde e defasagens), o programa SIGOP permite a análise de várias possibilidades de ciclo, estabelecendo as divisões para cada um, proporcionalmente aos volumes veiculares das correntes de tráfego na interseção, e as defasagens entre semáforos. Posteriormente, para cada seleção destas três variáveis, é feita a avaliação do desempenho do sistema simulando o tráfego em todos os segmentos da rede, a fim de escolher a seleção que gera a combinação do menor número de atraso e paradas.

Na década de 70, diversas avaliações das metodologias de coordenação existentes para redes foram realizadas através de estudos de campo e de simulação, sendo expressas em termos de medidas operacionais de eficiência. Gartner et al. (1975) analisaram o desempenho dos programas baseados na minimização de atraso e paradas, alertando sobre três deficiências no procedimento de otimização do SIGOP: a defasagem ótima gerada não parte de uma solução global, mas de uma análise local; as proporções de verde são determinadas independentemente; e os efeitos do atraso aleatório no desempenho dos segmentos de via são ignorados.

Considerando que o programa SIGOP ignora a importância da forte interrelação que existe entre divisão semafórica e defasagem, pois fixava os valores iniciais da divisão para depois otimizar as defasagens, sua versão inicial foi modificada em 1976, para o desenvolvimento do programa SIGOP II - New Signal Timing Optimization Program. Lieberman e Woo (1976) incorporaram ao programa dois componentes principais: um modelo que descreve o padrão do fluxo de tráfego, computando atraso, paradas e comprimentos de filas excedentes, e um procedimento de otimização que busca através de sucessivas aproximações as programações que atendam com maior eficiência as demandas de tráfego. Desta forma, o programa permite incluir a análise do bloqueio de interseções causado pelas filas, considerar a dispersão do pelotão, tratar os efeitos de movimentos de conversão e representar o controle de múltiplas fases.

Inicialmente o programa SIGOP II otimiza as defasagens mantendo os tempos de verde constantes e, em seguida, faz o ajuste dos verdes em cada interseção, repetindo o procedimento até que o índice de desempenho atinja um valor mínimo. As modificações promovidas no modelo $S I G O P$, que geraram o programa SIGOP II, visavam principalmente melhorar o procedimento de otimização, minimizando também o esforço de aprendizado e o tempo para uso do modelo, através da diminuição da quantidade dos dados de entrada, que foram substituídos como itens de lógica interna do programa. 


\subsubsection{TRANSYT - Traffic Network Study Tool}

O programa TRANSYT - Traffic Network Study Tool de simulação de tráfego e otimização semafórica em arteriais e redes foi criado em 1967 pelo Dr. Dennis I. Robertson, no RRL - Road Research Laboratory (hoje TRL - Transport Research Laboratory / United Kingdom), sendo definido como um procedimento macroscópico de otimização das divisões e defasagens para planos semafóricos fixos, que avalia o desempenho do sistema através da simulação do fluxo de tráfego ao longo da rede, considerando padrões de chegada, de saída e de saturação do tráfego em cada aproximação, enquanto busca minimizar uma combinação linear de atraso e paradas (Robertson et al., 1980).

TRANSYT atribui pesos aos atrasos e paradas sofridos pelos veículos que percorrem os segmentos viários da rede, e através de um procedimento de otimização (hill-climbing technique) procura a programação que minimiza uma medida de desempenho do fluxo de tráfego. Originalmente esta medida era avaliada através do Índice de Performance PI - Performance Index, conforme demonstra a Equação (4-27), que evoluiu ao longo do tempo nas novas versões e releases, incorporando elementos para a avaliação do desempenho:

$$
P I=D+K \times S
$$

em que $P I$ : Índice de Performance;

$D$ : atraso total obtido pela soma dos atrasos uniforme e aleatório sofridos por cada veículo, em certo período de tempo;

$K$ : constante que pode ser atribuída pelo usuário como qualquer número não negativo, permitindo o balanceamento da priorização entre atraso e paradas;

$S$ : paradas completas e também parciais, como porcentagem das completas.

O modelo TRANSYT foi desenvolvido para utilizar "CFPs" (cyclic flow profiles) - padrões cíclicos de tráfego, ou seja, um procedimento que grava os fluxos médios chegando e partindo de cada semáforo em pequenos intervalos de tempo durante um ciclo (1 a 5 segundos, definido pelo usuário), levando em consideração os efeitos da dispersão dos pelotões em cada segmento da rede em função do tempo de percurso. Sendo assim, o programa é sensível a qualquer alteração na programação semafórica que possa repercutir nos fluxos, filas e paradas dos outros semáforos.

O otimizador utiliza dados de espaçamento entre semáforos, limites de 
variação do ciclo, velocidades nos segmentos viários, número de faixas, fases mínimas, fluxos de saturação e volumes de meio de quadra e de conversões, buscando soluções mínimas locais de defasagens e divisões a cada semáforo, repetindo o cálculo diversas vezes em todos os semáforos, até que não seja possível obter melhorias no desempenho operacional na rede. A distância total viajada é obtida para todos os veículos que circulam na rede, assim como o atraso total sofrido e o número total de paradas, mas as soluções mínimas locais geradas pelo modelo não garantem que a solução ótima global será encontrada em um período de tempo computacional razoável.

O programa TRANSYT foi estabelecido como modelo internacional de comparação com os demais sistemas de controle semafórico (Green e Robertson, 1974), tendo sido dentro da coordenação semafórica, provavelmente o programa mais citado, conhecido e utilizado na engenharia de tráfego, merecendo especial atenção no relato de seu desenvolvimento ao longo das últimas quatro décadas. Até mesmo o Manual de Semáforos do DENATRAN (1984) reservou um capítulo somente para a apresentação do TRANSYT, indicando-o como programa para coordenação e otimização de semáforos. Abriremos portanto, parênteses na seqüência cronológica dos demais métodos, a fim de apresentar todas as atualizações ocorridas a cada nova versão comercial lançada deste programa, segundo relado produzido por Robertson (1997) quando da comemoração ao $30^{\circ}$ aniversário de criação do TRANSYT.

A primeira versão do TRANSYT foi escrita em código de máquina para computador Myriad, e começou a funcionar em Fevereiro de 1967. Em Novembro desse mesmo ano o primeiro teste com o TRANSYT demonstrou 15\% de redução no tempo total de viagem para uma via arterial com 6 semáforos e elevado volume de tráfego em West London. No ano seguinte, TRANSYT/2 era a primeira versão em FORTRAN que podia ser aplicada para semáforos com mais de três fases. As versões 3 e 4 foram revistas em 1970 e 1971, para melhorar os dados de entrada e saída do programa.

Em 1972, TRANSYT/5 incorporou um método de representação da distribuição dos períodos de permanência dos ônibus nas paradas, possibilitando otimizar planos para reduzir seus atrasos e tempos de viagem. Também uma fórmula foi introduzida para estimar os valores de atraso em regiões críticas, onde o volume de tráfego se aproxima ou até excede a capacidade, através da consideração das flutuações aleatórias do tráfego e da duração do período de pico. Esta versão passou a ser amplamente utilizada nos Estados Unidos.

TRANSYT/6 recebeu em 1975 um modelo aperfeiçoado para a análise de 
paradas, que considerava a maneira como os veículos aceleram e desaceleram entre os semáforos, tornando-se bastante eficaz para estimar o consumo de combustível e os níveis de emissão de poluentes. Uma pesquisa realizada em uma rede com 21 cruzamentos semaforizados na região central de Glasgow (Robertson et al., 1980) avaliou a utilização do programa TRANSYT/6 na coordenação de semáforos adjacentes com planos fixos, calculados off-line e considerando os fluxos médios para o pico e para o período fora do pico. A economia de combustível alcançada pela simulação com coordenação semafórica variou entre 13 a 16\%, dependendo do valor $K$ escolhido para balanceamento entre atraso e paradas, do espaçamento entre os semáforos, dos níveis de tráfego e do método anterior de controle. O estudo sugere que em média, as áreas centrais urbanas com redução de 10\% no tempo de viagem, economizariam entre 6 e 8\% no consumo de combustível.

Com a utilização da constante $K$ igual a zero, o programa minimiza o atraso e não considera o número de paradas, e se o valor de $K$ for muito alto a tendência é minimizar as paradas em detrimento do atraso. Conforme o valor da constante $K$ aumenta, o número de paradas diminui enquanto que o atraso aumenta.

Os resultados da pesquisa demonstraram que os semáforos coordenados para minimizar o atraso total (com $K=0$ ) podem atingir 31\% de redução no atraso, 4\% nas paradas e $22 \%$ no tempo de viagem, com economia de $13 \%$ de combustível. Caso a otimização seja realizada priorizando o número de paradas (com $K=20$ ), a redução chega a $21 \%$, mas com $9 \%$ de aumento no atraso e $5 \%$ de aumento no tempo de viagem, porém assim mesmo reduz de 1 a 3\% a mais de combustível do que com a priorização da diminuição do atraso. Considerando que as observações realizadas em Glasgow indicaram que os veículos permanecem parados em aproximadamente $40 \%$ do tempo de viagem, e que as paradas causam incômodo ao motorista/passageiros, poluição sonora e atmosférica e desgaste na mecânica dos veículos, Robertson et al. (1980) sugerem que a priorização da otimização não seja realizada pelo atraso, mas que seja feita para o número de paradas através da manipulação da constante $K$, recomendando a utilização de valores entre 5 e 10 quando a intenção é reduzir combustível e tempo de viagem, e valor igual a 20 para reduções de combustível e acidentes.

Na versão de 1978 - TRANSYT/7 - foram acrescentadas melhorias como: aumento da velocidade da rotina de otimização e introdução da modelagem de "gargalos", onde duas faixas convergem em uma ou filas que se formam mesmo sem semáforos. No Centro de Pesquisa de Transporte da Universidade da Flórida (TRC), o TRANSYT/7 foi adaptado e “americanizado” pela Federal Highway Administration 
(FHWA), tornando-se TRANSYT-7F sob o Projeto Nacional de Otimização da Programação Semafórica (NSTOP). Todas as versões subseqüentes do programa lançadas nos Estados Unidos baseiam-se no TRANSYT-7F, tendo incorporado diversas modificações e significativas melhorias ao longo de suas dez atualizações, tais como:

- Release 1 a 4 (entre 1981 e 1984): correções de bugs, alterações nos dados de entrada e saída do programa, e inclusão do Diagrama de Progressão do Pelotão, que segundo Hale (2005) representa graficamente a qualidade do pelotão e facilita a compreensão quando comparado à análise de resultados numéricos;

- Release 5 (1987): modelagem de movimentos permitidos e conflitantes, modelagem de controle por Parada Obrigatória e em faixas com movimentos compartilhados;

- Release 6 (1988): diversas mudanças sugeridas pelos usuários, como restrição da largura da banda para preservar o movimento de progressão e atribuição de pesos aos segmentos para privilegiar rotas específicas;

- Release 7 (1992): otimização das oportunidades de progressão (PROS) e estimativa do atraso aleatório conforme o HCM - Highway Capacity Manual;

- Release 8 (1998): uso de filas horizontais e modelagem de condições saturadas e de bloqueios de quadra;

- Release 9 (2001): introdução de algoritmo genético para otimização do ciclo, divisões e defasagens;

- Release 10 (2003): simulação e otimização com múltiplos ciclos e demonstração do diagrama espaço-tempo da progressão.

As atualizações inglesas também continuaram, e na versão do TRANSYT/8 em 1980 várias modificações foram introduzidas, possibilitando a estimativa dos custos do atraso e paradas, das emissões e do consumo de combustível, e a inclusão de um modelo para definição das prioridades de movimentos conflitantes.

A versão do TRANSYT/9 foi convertida em 1987 para operação DOS dos primeiros micro-computadores. Em 1996, TRANSYT/10 incluiu a avaliação das aproximações com alto fluxo de saturação inicial, que decresce durante o verde, de forma a fornecer ao usuário uma maior flexibilidade na modelagem do comportamento dos veículos durante a descarga da fila.

Diversas mudanças ocorreram na parte gráfica da versão 11 do TRANSYT, principalmente com a revisão das opções de comando apresentadas ao operador no 
menu principal, melhorando a interface com o usuário. Esta versão foi lançada em Janeiro de 2000, como a primeira possível de ser utilizada completamente em Windows 95 ou versões posteriores, incluindo a possibilidade de modelagem da operação em rotatórias e o aumento de limite dos dados para aplicação em redes maiores.

A página atualizada do site do TRL Software Bureau / United Kingdom (TRL, 2005) apresenta a última versão comercial disponível - TRANSYT/12 - lançada em Setembro de 2003 tanto para operação com a regra de circulação pela direita quanto para mão-inglesa, e que é considerada a versão verdadeiramente gráfica do programa, pois permite a apresentação gráfica dos resultados nos próprios tramos da rede, assim como a visualização ampliada de qualquer trecho da rede.

\subsubsection{MITROP - Mixed-Integer Traffic Optimization Program}

Usualmente, o procedimento para calcular as variáveis de controle de tráfego na coordenação semafórica era feito de forma seqüencial, em três estágios: um ciclo comum, geralmente aquele da interseção mais carregada, era selecionado a fim de ser sincronizado para toda rede; a proporção de verde em cada semáforo era calculada de acordo com valores de fluxo/capacidade; e posteriormente as defasagens eram estabelecidas para a coordenação entre semáforos. Porém estes três estágios não são independentes, e o processo de decisão seqüencial pode degradar significativamente o desempenho do sistema, sem necessariamente resultar na solução ótima.

O método computacional MITROP - Mixed-Integer Traffic Optimization Program foi apresentado por Gartner et al. (1975) e utilizou a programação MixedInteger Linear proposta por Little para coordenação semafórica em rede, aliada a um procedimento de otimização simultânea e global das variáveis interdependentes que afetam o desempenho dos semáforos (ciclo, proporções de verde e defasagens), e avaliadas juntamente com as funções de desempenho do tráfego (atraso por veículo e filas) que deverão ser minimizadas nos segmentos de via que compõem a rede.

O modelo matemático utilizado consiste de uma função objetivo que combina as funções individuais de desempenho nos segmentos de via às equações de conexão das vias da rede, que juntas unificam a interdependência de todas as variáveis de controle semafórico do sistema.

O programa MITROP lineariza em partes os componentes não-lineares da função objetivo para que o problema possa ser resolvido pela programação linear Mixed-Integer, e utiliza a técnica branch-and-bound para determinar simultaneamente 
os valores ótimos das variáveis de controle semafóricas e os valores inteiros dos laços da rede. Dados geométricos da rede, assim como as velocidades, os volumes, os comprimentos dos pelotões e o fluxo de saturação em cada segmento de via são considerados para a coordenação, gerando a programação semafórica (ciclo, divisões e defasagens) na busca do ponto de equilíbrio entre atrasos causados por efeitos determinísticos e estocásticos.

\subsubsection{INTEGRATION}

O modelo INTEGRATION foi desenvolvido entre os anos de 1984 e 1986 por Michel Van Aerde, durante sua dissertação na Universidade de Waterloo no Canadá. O nome do simulador indica a capacidade do modelo integrar a atribuição de tráfego e a simulação microscópica, unindo em uma mesma lógica a modelagem de rodovias e vias urbanas (Rakha, 2004). O INTEGRATION é caracterizado como um modelo microscópico de simulação do tráfego, pois modela individualmente a velocidade, a aceleração e a movimentação lateral e longitudinal dos veículos ao longo de suas rotas a cada décimo de segundo, representando através de modelos matemáticos integrados um sistema real de forma simplificada, e possibilitando a avaliação de sistemas complexos e de cenários alternativos.

De acordo com Michel Van Aerde (Rakha e Van Aerde, 1996; Rakha, 2004), a busca de um modelo que lidasse com problemas integrados de controle foi inspirada nos artigos de Robertson do início da década de 1980, e influenciada pelos principais modelos de simulação de tráfego da época, como o programa TRANSYT. O programa INTEGRATION é capaz de modelar a dispersão microscópica do pelotão utilizando um processo similar ao processo macroscópico do programa TRANSYT, e também realiza a coordenação entre semáforos baseado nos “CFPs” (cyclic flow profiles) - padrões cíclicos de tráfego, minimizando a cada ciclo a combinação entre atraso e paradas através do índice de performance PI semelhante ao TRANSYT.

Para utilizar o simulador INTEGRATION, faz-se necessário calibrá-lo com uma série de dados provenientes de arquivos de entrada do tipo texto. Segundo Demarchi (2000), seis arquivos de entrada devem ser obrigatoriamente utilizados para a simulação, e são chamados de arquivos fundamentais:

- arquivo mestre: especifica os parâmetros globais da simulação como sua duração, a localização e os nomes dos arquivos de entrada e de resultados, e a freqüência de saída dos dados estatísticos; 
- arquivo de nós: contém as coordenadas cartesianas dos nós da rede, representando as interseções ou os pontos de mudança nas características geométricas das vias;

- arquivo de tramos: promovem a ligação entre os nós da rede e representam os segmentos das vias por onde os veículos trafegam, contendo seus comprimentos, o número de faixas de cada tramo e os parâmetros que definem a relação entre fluxo, velocidade e densidade, ou seja, a velocidade de fluxo livre, a velocidade na capacidade, a capacidade e a densidade de congestionamento;

- arquivo de semáforos: contém informações sobre a programação semafórica, relacionando ciclos, defasagens, número de fases, proporções de verde, tempos perdidos e intervalos de otimização;

- arquivo da matriz $O-D$ : contém a matriz das viagens realizadas entre diferentes pontos de origem e destino da rede, indicando a magnitude de cada demanda, o instante de início e fim de sua geração, o padrão de geração das viagens e a composição veicular;

- arquivo de incidentes: contém informações que permitem simular a ocorrência de incidentes, tais como o fechamento temporário de uma faixa de tráfego, e caso não haja nenhum incidente a ser simulado este arquivo vazio deverá constar nos dados de entrada.

Alguns parâmetros adicionais podem ser incluídos em arquivos opcionais, denominados arquivos avançados, tais como:

- arquivo de greides: contém informações sobre a magnitude dos greides dos tramos codificados na rede;

- arquivo de utilização das faixas: permite que o usuário especifique faixas exclusivas para determinados movimentos ou faixas proibidas para determinados tipos de veículos;

- arquivo de características veiculares: contém os parâmetros relacionados ao desempenho dos diferentes tipos de veículos, tais como peso e potência do motor.

As informações contidas nos arquivos de dados definem os parâmetros para as lógicas fundamentais modeladas microscopicamente pelo programa, tais como: relação interveicular (car-following) que representa o fluxo de tráfego através da relação entre fluxo, velocidade, espaçamento entre veículos e densidade em cada segmento de via; mudanças de faixa em função da geometria da via e da rota utilizada pelo veículo (mudanças obrigatórias) ou para aumento da velocidade (mudanças desejáveis); e 
aceleração em função do espaçamento interveicular e do desempenho do veículo frente às forças de tração e de resistência ao movimento.

O programa também possibilita a modelagem de praças de pedágio, das emissões de poluentes pelos veículos, assim como a análise de gráficos em tempo-real e de estatísticas de veículos de sondagem ou investigação (probes), sendo capaz de simular redes com até 1.000 semáforos, 10.000 tramos, 100.000 pares origem-destino e 500.000 veículos na simulação, na sua versão de maior capacidade dentre as quatro versões disponíveis.

\subsection{Métodos Combinados}

O método da maximização da largura da banda sempre foi bem aceito na aplicação em vias arteriais, mas uma das dúvidas em relação à sua eficiência é se a solução ideal para a arterial causava prejuízos às vias secundárias. Esta abordagem também não produz bons resultados em redes bidirecionais, pois a largura máxima da banda não minimiza necessariamente os atrasos e paradas do tráfego que circula pela arterial (Wallace e Courage, 1982). Em contrapartida, a estratégia da minimização dos atrasos, paradas e filas adapta-se bem na otimização em redes, produzindo melhor desempenho geral do sistema, mas não foi bem aceita para aplicações em arteriais, pois não elimina as paradas do tráfego nas interseções ao longo das principais vias.

Ao longo da década de 70, muitos pesquisadores avaliaram os benefícios dos métodos disponíveis para programação semafórica (Rogness e Messer, 1983), emitindo suas opiniões a respeito da utilidade isolada de cada técnica. Basicamente, o método de progressão pela máxima largura da banda foi indicado apropriado para ser utilizado nos casos de volumes baixos ou moderados, enquanto a otimização dos atrasos e paradas deveria ser utilizada para saturações altas.

Constatando que a fraqueza de um método pode ser considerada o ponto forte do outro e vice-versa, as técnicas de maximização da largura da banda verde e da minimização de atraso e paradas foram consideradas complementares, sugerindo que o uso de ambas estratégias combinadas poderia prover melhorias substanciais nas medidas de eficiência de sistemas semafóricos. Duas opções são possíveis para aliar as vantagens de cada técnica, combinando a minimização do atraso/parada e a maximização da largura da banda: modificar o programa baseado na minimização do atraso para considerar a largura da banda (progressão) ou ajustar a programação baseada na largura da banda para reduzir o índice de atraso e paradas. 
A seguir são apresentados alguns métodos computacionais combinados, propostos para unir as vantagens da técnica de maximização da largura da banda verde e da minimização de atraso e paradas, de forma seqüencial ou por otimização simultânea.

\subsubsection{PROS / PI}

Considerando que o método de maximização da largura da banda não reconhece explicitamente a variação temporal do volume de tráfego, ignorando inclusive oportunidades de progressão que ocorrem fora da tradicional banda verde de progressão, Wallace e Courage (1982) aliaram a minimização do Índice de Performance (PI) no programa TRANSYT com a maximização das oportunidades parciais de progressão denominada PROS (Progression Opportunity).

O índice PROS foi desenvolvido inicialmente para melhorar a estratégia de maximização da largura da banda, representando o número de oportunidades que o motorista tem para atravessar uma seqüência de semáforos sem parar, sendo a qualidade deste índice definida pela soma de todas as oportunidades de progressão que ocorrem nos segmentos da via. O número de oportunidades de progressão apresentadas ao motorista em determinado momento é determinado pelo número de sucessivos semáforos verdes que serão encontrados sem paradas, viajando na velocidade de projeto. Através do método combinado PROS / PI, o programa TRANSYT tenta atingir o menor valor possível do $P I$, enquanto busca o maior valor possível para o índice $P R O S$, mantendo ainda tempo de verde suficiente para as vias transversais, de acordo com a ilustração da Figura 4-13.

Testes foram realizados com a versão TRANSYT-6C para avaliar o conceito de otimização $P R O S$ / PI, e quando comparados com o programa de maximização da largura da banda PASSER II demonstraram redução no atraso total e nas paradas da via principal, assim como redução no consumo de combustível. 


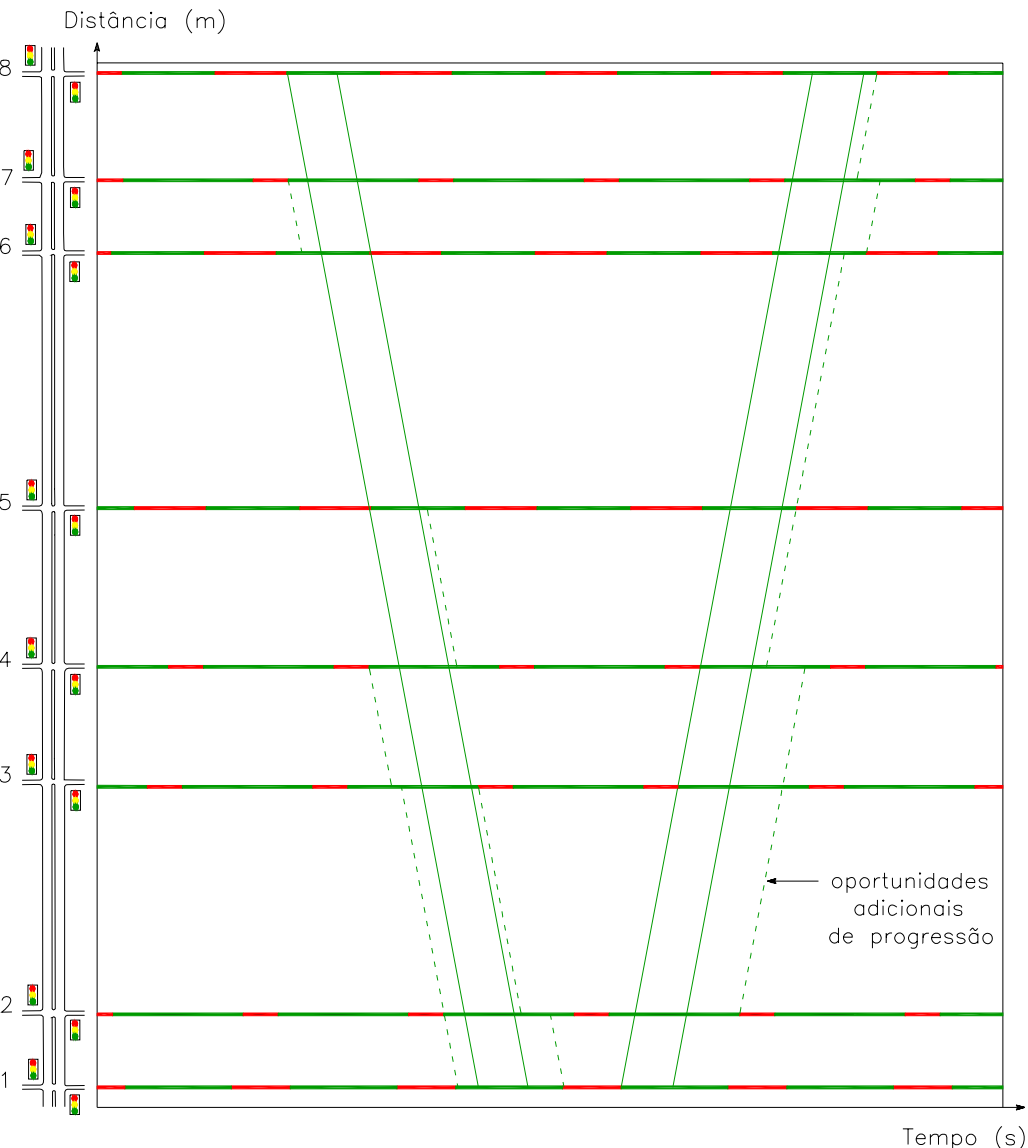

Figura 4-13: Diagrama espaço-tempo obtido com o método $P R O S / P I$, para o exemplo de 8 semáforos com ciclo $=90 \mathrm{~s}$

\subsubsection{PASSER II / TRANSYT 6}

Rogness e Messer (1983) propuseram um procedimento combinado seqüencial, que utiliza inicialmente o programa PASSER II de maximização da banda de progressão para selecionar o ciclo, as proporções de verde, a seqüência ótima das fases e as defasagens em cada interseção, a serem utilizados como dados iniciais pelo programa TRANSYT 6, a fim de gerar uma solução de mínimo atraso no índice de desempenho em vias arteriais.

Uma pesquisa foi realizada para comparar as soluções geradas pelo TRANSYT 6 através de sua própria rotina interna de dados iniciais, e os valores obtidos pelo procedimento combinado PASSER II / TRANSYT 6, demonstrando sempre soluções diferentes para as divisões de verde em todas as situações analisadas. Em geral, as melhores soluções foram aquelas apresentadas pelo procedimento combinado, quando comparadas à melhor solução do TRANSYT 6, embora poucos cenários tenham sido avaliados para certificar esta conclusão. Os autores concluem que embora as melhorias 
sejam pequenas, todas as soluções são melhores no método combinado, portanto sugere que novas pesquisas sejam feitas com diferentes volumes, diferentes ciclos e diferentes espaçamentos.

\subsubsection{MAXBAND / TRANSYT-7F}

O programa $M A X B A N D$ obtém uma solução ótima global de maximização da largura da banda sem precisar de solução inicial, otimizando defasagens, ciclo e seqüência das fases, porém o modelo de tráfego usado é bastante simplificado, e não considera o fluxo das vias secundárias, a dispersão e o formato do pelotão, o tráfego de conversão, e também não otimiza os tempos de verde. O programa TRANSYT utiliza a geometria da rede e os fluxos, ajustando as defasagens e os tempos de verde separadamente para minimizar o índice de performance $(P I)$. Sendo assim, não atinge a solução ótima global, não otimiza a seqüência das fases e depende de uma programação semafórica inicial como primeira solução. Também não otimiza o ciclo, mas pode-se rodar o programa para vários ciclos diferentes e selecionar aquele que gera a solução com menor $P I$.

Cohen (1983) propôs a combinação destes dois programas de forma seqüencial, utilizando a solução da maximização da largura da banda do MAXBAND como a programação inicial a ser utilizada para a otimização do programa TRANSYT$7 F$. Uma série de experimentos foi realizada para testar esta combinação em vias arteriais e determinar os efeitos produzidos na otimização, mostrando soluções melhores no método combinado do que aquelas obtidas por cada programa isoladamente. Os dados apontaram uma melhoria de $20 \%$ sobre os resultados obtidos pelo TRANSYT-7F com defasagens iniciais zero (aberturas simultâneas) e sem otimização da seqüência das fases, observados principalmente nos casos com permissão de conversão à esquerda na arterial.

\subsubsection{PASSER II - 84}

Chang e Messer (1985) realizaram em 1984 modificações no programa PASSER II-80 e geraram a versão combinada PASSER II-84, com procedimentos para seleção da programação semafórica com menor atraso possível na via arterial, que otimizasse suas defasagens baseado na solução ótima da largura máxima da banda verde.

O procedimento da banda máxima baseia-se principalmente na distância, velocidade e continuidade do tempo de verde para privilegiar movimentos progressivos, sem considerar diretamente o atraso, enquanto o algoritmo de atraso mínimo para a rede 
não privilegia os movimentos de progressão. O método combinado PASSER II-84 relaciona seqüencialmente a maximização da largura da banda e um algoritmo de mínimo atraso, sujeito ao ciclo, divisão de verdes, seqüência das fases e tempo de verde excedente para fluxo direto, gerado pelo PASSER II - 80 .

O programa NETSIM foi utilizado para a avaliação do método combinado PASSER II-84. NETSIM foi desenvolvido pela FHWA - Federal Highway Administration, e também utiliza o índice de performance $P I$ para somatória por peso do atraso e paradas, sendo utilizado em estratégias de controle semafórico de redes sofisticadas, pois foi validado através de dados de campo e gera análises estatísticas microscópicas de cada segmento de via (Chang et al., 1986). Os resultados dos testes experimentais indicaram que as defasagens resultantes da minimização do atraso pela otimização das defasagens obtidas pelo algoritmo da largura máxima da banda, geram melhoria no nível de serviço, apresentando até 4\% de redução no atraso total do sistema e atingindo $23 \%$ de redução no atraso das arteriais.

Esta técnica apresentou algumas vantagens sobre os métodos já descritos anteriormente, tais como: as vias secundárias não são discriminadas, pois os tempos de verde são mantidos fixos, o que não ocorre na técnica do Método Combinado PROS / PI (Wallace e Courage, 1982); e a banda bidirecional é preservada, o que não acontece na solução inicial da banda para o TRANSYT, descrita no Método Combinado MAXBAND / TRANSYT-7F (Cohen, 1983).

Também algumas desvantagens da técnica foram relacionadas por Cohen e Liu (1986), ressaltando que no ajuste das defasagens realizado em uma dada interseção, somente os efeitos da interseção imediatamente anterior estarão incluídos; que a dispersão do pelotão não é modelada neste método atraso-defasagem; e que o método combinado não é capaz de ajustar o tempo de verde e preservar as bandas simultaneamente.

\subsubsection{MAXBAND / TRANSYT - 7F (C)}

Após avaliar o desempenho dos métodos combinados existentes até 1985, Cohen e Liu (1986) propuseram uma combinação das técnicas de minimização do atraso e paradas com a limitação da largura da banda verde, para produzir programações semafóricas com os melhores aspectos de cada uma, através de um procedimento semelhante ao realizado por Cohen em 1983. O método proposto incorpora a solução de progressão da banda bidirecional obtida através do programa $M A X B A N D$, como dado de entrada na estrutura de otimização do programa TRANSYT-7F, incluindo também dados para a 
divisão das larguras de banda por sentido, das velocidades de progressão e do tempo de início e do fim da banda bidirecional em cada interseção.

O objetivo geral do método combinado MAXBAND / TRANSYT-7F (C) oriundo do termo constrained, que quer dizer restrito ou limitado - é limitar o programa TRANSYT-7F com ajustes de defasagem e de tempo de verde, enquanto preserva a progressão das bandas geradas pelo programa $M A X B A N D$, para possibilitar bandas desiguais nas duas direções, ao invés de acomodar fluxos desbalanceados.

Os resultados dos testes realizados em dez cenários de vias arteriais demonstraram que o método MAXBAND / TRANSYT-7F (C) reduz o índice PI das programações de maximização da largura da banda, sem discriminar as vias secundárias, ajustando os resultados aos padrões de tráfego e considerando o efeito da dispersão dos pelotões. A largura da banda somente aumenta caso seja vantajoso para o programa TRANSYT dividir o tempo de verde com os movimentos diretos da arterial, e este aumento no tempo de verde direto da arterial irá ocorrer se for vantajoso para reduzir o índice de desempenho PI do programa. Desta forma, o tempo de verde pode ser dividido com as vias secundárias, especialmente nos casos em que há razoável tempo verde disponível, diferentemente do que ocorre no Método Combinado PROS / PI (Wallace e Courage, 1982), que sempre privilegia o tempo verde para a via principal para melhorar o índice PROS.

\subsubsection{MAXBAND / NETSIM}

Programas como PASSER II e MAXBAND permitem o usuário ajustar a divisão da banda direcional em função da média de volume em cada direção, porém a simples proporcionalidade dos volumes não garante programações semafóricas com menor atraso, pois ignoram a capacidade, o tempo de verde e a largura da banda disponível em cada direção. Este problema de atribuição de peso para largura da banda foi estudado por Chang et al. (1986), a fim de avaliar os fatores que influenciam na distribuição direcional da largura da banda verde.

O programa $M A X B A N D$ foi utilizado para desenvolver os parâmetros da programação, estimando a divisão ótima da banda, para diversas proporções direcionais variando entre 1/10 e 10/1. Estes resultados foram então fornecidos como dados de entrada no programa de simulação e otimização NETSIM, para avaliar a importância dos fatores que influenciam no peso direcional.

O estudo apresentado por Chang et al. (1986) culminou no desenvolvimento de 
um algoritmo que determina a melhor distribuição da largura da banda, sendo compatível com os dados de entrada dos programas MAXBAND e PASSER II, e que agrega um modelo de estimativa de dispersão do pelotão semelhante ao modelo de dispersão do TRANSYT-7F. O modelo simplificado representa o comportamento do pelotão a cada segmento viário, dados os volumes nas interseções, fluxos de saturação, proporções de verde calculadas pelo $M A X B A N D$, tempos de viagem entre interseções, e fase de conversão à esquerda, gerando como dados de saída a proporção dos volumes e dos atrasos direcionais.

Alguns cenários não saturados foram testados, indicando que a solução obtida através da distribuição direcional gerada pelo algoritmo fornece melhores distribuições do que aquelas arbitradas de forma igual para as duas direções ou então proporcional à média do volume, conforme utilizado pelo programa MAXBAND, proporcionando melhorias no desempenho da arterial. A análise do algoritmo sugere sua eficiência principalmente nos casos em que a diferença de volume direcional é superior a 20\%.

\subsubsection{COMBAND (MAXBAND / MITROP)}

Considerando que os métodos combinados de minimização do atraso com limitação da largura da banda, em algumas situações produzem soluções ótimas locais sob o ponto de vista do sistema, Lan et al. (1992) criaram o modelo COMBAND a partir da formulação básica de maximização da largura da banda do $M A X B A N D$ e critérios de minimização de atraso originalmente propostos no programa MITROP.

Modificações foram feitas para obter resultados que buscassem simultaneamente a maximização da largura da banda e a minimização do atraso, avaliando os pesos direcionais das bandas em cada sentido e em cada tramo da via arterial, supondo condições de tráfego não saturadas, taxas de chegada e saída constantes nas interseções, sem dispersão do pelotão e sem fluxo entrando pelo meio da quadra.

Comparado com dados gerados pelo modelo $M A X B A N D$, a técnica de combinação simultânea dos programas MAXBAND / MITROP apresentou melhor solução global de otimização do ciclo, defasagens, proporções de verde e seqüência das fases, sob a análise do atraso, mantendo ainda a qualidade da progressão com pequena perda de largura da banda. 


\subsection{Esquema Geral dos Métodos Computacionais de Coordenação Semafórica}

A Tabela 4-1 esquematizada abaixo apresenta de forma resumida, a evolução cronológica dos métodos computacionais de coordenação semafórica mais citados nas referências bibliográficas, segundo a estratégia de otimização e sua aplicabilidade:

Tabela 4-1: Síntese dos métodos computacionais de coordenação semafórica

\begin{tabular}{|c|c|c|c|}
\hline ANO & TIPO & BASE & APLICAÇÃO \\
\hline 1964 & Half-Integer Synchronization Program & Largura da banda & Arterial - duas fases \\
\hline 1964 & SIGRID - Signal Grid Program & Atraso / Paradas & Rede - duas fases \\
\hline 1965 & SIGART - Signalized Arterial & Largura da banda & Arterial - duas fases \\
\hline 1965 & COMBINATION Method & Atraso / Paradas & Rede - duas fases \\
\hline 1966 & Interferência de Brooks e Bleyl & Largura da Banda & Arterial - duas fases \\
\hline 1966 & MILP - Mixed-Integer Linear Programming & Largura da banda & Rede - duas fases \\
\hline 1966 & SIGOP - Traffic Signal Optimization Program & Atraso / Paradas & Rede - duas fases \\
\hline 1967 & TRANSYT - Traffic Network Study Toll & Atraso / Paradas & Rede - múltiplas fases \\
\hline 1973 & PASSER - Progression Analysis and Signal System Evaluation Routine & Largura da banda & Arterial - múltiplas fases \\
\hline 1975 & MITROP - Mixed-Integer Traffic Optimization Program & Atraso / Paradas & Rede - duas fases \\
\hline 1976 & SIGOP II - New Signal Timing Optimization Program & Atraso / Paradas & Rede - múltiplas fases \\
\hline 1980 & MAXBAND - Maximal Bandwidth Program & Largura da banda & Arterial - múltiplas fases \\
\hline 1982 & Método Combinado PROS / PI & Banda e Atraso/Paradas & Arterial - múltiplas fases \\
\hline 1983 & Método Combinado PASSER II / TRANSYT 6 & Banda e Atraso/Paradas & Arterial - múltiplas fases \\
\hline 1983 & Método Combinado MAXBAND / TRANSYT-7F & Banda e Atraso/Paradas & Arterial - múltiplas fases \\
\hline 1984 & Método Combinado PASSER II - 84 & Banda e Atraso/Paradas & Arterial - múltiplas fases \\
\hline 1986 & Método Combinado MAXBAND / TRANSYT-7F (C) & Banda e Atraso/Paradas & Arterial - múltiplas fases \\
\hline 1986 & Método Combinado MAXBAND / NETSIM & Banda e Atraso/Paradas & Arterial - múltiplas fases \\
\hline 1986 & INTEGRATION & Atraso / Paradas & Rede - múltiplas fases \\
\hline 1986 & MAXBAND - 86 & Largura da banda & Rede - múltiplas fases \\
\hline 1988 & BANDTOP - Bandwidth of Timing Optimization Program & Largura da banda & Arterial - múltiplas fases \\
\hline 1989 & MULTIBAND - Variable Bandwidth Arterial Progression Scheme & Largura da banda & Arterial - múltiplas fases \\
\hline 1992 & Método Combinado COMBAND (MAXBAND / MITROP) & Banda e Atraso/Paradas & Arterial - múltiplas fases \\
\hline 1995 & U-BAND / V-BAND & Largura da banda & Arterial - múltiplas fases \\
\hline 1996 & MULTIBAND - 96 & Largura da banda & Rede - múltiplas fases \\
\hline
\end{tabular}

De forma geral, pôde ser constatado que a base dos métodos de maximização da largura da banda foi proposta por Little, no desenvolvimento das programações HalfInteger Synchronization e Mixed-Integer Linear, e que a base dos métodos de minimização do atraso e das paradas está na avaliação do índice de performance $P I$. Também a maioria das implementações computacionais desenvolvidas combinou de forma seqüencial ou simultânea as características dos métodos baseados em Little e no índice $P I$.

Portanto, existem poucos métodos de fato, mas sim diversos programas 
computacionais que foram desenvolvidos como formas adaptadas e evoluídas destas duas bases originais, e que ainda são pouco conhecidos e utilizados na maioria das prefeituras brasileiras.

Considerando que os esquemas de progressão são percebidos pelos usuários, que tomam esta forma de operação semafórica como qualidade do sistema, e que esta técnica requer poucos dados de entrada e menor esforço de aprendizado, uma das propostas deste trabalho é propor a implementação de um programa computacional baseado no primeiro método de maximização da banda verde desenvolvido por Morgan e Little (1964), que seja de utilização simplificada e compreensível por parte de analistas e operadores responsáveis pelo controle de tráfego nas cidades de médio porte. Este método alternativo poderá substituir os métodos manuais de tentativa e erro que demandam esforços repetitivos e os procedimentos de ajustes locais amplamente utilizados pelas prefeituras, para que através de interações computacionais entre ciclo, proporções de verde, velocidades dos pelotões e distâncias entre semáforos possam gerar defasagens apropriadas para a operação coordenada dos corredores de tráfego.

O desenvolvimento detalhado do método proposto será apresentado no capítulo 5 e avaliado no capítulo 6, com o auxílio de simulações de tráfego realizadas através do programa INTEGRATION, que também possibilita a coordenação de semáforos. Sendo assim, a análise poderá ser feita em função da comparação de medidas de desempenho entre cenários coordenados pelos dois programas, avaliando tanto a eficiência do aplicativo proposto para maximização da banda verde em corredores semaforizados, quanto à aplicabilidade do programa INTEGRATION na coordenação semafórica. 


\section{SBAND: UM APLICATIVO PARA MAXIMIZAÇÃO DA BANDA VERDE EM CORREDORES SEMAFORIZADOS}

Os métodos de maximização da banda verde são os que existem há mais tempo e são largamente utilizados, especialmente na forma de diagramas espaço-tempo. Uma evolução dos métodos gráficos é a utilização de programação inteira ou mista para definir o conjunto de defasagens ótimas e a largura máxima da banda verde. Sendo assim, um procedimento computacional baseado no método de Morgan e Little (1964), denominado SBAND, foi criado por Demarchi (2004) sendo que o desenvolvimento do método e a implementação do mesmo em uma planilha eletrônica é descrito por Demarchi e Dutra (2004a e 2004b).

SBAND consiste em uma adaptação do método de Morgan e Little (1964), considerando uma diferença básica: no método de Morgan e Little, a banda é calculada em função de suas trajetórias frontal e traseira, enquanto que no método proposto a largura da banda é obtida a partir do uso de diagramas de banda, cuja vantagem é permitir uma visualização mais simples e imediata de como a largura da banda varia em função da defasagem, além de facilitar a implementação do método em uma rotina computacional. Além disso, como não foi possível obter acesso ao código do programa original de Little, decidiu-se pela elaboração de rotinas próprias para implementação do método proposto.

Considerando que em problemas de programação inteira a busca pela solução ótima deve ser feita de maneira iterativa, torna-se impraticável coordenar manualmente uma rede semafórica contendo um número relativamente grande de semáforos. Como alternativa, é desejável utilizar aplicativos existentes no mercado ou, na falta desses programas, desenvolver uma rotina computacional que solucione esse tipo de problema. Portanto, a implementação do método de maximização da banda verde SBAND foi feita em uma planilha eletrônica do Excel, através de um conjunto de fórmulas do próprio programa e rotinas em Visual Basic utilizadas para automatizar o cálculo das larguras de banda para diferentes pares de semáforos e determinar o melhor esquema de coordenação, buscando a solução ótima dentre todas as soluções possíveis.

O procedimento para determinação das bandas verdes a partir de diagramas que expressam o valor da banda em função da defasagem, o método para elaboração dos diagramas para diferentes pares de semáforos e a definição das duas defasagens para as 
quais pelo menos uma delas a banda é máxima, são descritos no item 5.1 e seus subitens. No item 5.2, é definido o conjunto de defasagens que maximiza a banda verde para todo o sistema, considerando diferentes combinações de defasagens para diferentes pares de semáforos. Para isso, é utilizado um procedimento semelhante ao procedimento branch-and-bound utilizado por Little (1966).

\subsection{Diagramas de Banda Verde}

Os diagramas de banda são obtidos a partir da elaboração de diagramas espaço-tempo para diferentes defasagens e da identificação dos valores de banda verde obtidos para ambos os sentidos de tráfego. Eles representam a variação da largura das bandas $b_{i j}$ e $b_{j i}$, nos sentidos de tráfego $i-j e j-i$, respectivamente, em função da defasagem $\theta_{i j}$, observando que $\theta_{j i}=c-\theta_{i j}$. Como mostra a Figura 5-1, as larguras máxima e mínima da banda e respectivas defasagens podem ser definidas através de relações algébricas simples entre $c, r_{i}, r_{j}, t_{i j}$ e $t_{j i}$, onde:

$c$ : duração do ciclo [s];

$r_{i}, r_{j}$ : duração dos vermelhos dos semáforos $i$ e $j$ para a via analisada [s];

$x_{i}, x_{j}$ : instantes referentes aos centros dos vermelhos dos semáforos $i$ e $j[\mathrm{~s}]$;

$y_{i}, y_{j}$ : posições dos centros das interseções semaforizadas $i$ e $j$ em relação à origem do diagrama espaço-tempo [m];

$v_{i j}, v_{j i}$ : velocidades médias de percurso entre semáforos $i$ e $j$ e entre semáforos $j$ e $i[\mathrm{~km} / \mathrm{h}]$;

$b_{i j}, b_{j i}$ : largura das bandas verdes nos sentidos $i-j$ e $j-i[\mathrm{~s}]$;

$t_{i j}, t_{j i}:$ tempos de viagem nos segmentos $i-j$ e $j-i[\mathrm{~s}]$;

$\theta_{i j}, \theta_{j i}$ : defasagens entre semáforos nos sentidos $i-j$ e $j-i$ [s].

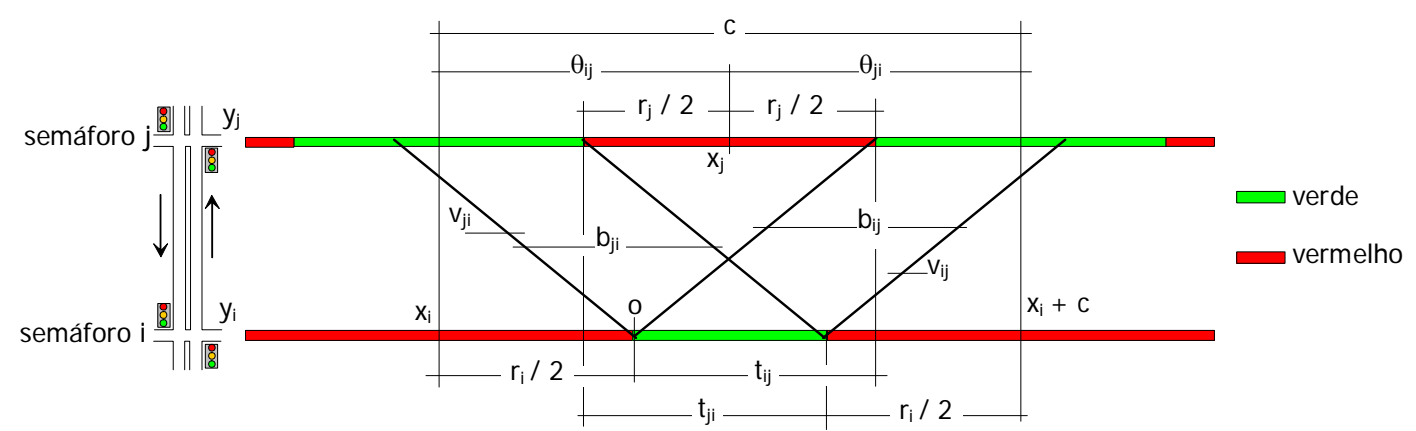

Figura 5-1: Variáveis utilizadas no método de maximização da banda verde 
Demarchi e Dutra (2004a) elaboraram diversos diagramas para diferentes combinações de $r_{i}, r_{j}, c, t_{i j}$ e $t_{j i}$. A título de exemplo, a Figura 5-2 apresenta o diagrama de bandas obtidas para um cenário em que $r_{i}=40 \mathrm{~s}, r_{j}=30 \mathrm{~s}, c=60 \mathrm{~s}$ e $t_{i j}=t_{j i}=10 \mathrm{~s}$, sendo que tanto $b_{i j}$ como $b_{j i}$ são plotados em função de $\theta i j$, e lembrando que $\theta j i=c-$ $\theta i j$. Deve ser observado que, para algumas defasagens, é possível obter uma banda verde negativa $\left(b_{i j}=-5 \mathrm{~s}\right.$ para $\theta i j=40 \mathrm{~s}$ e $b_{j i}=-5 \mathrm{~s}$ para $\left.\theta j i=20 \mathrm{~s}\right)$ o que, em termos práticos, equivale à inexistência de largura de banda.

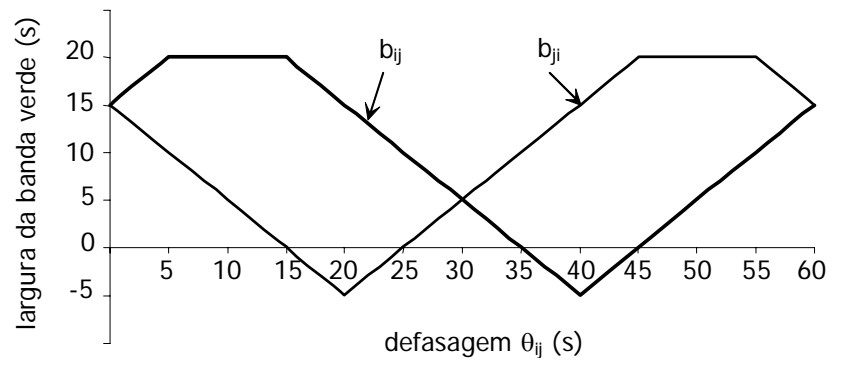

Figura 5-2: Diagrama de banda verde $b_{i j}$ e $b_{j i}$ em função da defasagem $\theta_{i j}$ $\left(r_{i}=40 \mathrm{~s}, r_{j}=30 \mathrm{~s}, c=60 \mathrm{~s}\right.$ e $\left.t_{i j}=t_{j i}=10 \mathrm{~s}\right)$

Após a comparação dos diagramas obtidos, foi constatado que alguns padrões eram observados em todos os diagramas, permitindo assim a formulação de um método mais prático para ser aplicado manualmente ou implementado em planilha eletrônica. Um desses padrões é que a banda máxima é sempre igual para ambas às direções de tráfego:

$$
b_{i j}{ }^{\max }=b_{j \mathrm{i}}{ }^{\max }=c-\max \left(r_{i}, r_{j}\right)
$$

e que $b_{i j}{ }^{\text {max }}$ ocorre para $\theta_{i j}=t_{i j}$. Da mesma forma, $b_{j i}{ }^{\text {max }}$ ocorre para $\theta_{i j}=c-t_{j i}$. Caso $r_{i}=r_{j}$, só existe um ponto de máximo, mas se $r_{i} \neq r_{j}$, o diagrama de banda apresenta um patamar com valores máximos entre as seguintes defasagens:

$$
\begin{aligned}
& \text { sentido } i-j:\left\{\left(t_{i j}-\left|\frac{r_{i}-r_{j}}{2}\right|\right) \bmod (c),\left(t_{i j}+\left|\frac{r_{i}-r_{j}}{2}\right|\right) \bmod (c)\right\} \\
& \text { sentido } j-i \text { : }\left(c-t_{j i}-\left|\frac{r_{i}-r_{j}}{2}\right|\right) \bmod (c),\left(c-t_{j i}+\left|\frac{r_{i}-r_{j}}{2}\right|\right) \bmod (c)
\end{aligned}
$$

A banda de maior largura ocorre quando são utilizadas defasagens iguais ao tempo de viagem entre interseções e os tempos de viagem são iguais ou múltiplos da metade do ciclo, ou seja, $t$ mod $(c / 2)$. Para o exemplo do cenário em que $r_{i}=40 \mathrm{~s}, r_{j}=$ $30 \mathrm{~s}$ e $c=60 \mathrm{~s}$, a banda máxima de 20 segundos ocorre para $t_{i j}=t_{j i}=30 \mathrm{~s}, 60 \mathrm{~s}, 90 \mathrm{~s}$ e 
assim por diante.

Os valores da banda mínima são também iguais para ambas às direções:

$$
b_{i j}^{\min }=b_{j i}^{\min }=\frac{c-\left(r_{i}+r_{j}\right)}{2}
$$

sendo que os valores mínimos de $b_{i j}{ }^{\text {min }}$ e $b_{j i}{ }^{\text {min }}$ ocorrem para as seguintes defasagens:

$$
\begin{aligned}
& \text { sentido } i-j \text { : } \theta_{i j}=\left(\frac{c}{2}+t_{i j}\right) \bmod (c) \\
& \text { sentido } j-i \text { : } \theta_{j i}=\left(\frac{c}{2}-t_{j i}\right) \bmod (c)
\end{aligned}
$$

A Figura 5-3 apresenta os diagramas de banda para os sentidos de tráfego $i-j e$ $j-i$, e as representações das relações algébricas para a definição da variação da largura das bandas $b_{i j}$ e $b_{j i}$ em função da defasagem $\theta_{i j}$.

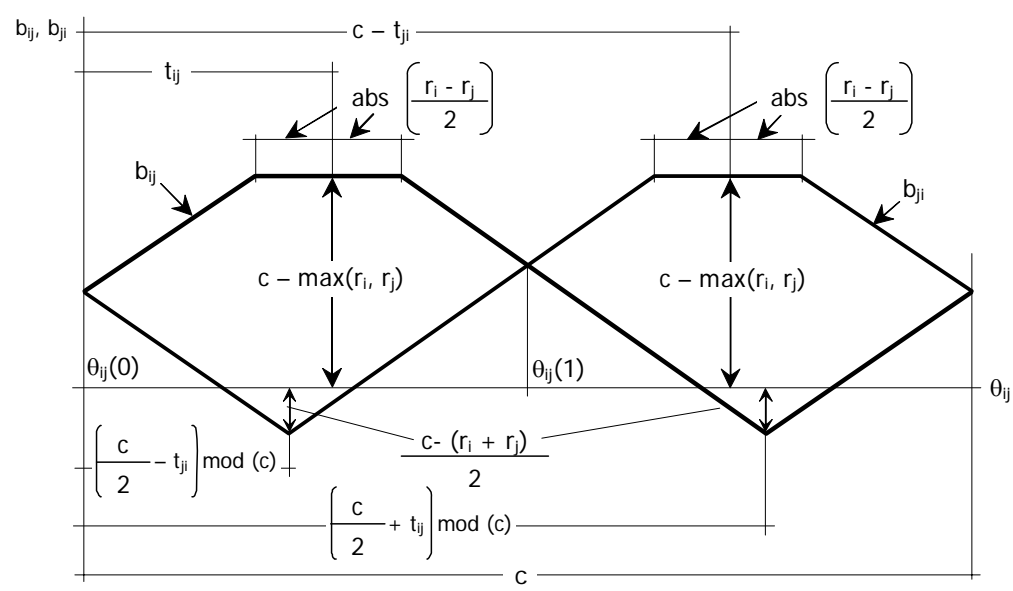

Figura 5-3: Diagramas de bandas típicos para os sentidos $i-j$ e $j-i$

\subsubsection{Montagem dos Diagramas de Banda}

Identificando os pontos de banda máxima e mínima, os diagramas de banda são construídos de acordo com o procedimento ilustrado na Figura 5-4 e descrito a seguir (Demarchi e Dutra, 2004a):

a) Os pontos de mínimo $m_{i j}$ e $m_{j i}$ são plotados na Figura 5-4a de acordo com as coordenadas obtidas pelas Equações (5-4), (5-5) e (5-6). Em seguida, são localizados no gráfico os pontos que definem o patamar de banda máxima $\left(M_{i j} \mathrm{e}\right.$ 
$M_{i j}^{\prime}$, no sentido $i-j$ e $M_{j i}$ e $M_{j i}^{\prime}$, no sentido $j-i$ ), com as coordenadas obtidas conforme as Equações (5-1), (5-2) e (5-3). Deve ser observado que se $r_{i}=r_{j}, M_{i j} \equiv$ $M_{i j}^{\prime}$ e $M_{i j} \equiv M_{j i}^{\prime}$.

b) O ponto $M_{i j}$ deve ser unido ao ponto $M_{i j}^{\prime}$ por uma reta, o mesmo sendo feito em relação aos pontos $M_{j i}$ e $M_{j i}^{\prime}$ (Figura 5-4b). Em seguida, o ponto $M_{i j}$ deve ser ligado ao ponto $m_{i j}$ e o ponto $M_{j i}$ unido ao ponto $m_{j i}$;

c) Considerando que num sistema cíclico (Figura 5-4c) qualquer ponto pode ser observado a cada $c$ segundos, existe outro ponto de mínimo $m^{\prime}{ }_{i j}$ localizado $-c$ segundos à esquerda de $m_{i j}$, bem como outro ponto de mínimo $m_{j i}^{\prime}$ localizado $+c$ segundos à direita de $m_{j i}$. Portanto, o ponto $M_{i j}^{\prime}$ deve ser ligado ao ponto $m_{j i}^{\prime}$ e o ponto $M_{j i}^{\prime}$ deve ser ligado ao ponto $m_{j i}^{\prime}$;

d) O segmento de reta à esquerda da origem do diagrama da banda $b_{i j}$ deve ser deslocado para a direita, no intervalo entre $m_{i j}$ e $c$, enquanto que o segmento do diagrama da banda $b_{j i}$ à direita de $c$ deve ser deslocado para a esquerda, completando o diagrama de bandas $b_{j i}$ no intervalo entre 0 e $m_{j i}$ (Figura 5-4d).
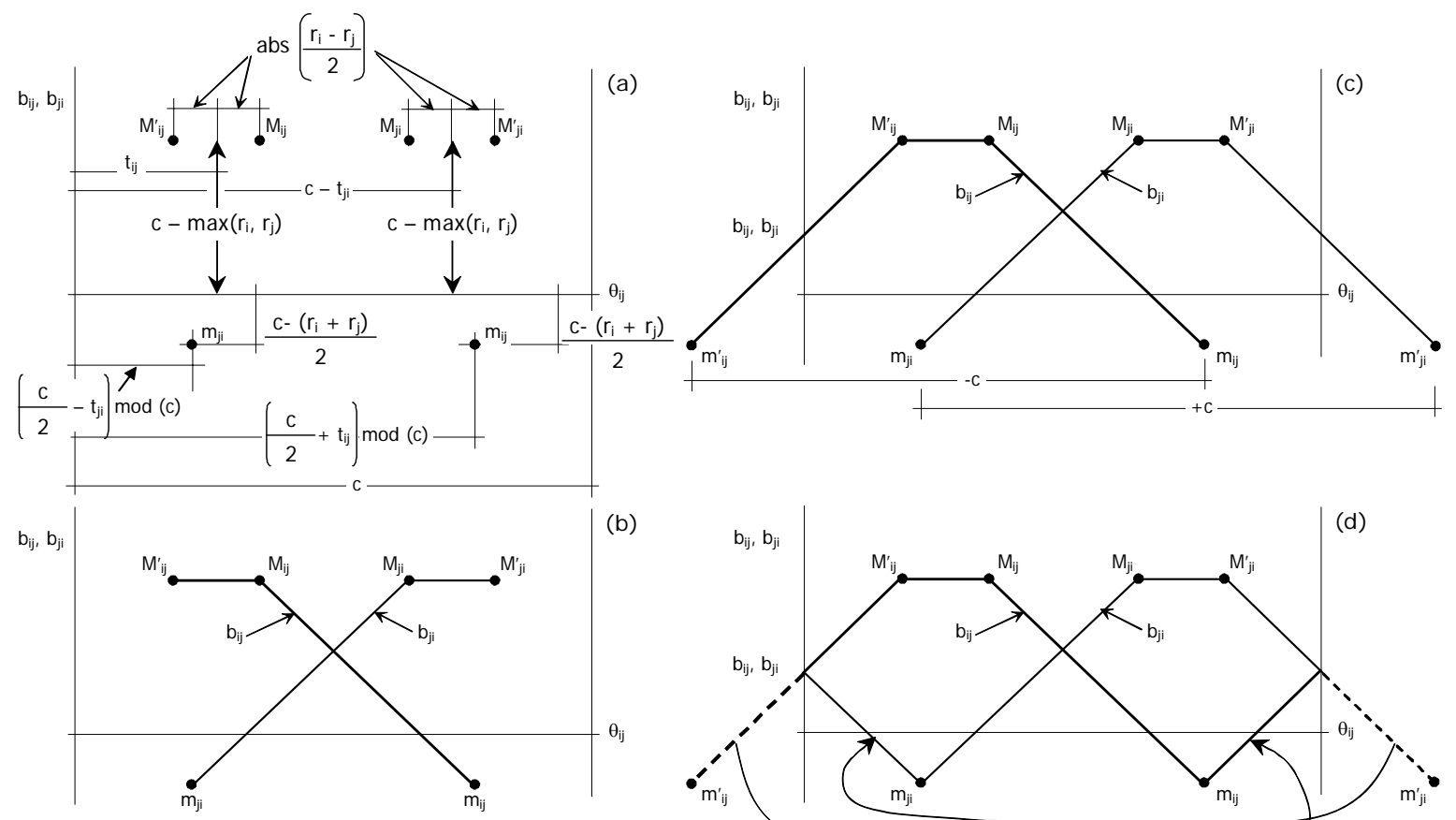

Figura 5-4: Montagem dos diagramas de banda para os sentidos $i-j$ e $j-i$

A Figura 5-4 foi elaborada para o caso em que $\theta_{i j}<c / 2$ e $\theta_{j i}<c / 2$. Para $\theta_{i j}>c / 2$ e $\theta_{j i}>c / 2$, o procedimento é similar, exceto que o diagrama de bandas $b_{i j}$ seria similar 
ao diagrama de bandas $b_{j i}$ na Figura 5-4 e vice-versa.

O procedimento descrito, no entanto, não é o mais simples de ser implementado em uma rotina computacional, considerando as inúmeras configurações de diagramas que podem ser obtidas em função da variação dos valores de $c, r_{i}, r_{j}, t_{i j} \mathrm{e}$ $t_{j i}$. É mais simples determinar bandas iguais para os sentidos $i-j$ e $j-i$ diretamente a partir de um diagrama padrão, que é aquele em que o tempo de viagem $t_{i j}$ ou $t_{j i}$ é igual a $c / 2$, conforme mostrado na Figura 5-5a. Para esse diagrama, a largura máxima de banda ocorre para $\theta_{i j}=c / 2$ e existem dois pontos de mínimo (que na verdade são um só num sistema cíclico) para as defasagens $\theta_{i j}=0$ e $\theta_{i j}=c$. Os diagramas de banda específicos para quaisquer valores $t_{i j}$ e $t_{j i}$ podem ser obtidos a partir do diagrama padrão através do seguinte procedimento:

a) Elabora-se um diagrama padrão com ordenadas e abscissas mostradas na Figura 5-5a;

b) O diagrama padrão deve ser deslocado horizontalmente no sentido do eixo das defasagens (Figura 5-5b), de tal forma que a defasagem referente à banda máxima (ou o ponto médio do patamar de banda máxima) coincida com $\theta_{i j}=t_{i j}$ (no caso do sentido $i-j$ ) ou então com $\theta_{i j}=c-t_{j i}$ (no caso do sentido $j-i$ );

c) A porção do diagrama da banda $b_{i j}$ que ficar à esquerda do ponto $\theta_{i j}=0$ (ou à direita do ponto $\theta_{i j}=c$ ) deve ser deslocada para a direita (ou esquerda), completando o diagrama, conforme mostrado na Figura 5-5c. O mesmo procedimento é adotado para a banda $b_{j i}$.
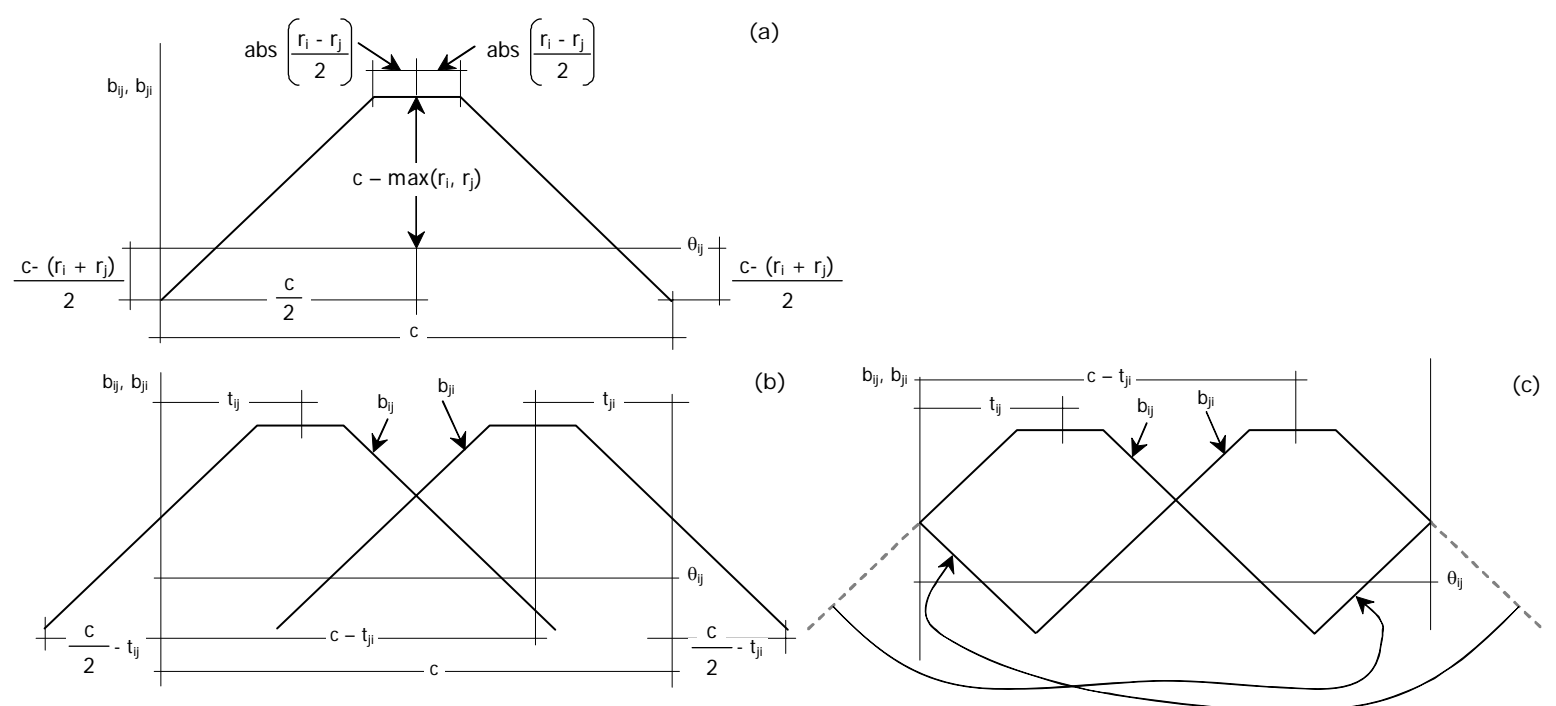

Figura 5-5: Obtenção dos diagramas de banda a partir do diagrama padrão 


\subsubsection{Definição de Defasagens Ótimas}

A maior largura de banda verde, cujo valor é igual para as direções $i-j e j-i$, ocorre para pelo menos uma das defasagens correspondentes aos pontos de cruzamento dos diagramas $b_{i j}$ e $b_{j i}$. De uma forma geral, tais defasagens são definidas através da expressão (5-7):

$$
\theta_{i j}=\left(\pi_{i j} \cdot \frac{c}{2}+\frac{t_{i j}-t_{j i}}{2}\right) \bmod (c), \quad \pi_{i j}=\{0,1\}
$$

Conforme demonstrado no item 5.1.1, os diagramas de banda também podem ser obtidos a partir da simples translação do diagrama padrão no eixo horizontal. Esta propriedade é útil na medida em que as defasagens determinadas através da Equação (5-7) podem ser transformadas em defasagens $\theta_{i j}{ }^{p}$ do diagrama padrão, utilizando para isso a expressão:

$$
\theta_{i j}^{p}\left(\pi_{i j}\right)=\left(\theta_{i j}\left(\pi_{i j}\right)+\frac{c}{2}-t_{i j}\right) \bmod (c)
$$

Substituindo (5-7) em (5-8), é obtida

$$
\theta_{i j}^{p}\left(\pi_{i j}\right)=\left(\frac{c}{2}+\pi_{i j} \cdot \frac{c}{2}-\frac{t_{i j}+t_{j i}}{2}\right) \bmod (c), \pi_{i j}=\{0,1\}
$$

Dessa forma, utilizando o único diagrama padrão, as larguras de banda $b_{i j}(0)$ e $b_{i j}(1)$ são determinadas através de interpolação linear para os valores de $\theta_{i j}{ }^{p}(0)$ e $\theta_{i j}{ }^{p}(1)$.

\subsubsection{Determinação das Defasagens para Bandas Iguais}

As defasagens para as quais as bandas são iguais são obtidas nos pontos de cruzamento dos diagramas das bandas $b_{i j}$ e $b_{j i}$, conforme ilustrado na Figura 5-4d. Dentre os valores obtidos, pelo menos um deles é o máximo possível para os dois semáforos considerados. Pode ser observado que, para a situação ilustrada em que $t_{i j}=t_{j i}$, os valores das defasagens que fornecem bandas iguais são $\theta_{i j}=0$ e $\theta_{i j}=c / 2$. De forma geral, os valores de banda para quaisquer valores de $t_{i j}$ e $t_{j i}$ podem ser obtidos através de interpolação linear dos diagramas de banda, para as defasagens calculadas pela Equação (5-9).

\subsection{Determinação da Banda Máxima para Mais de Dois Semáforos}

O procedimento descrito até agora se aplica somente para a determinação das bandas verdes considerando duas interseções semaforizadas. No caso de mais de duas 
interseções, é necessário considerar as interferências que o vermelho de um determinado semáforo causa na banda de quaisquer outros dois semáforos. Por exemplo, embora a largura máxima da banda no sentido $i-j$ entre os semáforos 2 e 3 na Figura 5-6 seja igual à 25 segundos, a posição do vermelho do semáforo 1 faz com que a largura efetiva da banda em todo o sistema seja reduzida para 15,3 segundos.

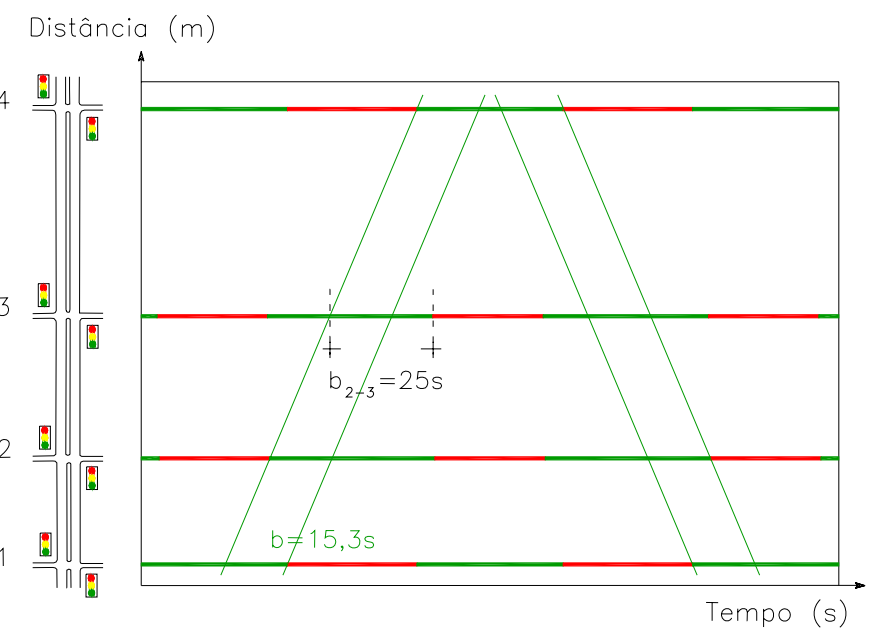

Figura 5-6: Exemplo de interferência da posição do vermelho na definição da largura da banda

Para ilustrar a aplicação do método SBAND, foi utilizado um segmento de via de pista dupla com 1844 metros e 10 interseções semaforizadas de duas fases, operando com ciclo de 65 segundos e velocidade de progressão de 54,9 km/h para ambos os sentidos de tráfego. Este mesmo corredor foi descrito como exemplo no artigo de Morgan e Little (1964), e sua utilização visa comparar os resultados obtidos com a aplicação do método proposto aos resultados obtidos através do método original. A Tabela 5-1 apresenta as distâncias e os tempos de viagem entre as interseções semaforizadas, assim como os tempos de vermelho em cada um dos semáforos da rede utilizada como exemplo.

Tabela 5-1: Características da rede semaforizada exemplo (valores obtidos de Morgan e Little, 1964)

\begin{tabular}{cccccccccccccc}
\hline Semáforo & 1 & 2 & 3 & 4 & 5 & 6 & 7 & 8 & 9 & 10 \\
\hline Tempo de vermelho $(\mathrm{s})$ & 30,5 & 26,0 & 26,0 & 30,5 & 31,0 & 27,0 & 26,0 & 26,0 & 26,0 & 27,0 \\
Distância entre interseções $(\mathrm{m})$ & 168 & 213 & 335 & 213 & 244 & 198 & 122 & 213 & 137 \\
Tempo de viagem $\mathrm{t}_{\mathrm{ij}}$ e $\mathrm{t}_{\mathrm{ji}}(\mathrm{s})$ & 11 & 14 & 22 & 14 & 16 & 13 & 8 & 14 & 9 \\
\hline
\end{tabular}

A seguir é descrito o procedimento para obtenção da maior largura possível de banda verde igual em ambos os sentidos de tráfego (item 5.2.1), assim como para a determinação da posição das trajetórias que definem a banda verde (item 5.2.2). Em 
função da solução de banda obtida, é possível aumentar a largura de banda em um sentido, diminuindo-a no outro, em situações em que a proporção do volume de tráfego que circula em ambos os sentidos é desigual ou quando se deseja favorecer uma corrente de tráfego em detrimento da outra (ver item 5.2.3).

\subsubsection{Determinação de Bandas Iguais para Ambos os Sentidos}

Os procedimentos para determinar a banda máxima de valor igual para as direções $i-j$ e $j-i$, bem como as defasagens entre semáforos são descritos a seguir:

1) Os valores das larguras de banda verde devem ser calculados para todos os pares de semáforos $i, j$ e defasagens definidas pela Equação (5-9), ou seja, para $\pi_{i j}=0 \mathrm{e}$ $\pi_{i j}=1(1 \leq i<n, j>i)$, conforme descrito nos itens 5.1.1 e 5.1.3. Para o caso específico apresentado em que $t_{i j}=t_{j i}$, quando $\pi_{1 j}=0$ os centros dos vermelhos de todos os semáforos ficam alinhados, enquanto que para $\pi_{1 j}=1$ todos os vermelhos ficam defasados de $c / 2$. As bandas de cada par de semáforos são colocadas no formato de matrizes em que só as células das diagonais superiores são preenchidas. Assim, na matriz (a) da Figura 5-7 são colocados os valores de $b_{i j}$ calculados para $\pi_{i j}=0$ e, na matriz (b) da mesma Figura, as larguras de banda para $\pi_{i j}=1$.

(a) largura de banda $\left(\pi_{1 j}=0\right)$

\begin{tabular}{|c|c|c|c|c|c|}
\hline$\pi_{\mathbf{1 j}}$ & 0 & 0 & $\ldots$ & 0 & 0 \\
\hline $\mathbf{i} \backslash \mathbf{j}$ & $\mathbf{1}$ & $\mathbf{2}$ & $\ldots$ & $\mathbf{n - 1}$ & $\mathbf{n}$ \\
\hline $\mathbf{1}$ & - & $\mathrm{b}_{12}$ & $\ldots$ & $\mathrm{b}_{1 \mathrm{n}-1}$ & $\mathrm{~b}_{1 \mathrm{n}}$ \\
\hline $\mathbf{2}$ & & - & $\mathrm{b}_{12}$ & $\mathrm{~b}_{2 \mathrm{n}-1}$ & $\mathrm{~b}_{2 \mathrm{n}}$ \\
\hline$\vdots$ & & & - & $\ldots$ & $\ldots$ \\
\hline $\mathbf{n - 1}$ & & & & $\mathrm{b}_{\mathrm{n}-1 \mathrm{n}-1}$ & $\mathrm{~b}_{\mathrm{n}-1 \mathrm{n}}$ \\
\hline $\mathbf{n}$ & & & & & - \\
\hline
\end{tabular}

(c) valores de $\pi_{\mathrm{ij}}$

\begin{tabular}{|c|c|c|c|c|c|}
\hline $\mathbf{i} \backslash \mathbf{j}$ & $\mathbf{1}$ & $\mathbf{2}$ & $\cdots$ & $\mathbf{n}-\mathbf{1}$ & $\mathbf{n}$ \\
\hline $\mathbf{1}$ & - & $\pi_{12}$ & $\ldots$ & $\pi_{1 \mathrm{n}-1}$ & $\pi_{1 \mathrm{n}}$ \\
\hline $\mathbf{2}$ & & - & $\pi_{12}$ & $\pi_{2 \mathrm{n}-1}$ & $\pi_{2 \mathrm{n}}$ \\
\hline$\vdots$ & & & - & $\ldots$ & $\ldots$ \\
\hline $\mathbf{n - 1}$ & & & & $\pi_{\mathrm{n}-1 \mathrm{n}-1}$ & $\pi_{\mathrm{n}-1 \mathrm{n}}$ \\
\hline $\mathbf{n}$ & & & & & - \\
\hline
\end{tabular}

(b) largura de banda $\left(\pi_{1 j}=1\right)$

\begin{tabular}{|c|c|c|c|c|c|}
\hline$\pi_{\mathbf{1 j}}$ & 0 & 1 & $\ldots$ & 1 & 1 \\
\hline $\mathbf{i} \backslash \mathbf{j}$ & $\mathbf{1}$ & $\mathbf{2}$ & $\ldots$ & $\mathbf{n - 1}$ & $\mathbf{n}$ \\
\hline $\mathbf{1}$ & - & $\mathrm{b}_{12}$ & $\ldots$ & $\mathrm{b}_{1 \mathrm{n}-1}$ & $\mathrm{~b}_{1 \mathrm{n}}$ \\
\hline $\mathbf{2}$ & & - & $\mathrm{b}_{12}$ & $\mathrm{~b}_{2 \mathrm{n}-1}$ & $\mathrm{~b}_{2 \mathrm{n}}$ \\
\hline $\mathbf{\vdots}$ & & & - & $\ldots$ & $\ldots$ \\
\hline $\mathbf{n - 1}$ & & & & $\mathrm{b}_{\mathrm{n}-1 \mathrm{n}-1}$ & $\mathrm{~b}_{\mathrm{n}-1 \mathrm{n}}$ \\
\hline $\mathbf{n}$ & & & & & - \\
\hline
\end{tabular}

(d) largura de banda (solução)

\begin{tabular}{|c|c|c|c|c|c|}
\hline$\pi_{\mathbf{1 j}}$ & $\pi_{11}=0$ & $\pi_{12}$ & $\ldots$ & $\pi_{1 \mathrm{n}-1}$ & $\pi_{1 \mathrm{n}}$ \\
\hline $\mathbf{i} \backslash \mathbf{j}$ & $\mathbf{1}$ & $\mathbf{2}$ & $\ldots$ & $\mathbf{n - 1}$ & $\mathbf{n}$ \\
\hline $\mathbf{1}$ & - & $\mathrm{b}_{12}$ & $\ldots$ & $\mathrm{b}_{1 \mathrm{n}-1}$ & $\mathrm{~b}_{1 \mathrm{n}}$ \\
\hline $\mathbf{2}$ & & - & $\mathrm{b}_{12}$ & $\mathrm{~b}_{2 \mathrm{n}-1}$ & $\mathrm{~b}_{2 \mathrm{n}}$ \\
\hline$\vdots$ & & & - & $\ldots$ & $\ldots$ \\
\hline $\mathbf{n - 1}$ & & & & $\mathrm{b}_{\mathrm{n}-1 \mathrm{n}-1}$ & $\mathrm{~b}_{\mathrm{n}-1 \mathrm{n}}$ \\
\hline $\mathbf{n}$ & & & & & - \\
\hline
\end{tabular}

(e): banda máxima $b=\min \left(b_{i j}\right)$

Figura 5-7: Montagem da planilha para determinação da banda máxima global

2) Em seguida é definida uma seqüência de valores de $\pi_{1 j}(1 \leq j<n)$ contendo uma 
solução inicial qualquer (por exemplo $\pi_{1 j}=0, \forall j$ ). A posição relativa do centro do vermelho de qualquer semáforo em relação ao semáforo 1 permite determinar as posições relativas $\pi_{j k}$ para quaisquer outros pares de semáforos $j, k$ :

$$
\pi_{j k}=\left\{\begin{array}{ll}
\pi_{i j}+\pi_{i k}, & \pi_{i j}+\pi_{i k}<2 \\
0, & \pi_{i j}+\pi_{i k}=2
\end{array},\right.
$$

sendo $1 \leq i<n-2$, $i<j \leq n-1$ e $j<k \leq n$, e $n$ o número de semáforos do sistema. Para isso, utiliza-se a matriz (c), mostrada na Figura 5-7, na qual a primeira linha é preenchida com valores de $\pi_{1 j}=0, \forall j$, como solução inicial do problema. Nas outras linhas dessa matriz são colocadas fórmulas para cálculo das posições relativas $\pi_{j k}$ para quaisquer outros pares de semáforos $j, k$, tomando como base a expressão 5-10. Dessa maneira, qualquer alteração nos valores de $\pi_{1 j}$ na primeira linha da matriz altera os valores das outras células automaticamente.

3) A etapa seguinte consiste na criação da matriz (d), contendo larguras de banda que podem ser alteradas automaticamente em função da modificação dos respectivos valores de $\pi_{i j}$ na matriz (c). Isso é possível graças ao uso da função "DESLOC” do Excel, que permite referenciar células deslocadas de um certo número de linhas ou colunas uma da outra. Por exemplo, supondo que a banda $b_{12}$ na matriz (a) esteja na célula K3 do Excel, que a banda $b_{12}$ da matriz (b) esteja na célula W3, e que $\pi_{12}$ esteja na célula K16, a fórmula:

$$
=\operatorname{DESLOC}(\mathrm{K} 3 ; 0 ; \mathrm{K} 16 * 12)
$$

faz com que o valor de $b_{12}$ mostrado na matriz (d) seja igual ao valor da célula K3 se $\pi_{12}=0$ ou então igual ao valor da célula W3 se $\pi_{12}=1$. Na fórmula, K3 é a célula de referência e o número 12 serve para indicar o número de colunas que W3 está à direita de K3. Neste caso, como as matrizes (a) e (b) estão posicionadas lado a lado, o deslocamento do número de linhas é nulo, indicado pelo “0” na Equação (5-11).

4) A próxima etapa consiste em determinar o mínimo dos valores da matriz (d), o que é feito através da função “MíNIMO” do Excel, colocada em uma célula logo abaixo da matriz (d) - ver o item (e) da Figura 5-7. Para facilitar a execução destas etapas, uma rotina em Visual Basic coloca na planilha as fórmulas da matriz (c) e a fórmula para cálculo da banda máxima em (e). O problema então consiste em encontrar a maior das menores larguras de banda dentre as determinadas para diferentes combinações de $\pi_{i j}=0$ ou $\pi_{i j}=1,(1<i<n, j>i)$ que maximiza o valor da célula (e) de banda verde global, ou seja: 


$$
b=\max \min b_{i j}\left(\pi_{i j}\right)
$$

A etapa 4 pode ser executada de duas formas distintas. A forma mais intuitiva, porém mais trabalhosa, de obter a solução seria verificar $2^{(n-1)}$ combinações de 0 's e 1's e identificar aquela que fornece a banda máxima. Deve ser lembrado que são testadas $n-1$ combinações ao invés de $n$, pois não é necessário testar a posição do vermelho do semáforo 1 , já que a combinação $\pi_{11}=0$ e $\pi_{12}=1$, por exemplo, produz solução idêntica a $\pi_{11}=1$ e $\pi_{12}=0$. Para isso, uma rotina em Visual Basic testa sistematicamente $2^{(n-1)}$ combinações de valores de $\pi_{1 j}$ na primeira linha da matriz (c) e identifica a combinação que produz a maior largura de banda para todo o sistema. Em um computador com processador Pentium $42.8 \mathrm{Ghz}$ e 512 Mb de RAM, a solução ótima para uma rede composta por 10 semáforos é encontrada em pouco mais de $7 \mathrm{~s}$, incluindo a etapa de cálculo das larguras de banda. No entanto, utilizando um Pentium 100 Mhz com 64 Mb de RAM, a solução ótima demora 3 minutos para ser encontrada.

A forma mais simples, que entretanto deve ser feita de maneira ainda manual na versão atual do SBAND, é utilizar um procedimento do tipo branch-and-bound semelhante ao utilizado por Little (1966). O procedimento consiste em modificar manualmente na primeira linha da matriz (c) os valores de $\pi_{1 j}$ relativos aos pares de semáforos que limitam o valor da banda, de forma a obter uma nova combinação de valores de $\pi_{\mathrm{i} j}$ que façam com que a largura da banda máxima aumente. A aplicação do procedimento para o exemplo apresentado na Tabela 5-1 é ilustrada na Figura 5-8 e descrita a seguir:

1) Uma solução inicial é adotada de forma que todos $\pi_{1 j}=0, \forall j$. Para esta solução, a banda máxima obtida no exemplo seria 4,7 segundos;

2) O próximo passo consiste em identificar o par (ou pares) de semáforos $i, j$ que limitam o valor da banda máxima ao valor da solução obtido em (1). No exemplo, seriam os semáforos 1 e 8;

3) Como o vermelho do semáforo 1 pode ser mantido fixo pelas razões já mencionadas, basta verificar se $\pi_{18}=1$ fornece um maior valor de banda do que $\pi_{18}=0$. Neste caso, a banda máxima obtida é 6,3 segundos, indicando que o semáforo 8 deve ser defasado de $c / 2$ do semáforo 1 ;

4) Após fazer $\pi_{18}=1$, o par a ser testado é composto pelos semáforos 4 e 6 . Para esse par, a maior banda ( $b=7,0 \mathrm{~s}$ ) é obtida para $\pi_{14}=0$ e $\pi_{16}=1$;

5) Em seguida, o par crítico é composto pelos semáforos 1 e 2 e, adotando $\pi_{12}=1$, é 
obtido $b=7,5 \mathrm{~s}$, valor de banda que identifica os pares de semáforos 3-5, 3-10, 5-7 e 7-10 como limitantes. Testando então 16 combinações possíveis de valores de $\pi_{13}$, $\pi_{15}, \pi_{17}$ e $\pi_{110}$, verifica-se que o novo valor de banda máxima passa para 15,3 segundos ao adotar $\pi_{13}=1, \pi_{15}=0, \pi_{17}=1$ e $\pi_{110}=0$. O processo é então interrompido, pois o par 1-2 passa a ser o limitante e esse par já foi testado anteriormente.

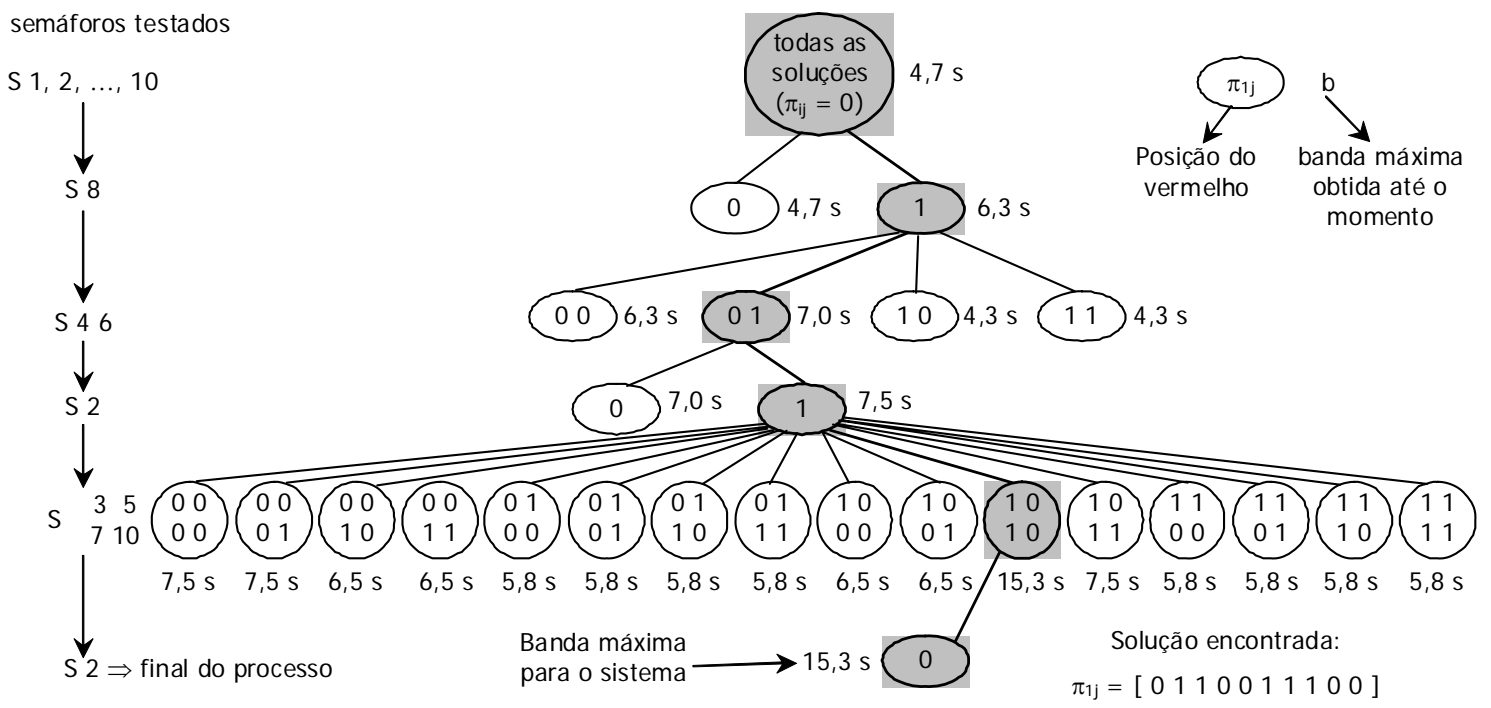

Figura 5-8: Árvore de busca da banda máxima para o sistema de 10 semáforos

A Tabela 5-2 apresenta também as etapas de busca das defasagens que maximizam a banda verde em ambos os sentidos de tráfego. A largura de banda obtida (15,3 segundos) é semelhante ao valor obtido por Morgan e Little (1964).

Tabela 5-2: Busca da solução ótima para a rede de 10 semáforos

\begin{tabular}{|c|c|c|c|c|c|c|c|c|c|c|c|c|}
\hline \multirow{2}{*}{ Iteração } & \multicolumn{10}{|c|}{ valores de $\pi_{1 j}$ por semáforo } & \multirow{2}{*}{$\begin{array}{c}\text { banda } \\
b(\mathrm{~s})\end{array}$} & \multirow{2}{*}{$\begin{array}{c}\text { Semáforos } \\
\text { críticos* }\end{array}$} \\
\hline & 1 & 2 & 3 & 4 & 5 & 6 & 7 & 8 & 9 & 10 & & \\
\hline 0 & 0 & 0 & 0 & 0 & 0 & 0 & 0 & 0 & 0 & 0 & 4,7 & 1,8 \\
\hline 1 & 0 & 0 & 0 & 0 & 0 & 0 & 0 & 1 & 0 & 0 & 6,3 & 4,6 \\
\hline 2 & 0 & 0 & 0 & 0 & 0 & 1 & 0 & 1 & 0 & 0 & 7,0 & 1,2 \\
\hline 3 & 0 & 1 & 0 & 0 & 0 & 1 & 0 & 1 & 0 & 0 & 7,5 & $3,5,7$ e 10 \\
\hline 4 & 0 & 1 & 1 & 0 & 0 & 1 & 1 & 1 & 0 & 0 & 15,3 & 1,2 \\
\hline defasagens (s) & 0,0 & 32,5 & 32,5 & 0,0 & 0,0 & 32,5 & 32,5 & 32,5 & 0,0 & 0,0 & & \\
\hline
\end{tabular}

*os semáforos críticos são aqueles que limitam a largura da banda após a mudança dos valores de $\pi_{1 j}$ em cada iteração

\subsubsection{Determinação da Posição das Trajetórias que Definem a Banda Verde}

Após obter as defasagens ótimas e a largura máxima da banda verde, é necessário definir os pontos de passagem das trajetórias frontal e traseira da banda em relação ao 
verde e vermelho de cada semáforo, podendo ser feito através de rotinas em Visual Basic. Para plotar as trajetórias frontal e traseira da banda nos sentidos $i-j$ e $j-i$, determina-se inicialmente valores de $\omega f_{k}(k=1,2, \ldots, n)$ :

$$
\omega f_{k}=r_{1}-\left(\frac{r_{1}}{2}+\theta_{1 k}+\frac{r_{k}}{2}-t_{1 k}\right) \bmod (c)
$$

Sempre que a banda é máxima, a trajetória frontal da banda toca o lado direito do vermelho de pelo menos um semáforo. Para que $w f_{k}=0$ para esse semáforo, é usada a seguinte equação:

$$
w f_{k}=\omega f_{k}-\min (\omega f), k=1,2, \ldots, n
$$

O mesmo cálculo é feito para todos os outros semáforos. A distância entre a trajetória traseira da banda no sentido $i-j$ (ou frontal no sentido $j-i$ ), é dada por

$$
w h_{k}=g_{k}-b-w f_{k}, k=1,2, \ldots, n
$$

\subsubsection{Determinação de Bandas Distintas}

Após a determinação de um valor de banda igual para ambos os sentidos de tráfego, Demarchi e Dutra (2004a) apresentam a possibilidade de aumentar a largura da banda no sentido em que o tráfego é maior, diminuindo porém a banda no sentido contrário e, em função das novas larguras de banda são definidas as novas trajetórias. Por exemplo, caso seja desejável aumentar a largura da banda no sentido $i-j$ de $b$ para $b^{i-j}$, utiliza-se a seguinte expressão, que também foi implementada em Visual Basic:

$$
b^{i-j}=b+\delta b, \delta b \leq g_{\min }-b
$$

sendo $\delta b$ o incremento da largura da banda no sentido $i-j$. Conseqüentemente, a banda no sentido $j-i$ deve ser reduzida de $b$ para $b^{j-i}$ :

$$
b^{j-i}=b-\delta b, \delta b \leq b
$$

Ao aumentar a banda no sentido $i-j$, é necessário modificar o valor de $w f_{k}$ para $w f_{k}^{i-j}$ :

$$
w f_{k}^{i-j}= \begin{cases}w f_{k}, & w h_{k}-\delta b \geq 0 \\ w f_{k}-\delta b+w h_{k}, & w h_{k}-\delta b<0\end{cases}
$$

e $w f_{k}$ para $w f_{k}^{j-i}$ :

$$
w f_{k}^{j-i}= \begin{cases}w f_{k}, & w h_{k}-\delta b \geq 0 \\ w f_{k}+\delta b-w h_{k}, & w h_{k}-\delta b<0\end{cases}
$$


Também é preciso verificar se é necessário modificar a defasagem dos semáforos para acomodar a nova largura da banda. Para isso, basta calcular novos valores das defasagens $\theta^{*}{ }_{1 k}$ em relação ao semáforo $1, k=1, \ldots, n$. Deve ser observado que $\theta^{*}$ não é uma defasagem propriamente dita, mas serve para indicar posição do centro do vermelho do semáforo 1, que é a referência para cálculo das defasagens dos outros semáforos em relação ao semáforo 1:

$$
\theta_{1 k}^{*}= \begin{cases}\theta_{1 k}, & w h_{k}-\delta b \geq 0 \\ \theta_{1 k}+\delta b-w h_{k} \bmod (c), & w h_{k}-\delta b<0\end{cases}
$$

Cabe lembrar ainda que se $\theta^{*}{ }_{11} \neq 0$, é necessário fazer $\theta^{*}{ }_{11}=0$, defasando todos os centros dos vermelhos de forma compatível. Por exemplo, se $\theta^{*}{ }_{11}=5$, é necessário descontar 5 segundos de todas as defasagens, obtendo então $\theta^{*}{ }_{11}=0$ (lembrando que para defasagens negativas deve ser somado o valor do ciclo $c$ ).

A Figura 5-9 mostra a solução obtida para a situação em que a banda no sentido $i-j$ passa de 15,3 para 23,1 segundos, enquanto que a banda no sentido $j-i$ diminui para 7,5 segundos. Também neste caso, os resultados são idênticos aos obtidos por Morgan e Little (1964). Caso fosse desejado aumentar a banda no sentido $j-i$, as expressões (5-16) a (5-20) poderiam ser utilizadas, bastando para isso trocar os índices $i$ por $j$ e $j$ por $i$.

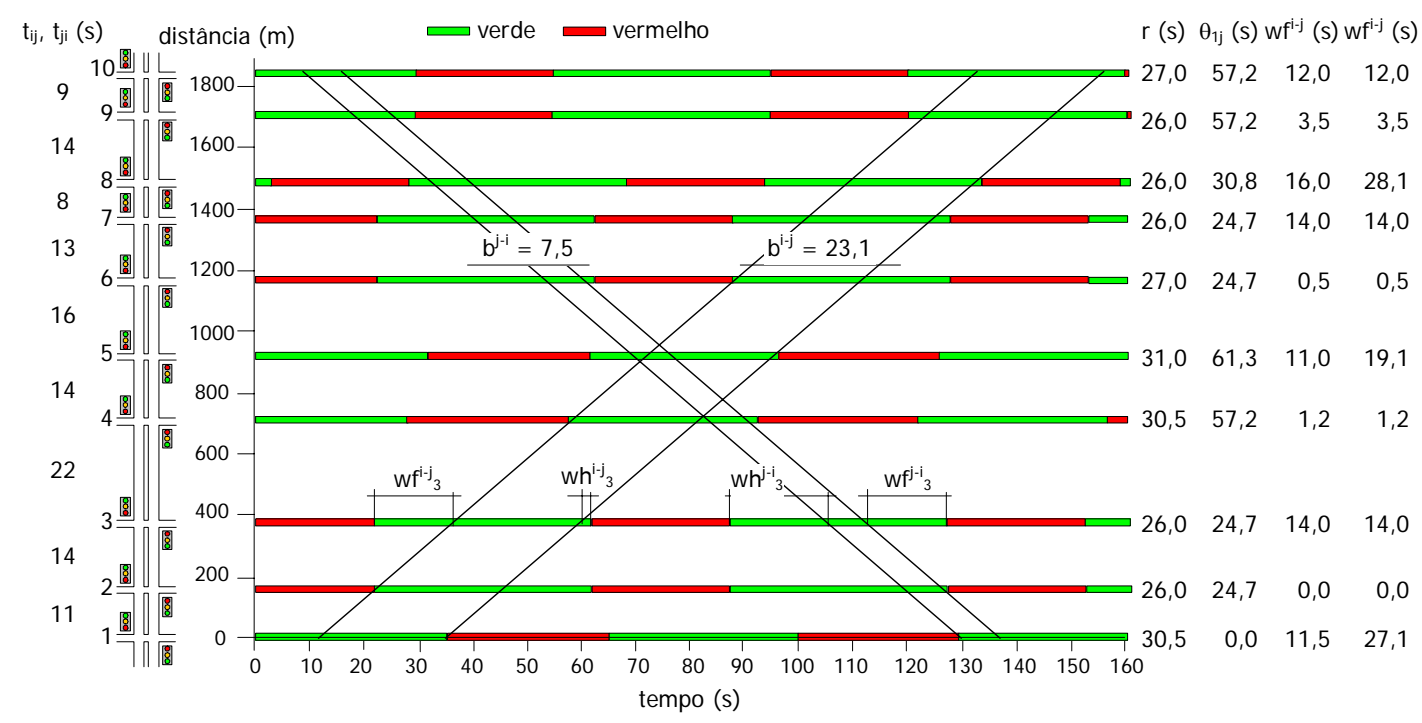

Figura 5-9: Coordenação de uma rede composta por 10 interseções semaforizadas com ciclo $=65 \mathrm{~s}, b^{i-j}=23,1 \mathrm{~s}, b^{j-i}=7,5 \mathrm{~s}$ 


\subsubsection{Montagem do Diagrama Espaço-Tempo}

A etapa final do procedimento é a elaboração do diagrama espaço-tempo, utilizando rotinas em Visual Basic. Para isso, é necessário calcular as posições da trajetória e dos instantes de início e fim do verde e vermelho dos semáforos e plotar os valores obtidos em um gráfico semelhante ao mostrado na Figura 5-9.

\subsection{Considerações Finais do Capítulo}

Com o diagrama espaço-tempo montado, o método alternativo SBAND apresenta o esquema de coordenação flexível com a largura da banda máxima de uma forma relativamente rápida e simples. Os dados necessários para utilização de SBAND são as distâncias entre interseções semaforizadas, o tempo de ciclo e tempos de vermelho dos semáforos, além da velocidade de progressão em cada sentido, facilmente obtidos a partir de observações em campo ou bases cadastrais do setor de trânsito do município, podendo ser útil na definição das estratégias operacionais em vias arteriais.

A Figura 5-10 ilustra a forma de apresentação dos dados de entrada e das defasagens geradas pelo programa SBAND, para o exemplo de corredor utilizado no artigo de Morgan e Little (1964), com 10 interseções semaforizadas de duas fases, operando com ciclo de 65 segundos e velocidade de progressão de 54,9 km/h.
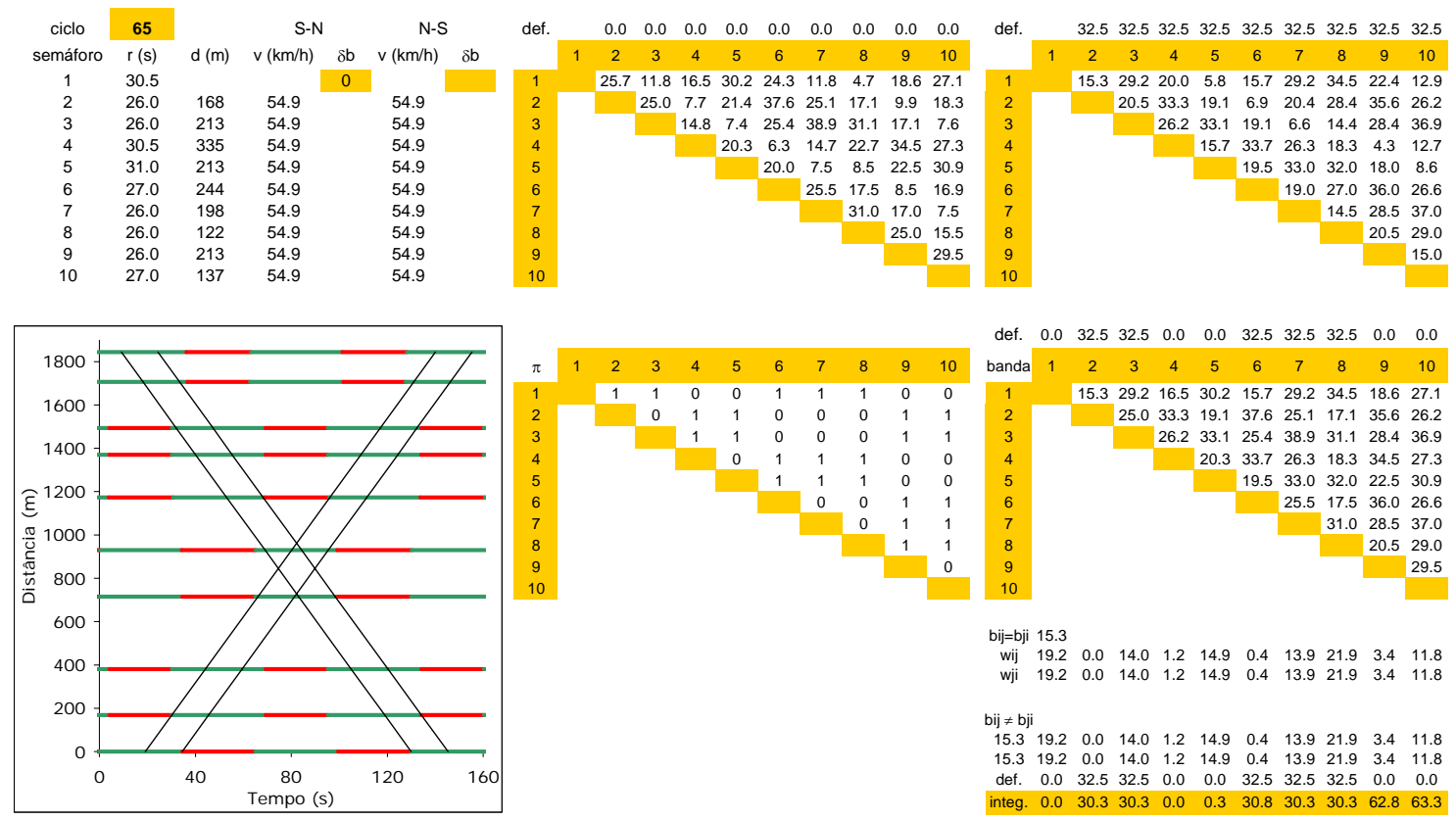

Figura 5-10: Dados de entrada e resultados gerados pelo programa SBAND

No entanto, é necessário que sejam realizados diversos testes para verificar se 
o aplicativo é capaz de definir esquemas de coordenação que produzam melhorias significativas na fluidez do tráfego e na qualidade operacional da via semaforizada.

Considerando que as velocidades das vias públicas são regulamentadas pelo corpo técnico municipal em função de suas características funcionais, de projeto e em função do Código de Trânsito Brasileiro, existe uma faixa de variação de velocidades de progressão possíveis que também podem ser testadas com o uso de SBAND, visando identificar a solução que gera maiores larguras de banda para uma velocidade de progressão compatível com o tipo de via analisado.

Outra possibilidade é definir larguras de banda proporcionais à demanda de tráfego nos dois sentidos da via, possibilitando inclusive o uso de programações diferenciadas para períodos distintos do dia. Entretanto, com a versão atual de SBAND, tais testes devem ser realizados com a modificação manual e sistemática dos parâmetros investigados. A análise da eficiência deste método proposto, assim como as simulações para testar diferentes parâmetros de tráfego e de características geométricas são descritos nos Capítulos 6 e 7. 


\section{CENÁRIOS SIMULADOS PARA AVALIAÇÃO DOS MÉTODOS DE COORDENAÇÃO SEMAFÓRICA}

Para testar a eficiência do algoritmo apresentado no capítulo anterior, é necessário avaliar quais condições de tráfego podem ser beneficiadas pela solução fornecida pelo programa SBAND e qual é a melhoria no desempenho operacional do sistema viário em decorrência da coordenação adotada. A eventual melhoria na qualidade operacional da via pode ser avaliada através das medidas de desempenho do sistema, tais como tempo de viagem, atrasos nas interseções e número de paradas. Como é relativamente difícil coletar estas medidas de desempenho em campo, além do que não seria recomendado testar estratégias de coordenação diretamente no sistema real, as medidas de desempenho foram obtidas através do uso do simulador INTEGRATION (Rakha, 2004).

A escolha do simulador INTEGRATION ao invés do TRANSYT, que tem sido o programa mais utilizado pelas prefeituras que dispõem de software de coordenação, ocorreu em função da disponibilidade da ferramenta na Universidade de São Paulo Escola de Engenharia de São Carlos, além da facilidade de acesso a seu manual de procedimentos e aos diversos artigos desenvolvidos com base neste simulador. Vários parâmetros do INTEGRATION já foram calibrados anteriormente por Demarchi et al. (2003), Demarchi et al. (2004), Demarchi e Bertoncini, 2004, e Colella et al. (2004), possibilitando a utilização destes valores na codificação dos corredores de tráfego sob análise nesta dissertação, considerando as semelhanças destes com os cenários avaliados nos trabalhos de calibração.

Portanto, o programa INTEGRATION é utilizado como ferramenta para as simulações e análise do método SBAND, ao mesmo tempo em que também é avaliado quanto sua aplicabilidade para a programação semafórica em situações com diferentes geometrias viárias e demandas de veículos, pois possui uma rotina interna para otimização e coordenação semafórica.

Além da escolha de três corredores com características diferentes na cidade de Londrina e uma rede também composta por três corredores na cidade de São Carlos, cada qual com seu plano de operação semafórica vigente, alguns cenários distintos são testados para considerar as diferentes possibilidades de coordenação geradas pelos métodos a serem avaliados. Inicialmente, as principais características geométricas, de controle e de tráfego dos corredores arteriais escolhidos são identificadas pela análise 
da base digitalizada de cada cidade e principalmente através de observações e medições realizadas in loco, conforme descrição realizada no item 6.1 e codificação detalhada no item 6.2. O item 6.3 apresenta os dados adotados na calibração de cada corredor, assim como o procedimento de validação das redes, para que as simulações representem da maneira mais fiel possível as condições das vias, dos motoristas, dos veículos e do tráfego nos diferentes cenários descritos no item 6.4.

\subsection{Caracterização dos Corredores Arteriais Analisados}

Vários são os fatores que afetam a capacidade de uma via e, conseqüentemente, seu nível de serviço, ou seja, a qualidade das condições operacionais. Na tentativa de reproduzir e avaliar situações distintas de tráfego e de sistema viário em cidades de médio porte, que apresentem diferenças de largura de pista e faixa de rolamento, espaçamento entre os semáforos, greides, volumes de tráfego e formas de controle, três avenidas de duplo sentido de circulação foram selecionadas na cidade de Londrina, Paraná, e uma rede contendo três ruas de sentido único de tráfego foi selecionada na cidade de São Carlos, São Paulo, conforme respectivas descrições nos itens 6.1.1 e 6.1.2 a seguir.

\subsubsection{Corredores Selecionados na Cidade de Londrina}

Londrina está situada ao norte do estado do Paraná, ocupando segundo o IBGE 1.724,70 $\mathrm{km}^{2}$, o que representa cerca de $1 \%$ da área total do Estado do Paraná. A zona urbana de Londrina tem $118,50 \mathrm{~km}^{2}$ e a zona de expansão urbana tem $119,80 \mathrm{~km}^{2}$, totalizando 238,30 $\mathrm{km}^{2}$. A foto da Figura 6-1 mostra parte da região central da cidade, cuja população aproxima-se de 500 mil habitantes e a frota registrada ultrapassa 190 mil veículos (site da Prefeitura de Londrina, 2005). O município é servido por ônibus do transporte público coletivo, através de 93 linhas urbanas diferenciadas, operadas por duas empresas sob o regime de concessão, transportando cerca de 175.000 passageiros/dia em sistema integrado que utiliza oito terminais, sendo um central e os demais de bairro.

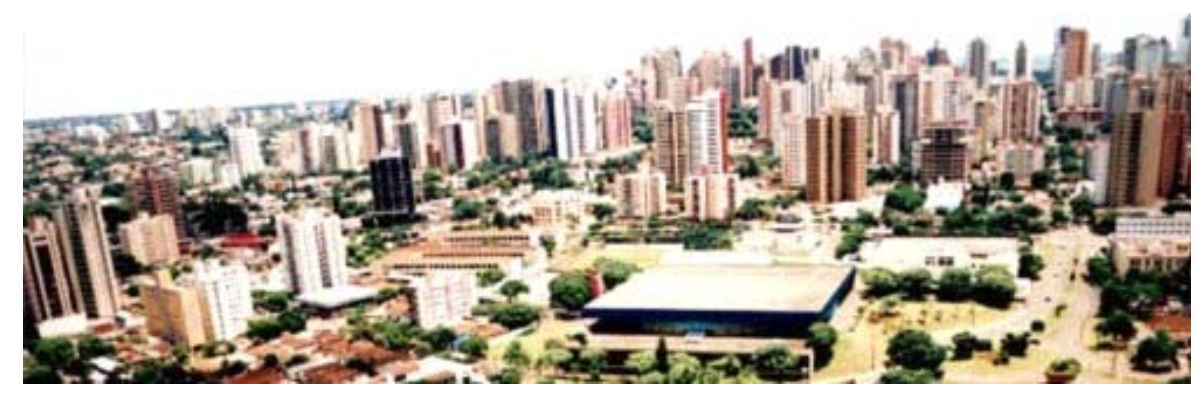

Figura 6-1: Vista da cidade de Londrina (site da Prefeitura de Londrina, 2005) 
A malha viária do quadrilátero central da cidade de Londrina faz parte da proposta original da criação do município na década de 1930, e tem formato de tabuleiro de xadrez, conforme ilustra a Figura 6-2. A região central é altamente adensada e conta com elevada atividade comercial, sendo constituída atualmente de algumas avenidas duplas e demais ruas de sentido único de circulação binária, com pistas de aproximadamente nove metros de largura e calçadas laterais de três metros. As vias são sinalizadas vertical e horizontalmente de forma a segregar duas ou três faixas de rolamento variando entre 2,50 e 3,50 metros e ainda faixas de estacionamento com 2 metros, quando permitido.

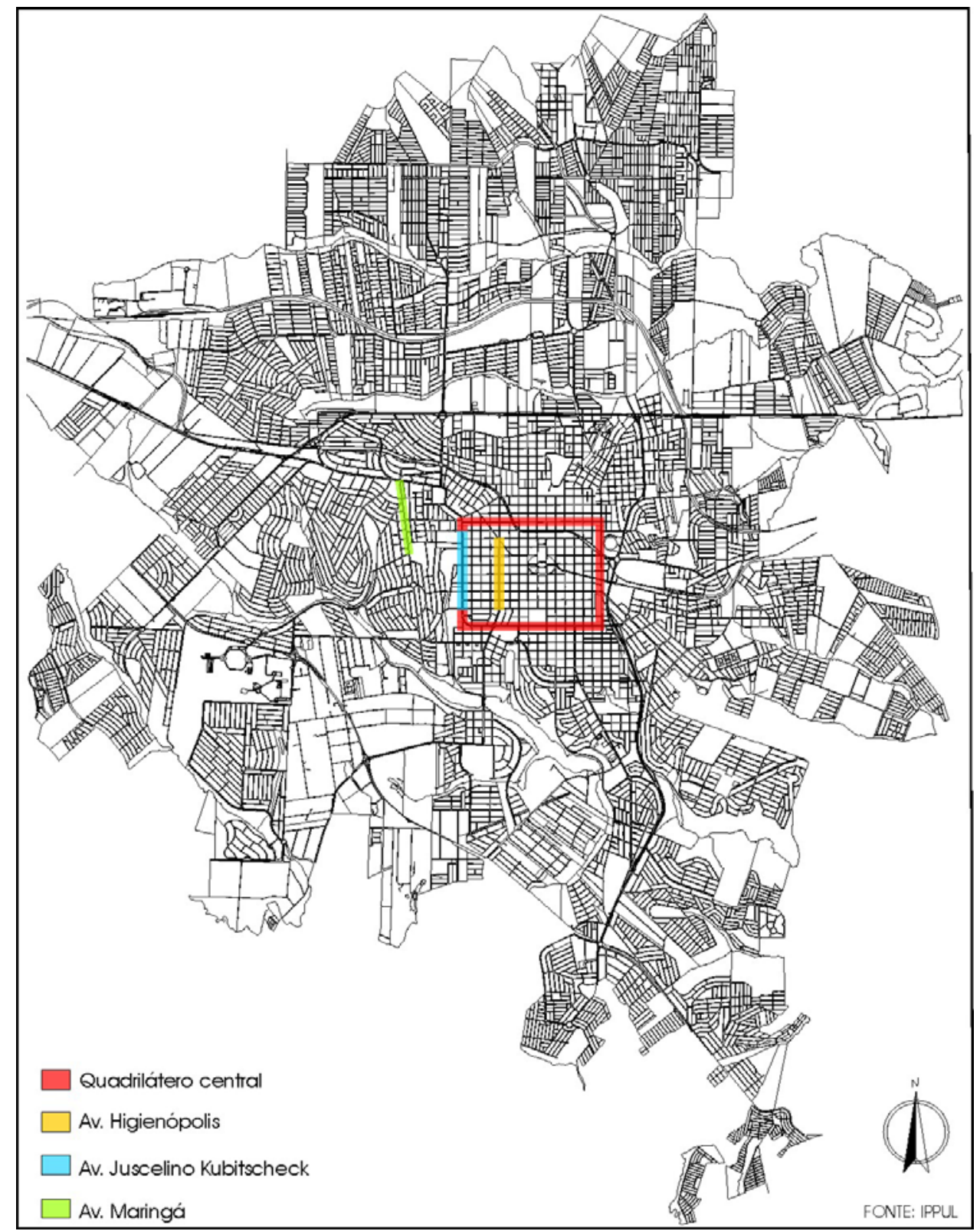

Figura 6-2: Corredores selecionados na cidade de Londrina, Paraná 
Os corredores selecionados - Avenida Higienópolis, Avenida Juscelino Kubitscheck e Avenida Maringá - são apenas trechos de vias que desempenham função arterial no sistema viário da cidade, possibilitando viagens para as diversas regiões do município. As principais características destes três corredores arteriais escolhidos na cidade de Londrina estão descritas na Tabela 6-1.

Tabela 6-1: Resumo de características dos corredores arteriais de Londrina

\begin{tabular}{cccc} 
& Av. Higienópolis & Av. J.K. & Av. Maringá \\
\cline { 2 - 4 } Nós & 26 & 34 & 24 \\
Tramos & 33 & 49 & 41 \\
Semáforos & 8 & 10 & 5 \\
Ciclo $(\mathrm{s})$ & 75 & 74 & 88 \\
Velocidade Principal $(\mathrm{km} / \mathrm{h})$ & 50 & 50 & 40 \\
Velocidade Secundárias $(\mathrm{km} / \mathrm{h})$ & 40 & 40 & não regulamentada \\
\hline
\end{tabular}

- Avenida Higienópolis (1.097 m): via integrante da área central da cidade, com tráfego elevado tanto na via principal quanto nas vias transversais. Possui no trecho analisado 8 cruzamentos semaforizados praticamente eqüidistantes uns dos outros, todos com operação de 2 fases em ciclos de 75 segundos. A primeira fase controla os movimentos ao longo da avenida (fluxo direto e conversão à direita) e a segunda fase controla os movimentos das vias transversais. Conforme ilustrada na Figura 63 , a rede conta com 33 tramos e 26 nós, sendo 1 nó origem/destino, 9 nós de destino, 8 nós de origem e 8 nós de passagem. A via principal está sinalizada com placas de regulamentação de velocidade de $50 \mathrm{~km} / \mathrm{h}$, e as vias secundárias com 40 $\mathrm{km} / \mathrm{h}$.

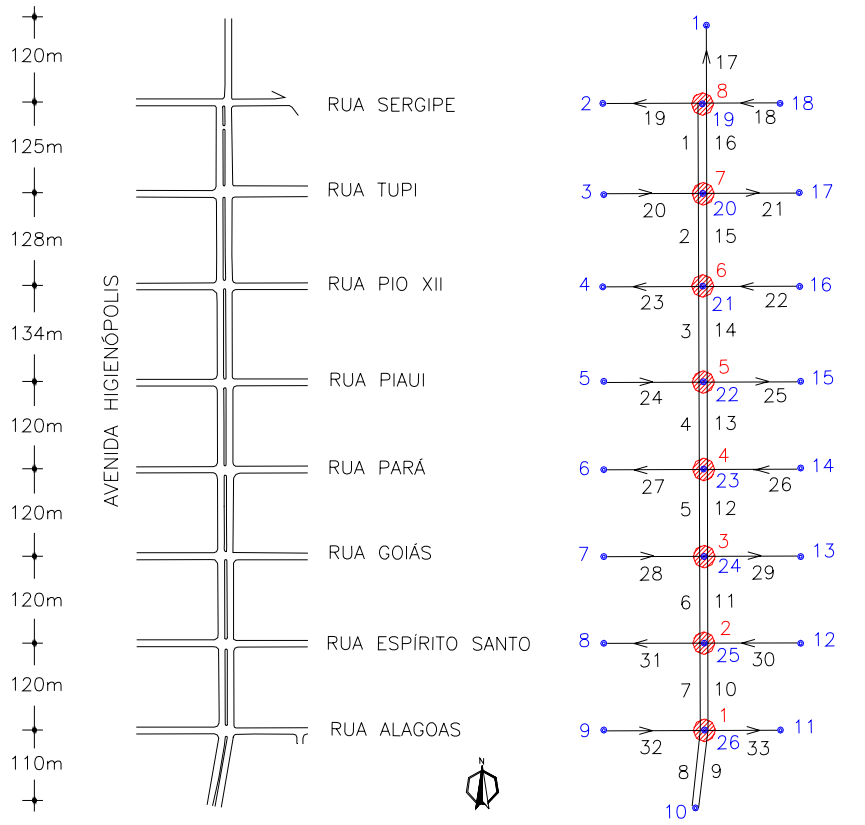

Figura 6-3: Características da Avenida Higienópolis 
- Avenida Juscelino Kubitscheck (1.437 m): via que compõe o perímetro do quadrilátero central da cidade, constituindo parte de uma das principais ligações Leste-Oeste da circulação londrinense, com elevado tráfego de passagem na via principal e tráfego moderado nas vias secundárias. Apresenta 10 cruzamentos semaforizados no trecho analisado, com diferentes espaçamentos entre eles, todos com operação de 2 fases em ciclos de 74 segundos. Os movimentos da avenida (fluxo direto e conversão à direita) são controlados pela primeira fase, ficando a segunda fase para o controle dos movimentos das vias transversais. Fazem parte desta rede, 49 tramos e 34 nós, sendo 4 nós origem/destino, 10 nós de destino, 7 nós de origem e 13 nós de passagem, de acordo com a representação da Figura 6-4. Placas de $50 \mathrm{~km} / \mathrm{h}$ regulamentam a velocidade máxima permitida ao longo da via principal, e placas de $40 \mathrm{~km} / \mathrm{h}$ nas vias secundárias.
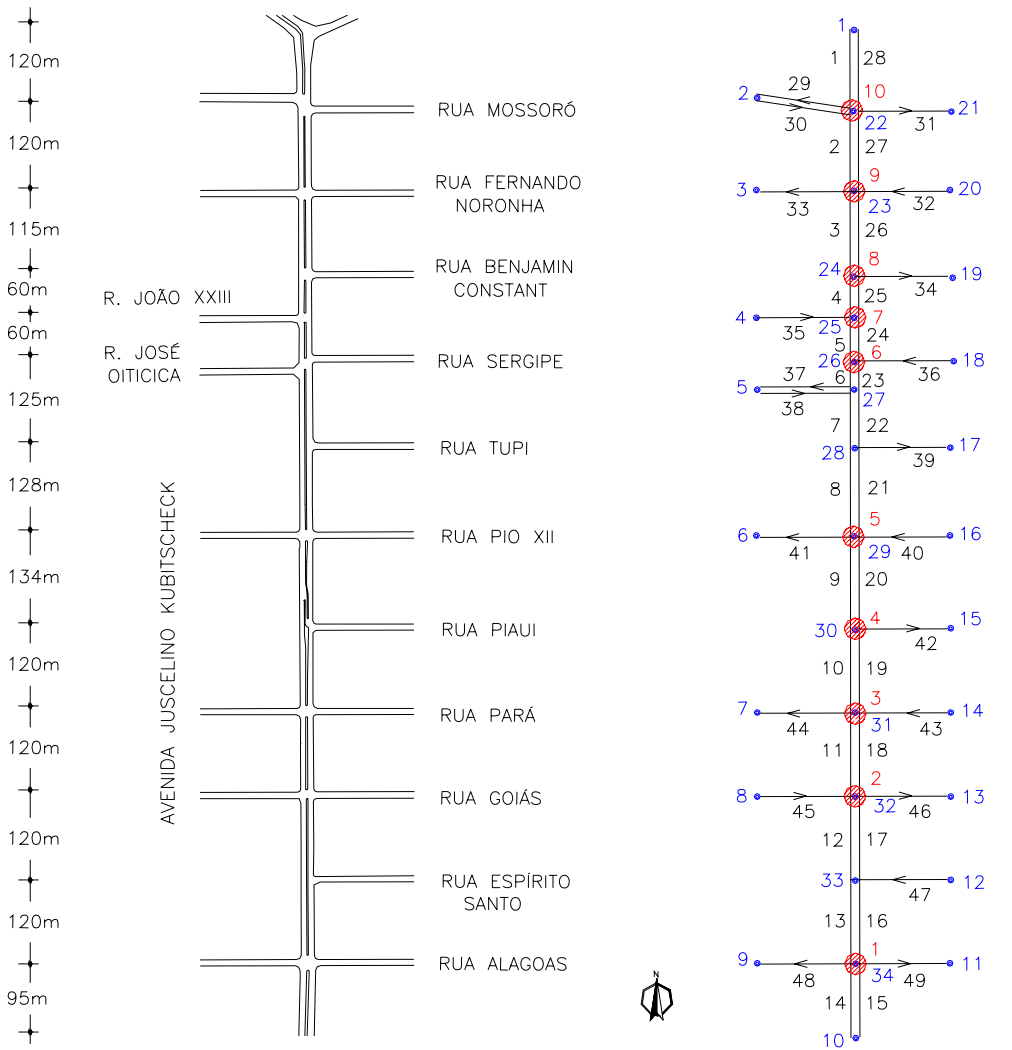

Figura 6-4: Características da Avenida Juscelino Kubitscheck

- Avenida Maringá (1.147 m): via que permite parte do escoamento Norte-Sul da cidade, mas que está situada fora do centro antigo ou expandido de Londrina, apresentando moderado tráfego de passagem na via principal e tráfego baixo nas vias secundárias. Possui no trecho analisado 5 cruzamentos semaforizados com espaçamentos diversos entre eles, com operação de 3 ou 4 fases em ciclos de 88 segundos, sendo a primeira fase destinada ao tráfego da via principal, uma ou duas 
fases seguintes para as vias secundárias e a última fase exclusiva para pedestres. A Figura 6-5 ilustra a rede composta por 41 tramos e 24 nós, sendo 9 nós origem/destino, 2 nós de destino, 3 nós de origem e 10 nós de passagem. A velocidade máxima regulamentada na via principal é de $40 \mathrm{~km} / \mathrm{h}$, não havendo placas com regulamentação de velocidade nas vias secundárias.

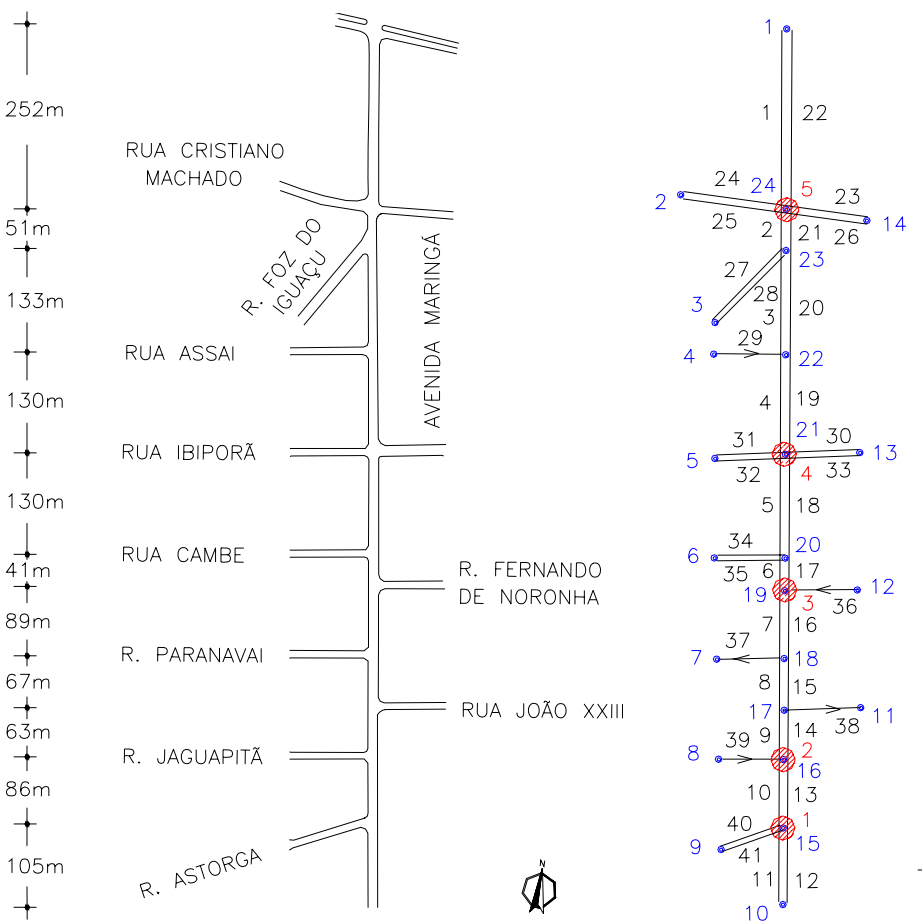

Figura 6-5: Características da Avenida Maringá

\subsubsection{Rede Selecionada na Cidade de São Carlos}

São Carlos está localizada na região central do estado de São Paulo (cerca de 240 km da cidade de São Paulo), e segundo o IBGE, possui área territorial de 1.141 km², com 95\% dos residentes na área urbana da cidade. Em 1953 a cidade recebeu um grande impulso para seu desenvolvimento tecnológico e educacional com a implantação da Escola de Engenharia de São Carlos, vinculada à Universidade de São Paulo, e na década de 70, com a criação da Universidade Federal de São Carlos. A foto da Figura 6-6 registra uma vista parcial da cidade, que conta com população superior a 200 mil habitantes e frota que ultrapassa 80 mil veículos (site da Prefeitura de São Carlos, 2005).

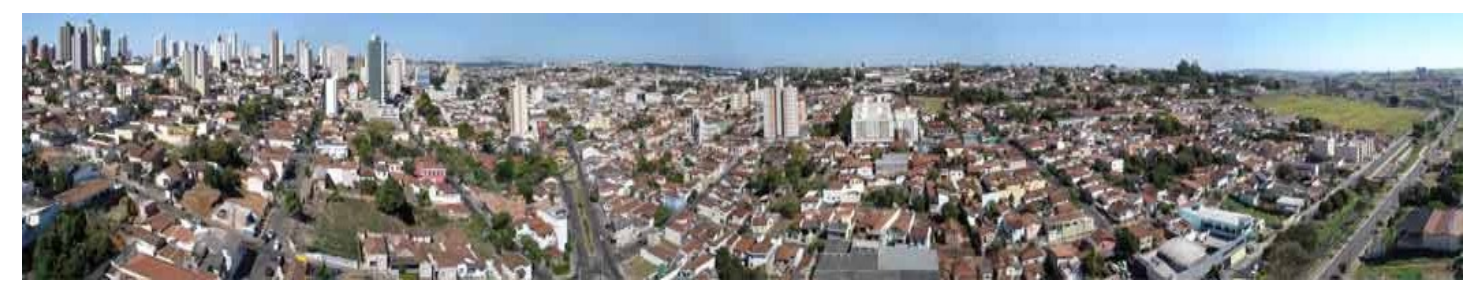

Figura 6-6: Vista da cidade de São Carlos (site da Prefeitura de São Carlos, 2005) 
As três vias selecionadas compõem o sistema de circulação central da cidade, através da Avenida São Carlos com elevado fluxo de tráfego no sentido Sul-Norte e das Ruas D. Alexandrina e Episcopal com volume moderado no sentido Norte-Sul, conforme ilustra a Figura 6-7. Entre elas, a Avenida São Carlos é que apresenta maior concentração de estabelecimentos comerciais varejistas e de serviços, atraindo tráfego intenso de veículos e ônibus, e a maior circulação de pedestres da cidade.

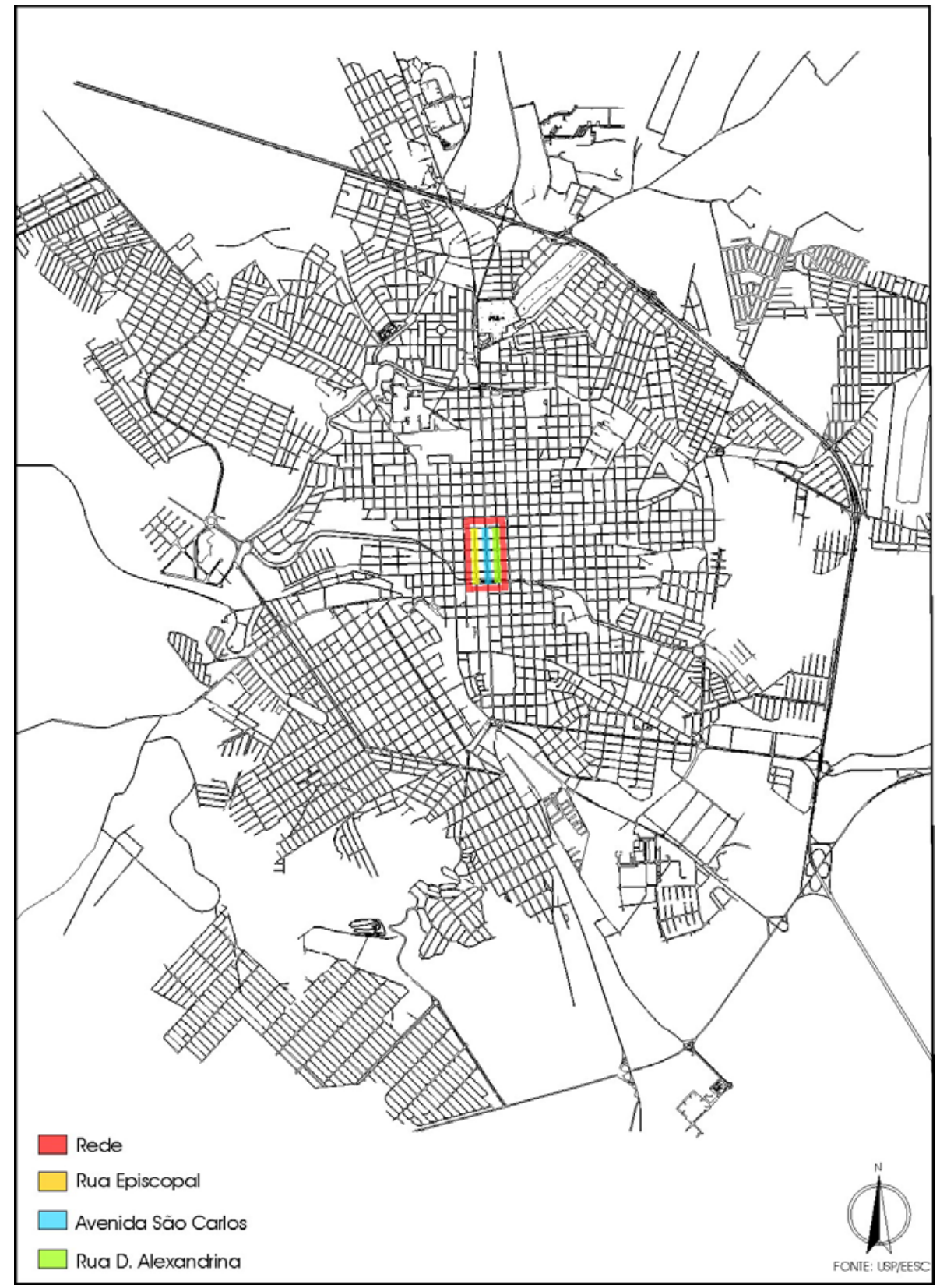

Figura 6-7: Corredores da rede selecionada na cidade de São Carlos, São Paulo

As características da rede selecionada na cidade de São Carlos estão descritas na Tabela 6-2, composta por três corredores de sentido único de tráfego - Avenida São 
Carlos, Rua D. Alexandrina e Rua Episcopal - com extensão de aproximadamente 620 m cada, e com sinalização vertical e horizontal que segrega duas ou três faixas de rolamento variando entre 2,50 e 3,15 metros e faixa de estacionamento com 2 metros.

Tabela 6-2: Resumo de características da rede de São Carlos

\begin{tabular}{ccccc} 
& Rede & Av. São Carlos & R. D. Alexandrina & R. Episcopal \\
\cline { 2 - 5 } Nós & 41 & - & - & - \\
Tramos & 51 & - & - & - \\
Semáforos & 13 & 5 & 4 & 4 \\
Ciclo $(\mathrm{s})$ & 65 & - & - & - \\
Velocidade Principal $(\mathrm{km} / \mathrm{h})$ & - & 50 & 40 & 50 \\
Velocidade Secundárias $(\mathrm{km} / \mathrm{h})$ & 40 & - & - & - \\
\hline
\end{tabular}

A rede é composta por 51 tramos e 41 nós, sendo 10 nós de destino, 10 nós de origem e 21 nós de passagem, segundo a representação da Figura 6-8. Os semáforos da rede operam com ciclo de 65 segundos e duas fases, com exceção de dois semáforos da Avenida São Carlos (semáforos 8 e 9) que apresentam a terceira fase exclusiva para pedestres. A primeira fase controla os movimentos ao longo das vias principais (fluxo direto e conversão à direita ou à esquerda), e a segunda fase controla os movimentos das vias transversais. A Avenida São Carlos e a Rua Episcopal estão sinalizadas com placas de regulamentação de velocidade máxima de $50 \mathrm{~km} / \mathrm{h}$, enquanto a Rua D. Alexandrina e as vias secundárias possuem placas de $40 \mathrm{~km} / \mathrm{h}$.

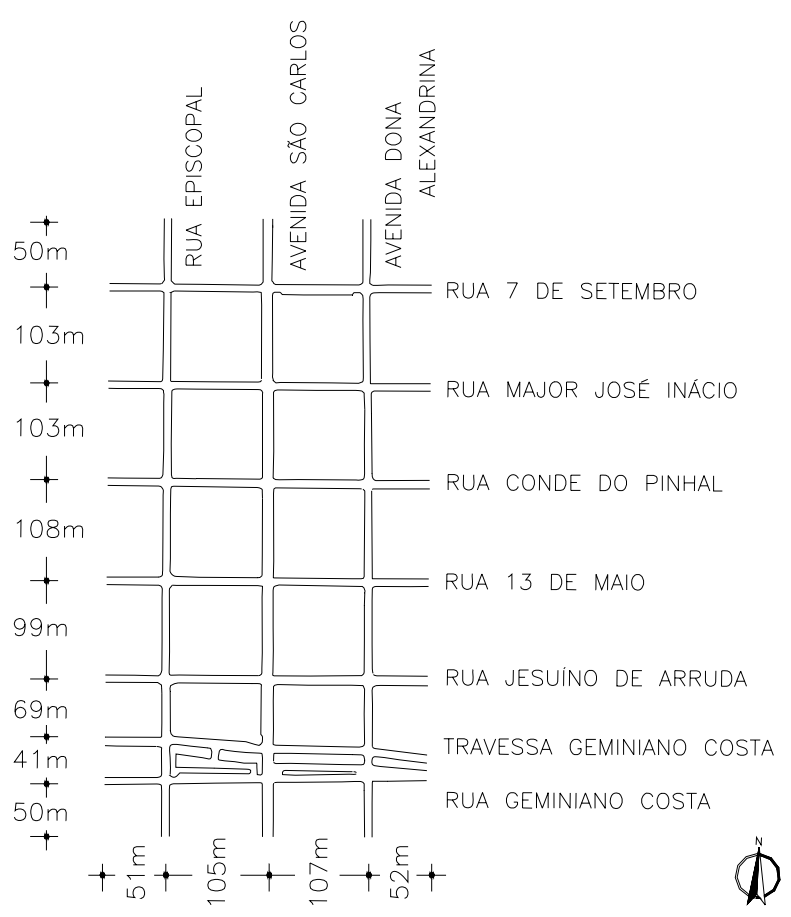

Figura 6-8: Características da rede de São Carlos 


\subsection{Codificação dos Corredores no INTEGRATION}

Para codificar no simulador INTEGRATION os cenários selecionados nas cidades de Londrina e São Carlos, várias coletas de dados foram necessárias, tais como a geometria e configuração das vias, as características de controle (formas de sinalização, restrições de movimentos) e as características do tráfego (magnitude e composição). Os dados referentes aos corredores arteriais da cidade de Londrina foram obtidos in loco ou através de consulta aos registros da prefeitura, enquanto que os dados utilizados na rede de São Carlos foram coletados e codificados como parte das atividades previstas no projeto "Avaliação da adequabilidade do HCM2000 na análise de capacidade e nível de serviço de vias arteriais urbanas brasileiras", desenvolvido pela RedeTráfego (Loureiro et al., 2005). A RedeTráfego é composta por 7 instituições universitárias, inclusive a Escola de Engenharia de São Carlos - Universidade de São Paulo (USP).

Todas as simulações para estudo dos casos foram realizadas durante 9000 segundos, com freqüência dos dados para arquivos de saída de 300 segundos. Os arquivos são codificados em formato texto, conforme descritos a seguir:

- arquivo de nós: as coordenadas geométricas dos nós foram obtidas a partir da base digitalizada da cidade, representada em programa AutoCAD no formato $D W G$, pertencente às prefeituras locais;

- arquivo de tramos: os comprimentos dos tramos da rede foram medidos no local com a utilização de trena, assim como as demais características como sentido de circulação, número de faixas, forma de controle de tráfego exercida na saída dos tramos e proibições de movimentos de conversão também foram obtidos diretamente a partir de observações em campo;

- arquivo de semáforos: a programação semafórica em operação em cada uma das vias selecionadas foi obtida in loco, através da observação e registro por cronômetro dos tempos de verde, amarelo e vermelho em cada fase dos cruzamentos semaforizados, assim como das defasagens existentes entre eles. A opção de otimização dos tempos de verde existente no INTEGRATION não foi utilizada, e a opção de coordenação somente foi utilizada nas simulações para obtenção das defasagens geradas pelo INTEGRATION;

- arquivo da matriz $O-D$ : a matriz origem-destino de cada rede foi gerada através do programa QUEENSOD - Release 2.10, utilizando os mesmos arquivos de nós, tramos e semáforos montados para o INTEGRATION e introduzindo os dados dos fluxos de veículos observados em contagens volumétricas de tráfego com os 
respectivos movimentos permitidos;

- arquivo de incidentes: nenhum incidente ou obstrução de faixa temporário ou permanente foi introduzido nas simulações;

- arquivo de greides: as inclinações longitudinais nos segmentos das vias de Londrina foram obtidas através das curvas de nível constantes na base cartográfica da cidade, e em São Carlos as declividades das rampas foram obtidas em campo com o auxílio de um declinômetro;

- arquivo de utilização de faixas: as faixas de rolamento com restrição de movimento foram identificadas in loco, não havendo nenhuma faixa com restrição por tipo de veículo nas redes simuladas;

- arquivo de características veiculares: considerando limitações de tempo e de recursos para coletar estes dados em Londrina, a montagem deste arquivo foi baseada em um automóvel de potência e peso hipotéticos, que representa a média ponderada de 4 veículos adotados por Colella et al. (2004) como representativos da frota típica de Maringá, no estado do Paraná. A adoção destes parâmetros pode ser aceita em função da semelhança entre as duas cidades, ambos municípios de porte médio no estado do Paraná, localizados a uma distância aproximada de 100 quilômetros um do outro. Os mesmos valores de características veiculares também foram adotados para as simulações da cidade de São Carlos.

\subsection{Calibração e Validação do Simulador INTEGRATION}

Buscando reproduzir o mais fielmente possível as características dos veículos e o comportamento dos motoristas em cada cenário simulado, refletindo também as condições locais das vias, faz-se necessário quantificar com dados coletados in loco os parâmetros utilizados na lógica do modelo INTEGRATION. Sendo assim, o item 6.3.1 descreve a forma de obtenção dos valores utilizados para definição da relação fluxovelocidade, como a densidade de congestionamento dos veículos, a velocidade de fluxo livre e os fluxos de saturação. As distribuições das viagens nas redes simuladas são descritas no item 6.3.2, através das contagens volumétricas de tráfego que servem de subsídio para a geração da matriz origem-destino de cada corredor avaliado.

Embora seja recomendado no processo de validação do modelo utilizado, a comparação entre os resultados gerados pelo simulador e os dados observados em campo, através de informações sobre tempo de viagem, velocidade, atraso ou comprimento de fila, a análise das simulações foi realizada pela observação visual das 
animações ao longo do período de simulação, para confirmação da representação realística destes resultados.

\subsubsection{Relação Fluxo-Velocidade}

Os parâmetros utilizados pelo INTEGRATION para modelar o comportamento dos veículos nos corredores da cidade de Londrina foram adaptados de Colella et al. (2004), que calibraram e validaram o modelo fluxo-velocidade a partir de espaçamentos e velocidades observados em vias urbanas semaforizadas de Maringá, para volumes leves de tráfego e densidade de congestionamento dos veículos nas filas formadas a montante das interseções. O simulador INTEGRATION foi utilizado para, de forma iterativa, produzir dispersões de espaçamentos e velocidades similares às registradas em campo por câmeras filmadoras digitais, onde posteriormente os dados da filmagem foram tabulados em planilha eletrônica, obtendo valores representativos de fluxo livre e congestionado para todas as regiões da curva fluxo-velocidade.
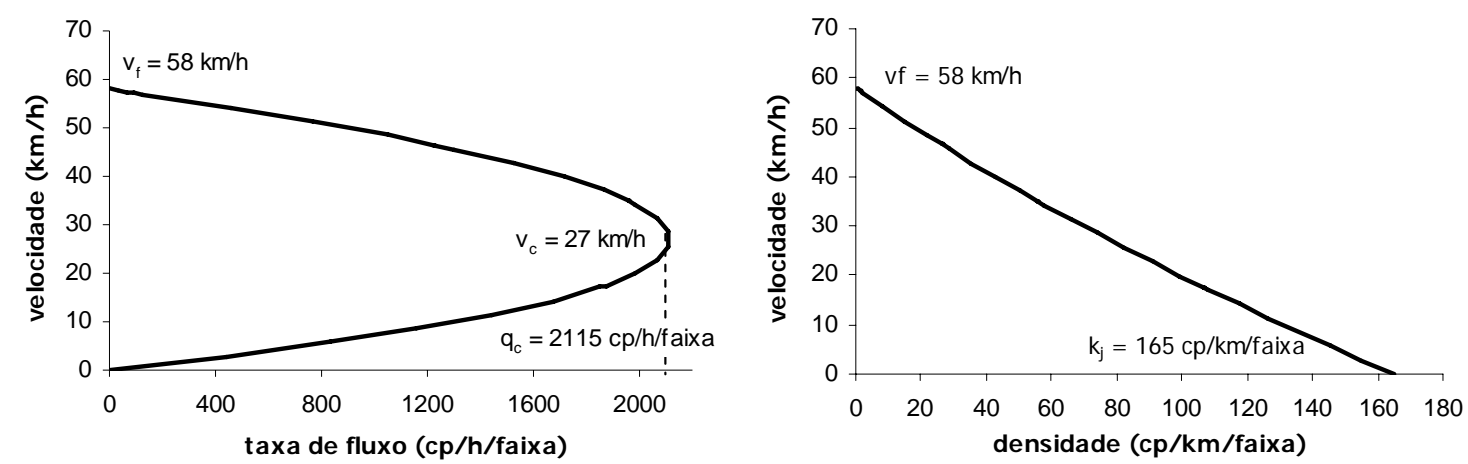

Figura 6-9: Relação fluxo-velocidade e densidade-velocidade obtida

A capacidade do tramo $q_{c}=2115 \mathrm{cp} / \mathrm{h} /$ faixa e a velocidade na capacidade $v_{c}=27 \mathrm{~km} / \mathrm{h}$ obtidas sugerem uma curva fluxo-velocidade demonstrada na Figura 6-9, um pouco achatada se comparada ao formato parabólico do modelo de Greenshields. Estes valores foram utilizados, considerando a similaridade das avenidas de Maringá onde os dados foram coletados, e aquelas simuladas nos cenários de Londrina. Como a capacidade da via é influenciada também pela largura das faixas de rolamento, valores distintos de fluxo de saturação foram adotados para as faixas com larguras diferentes de 3,50 metros (largura das faixas observadas em Maringá), buscando manter razoável proporcionalidade nas variações das faixas entre 2,50 e 4,00 metros, conforme apresenta a Tabela 6-3. 
Tabela 6-3: Fluxos de saturação na cidade de Londrina

\begin{tabular}{cc}
\hline Largura de Faixa $(\mathrm{m})$ & Fluxo de Saturação (cp/h/faixa) \\
\hline 2,50 & 1865 \\
2,80 & 1940 \\
3,00 & 2015 \\
3,25 & 2065 \\
$\mathbf{3 , 5 0}$ & $\mathbf{2 1 1 5}$ \\
3,75 & 2140 \\
4,00 & 2165 \\
\hline
\end{tabular}

A velocidade de fluxo livre encontrada de $v_{f}=58 \mathrm{~km} / \mathrm{h}$ foi considerada razoável por estar próxima do limite de velocidade estabelecido para as vias regulamentadas com placas de $50 \mathrm{~km} / \mathrm{h}$, sendo adotado $v_{f}=50 \mathrm{~km} / \mathrm{h}$ para as vias com placas de velocidade máxima de $40 \mathrm{~km} / \mathrm{h}$. A densidade de congestionamento correspondente a $k_{j}=165 \mathrm{cp} / \mathrm{km} /$ faixa foi obtida a partir do espaçamento de congestionamento estimado por Demarchi et al. (2003) igual a 6,06 metros.

Após a publicação de Colella et al. (2004), novos estudos foram feitos por Colella (2004), indicando para utilização da proporção da potência máxima do motor o valor de $P_{P \max }=0,8$ a fim de modelar as características de desempenho dos veículos que aceleram assim que ocorre a abertura do semáforo, constituindo um artifício para considerar indiretamente a agressividade dos motoristas durante o processo de aceleração e retomada de velocidade. Também o coeficiente de variação da velocidade $C v v=0,19$ foi sugerido neste estudo, fazendo com que as velocidades dos veículos sejam distribuídas aleatoriamente em torno da curva fluxo-velocidade, descrita pela Equação (6-1). Estes dois valores foram utilizados tanto nas simulações da cidade de Londrina, quanto para a rede da cidade de São Carlos.

$$
q=\frac{v}{\frac{1}{k_{j}}\left[\frac{v_{f}\left(v-v_{c}\right)^{2}}{v_{c}^{2}\left(v_{f}-v\right)}\right]+\frac{v}{q_{c}}}
$$

em que $\quad q$ : fluxo de tráfego [veíc/h/faixa];

$v: \quad$ velocidade $[\mathrm{km} / \mathrm{h}]$;

$v_{f}: \quad$ velocidade de fluxo livre $[\mathrm{km} / \mathrm{h}]$;

$v_{\mathrm{c}}: \quad$ velocidade na capacidade do segmento $[\mathrm{km} / \mathrm{h}]$;

$q_{\mathrm{c}}: \quad$ capacidade do segmento [veíc/h/faixa];

$k_{\mathrm{j}}$ : densidade de congestionamento [veíc/km/faixa]. 
Os valores dos fluxos de saturação utilizados na cidade de São Carlos foram medidos in loco pela equipe coordenada pelo professor Dr. José Reynaldo Anselmo Setti, através da avaliação da variação do número acumulado de veículos atendidos durante o tempo de verde dos semáforos. A Tabela 6-4 resume as informações referentes aos fluxos de saturação identificados em cada corredor da rede de São Carlos, de acordo com o relatório elaborado pelo Departamento de Transportes da Escola de Engenharia de São Carlos - Universidade de São Paulo para a RedeTráfego (Loureiro et al., 2005).

Tabela 6-4: Fluxos de saturação na cidade de São Carlos (Loureiro et al., 2005)

\begin{tabular}{cc}
\hline Via & Fluxo de Saturação (cp/h/faixa) \\
\hline Avenida São Carlos & 1823 \\
Rua Dona Alexandrina & 1782 \\
Rua Episcopal & 1721 \\
Transversais & 1766 \\
\hline
\end{tabular}

As velocidades de fluxo livre sugeridas no relatório da RedeTráfego (Loureiro et al., 2005) correspondem à velocidade máxima regulamentada nas vias da rede selecionada na cidade de São Carlos, confirmadas por coletas de velocidade realizadas em horários de baixo fluxo (após as 20:00 horas) através de um veículo-teste que acompanhava outros veículos trafegando em condições de fluxo totalmente desimpedido. As densidades de congestionamento nas vias da rede de São Carlos foram determinadas in loco pelo número de veículos parados em fila, relativos a um segmento de um quilômetro de extensão, e seus valores estão resumidos na Tabela 6-5.

Tabela 6-5: Densidades de congestionamento na cidade de São Carlos (Loureiro et al., 2005)

\begin{tabular}{cc}
\hline Via & Densidade de Congestionamento $(\mathrm{cp} / \mathrm{km})$ \\
\hline Avenida São Carlos & 151 \\
Rua Dona Alexandrina & 137 \\
Rua Episcopal & 169 \\
Transversais & 173 \\
\hline
\end{tabular}

\subsubsection{Matriz Origem-Destino}

De acordo com Demarchi e Bertoncini (2004), uma das etapas de grande importância nas análises e estudos de planejamento e operação do sistema viário é a determinação da quantidade de deslocamentos realizados entre pontos de uma cidade ou região, ou seja, a estimativa da matriz de viagens originadas em decorrência da necessidade de se realizar atividades principalmente por motivo trabalho, estudo ou lazer. 
No intuito de melhor representar os cenários reais selecionados na cidade de Londrina e replicar o mais fielmente possível os volumes de tráfego observados, as matrizes O-D utilizadas na calibração do INTEGRATION foram determinadas sinteticamente a partir de contagens volumétricas manuais e percentuais dos movimentos de conversão obtidos em todas as interseções (nós) das três redes viárias. O aplicativo QUEENSOD criado por Van Aerde (1998) foi utilizado, considerando que não seria prático determinar as matrizes através de entrevistas domiciliares, entrevistas em locais estratégicos da rede viária ou pelo monitoramento de veículos, devido à escassez de tempo, recursos humanos e financeiros para a coleta destas informações. Além do mais, o QUEENSOD também compartilha o mesmo formato de arquivos de dados do simulador INTEGRATION (Rakha, 2004), o que facilita o processo de estimativa das matrizes.

Van Aerde (1998) propõe que as matrizes O-D sintéticas sejam determinadas de tal forma que os volumes resultantes das demandas estimadas sejam os mais próximos possíveis dos respectivos volumes observados, o que é obtido ao se minimizar a soma das diferenças quadráticas entre os volumes observados e respectivos volumes estimados (maiores detalhes sobre esse processo podem ser obtidos em Demarchi e Bertoncini, 2004, e Demarchi et al., 2004).

Os dados das contagens volumétricas de tráfego utilizados nos corredores selecionados na cidade de Londrina foram obtidos junto ao IPPUL - Instituto de Pesquisa e Planejamento Urbano de Londrina, órgão da prefeitura responsável desde 1993 por organizar o crescimento do município de forma integrada através do gerenciamento do desenvolvimento urbano, onde a autora deste trabalho ocupa o cargo de Gerente de Projetos de Sinalização e Controle de Tráfego na Diretoria de Trânsito e Sistema Viário. As pesquisas foram realizadas por uma equipe de estagiários, que sistematicamente coletam dados sobre o fluxo de veículos na cidade, a fim de subsidiar os estudos de intervenções no sistema viário. Porém, como algumas das contagens utilizadas foram realizadas há mais de um ano, a frota de veículos daquela época serviu de base para expandir os dados proporcionalmente à frota do mês utilizado como referência para os cenários de Londrina - Junho/2003.

Apesar das contagens terem sido realizadas durante 12 horas ininterruptas, sempre entre o período das 7:00 e 19:00 horas em dias úteis da semana, com dados separados a cada 15 minutos, oferecendo a variação do volume ao longo das horas mais movimentadas do dia, somente o montante da hora-pico constatada na cidade (das 17:45 
às 18:45) foi utilizado como forma de simplificação, e transformado em veículos equivalentes de acordo com os valores demonstrados na Tabela 6-6, utilizados na prefeitura de Londrina.

Tabela 6-6: Fatores de equivalência veicular utilizados no município de Londrina

\begin{tabular}{cc}
\hline Tipo de Veículo & Fator \\
\hline Passeio & 1,00 \\
Moto & 1,00 \\
Caminhão & 1,50 \\
Ônibus & 2,25 \\
\hline
\end{tabular}

Como o aplicativo QUEENSOD oferece diferentes parâmetros e opções que influenciam no cálculo do erro volumétrico, o critério de combinação tipo “31” que considera o erro relativo para estimar a matriz O-D e o erro quadrático para minimizar as diferenças volumétricas foi adotado, conforme sugerido por Demarchi et al. (2004) para a região central da cidade de Maringá. Como não havia uma matriz semente para ser utilizada nos três corredores arteriais analisados em Londrina, o programa QUEENSOD foi rodado para gerar uma matriz preliminar, e após a eliminação dos pares O-D improváveis ou conectados por rotas inexistentes, o programa foi rodado novamente para gerar somente as viagens para os pares O-D restantes, como recomendado por Demarchi et al. (2004).

Por fim, por motivo de simplificação, 25\% dos pares origem-destino foram suprimidos, sendo basicamente aqueles que apresentavam as menores quantidades de viagens, a fim de facilitar as análises da eficiência do programa proposto SBAND e do simulador INTEGRATION na coordenação semafórica das redes apresentadas. Desta forma, os volumes utilizados nas simulações da cidade de Londrina, que buscam replicar a situação real, são apresentados na Tabela 6-7 na forma de matriz dos pares O$\mathrm{D}$, para a hora-pico (17:45 às 18:45) identificada na cidade. A matriz de viagens obtida para a Avenida Higienópolis resultou em 37 pares origem-destino que totalizam 8.366 viagens por hora simulada (Tabela 6-7a), 8.825 viagens para os 76 pares da matriz origem-destino gerada para a Avenida Juscelino Kubitscheck (Tabela 6-7b), e 50 pares origem-destino que resultam em 3.459 viagens por hora de simulação para a Avenida Maringá (Tabela 6-7c). 
Tabela 6-7: Matrizes origem-destino dos corredores de Londrina

\begin{tabular}{|c|c|c|c|c|c|c|c|c|c|c|c|}
\hline$O / D$ & 1 & 2 & 4 & 6 & 8 & 10 & 11 & 13 & 15 & 17 & $\Sigma$ \\
\hline 3 & 110.3 & - & 98.8 & 54.5 & - & 175.6 & - & - & - & 92.5 & 531.7 \\
\hline 5 & 68.5 & - & - & - & - & 232.2 & - & - & 580.8 & - & 881.5 \\
\hline 7 & 108.1 & 108.4 & - & - & - & 49.8 & - & 960.2 & - & - & 1226.5 \\
\hline 9 & 87.9 & - & - & - & - & 140.3 & 548.9 & - & - & - & 777.1 \\
\hline 10 & 231.9 & 233.6 & - & - & - & - & 278.8 & 147.2 & 166.1 & 106.1 & 1163.7 \\
\hline 12 & 88.3 & - & - & - & 594.4 & 180.0 & - & - & - & - & 862.7 \\
\hline 14 & 80.3 & 80.9 & - & 888.3 & - & 256.1 & - & - & - & - & 1305.6 \\
\hline 16 & 110.5 & - & 567.0 & 58.3 & - & 214.0 & - & - & - & - & 949.8 \\
\hline 18 & - & 229.2 & 106.6 & 64.0 & 98.2 & 170.0 & - & - & - & - & 668.0 \\
\hline$\Sigma$ & 885.8 & 652.1 & 772.4 & 1065.1 & 692.6 & 1418.0 & 827.7 & 1107.4 & 746.9 & 198.6 & 8366.6 \\
\hline
\end{tabular}

(a) matriz origem-destino obtida para a Avenida Higienópolis

\begin{tabular}{|c|c|c|c|c|c|c|c|c|c|c|c|c|c|c|c|}
\hline O/D & 1 & 2 & 3 & 5 & 6 & 7 & 9 & 10 & 11 & 13 & 15 & 17 & 19 & 21 & $\Sigma$ \\
\hline 1 & - & 92.9 & 57.3 & 65.7 & 56.1 & 44.9 & 73.4 & 169.5 & 72.7 & - & 218.9 & - & 537.5 & - & 1388.9 \\
\hline 2 & 99.1 & - & - & - & - & - & 16.1 & 37.8 & 15.9 & - & 26.1 & - & - & 175.1 & 370.1 \\
\hline 4 & 212.9 & - & - & - & 11.7 & 12.9 & 34.8 & 103.5 & 34.3 & - & 111.7 & - & 78.7 & 34.8 & 635.3 \\
\hline 5 & - & - & - & - & - & - & - & 26.5 & - & - & - & - & - & - & 26.5 \\
\hline 8 & 76.2 & - & - & - & - & - & 10.7 & 265.6 & 10.5 & 848.2 & - & 16.5 & 48.0 & 37.3 & 1313.0 \\
\hline 10 & 172.9 & - & - & - & - & - & 413.5 & - & 205.7 & 275.9 & 151.2 & 111.6 & 135.9 & 94.9 & 1561.6 \\
\hline 12 & 79.5 & - & - & - & - & - & - & - & - & - & 16.7 & 22.1 & 52.6 & 41.1 & 212.0 \\
\hline 14 & 100.1 & - & - & - & - & 572.2 & - & 81.5 & - & - & 12.7 & 22.1 & 63.5 & 45.9 & 898.0 \\
\hline 16 & 118.8 & - & - & - & 405.0 & - & 11.6 & 68.3 & 11.5 & - & 40.3 & - & 69.1 & 45.5 & 770.1 \\
\hline 18 & 112.3 & - & - & - & - & - & 25.8 & 86.4 & 25.4 & - & 83.0 & - & 38.8 & 25.3 & 397.0 \\
\hline 20 & 120.9 & - & 942.2 & - & - & 11.3 & 26.8 & 66.9 & 26.5 & - & 57.9 & - & - & - & 1252.5 \\
\hline$\Sigma$ & 1092.7 & 92.9 & 999.5 & 65.7 & 472.8 & 641.3 & 612.7 & 906.0 & 402.5 & 1124.1 & 718.5 & 172.3 & 1024.1 & 499.9 & 8825.0 \\
\hline
\end{tabular}

(b) matriz origem-destino obtida para a Avenida Juscelino Kubitscheck

\begin{tabular}{|c|c|c|c|c|c|c|c|c|c|c|c|c|}
\hline$O / D$ & 1 & 2 & 3 & 5 & 6 & 7 & 9 & 10 & 11 & 13 & 14 & $\Sigma$ \\
\hline 1 & - & 97.1 & 120.9 & 230.9 & 43.9 & 51.7 & 35.2 & 121.6 & - & - & - & 701.3 \\
\hline 2 & 55.2 & - & - & 14.2 & - & - & - & 37.3 & - & - & 126.4 & 233.1 \\
\hline 3 & 17.0 & - & - & - & - & - & 14.2 & 59.1 & - & - & - & 90.3 \\
\hline 4 & 91.9 & - & - & - & - & 14.2 & 14.5 & 70.5 & - & - & - & 191.1 \\
\hline 5 & 36.8 & - & - & - & - & - & - & 23.6 & - & 52.5 & - & 112.9 \\
\hline 6 & 47.6 & - & - & - & - & - & - & 43.7 & - & - & - & 91.3 \\
\hline 8 & 72.4 & - & - & - & - & - & - & 64.8 & - & 33.6 & 32.6 & 203.4 \\
\hline 9 & 54.2 & - & - & - & - & - & - & 47.7 & - & 25.2 & 26.7 & 153.8 \\
\hline 10 & 192.8 & - & - & - & - & - & - & & 317.9 & 152.9 & 97.8 & 761.4 \\
\hline 12 & 58.2 & - & - & - & - & 47.9 & 24.3 & 250.9 & - & 11.8 & 18.5 & 411.6 \\
\hline 13 & 55.4 & - & - & 77.2 & - & - & - & 74.9 & - & - & - & 207.5 \\
\hline 14 & 53.7 & 152.9 & - & 23.3 & - & 12.4 & 12.9 & 46.2 & - & - & - & 301.4 \\
\hline$\Sigma$ & 735.2 & 250.0 & 120.9 & 345.6 & 43.9 & 126.2 & 101.1 & 840.3 & 317.9 & 276.0 & 302.0 & 3459.1 \\
\hline
\end{tabular}

(c) matriz origem-destino obtida para a Avenida Maringá

O programa QUEENSOD também foi utilizado na geração da matriz O-D sintética para a rede da cidade de São Carlos, através dos dados resultantes das contagens volumétricas de tráfego realizadas no período de pico das 11:30 às 12:30 horas, obtidos no relatório da RedeTráfego (Loureiro et al., 2005). A Tabela 6-8 apresenta a matriz dos pares origem-destino da rede de São Carlos, e os prováveis 
volumes de tráfego observados durante a hora-pico.

Tabela 6-8: Matriz origem-destino da rede de São Carlos (Loureiro et al., 2005)

\begin{tabular}{r|cccccccccccc}
\multicolumn{1}{c}{$O / D$} & \multicolumn{1}{c}{2} & 4 & 6 & 7 & 9 & 11 & 13 & 15 & 17 & 20 & $\Sigma$ \\
\cline { 2 - 10 } & 58 & 18 & 123 & 21 & 63 & 106 & 71 & 54 & 35 & 50 & 599 \\
3 & 86 & 265 & 15 & 1 & 22 & 48 & 10 & 57 & 40 & 27 & 571 \\
5 & 397 & 37 & 15 & 20 & 59 & 45 & 1 & 26 & 54 & 92 & 746 \\
8 & 7 & 61 & 46 & 42 & - & 16 & - & 3 & 12 & 76 & 263 \\
10 & 9 & 25 & 31 & 17 & 17 & 29 & 1 & 16 & 125 & 24 & 294 \\
12 & 51 & 38 & 18 & 5 & 27 & 33 & 3 & 86 & 5 & 8 & 274 \\
14 & 177 & 32 & 12 & 6 & 18 & 38 & 128 & 16 & 15 & 13 & 455 \\
16 & 30 & 55 & 6 & - & 60 & 142 & 1 & 15 & 47 & 25 & 381 \\
18 & 8 & 52 & 17 & 13 & 98 & 28 & 1 & - & 8 & 38 & 263 \\
19 & 25 & 77 & 19 & 21 & 48 & 17 & 1 & 8 & 8 & 39 & 263 \\
$\Sigma$ & 848 & 660 & 302 & 146 & 412 & 502 & 217 & 281 & 349 & 392 & 4109
\end{tabular}

A matriz de deslocamentos obtida para a rede selecionada em São Carlos resultou em 96 pares origem-destino, que totalizam 4.109 viagens distribuídas por hora simulada.

\subsection{Descrição dos Cenários}

Utilizando os dados coletados em campo nas operações vigentes dos três corredores arteriais selecionados no município de Londrina, com os demais parâmetros de calibração descritos anteriormente e que são comuns a todos os cenários da cidade, foi possível executar as simulações representadas pelas programações vigentes nas vias, além das seguintes situações distintas de operação:

- Cenário 1: situação em que os semáforos do corredor são coordenados através de progressão simultânea, isto é, todos os tempos de verde dos semáforos abrem ao mesmo tempo;

- Cenário 2: situação existente, sem coordenação semafórica ou com coordenação feita por métodos convencionais;

- Cenários 3 a 7: situações em que os semáforos são coordenados através do programa SBAND, tanto para bandas bidirecionais com larguras iguais quanto desiguais, e para diferentes opções de velocidades na via principal; e

- Cenário 8: situação em que os semáforos são coordenados através de rotinas internas existentes no simulador INTEGRATION.

A obtenção do melhor plano coordenado pelo programa INTEGRATION requer a verificação da possibilidade do semáforo ser "mestre" entre todos os cruzamentos 
semaforizados do corredor, através da repetição da simulação para cada semáforo selecionado como mestre, e observando no arquivo de resumo dos resultados gerados (arquivo 28) qual o esquema que resulta nos menores valores das medidas de desempenho atraso total e atraso parado. Após a identificação da melhor opção de semáforo mestre, e para esta simulação, é necessário verificar qual conjunto de defasagens entre aquelas geradas pelo programa durante o período de simulação (arquivo 12) que apresenta a menor média dos tempos de viagem, e para o intervalo de tempo que possui a menor média identificar seu plano referente (arquivo 14).

Este procedimento é necessário em função do programa INTEGRATION modificar constantemente o conjunto de defasagens, ou seja, o plano de coordenação ao longo da simulação. Como o objetivo da avaliação é verificar o efeito da coordenação em semáforos de tempo fixo, que são típicos nos controladores e nas operações semafóricas das cidades de médio porte, somente depois de verificar o melhor semáforo mestre e o melhor conjunto de defasagens é que o plano gerado pelo INTEGRATION deve ser simulado.

Para realizar a análise de sensibilidade do desempenho do programa proposto SBAND e do simulador INTEGRATION em relação às variações de volume, e considerando principalmente que nos três cenários vigentes da cidade de Londrina a volumetria existente se aproxima da saturação, todos os pares origem-destino apresentados na Tabela 6-7 foram alterados na mesma porcentagem, em variações com reduções de 15, 25, 35, 45, 55, 65, 75 e 85\% da matriz O-D estimada a partir dos volumes observados. Desta forma, outras 8 situações com demandas reduzidas foram geradas para cada um dos 8 cenários avaliados em cada corredor escolhido em Londrina.

Por fim, mais oito simulações foram realizadas somente para a Avenida Higienópolis, para as situações com progressão simultânea e com coordenação gerada pelo programa SBAND, a fim de verificar as alterações nas medidas de desempenho promovidas pela programação obtida pelo SBAND, em função das distâncias entre as interseções semaforizadas. Os supostos espaçamentos de 220, 320, 420 e 520 metros entre os oito semáforos da Avenida Higienópolis foram testados, em comparação à característica real desta via, que apresenta interseções semaforizadas com aproximadamente 120 metros de distância umas das outras. Para a situação que supõe espaçamentos de 520 metros entre os semáforos (e que requer metade do tempo do ciclo para que os veículos percorram a distância entre as interseções a $50 \mathrm{~km} / \mathrm{h}$ ), o plano de coordenação gerado pelo programa INTEGRATION também foi testado. 
Para as simulações da rede selecionada na cidade de São Carlos, utilizando os parâmetros de calibração especificados no item 6.3, cinco cenários distintos foram testados, incluindo a situação de operação vigente nas vias:

- Cenário 1: situação em que os semáforos dos três corredores principais da rede são coordenados através de progressão simultânea, supondo que todos os tempos de verde dos semáforos abram ao mesmo tempo;

- Cenário 2: situação existente, sem coordenação semafórica ou com coordenação feita por métodos convencionais;

- Cenários 3 e 4: situações em que os semáforos são coordenados através do programa SBAND, para bandas unidirecionais e com duas possibilidades diferentes de velocidade; e

- Cenário 5: situação em que os semáforos existentes ao longo das vias principais da rede são coordenados simultaneamente através de rotinas internas existentes no simulador INTEGRATION.

Assim como realizado nos corredores da cidade de Londrina, o procedimento para identificação do melhor conjunto de defasagens gerado pelo simulador INTEGRATION também foi utilizado para a rede da cidade de São Carlos, porém sem a necessidade de verificar o melhor semáforo mestre, visto que nas vias de sentido único de circulação foi considerado como mestre o primeiro semáforo de cada corredor.

Na seqüência, os dados das avenidas selecionadas e simuladas da cidade de Londrina e da rede da cidade de São Carlos são apresentados separadamente, incluindo a representação dos respectivos Diagramas Espaço-Tempo resultantes de cada cenário. Independente do cenário simulado, as defasagens são referenciadas pelo início do tempo de verde dos semáforos, além da duração do ciclo e a divisão dos tempos de verde e vermelho permaneceram as mesmas daquelas identificadas na condição vigente.

\subsubsection{Avenida Higienópolis}

- Cenário 1 - coordenado através de progressão simultânea: supondo que todos os tempos de verde da via principal abram simultaneamente e que a velocidade de progressão seja $50 \mathrm{~km} / \mathrm{h}$, o diagrama Espaço-Tempo desta condição demonstra a formação de bandas iguais com largura de 14 segundos entre os semáforos 1 a 4 em ambos os sentidos, e entre os semáforos 5 a 8 a banda máxima formada é de 12 segundos no sentido Norte-Sul e 18 segundos no sentido Sul-Norte, conforme ilustrado na Figura 6-10. 


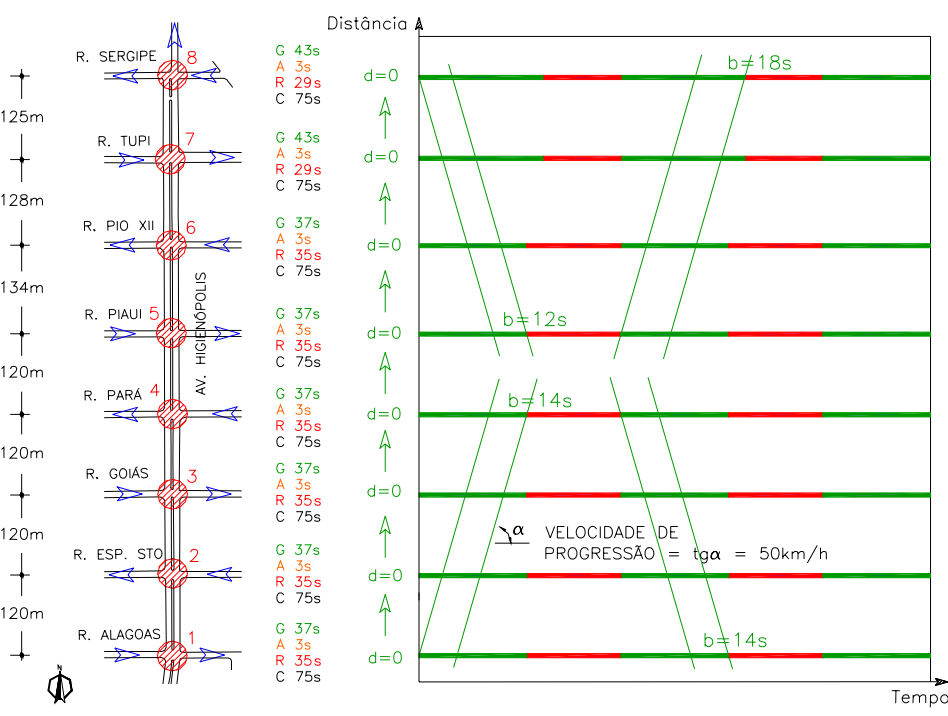

Figura 6-10: Diagrama Espaço-Tempo simultâneo da Av. Higienópolis

- Cenário 2 - operação vigente: o diagrama Espaço-Tempo foi elaborado com os dados coletados em campo para a situação em operação no horário de pico da avenida (17:45 - 18:45), a fim de possibilitar a identificação da progressão em onda-verde em cada um dos sentidos da via, representada na Figura 6-11. A velocidade de $50 \mathrm{~km} / \mathrm{h}$ é considerada para progressão do pelotão, por ser a máxima permitida regulamentada na avenida. O sentido Sul-Norte é contemplado por duas bandas interrompidas no semáforo 5 com larguras máximas de 20 e 36 segundos, enquanto o sentido Norte-Sul apresenta três bandas interrompidas com larguras máximas que variam entre 22 e 31 segundos, podendo ocasionar paradas nos semáforos 3 e 6.

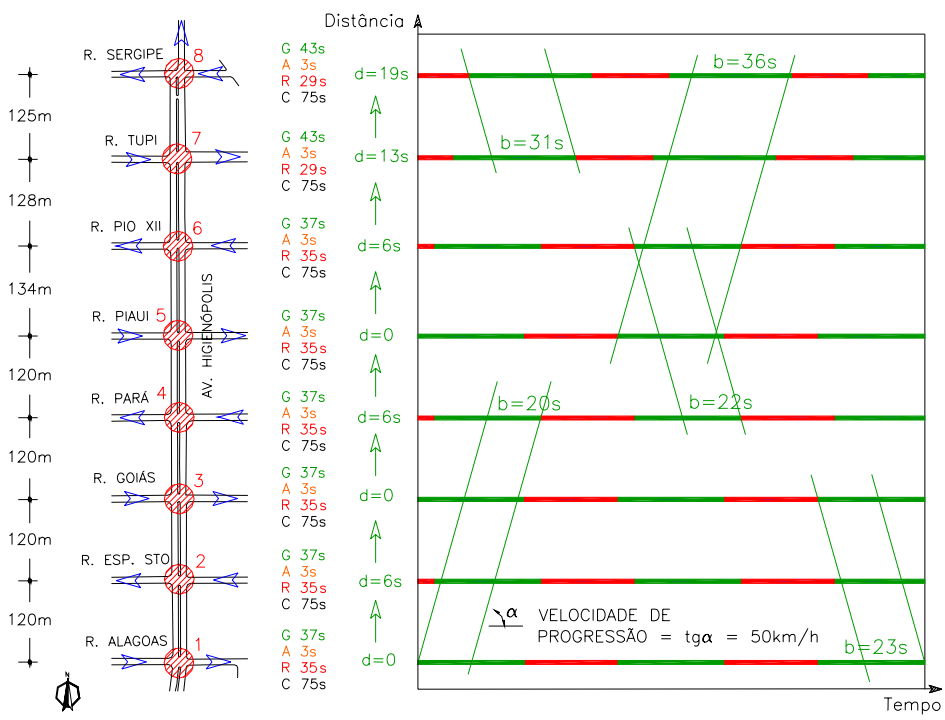

Figura 6-11: Diagrama Espaço-Tempo vigente da Av. Higienópolis

- Cenários 3 e 4 - coordenações geradas pelo programa SBAND para bandas iguais: 
duas opções de coordenação geradas pelo SBAND foram testadas, considerando a velocidade de progressão de 40 e de $50 \mathrm{~km} / \mathrm{h}$, gerando soluções com bandas iguais em ambos os sentidos com larguras de 13,2 e 11,1 segundos respectivamente. A Figura 6-12 apresenta as defasagens e os diagramas obtidos através do programa SBAND, com bandas iguais para os oito semáforos da Avenida Higienópolis.
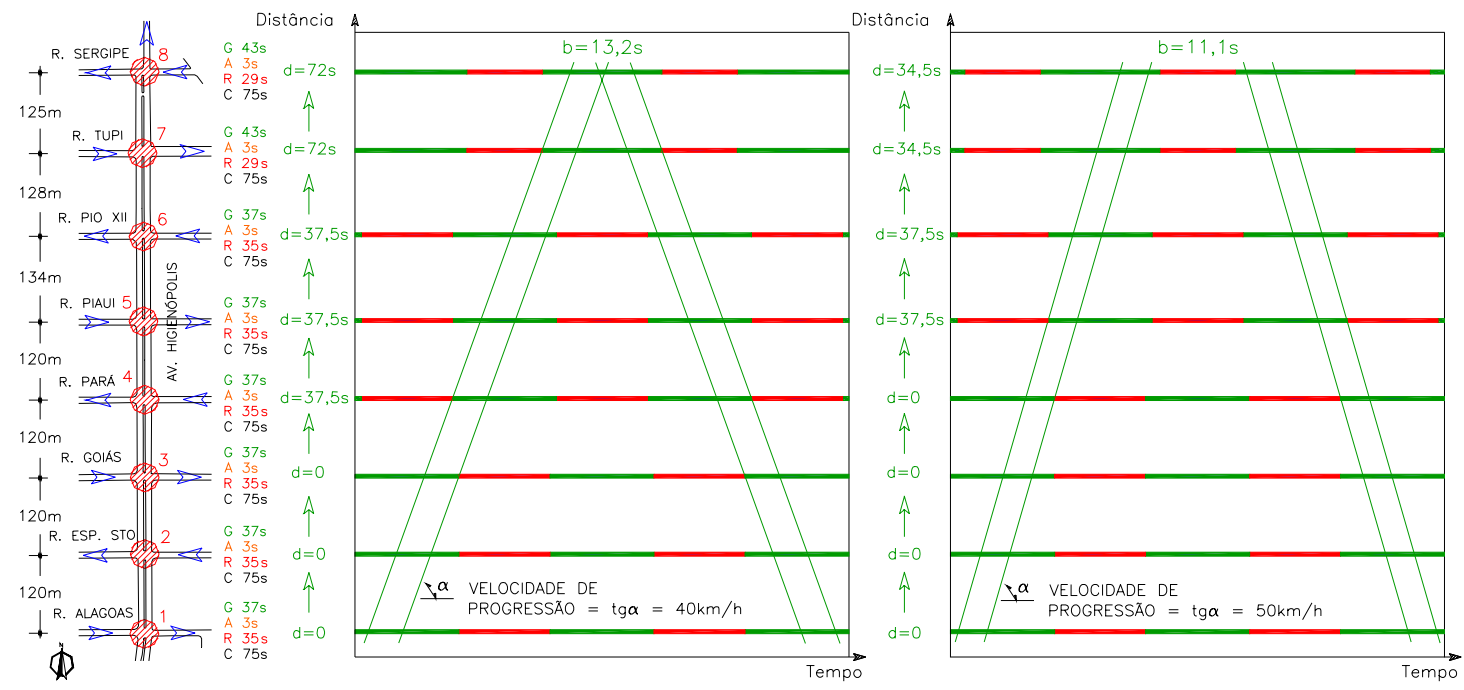

Figura 6-12: Diagramas Espaço-Tempo gerados pelo SBAND com bandas iguais para a Av. Higienópolis

- Cenários 5 e 6 - coordenações geradas pelo programa SBAND para bandas diferentes: duas opções de coordenação foram testadas, considerando a velocidade de progressão de 40 e de $50 \mathrm{~km} / \mathrm{h}$, gerando soluções com bandas diferentes nos dois sentidos, de forma a priorizar em $15 \%$ a banda no sentido Sul-Norte, em função de seu volume médio ser 15\% maior do que no sentido Norte-Sul. As defasagens e os diagramas gerados com bandas diferentes estão representados na Figura 6-13.
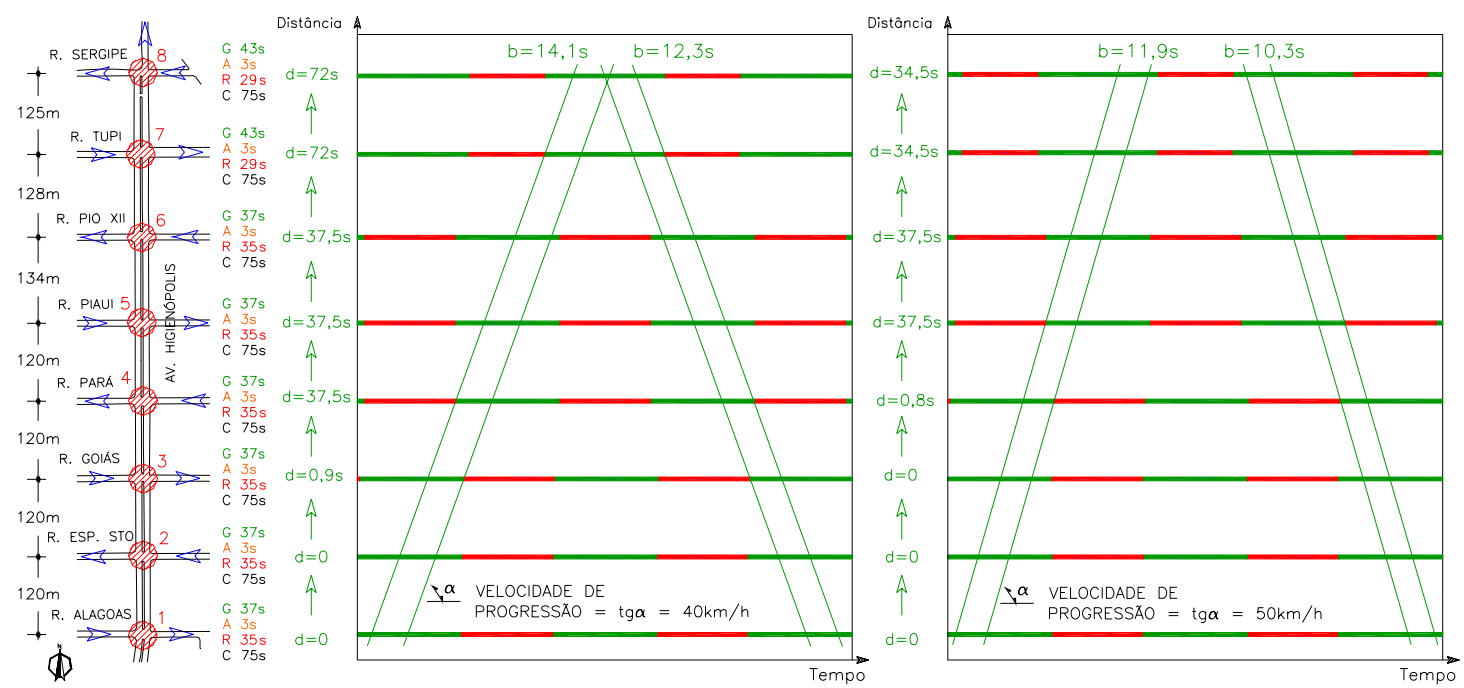

Figura 6-13: Diagramas Espaço-Tempo gerados pelo SBAND com bandas diferentes para a Av. Higienópolis 
- Cenário 7 - coordenação gerada pelo programa SBAND em duas etapas: opção de coordenação com velocidade de progressão de $50 \mathrm{~km} / \mathrm{h}$ para bandas iguais nos dois sentidos, obtidas para os 4 primeiros semáforos e para os 4 últimos separadamente. A Figura 6-14 ilustra os diagramas obtidos nas duas etapas, e que posteriormente foram defasados 24,6 segundos entre si, na tentativa de dar continuidade às bandas geradas em cada etapa, considerando a distância de 120 m entre os semáforos 4 e 5 .

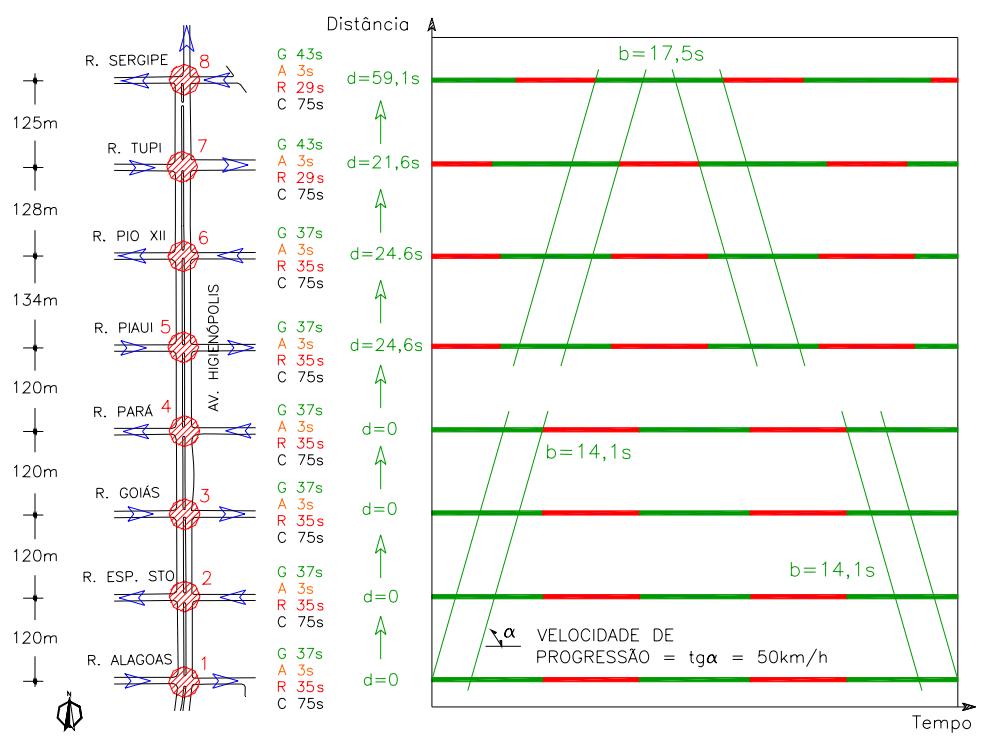

Figura 6-14: Diagramas Espaço-Tempo gerados pelo SBAND em duas etapas para a Av. Higienópolis

- Cenário 8 - coordenado através do INTEGRATION: a opção de coordenação existente na rotina do simulador INTEGRATION foi utilizada para gerar as defasagens ótimas, mas sem permitir que o programa otimizasse o ciclo ou as fases. As bandas obtidas com o semáforo 7 como mestre estão representadas no diagrama Espaço-Tempo da Figura 6-15, e não apresentam continuidade das bandas ao longo do corredor, criando dois trechos de banda com larguras distintas em cada sentido.

Considerando que o corredor da Avenida Higienópolis apresenta interseções semaforizadas praticamente eqüidistantes umas das outras, com aproximadamente 120 metros entre elas, mais oito cenários distintos foram testados para esta via, com o intuito de verificar a melhoria nas medidas de desempenho promovidas pela coordenação gerada pelo programa SBAND em função de diferentes espaçamentos entre semáforos. Desta forma, sempre utilizando a velocidade de progressão de $50 \mathrm{~km} / \mathrm{h}$, quatro cenários com progressão simultânea foram simulados supondo as condições de interseções distanciadas em 220, 320, 420 e 520 metros entre os oito semáforos da Avenida Higienópolis, assim como outros quatro cenários desta via com os mesmos espaçamentos citados porém com operação coordenada gerada pelo programa SBAND. 


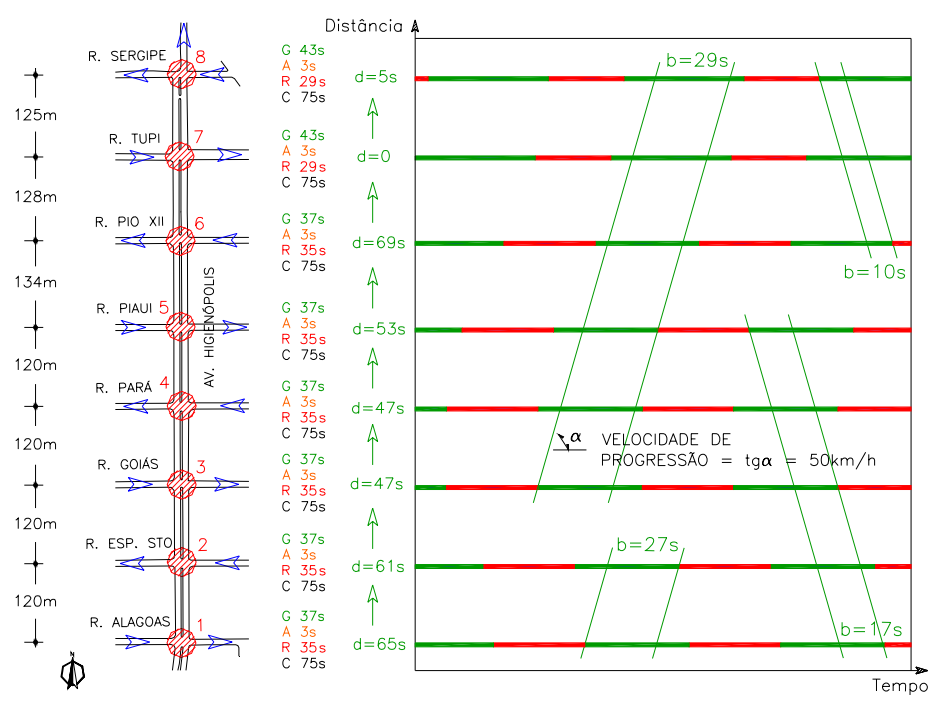

Figura 6-15: Diagrama Espaço-Tempo gerado pelo INTEGRATION para a Av.

Higienópolis

A Figura 6-16 ilustra os diagramas Espaço-Tempo tanto para a condição de progressão simultânea na Avenida Higienópolis supondo o espaçamento de 220 metros entre os semáforos (que não gera banda contínua ao longo do corredor), quanto para as defasagens obtidas pelo programa SBAND (bandas iguais com largura de 11,3s).

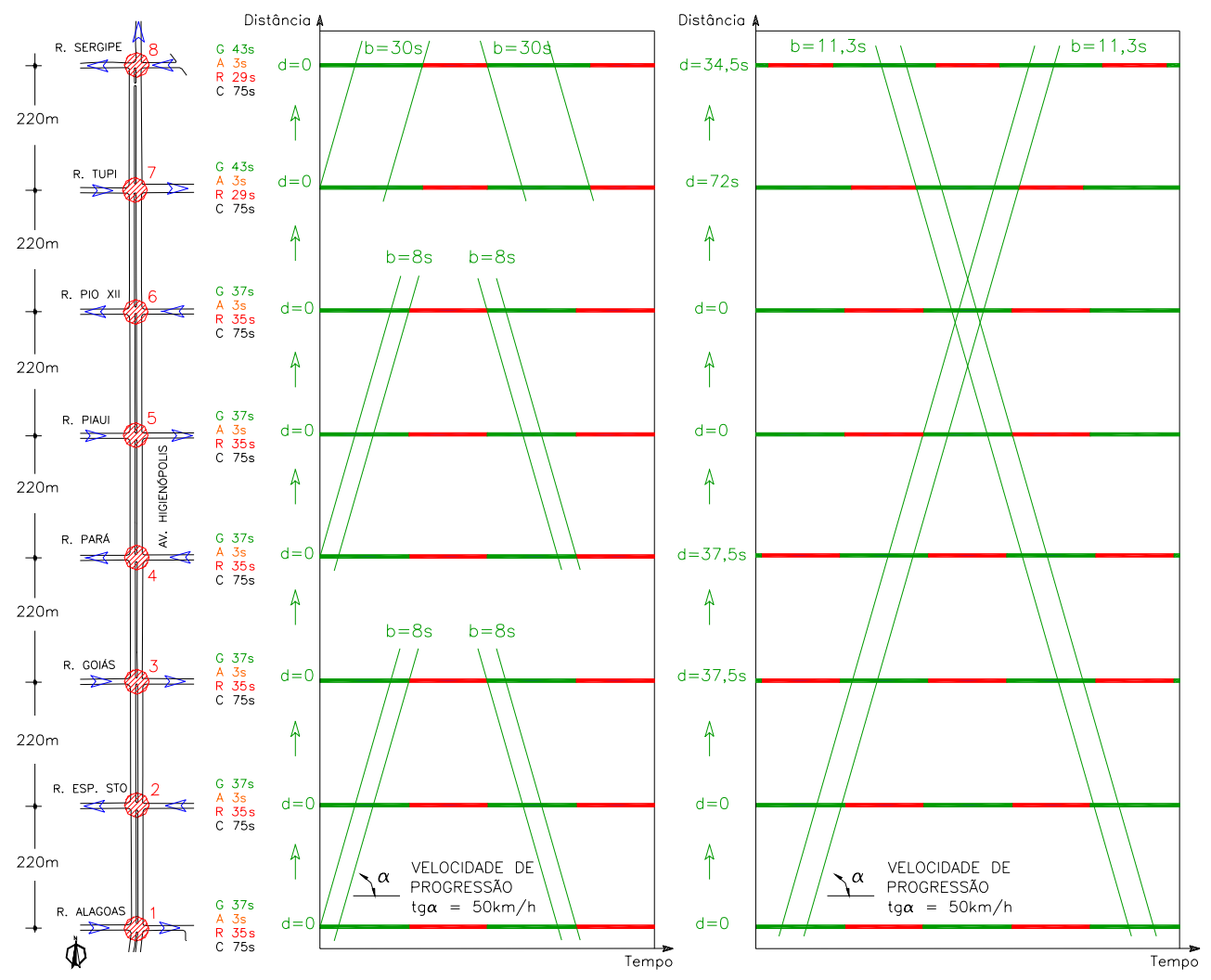

Figura 6-16: Diagramas Espaço-Tempo simultâneo e gerado pelo SBAND com bandas iguais para a Av. Higienópolis supondo distância de 220 metros entre semáforos 
O diagrama Espaço-Tempo da progressão simultânea na Avenida Higienópolis, supondo o espaçamento de 320 metros entre as oito interseções semaforizadas, demonstra que esta condição também não gera banda contínua ao longo do corredor, e que as defasagens obtidas pelo programa SBAND proporcionam bandas iguais com largura de 11,1 segundos, conforme ilustrado na Figura 6-17.

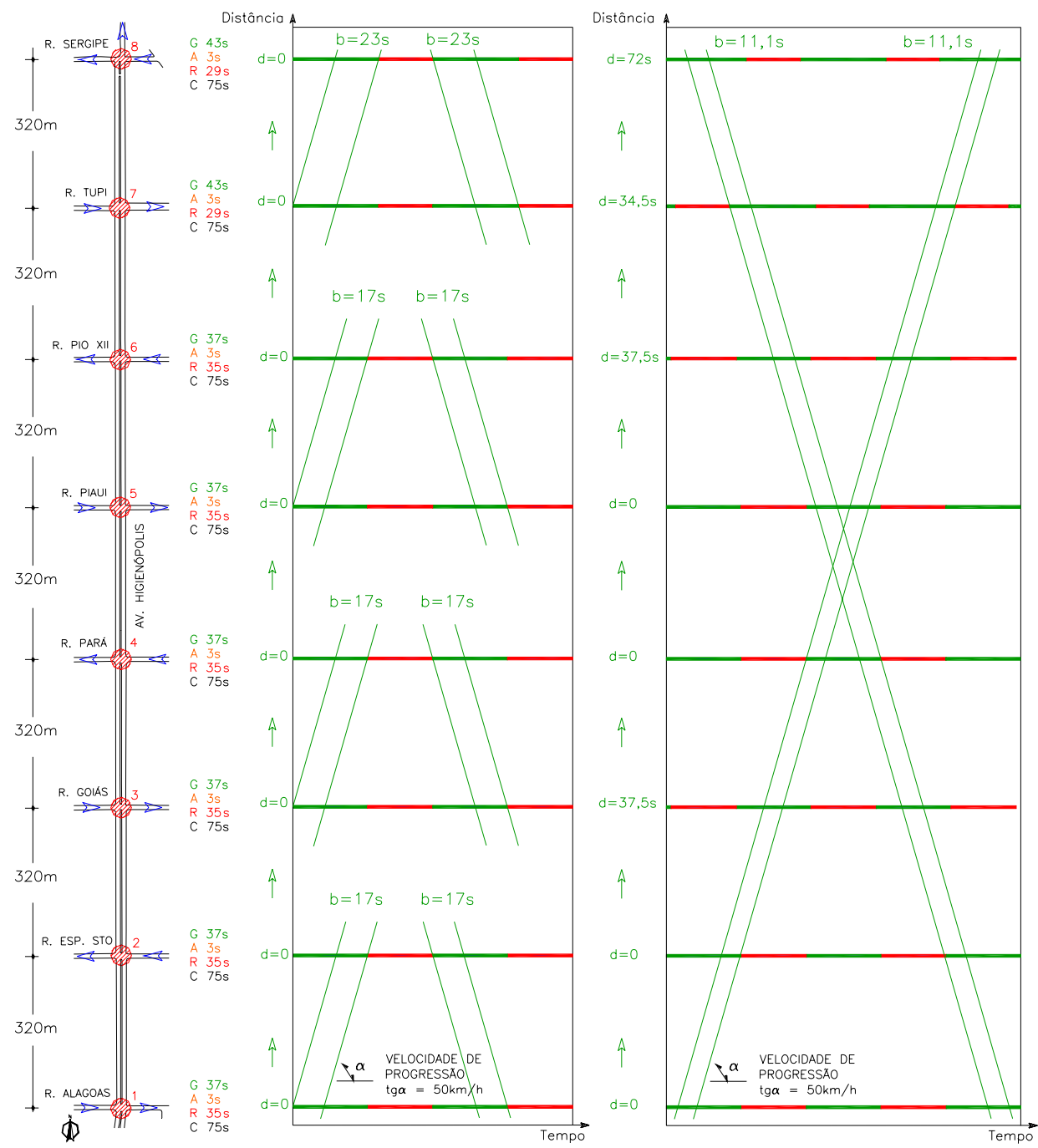

Figura 6-17: Diagramas Espaço-Tempo simultâneo e gerado pelo SBAND com bandas iguais para a Av. Higienópolis supondo distância de 320 metros entre semáforos

A ilustração da Figura 6-18 apresenta os diagramas Espaço-Tempo da Avenida Higienópolis, supondo o espaçamento de 420 metros entre as interseções semaforizadas, e considerando a condição de progressão simultânea (que não gera banda contínua ao longo dos oito semáforos do corredor, mas somente trechos de banda a cada par de semáforos), e a coordenação obtida pelo programa SBAND (que resulta em bandas iguais com largura de 9,8 segundos). 


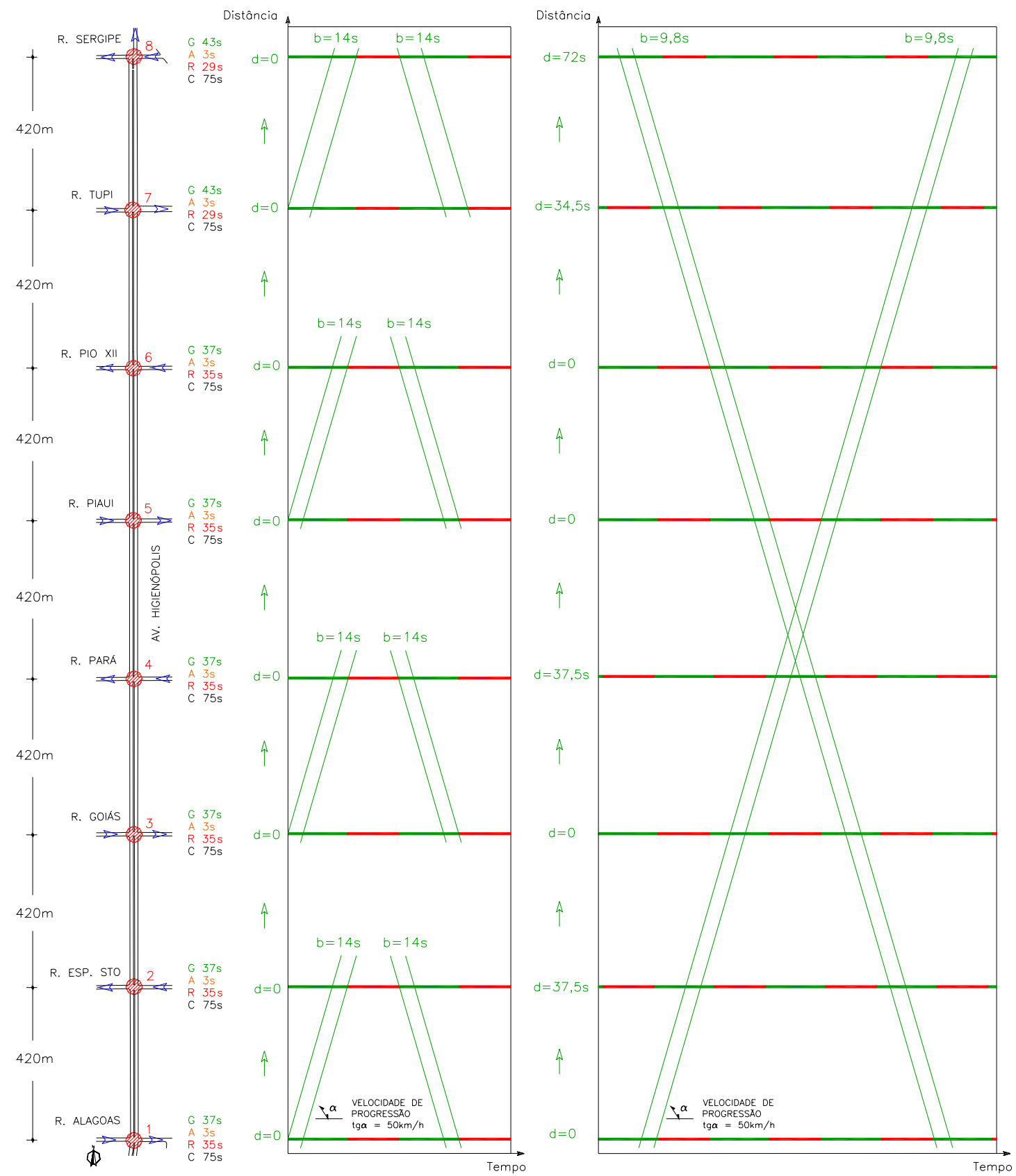

Figura 6-18: Diagramas Espaço-Tempo simultâneo e gerado pelo SBAND com bandas iguais para a Av. Higienópolis supondo distância de 420 metros entre semáforos

A condição de progressão simultânea nos semáforos da Avenida Higienópolis, supondo o espaçamento de 520 metros entre as interseções, também não gera banda contínua ao longo do corredor, como ilustra o diagrama Espaço-Tempo apresentado na Figura 6-19. Para as defasagens obtidas pelo programa SBAND, as bandas iguais são formadas com largura de 40 segundos, relativo ao menor tempo de verde com amarelo existente nos semáforos da via principal. Por fim, os trechos de banda formados através 
da coordenação gerada pelo programa INTEGRATION resultam em larguras de 31 e 35 segundos, interrompidas entre os semáforos 3 e 4.

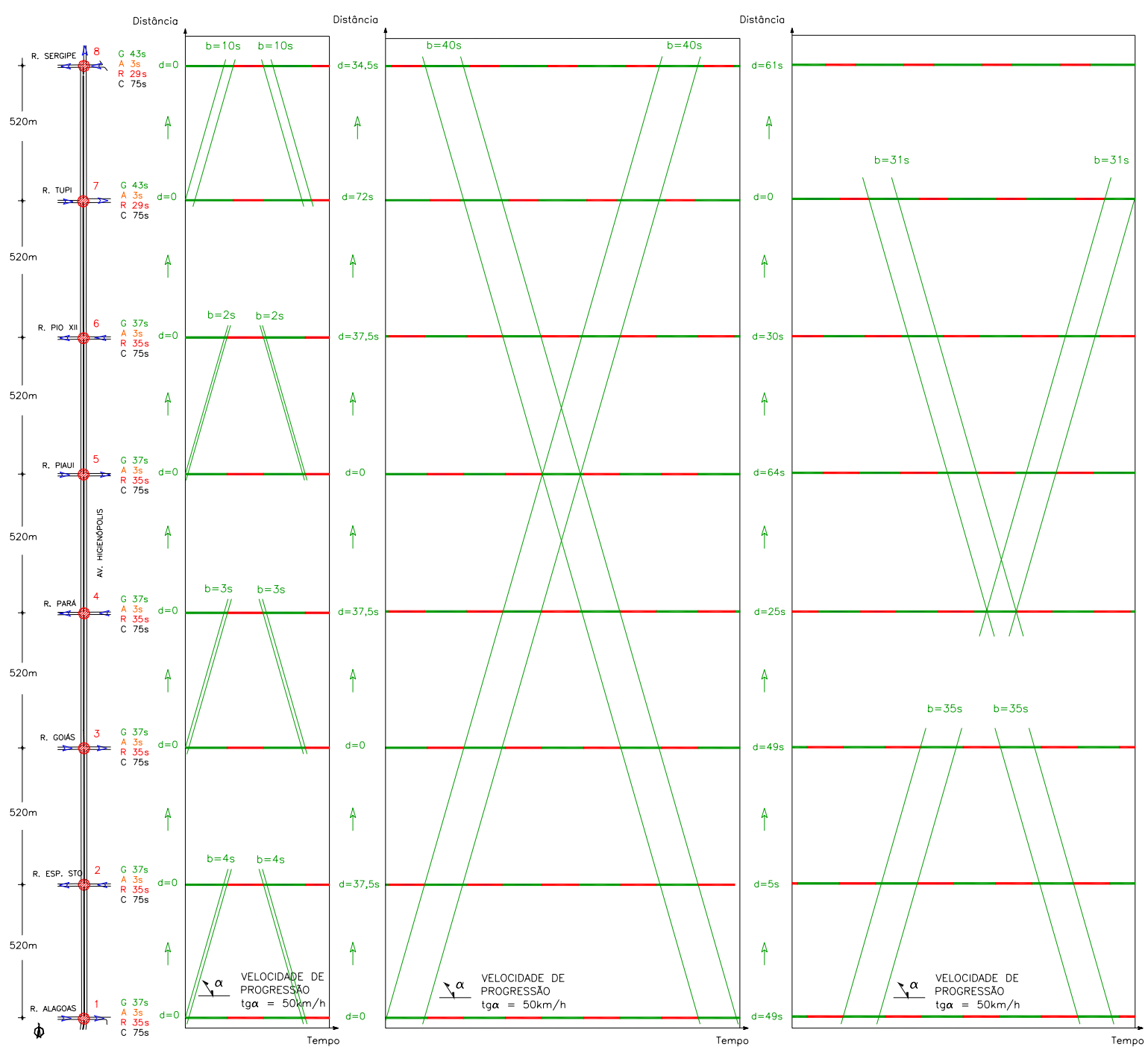

Figura 6-19: Diagramas Espaço-Tempo simultâneo, gerado pelo SBAND com bandas iguais e pelo INTEGRATION respectivamente, para a Av. Higienópolis supondo distância de 520 metros entre semáforos

Os oito cenários descritos para avaliação das medidas de desempenho da Avenida Higienópolis (simultâneo, vigente, coordenados pelo SBAND e pelo programa INTEGRATION) também foram avaliados para demandas menores do que a demanda real, reproduzindo simulações com reduções entre 15 e $85 \%$ nos valores dos pares origem-destino, totalizando portanto 81 cenários avaliados para este corredor, conforme dados esquematizados na Tabela 6-9. 
Tabela 6-9: Cenários simulados para a Avenida Higienópolis

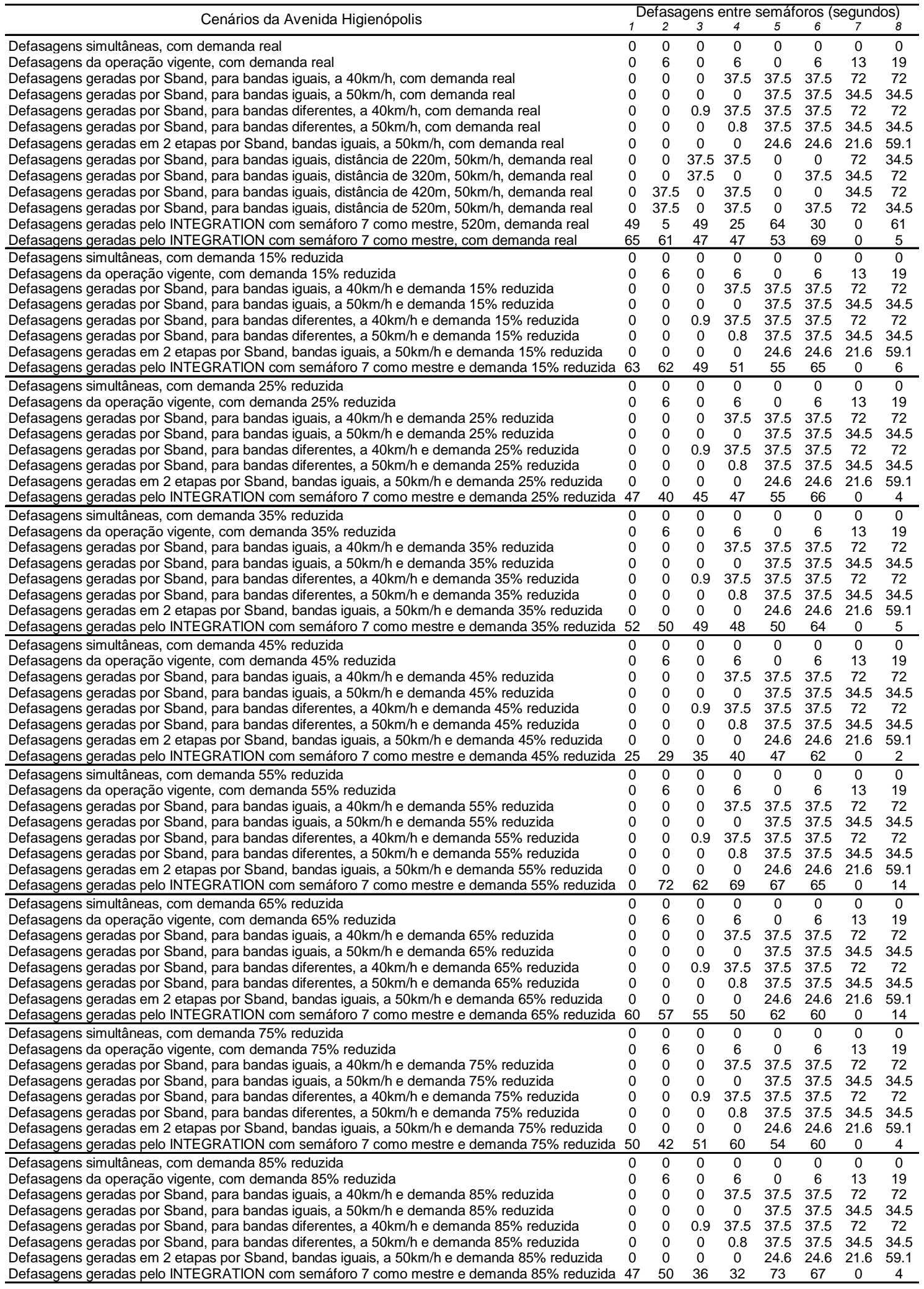




\subsubsection{Avenida Juscelino Kubitscheck}

- Cenário 1 - coordenado através de progressão simultânea: todos os tempos de verde nos semáforos da via principal abrem simultaneamente, gerando trechos de banda com interrupções ao longo da Avenida Juscelino Kubitscheck em ambos os sentido, com larguras que variam entre 12 e 19 segundos, conforme esquematizado no diagrama Espaço-Tempo da Figura 6-20, supondo que a velocidade de progressão seja $50 \mathrm{~km} / \mathrm{h}$.

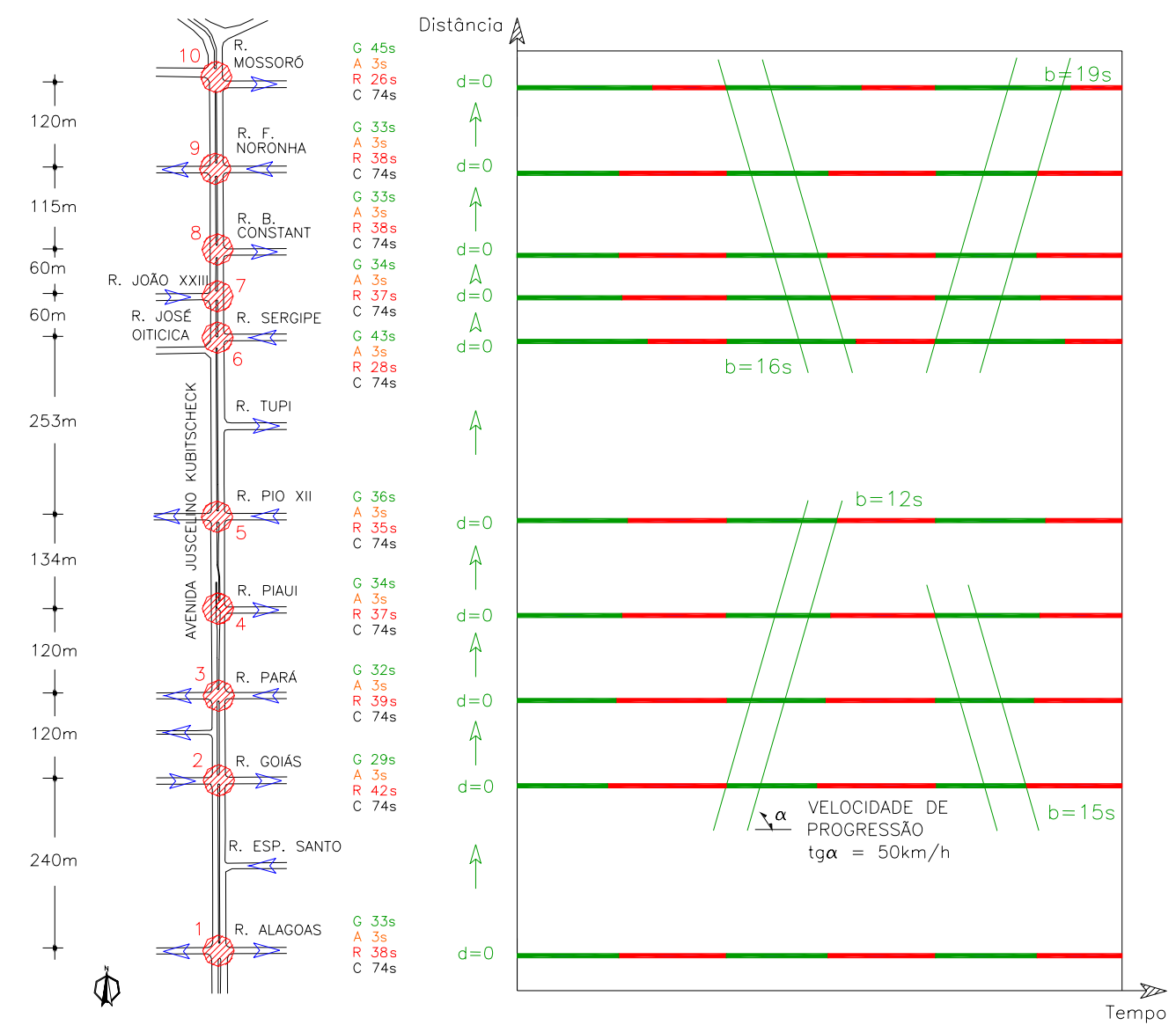

Figura 6-20: Diagrama Espaço-Tempo simultâneo da Av. Juscelino Kubitscheck

- Cenário 2 - operação vigente: o diagrama Espaço-Tempo gerado para as condições vigentes no horário de pico (17:45 - 18:45) da Avenida Juscelino Kubitscheck indica a formação de uma banda contínua no sentido Sul-Norte sem interrupção ao longo dos dez cruzamentos semaforizados, com largura máxima de 26 segundos, conforme representação da Figura 6-21. A velocidade de $50 \mathrm{~km} / \mathrm{h}$ é considerada para progressão do pelotão, por ser a máxima permitida regulamentada na via. No entanto, o sentido Norte-Sul não é contemplado por uma única banda, apresentando quatro trechos de bandas interrompidas com larguras variando entre 17 e 23 segundos, podendo ocasionar paradas nos semáforos 2, 4, 6 e 9. 


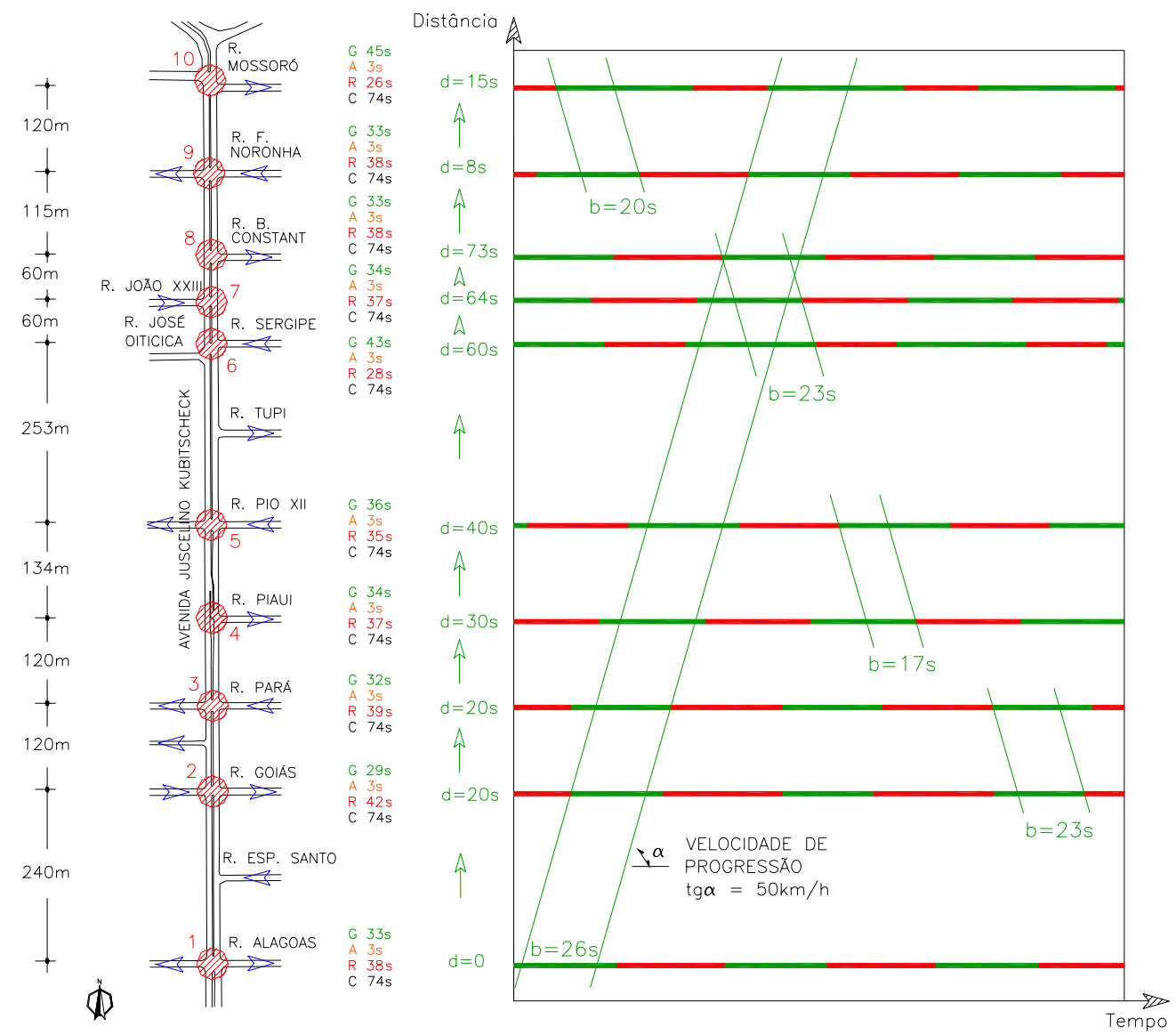

Figura 6-21: Diagrama Espaço-Tempo vigente da Av. Juscelino Kubitscheck

- Cenários 3 e 4 - coordenados através do programa SBAND para bandas iguais: duas opções de coordenação geradas pelo SBAND foram testadas, considerando a velocidade de progressão de 50 e de $55 \mathrm{~km} / \mathrm{h}$, gerando soluções com bandas iguais em ambos os sentidos com larguras de 8,6 e 11 segundos respectivamente. A Figura 6-22 ilustra as defasagens e os diagramas obtidos, com bandas iguais para os dez semáforos ao longo da Avenida Juscelino Kubitscheck.

- Cenários 5 e 6 - coordenações geradas pelo programa SBAND para bandas diferentes: duas opções de coordenação geradas pelo SBAND foram testadas, considerando a velocidade de progressão de 50 e $55 \mathrm{~km} / \mathrm{h}$, gerando soluções com bandas diferentes nos dois sentidos, a fim de priorizar em $5 \%$ a banda no sentido Norte-Sul, em função de seu volume médio ser 5\% maior que o volume médio do sentido Sul-Norte. As defasagens e os diagramas Espaço-Tempo gerados pelo programa SBAND com bandas diferentes na Avenida Juscelino Kubitscheck estão representados na Figura 6-23. 


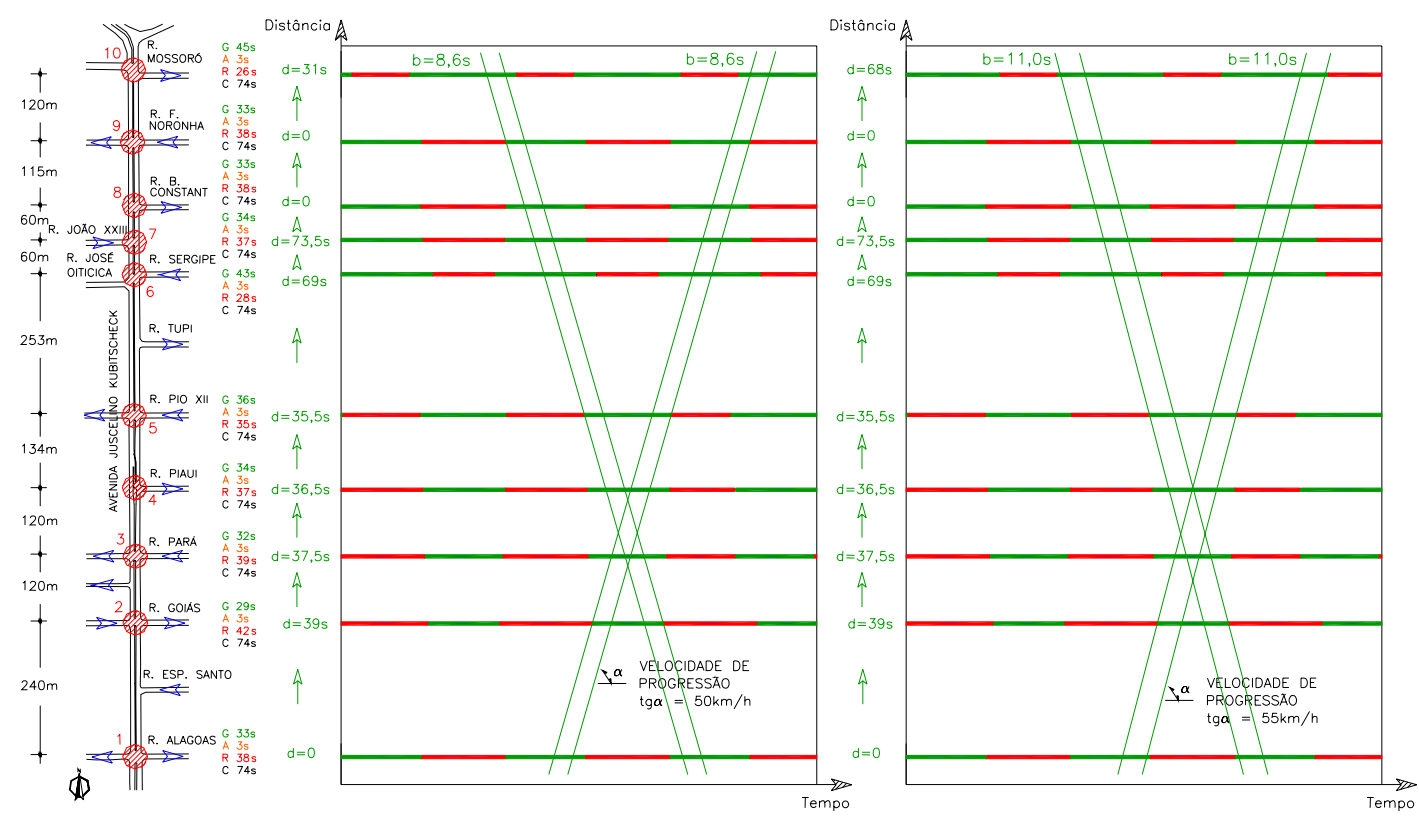

Figura 6-22: Diagramas Espaço-Tempo gerados pelo SBAND com bandas iguais para a Av. Juscelino Kubitscheck
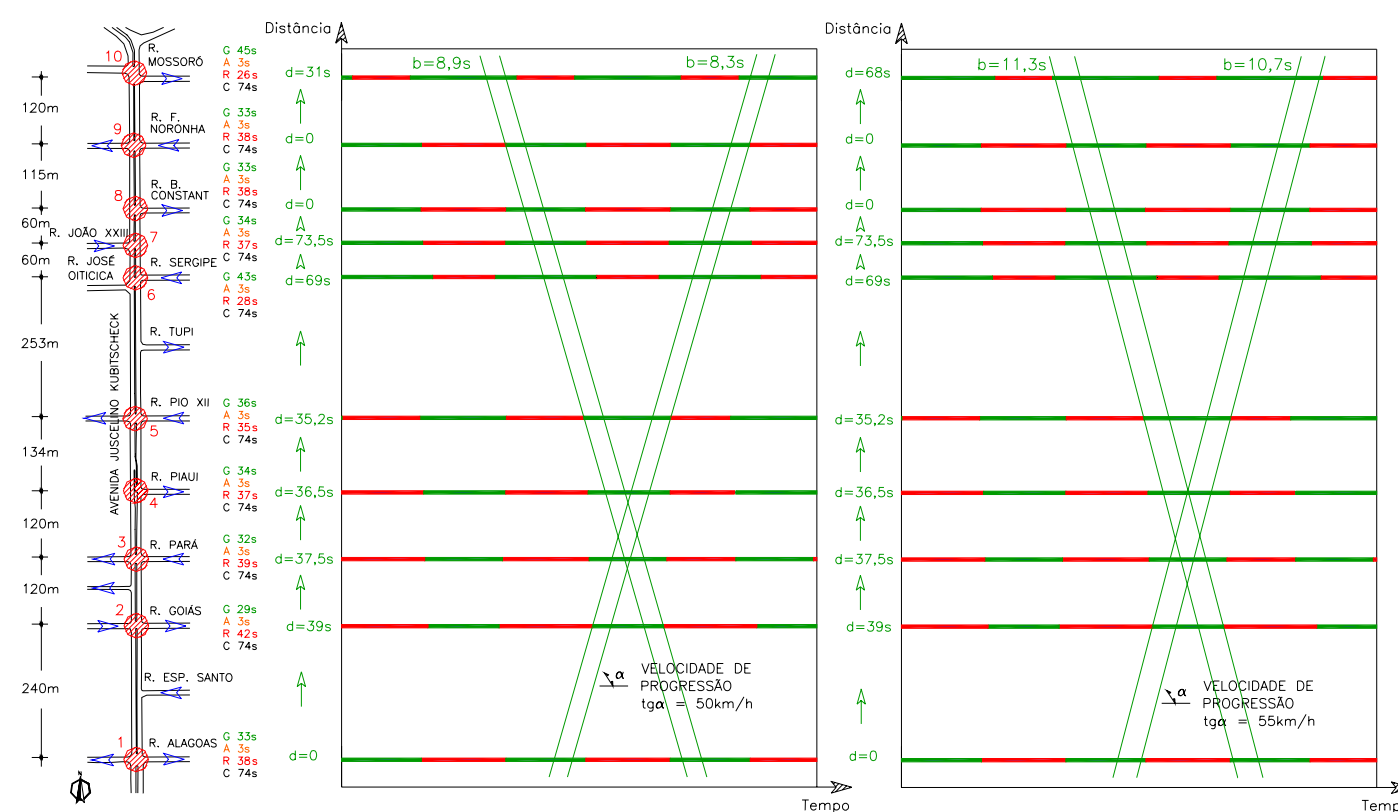

Figura 6-23: Diagramas Espaço-Tempo gerados pelo SBAND com bandas diferentes para a Av. Juscelino Kubitscheck

- Cenário 7 - coordenação gerada pelo programa SBAND em duas etapas: opção de coordenação com velocidade de progressão de $55 \mathrm{~km} / \mathrm{h}$ para bandas iguais nos dois sentidos, porém obtidas separadamente para os 5 primeiros semáforos e para os 5 últimos. Os diagramas gerados em duas etapas para a velocidade de $55 \mathrm{~km} / \mathrm{h}$ foram posteriormente defasados entre si em 72,3 segundos, na tentativa de acomodar a continuidade das bandas geradas em uma das etapas, considerando o espaçamento de 253 metros entre os semáforos 5 e 6, conforme ilustra a Figura 6-24. 


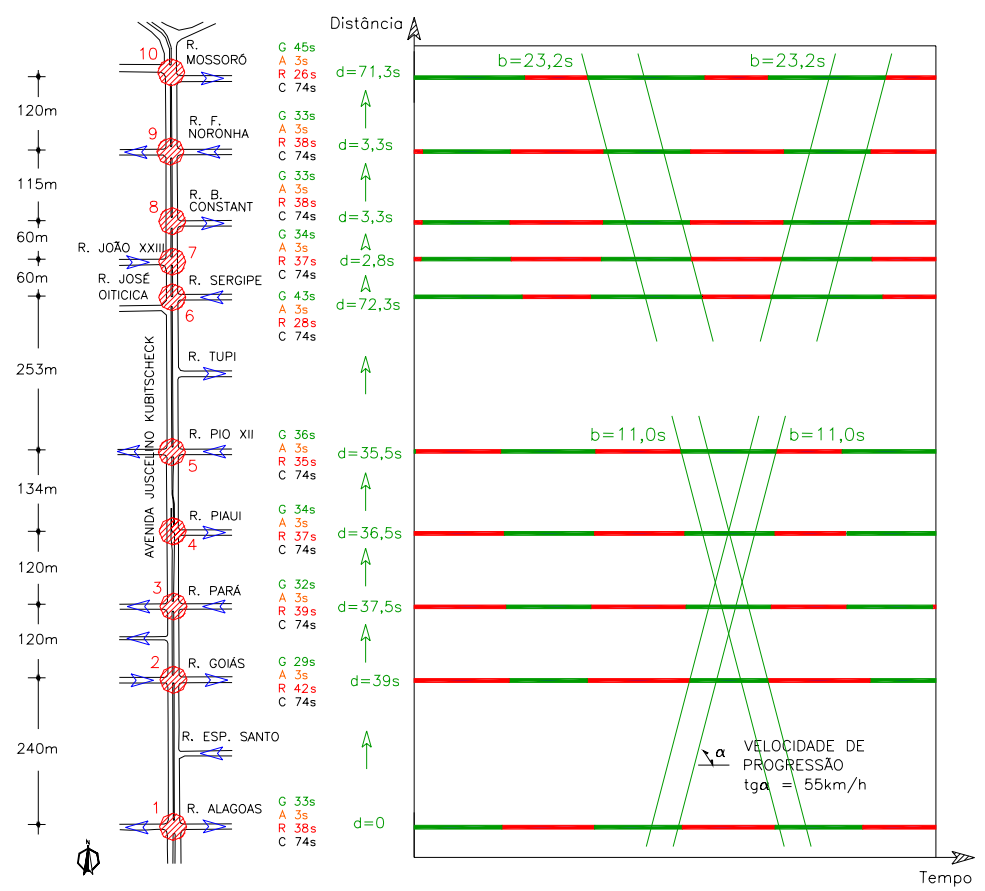

Figura 6-24: Diagramas Espaço-Tempo gerados pelo SBAND em duas etapas para a Av. Juscelino Kubitscheck

- Cenário 8 - coordenado através do INTEGRATION: a opção de coordenação do simulador INTEGRATION foi utilizada para gerar as defasagens ótimas, porém sem alteração do ciclo ou das fases. A Figura 6-25 ilustra as bandas resultantes das defasagens obtidas com o semáforo 8 como mestre, não apresentando continuidade ao longo do corredor, mas formando trechos com larguras que variam de 15 a $27 \mathrm{~s}$.

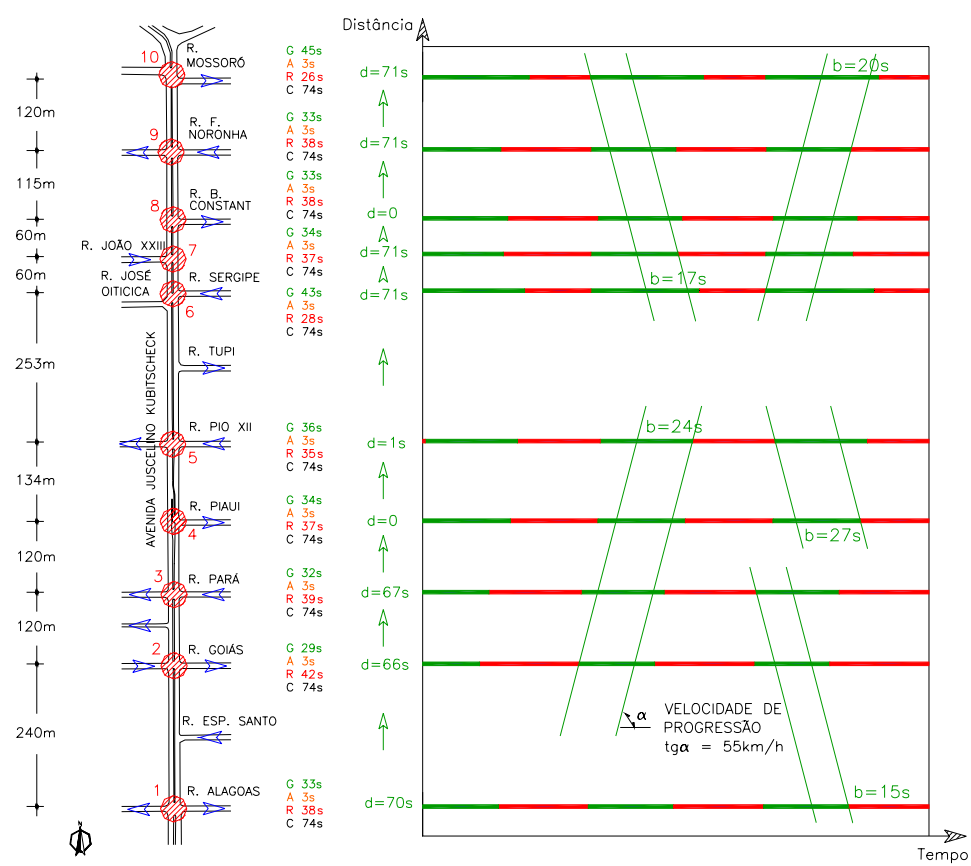

Figura 6-25: Diagrama Espaço-Tempo gerado pelo INTEGRATION para a Av. Juscelino Kubitscheck 
Estes oito cenários descritos também foram avaliados para demandas menores do que a demanda real, com reduções de 15 a 85\% nos valores dos pares origemdestino, totalizando 72 cenários avaliados para o corredor da Avenida Juscelino Kubitscheck, conforme esquematizado na Tabela 6-10.

Tabela 6-10: Cenários simulados para a Avenida Juscelino Kubitscheck

\begin{tabular}{|c|c|c|c|c|c|c|c|c|c|c|}
\hline \multirow{2}{*}{ Cenários da Avenida Juscelino Kubitscheck } & \multicolumn{10}{|c|}{ Defasagens entre semáforos (segundos) } \\
\hline & 1 & 2 & 3 & 4 & 5 & 6 & 7 & 8 & 9 & 10 \\
\hline Defasagens simultâneas, com demanda real & 0 & 0 & 0 & 0 & 0 & 0 & 0 & 0 & 0 & 0 \\
\hline Defasagens da operação vigente, com demanda real & 0 & 20 & 20 & 30 & 40 & 60 & 64 & 73 & 8 & 15 \\
\hline Defasagens geradas por Sband, para bandas iguais, a $50 \mathrm{~km} / \mathrm{h}$, com demanda real & 0 & 39 & 37.5 & 36.5 & 35.5 & 69 & 73.5 & 0 & 0 & 31 \\
\hline Defasagens geradas por Sband, para bandas iguais, a $55 \mathrm{~km} / \mathrm{h}$, com demanda real & 0 & 39 & 37.5 & 36.5 & 35.5 & 69 & 73.5 & 0 & 0 & 68 \\
\hline Defasagens geradas por Sband, para bandas diferentes, a $50 \mathrm{~km} / \mathrm{h}$, com demanda real & 0 & 39 & 37.5 & 36.5 & 35.2 & 69 & 73.5 & 0 & 0 & 31 \\
\hline Defasagens geradas por Sband, para bandas diferentes, a $55 \mathrm{~km} / \mathrm{h}$, com demanda real & 0 & 39 & 37.5 & 36.5 & 35.2 & 69 & 73.5 & 0 & 0 & 68 \\
\hline Defasagens geradas em 2 etapas por Sband, bandas iguais, a $55 \mathrm{~km} / \mathrm{h}$, com demanda real & 0 & 39 & 37.5 & 36.5 & 35.5 & 72.3 & 2.8 & 3.3 & 3.3 & 71.3 \\
\hline Defasagens geradas pelo INTEGRATION com semáforo 8 como mestre, com demanda real & 70 & 66 & 67 & 0 & 1 & 71 & 71 & 0 & 71 & 71 \\
\hline Defasagens simultâneas, com demanda 15\% reduzida & 0 & 0 & 0 & 0 & 0 & 0 & 0 & 0 & 0 & 0 \\
\hline Defasagens da operação vigente, com demanda 15\% reduzida & 0 & 20 & 20 & 30 & 40 & 60 & 64 & 73 & 8 & 15 \\
\hline Defasagens geradas por Sband, para bandas iguais, a $50 \mathrm{~km} / \mathrm{h}$ e demanda $15 \%$ reduzida & 0 & 39 & 37.5 & 36.5 & 35.5 & 69 & 73.5 & 0 & 0 & 31 \\
\hline Defasagens geradas por Sband, para bandas iguais, a $55 \mathrm{~km} / \mathrm{h}$ e demanda $15 \%$ reduzida & 0 & 39 & 37.5 & 36.5 & 35.5 & 69 & 73.5 & 0 & 0 & 68 \\
\hline Defasagens geradas por Sband, para bandas diferentes, a $50 \mathrm{k}$ & 0 & 39 & 37.5 & 36.5 & 35.2 & 69 & 73.5 & 0 & 0 & 31 \\
\hline Defasagens geradas por Sband, para bandas diferentes, a $55 \mathrm{~km} / \mathrm{h}$ e demanda $15 \%$ reduzida & 0 & 39 & 37.5 & 36.5 & 35.2 & 69 & 73.5 & 0 & 0 & 68 \\
\hline Defasagens geradas em 2 etapas por Sband, bandas iguais, a $55 \mathrm{~km} / \mathrm{h}$ e demanda $15 \%$ reduzida & 0 & 39 & 37.5 & 36.5 & 35.5 & 72.3 & 2.8 & 3.3 & 3.3 & 71.3 \\
\hline Defasagens geradas pelo INTEGRATION com semáforo $8 \mathrm{me}$ & 24 & 39 & 44 & 68 & 2 & 6 & 0 & 0 & 0 & 6 \\
\hline Defasagens simultâneas, com demanda 25\% reduzida & 0 & 0 & 0 & 0 & 0 & 0 & 0 & 0 & 0 & 0 \\
\hline Defasagens da op & 0 & 20 & 20 & 30 & 40 & 60 & 64 & 73 & 8 & 15 \\
\hline Defasagens geradas por Sband, & 0 & 39 & 37.5 & 36.5 & 35.5 & 69 & 73.5 & 0 & 0 & 31 \\
\hline Defasagens geradas por Sband, & 0 & 39 & 37.5 & 36.5 & & 69 & 73.5 & 0 & 0 & 68 \\
\hline Defasagens geradas por Sband, para bandas diferentes, a $50 \mathrm{~km} / \mathrm{h}$ e demanda $25 \%$, & 0 & 39 & 37.5 & 36.5 & 35.2 & 69 & 73.5 & 0 & 0 & 31 \\
\hline Defasagens geradas por Sband, para bandas diferentes, a $55 \mathrm{~km} / \mathrm{h}$ e demanda $25 \%$ reduzida & 0 & 39 & 37.5 & 36.5 & 35.2 & 69 & 73.5 & 0 & 0 & 68 \\
\hline Defasagens geradas em 2 etapas por Sband, bandas ig & 0 & 39 & 37.5 & 36.5 & 35.5 & 72.3 & 2.8 & 3.3 & 3.3 & 71.3 \\
\hline Defasagens geradas pelo INTEGRATION com semáforo 8 mestre e demanda $25 \%$ reduzida & 19 & 37 & 33 & 53 & 56 & 64 & 0 & 0 & 0 & 2 \\
\hline Defasagens simultâneas, com demanda 35\% reduzida & 0 & 0 & 0 & 0 & 0 & 0 & 0 & 0 & 0 & 0 \\
\hline reduzida & 0 & 20 & 20 & 30 & 40 & 60 & 64 & 73 & 8 & 15 \\
\hline Defasagens geradas por Sband, $p$ & 0 & 39 & 37.5 & 36.5 & 35.5 & 69 & 73.5 & 0 & 0 & 31 \\
\hline Defasagens geradas por Sband, para bandas iguai & 0 & 39 & 37.5 & 36.5 & 35.5 & 69 & 73.5 & 0 & 0 & 68 \\
\hline Defasagens geradas por Sband, para bandas $\mathrm{d}$ & 0 & 39 & 37.5 & 36.5 & 35.2 & 69 & 73.5 & 0 & 0 & 31 \\
\hline & 0 & 39 & 37.5 & 36.5 & 35.2 & 69 & 73.5 & 0 & 0 & 68 \\
\hline Defasagens geradas em 2 etapas por Sband, bandas & 0 & 39 & 37.5 & 36.5 & 35.5 & 72.3 & 2.8 & 3.3 & 3.3 & 71.3 \\
\hline Defasagens geradas pelo INTEGRATION com semáforo 8 mestre & 46 & 66 & 65 & 70 & 6 & 0 & 70 & 0 & 4 & 70 \\
\hline Defasagens simultâneas, col & 0 & 0 & 0 & 0 & 0 & 0 & 0 & 0 & 0 & 0 \\
\hline Defa & 0 & 20 & 20 & 30 & 40 & 60 & 64 & 73 & 8 & 15 \\
\hline & 0 & 39 & 37.5 & 36.5 & 35.5 & 69 & 73.5 & 0 & 0 & 31 \\
\hline Defasag & 0 & 39 & 37.5 & 36.5 & 35.5 & 69 & 73.5 & 0 & 0 & 68 \\
\hline Defasagens geradas por Sband, $\mathrm{p}$ & 0 & 39 & 37.5 & 36.5 & 35.2 & 69 & 73.5 & 0 & 0 & 31 \\
\hline Defas & 0 & 39 & 37.5 & 36.5 & 35.2 & 69 & 73.5 & 0 & 0 & 68 \\
\hline Defasagens geradas em 2 etapas por Sband, bandas iguais, a $55 \mathrm{~km} / \mathrm{h}$ e demanda $45 \%$ reduzida & 0 & 39 & 37.5 & 36.5 & 35.5 & 72.3 & 2.8 & 3.3 & 3.3 & 71.3 \\
\hline Defasagens geradas pelo INTEGRATION com semáforo 8 mestre e demanda $45 \%$ reduzida & 26 & 39 & 38 & 54 & 52 & 52 & 4 & 0 & 1 & 67 \\
\hline Defasagens simultâneas, com demanda 55\% reduzida & 0 & 0 & 0 & 0 & 0 & 0 & 0 & 0 & 0 & 0 \\
\hline & 0 & 20 & 20 & & & 60 & 64 & 73 & & 15 \\
\hline Defas & 0 & 39 & 37.5 & 36.5 & 35.5 & 69 & 73.5 & 0 & 0 & 31 \\
\hline Defas & 0 & 39 & 37.5 & 36.5 & 35.5 & 69 & 73.5 & 0 & 0 & 68 \\
\hline & 0 & 39 & 37.5 & 36.5 & 35.2 & 69 & 73.5 & 0 & 0 & 31 \\
\hline & 0 & 39 & 37.5 & 36.5 & 35.2 & 69 & 73.5 & 0 & 0 & 68 \\
\hline Defasagens geradas em 2 etapas & 0 & 39 & 37.5 & 36.5 & 35.5 & 72.3 & 2.8 & 3.3 & 3.3 & 71.3 \\
\hline Defasagens geradas pelo INTEGRATION com semáforo 8 mestre e dem & 54 & 0 & 0 & & 3 & 3 & 2 & 0 & 0 & 3 \\
\hline Defasagens simultâneas, com demanda $65 \%$ reduzida & 0 & 0 & 0 & 0 & 0 & 0 & 0 & 0 & 0 & 0 \\
\hline & 0 & 20 & & & 40 & 60 & 64 & 73 & 8 & 15 \\
\hline & 0 & 39 & 37.5 & 36.5 & 35.5 & 69 & 73.5 & 0 & 0 & 31 \\
\hline Defasagens geradas por Sband, para bandas iguais, a $55 \mathrm{~km} / \mathrm{h}$ & 0 & 39 & 37.5 & 36.5 & 35.5 & 69 & 73.5 & 0 & 0 & 68 \\
\hline Defasagens geradas $p$ & 0 & 39 & 37.5 & 36.5 & 35.2 & 69 & 73.5 & 0 & 0 & 31 \\
\hline & 0 & 39 & 37.5 & 36.5 & 35.2 & 69 & 73.5 & 0 & 0 & 68 \\
\hline Defasagens geradas em 2 etapas por Sband, bandas ig & 0 & 39 & 37.5 & 36.5 & 35.5 & 72.3 & 2.8 & 3.3 & 3.3 & 71.3 \\
\hline Defasagens geradas pelo INTEGRATION com semáforo 8 mes & 50 & 66 & 71 & 64 & 1 & 66 & 0 & 0 & 9 & 0 \\
\hline Defasagens simultâneas, com demanda 75\% reduzida & 0 & 0 & 0 & 0 & 0 & 0 & 0 & 0 & 0 & 0 \\
\hline & & 20 & & & & 60 & & 73 & & \\
\hline Defasagens geradas por Sband, para bandas iguais, a $50 \mathrm{~km} / \mathrm{h}$ e deman & 0 & 39 & 37.5 & 36.5 & 35.5 & 69 & 73.5 & 0 & 0 & 31 \\
\hline & 0 & 39 & 37.5 & 36.5 & 35.5 & 69 & 73.5 & 0 & 0 & 68 \\
\hline 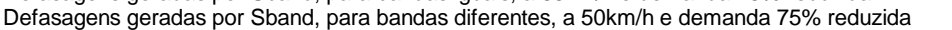 & 0 & 39 & 37.5 & 36.5 & 35.2 & 69 & 73.5 & 0 & 0 & 31 \\
\hline Defasagens geradas por Sband, para bandas diferentes, & 0 & 39 & 37.5 & 36.5 & 35.2 & 69 & 73.5 & 0 & 0 & 68 \\
\hline ns geradas em 2 etapas por Sband, ban & 0 & 39 & 37.5 & 36.5 & 35.5 & 72.3 & 2.8 & 3.3 & 3.3 & 71.3 \\
\hline Defasagens geradas pelo INTEGRATION com semáforo $8 \mathrm{~m}$ & 32 & 42 & 49 & 58 & 71 & 73 & 0 & 0 & 72 & 0 \\
\hline Defasagens simultâneas, com demanda 85\% reduzida & 0 & 0 & 0 & 0 & 0 & 0 & 0 & 0 & 0 & 0 \\
\hline & & 20 & & & & 60 & 64 & 73 & & \\
\hline Defasagens geradas por Sband, para bandas iguais, a $50 \mathrm{~km} / \mathrm{h}$ e demanc & 0 & 39 & 37.5 & 36.5 & 35.5 & 69 & 73.5 & 0 & 0 & 31 \\
\hline & 0 & 39 & & & 35.5 & 69 & 73.5 & 0 & 0 & \\
\hline Defasagens geradas por Sband, para bandas diferentes, a $50 \mathrm{~km} / \mathrm{h}$ e demanda $85 \%$ reduzida & 0 & 39 & 37.5 & 36.5 & 35.2 & 69 & 73.5 & 0 & 0 & 31 \\
\hline Defasagens geradas por Sband, para bandas diferentes, a $55 \mathrm{~km} / \mathrm{h}$ e demanda $85 \%$ reduzida & 0 & 39 & 37.5 & 36.5 & 35.2 & 69 & 73.5 & 0 & 0 & 68 \\
\hline Defasagens geradas em 2 etapas por Sband, banda & 0 & 39 & 37.5 & 36.5 & 35.5 & 72.3 & 2.8 & 3.3 & 3.3 & 71.3 \\
\hline Defasagens geradas pelo INTEGRATION com ser & 42 & 61 & 51 & 46 & 56 & 62 & 67 & 0 & 71 & 67 \\
\hline
\end{tabular}




\subsubsection{Avenida Maringá}

- Cenário 1 - coordenado através de progressão simultânea: todos os tempos de verde da via principal abrem simultaneamente, gerando apenas trechos de bandas a cada par de semáforos, com larguras que variam entre 18 e 40 segundos, conforme esquematizado na Figura 6-26, supondo que a velocidade de progressão na Avenida Maringá seja de $40 \mathrm{~km} / \mathrm{h}$.

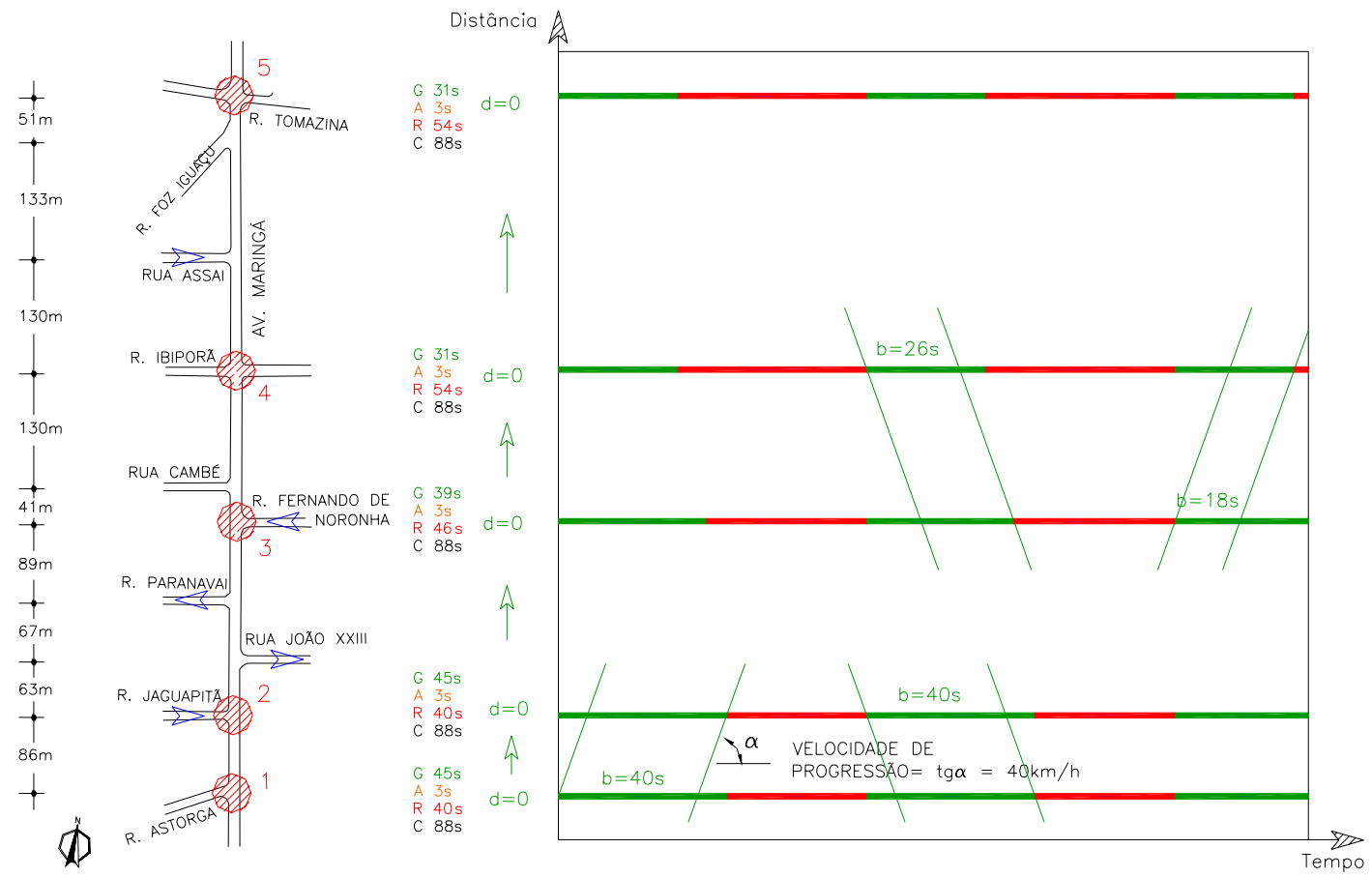

Figura 6-26: Diagrama Espaço-Tempo simultâneo da Avenida Maringá

- Cenário 2 - operação vigente: o diagrama Espaço-Tempo da Avenida Maringá foi elaborado a fim possibilitar a identificação da progressão em onda-verde em cada um dos sentidos da via. Somente o sentido Norte-Sul apresenta banda contínua ao longo dos cinco cruzamentos semaforizados, com largura máxima de 21 segundos considerando-se velocidade de progressão de $40 \mathrm{~km} / \mathrm{h}$, conforme demonstrado na Figura 6-27. O sentido Sul-Norte apresenta bandas interrompidas com larguras máximas de 40 e 5,5 segundos, que ocasionam paradas nos semáforos 3 e 5 .

- Cenários 3 e 4 - coordenados através do programa SBAND para bandas iguais: duas opções de coordenação foram testadas, considerando a velocidade de progressão de 35 e de $40 \mathrm{~km} / \mathrm{h}$, gerando soluções com bandas iguais em ambos os sentidos com larguras de 20,4 e 16,4 segundos respectivamente. A Figura 6-28 ilustra as defasagens e os diagramas obtidos através do programa SBAND, com bandas iguais para os cinco semáforos ao longo da Avenida Maringá. 


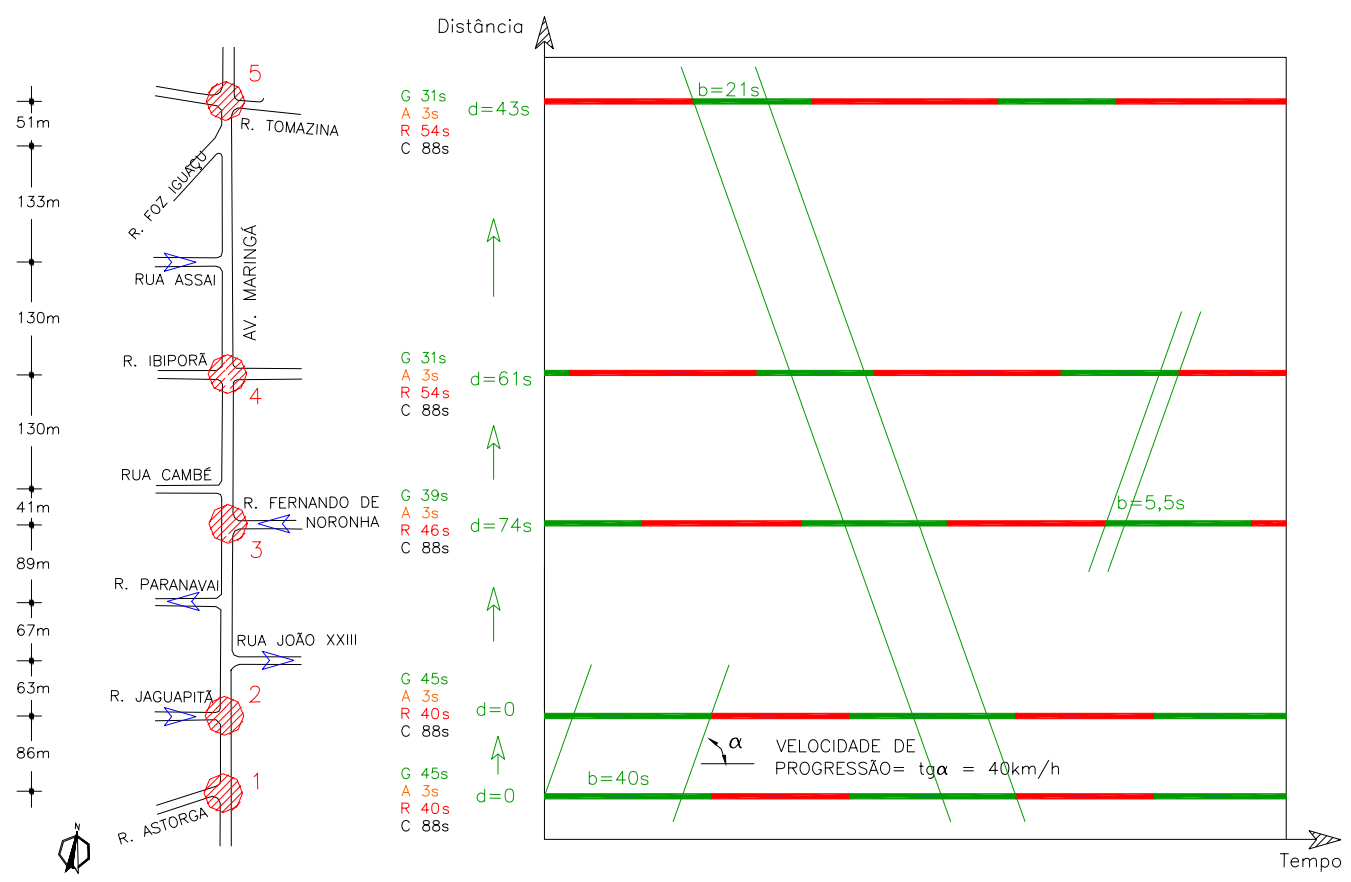

Figura 6-27: Diagrama Espaço-Tempo vigente da Avenida Maringá

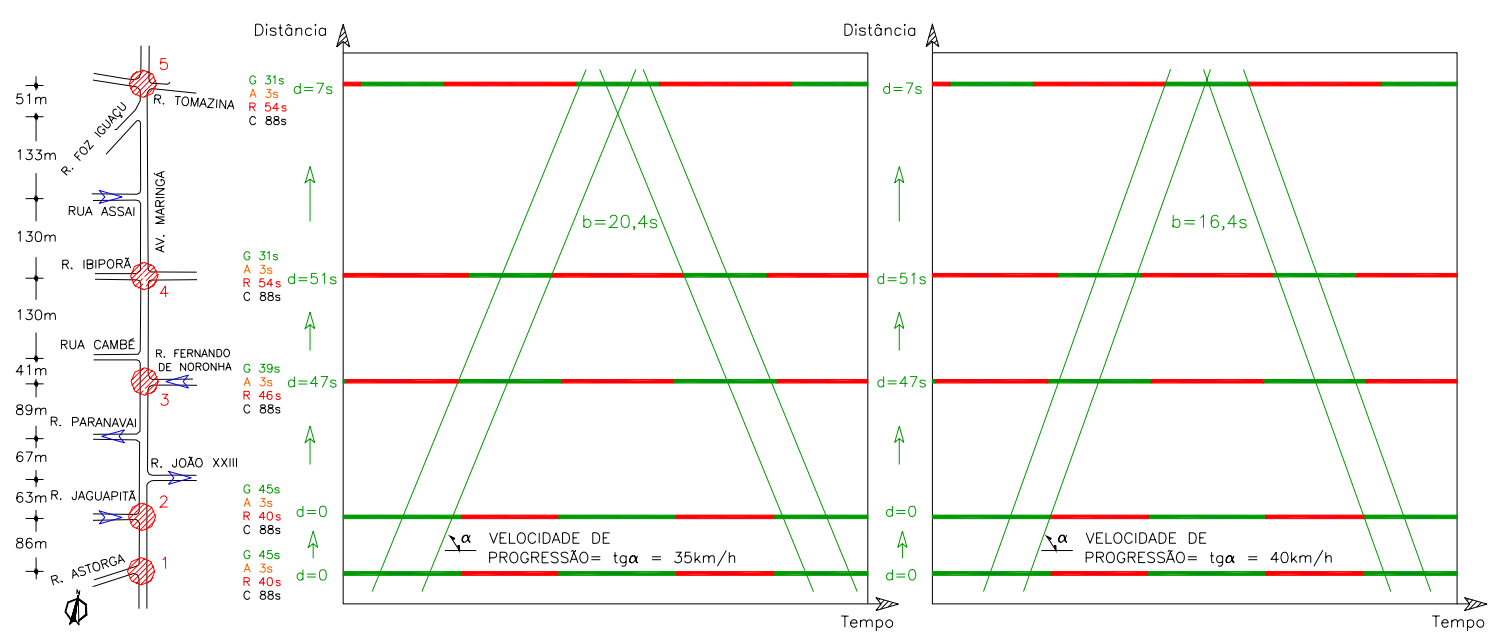

Figura 6-28: Diagramas Espaço-Tempo gerados pelo SBAND com bandas iguais para a Avenida Maringá

- Cenários 5 e 6 - coordenações geradas pelo SBAND para bandas diferentes: duas opções de coordenação geradas pelo programa SBAND foram testadas, considerando a velocidade de progressão de 35 e $40 \mathrm{~km} / \mathrm{h}$, gerando soluções com bandas diferentes nos dois sentidos, com intuito de priorizar em $5 \%$ a banda no sentido Sul-Norte, em função de seu volume médio ser 5\% maior que o volume médio do sentido Norte-Sul. As defasagens e os diagramas Espaço-Tempo gerados pelo programa SBAND com bandas diferentes na Avenida Maringá estão representados na Figura 6-29. 


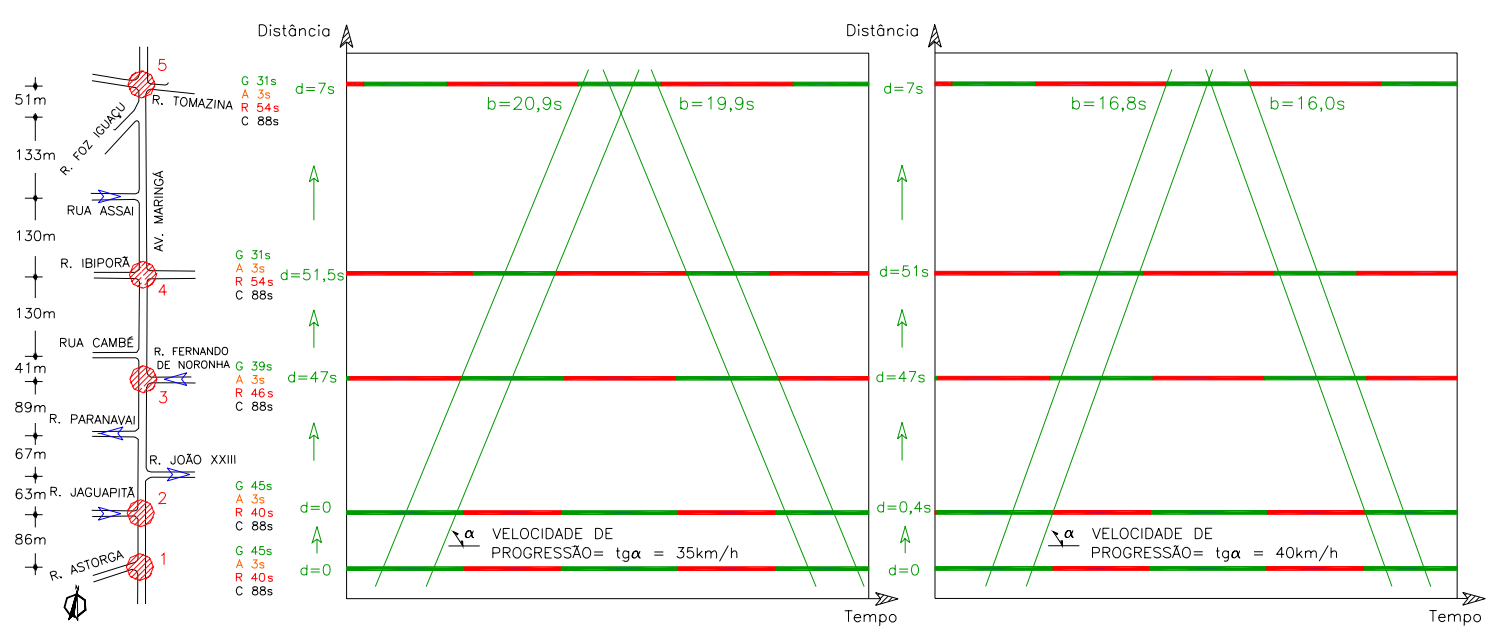

Figura 6-29: Diagramas Espaço-Tempo gerados pelo SBAND com bandas diferentes para a Avenida Maringá

- Cenário 7 - coordenação gerada pelo programa SBAND em duas etapas: opção de coordenação com velocidade de progressão de $40 \mathrm{~km} / \mathrm{h}$ para bandas iguais nos dois sentidos, porém obtidas separadamente para os 3 primeiros semáforos e para os 2 últimos semáforos. A Figura 6-30 apresenta as defasagens e os diagramas EspaçoTempo gerados pelo programa SBAND para a Avenida Maringá, sendo que os diagramas obtidos em duas etapas para a velocidade de $40 \mathrm{~km} / \mathrm{h}$ foram defasados entre si em 43 segundos na tentativa de acomodar a continuidade das bandas em cada etapa, considerando o espaçamento de 171 metros entre os semáforos 3 e 4 .

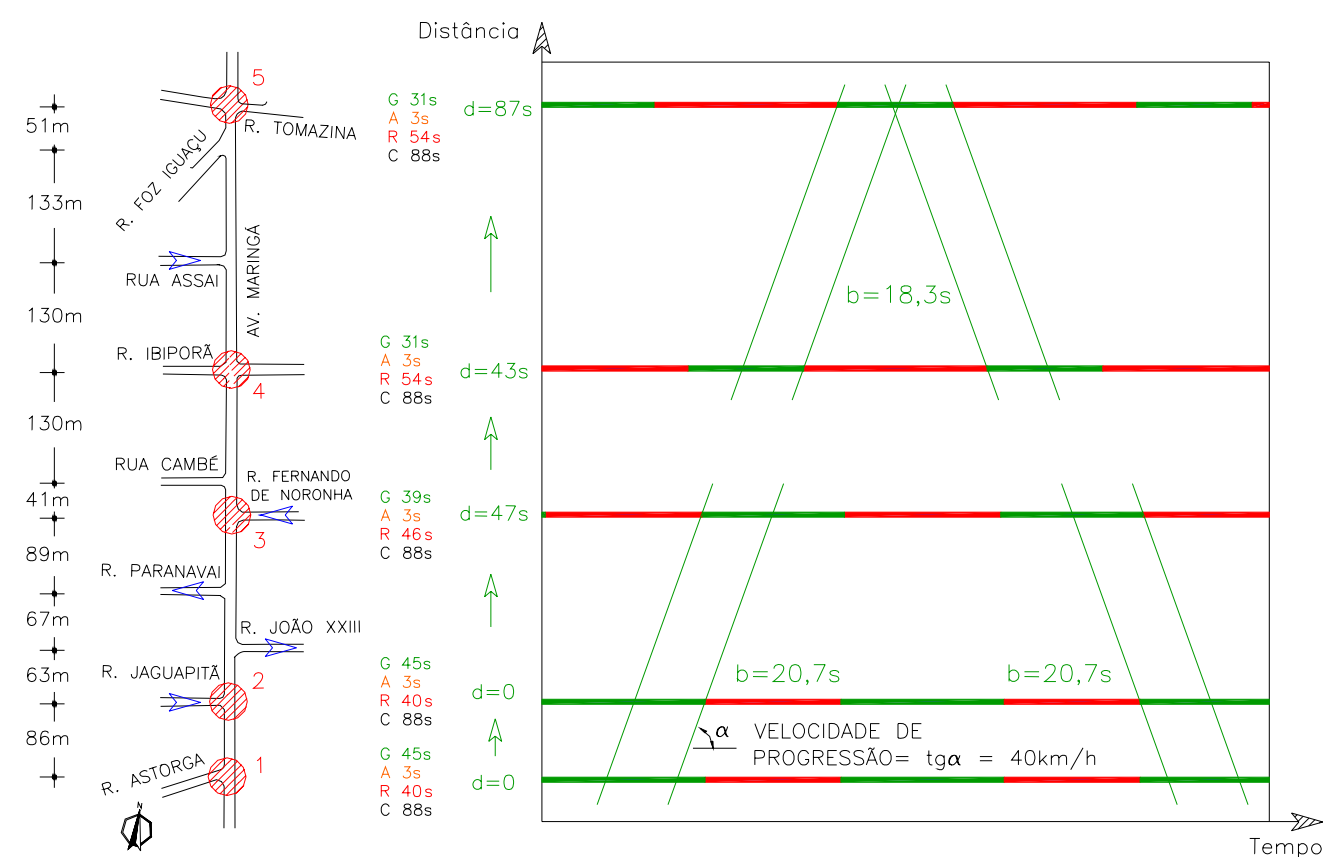

Figura 6-30: Diagramas Espaço-Tempo gerados pelo SBAND em duas etapas para a Avenida Maringá 
- Cenário 8 - coordenado através do INTEGRATION: a opção de coordenação existente na rotina do simulador INTEGRATION foi utilizada para gerar as defasagens ótimas, mas sem permitir que o programa otimizasse o ciclo ou as fases. As bandas obtidas estão representadas no Diagrama Espaço-Tempo da Figura 6-31, gerando trechos de bandas com larguras que variam de 15 a 20 segundos.
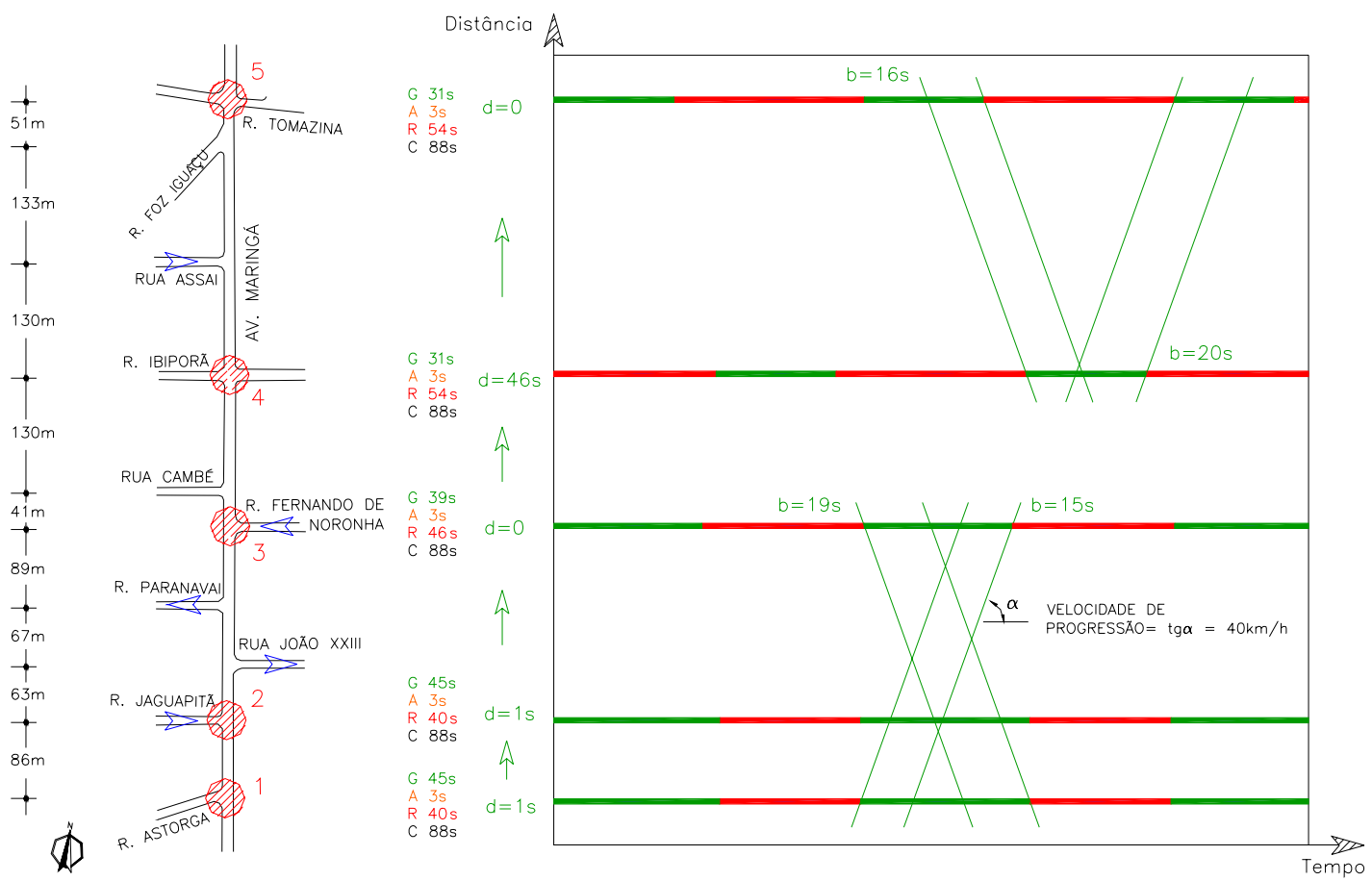

Figura 6-31: Diagrama Espaço-Tempo gerados pelo INTEGRATION para a Avenida Maringá

Estes oito diferentes cenários foram também avaliados para demandas menores do que a demanda real, reduzindo de 15 a $85 \%$ nos valores dos pares origem-destino, totalizando 72 cenários avaliados, conforme esquematizado na Tabela 6-11.

\subsubsection{Rede da Cidade de São Carlos}

- Cenário 1 - coordenado através de progressão simultânea: supondo que todos os tempos de verde nos três corredores principais da rede de São Carlos abram simultaneamente, e que a velocidade de progressão seja de $40 \mathrm{~km} / \mathrm{h}$ na Rua D. Alexandrina e $50 \mathrm{~km} / \mathrm{h}$ na Avenida São Carlos e na Rua Episcopal, conforme regulamentação máxima existente nas vias, os diagramas Espaço-Tempo demonstram que não há formação de bandas contínuas ao longo de nenhum dos corredores, conforme ilustra a Figura 6-32. 
Tabela 6-11: Cenários simulados para a Avenida Maringá

\begin{tabular}{|c|c|c|c|c|c|}
\hline \multirow{2}{*}{ Cenários da Avenida Maringá } & \multicolumn{5}{|c|}{ Defasagens entre semáforos (segundos) } \\
\hline & 1 & 2 & 3 & 4 & 5 \\
\hline Defasagens simultâneas, com demanda real & 0 & 0 & 0 & 0 & 0 \\
\hline Defasagens da operação vigente, com demanda real & 0 & 0 & 74 & 61 & 43 \\
\hline Defasagens geradas por Sband, para bandas iguais, a $35 \mathrm{~km} / \mathrm{h}$, com demanda real & 0 & 0 & 47 & 51 & 7 \\
\hline Defasagens geradas por Sband, para bandas iguais, a $40 \mathrm{~km} / \mathrm{h}$, com demanda real & 0 & 0 & 47 & 51 & 7 \\
\hline Defasagens geradas por Sband, para bandas diferentes, a $35 \mathrm{~km} / \mathrm{h}$, com demanda real & 0 & 0 & 47 & 51.5 & 7 \\
\hline Defasagens geradas por Sband, para bandas diferentes, a $40 \mathrm{~km} / \mathrm{h}$, com demanda real & 0 & 0.4 & 47 & 51 & 7 \\
\hline Defasagens geradas em 2 etapas por Sband, bandas iguais, a 40km/h, com demanda real & 0 & 0 & 47 & 43 & 87 \\
\hline Defasagens geradas pelo INTEGRATION com semáforo 5 como mestre, com demanda real & 1 & 1 & 0 & 46 & 0 \\
\hline Defasagens simultâneas, com demanda 15\% reduzida & 0 & 0 & 0 & 0 & 0 \\
\hline Defasagens da operação vigente, com demanda 15\% reduzida & 0 & 0 & 74 & 61 & 43 \\
\hline Defasagens geradas por Sband, para bandas iguais, a $35 \mathrm{~km} / \mathrm{h}$, com demanda $15 \%$ reduzida & 0 & 0 & 47 & 51 & 7 \\
\hline Defasagens geradas por Sband, para bandas iguais, a $40 \mathrm{~km} / \mathrm{h}$, com demanda $15 \%$ reduzida & 0 & 0 & 47 & 51 & 7 \\
\hline Defasagens geradas por Sband, para bandas diferentes, a $35 \mathrm{~km} / \mathrm{h}$, com demanda $15 \%$ reduzida & 0 & 0 & 47 & 51.5 & 7 \\
\hline Defasagens geradas por Sband, para bandas diferentes, a $40 \mathrm{~km} / \mathrm{h}$, com demanda $15 \%$ reduzida & 0 & 0.4 & 47 & 51 & 7 \\
\hline Defasagens geradas em 2 etapas por Sband, bandas iguais, a $40 \mathrm{~km} / \mathrm{h}$, com demanda $15 \%$ reduzida & 0 & 0 & 47 & 43 & 87 \\
\hline Defasagens geradas pelo INTEGRATION com semáforo 5 como mestre, com demanda $15 \%$ reduzida & 82 & 73 & 70 & 48 & 0 \\
\hline Defasagens simultâneas, com demanda 25\% reduzida & 0 & 0 & 0 & 0 & 0 \\
\hline Defasagens da operação vigente, com demanda $25 \%$ reduzida & 0 & 0 & 74 & 61 & 43 \\
\hline Defasagens geradas por Sband, para bandas iguais, a $35 \mathrm{~km} / \mathrm{h}$, com demanda $25 \%$ reduzida & 0 & 0 & 47 & 51 & 7 \\
\hline Defasagens geradas por Sband, para bandas iguais, a $40 \mathrm{~km} / \mathrm{h}$, com demanda $25 \%$ reduzida & 0 & 0 & 47 & 51 & 7 \\
\hline Defasagens geradas por Sband, para bandas diferentes, a $35 \mathrm{~km} / \mathrm{h}$, com demanda $25 \%$ reduzida & 0 & 0 & 47 & 51.5 & 7 \\
\hline Defasagens geradas por Sband, para bandas diferentes, a $40 \mathrm{~km} / \mathrm{h}$, com demanda $25 \%$ reduzida & 0 & 0.4 & 47 & 51 & 7 \\
\hline Defasagens geradas em 2 etapas por Sband, bandas iguais, a $40 \mathrm{~km} / \mathrm{h}$, com demanda $25 \%$ reduzida & 0 & 0 & 47 & 43 & 87 \\
\hline Defasagens geradas pelo INTEGRATION com semáforo 5 como mestre, com demanda $25 \%$ reduzida & 2 & 85 & 11 & 34 & 0 \\
\hline Defasagens simultâneas, com demanda 35\% reduzida & 0 & 0 & 0 & 0 & 0 \\
\hline Defasagens da operação vigente, com demanda $35 \%$ reduzida & 0 & 0 & 74 & 61 & 43 \\
\hline Defasagens geradas por Sband, para bandas iguais, a $35 \mathrm{~km} / \mathrm{h}$, com demanda $35 \%$ reduzida & 0 & 0 & 47 & 51 & 7 \\
\hline Defasagens geradas por Sband, para bandas iguais, a $40 \mathrm{~km} / \mathrm{h}$, com demanda $35 \%$ reduzida & 0 & 0 & 47 & 51 & 7 \\
\hline Defasagens geradas por Sband, para bandas diferentes, a $35 \mathrm{~km} / \mathrm{h}$, com demanda $35 \%$ reduzida & 0 & 0 & 47 & 51.5 & 7 \\
\hline Defasagens geradas por Sband, para bandas diferentes, a $40 \mathrm{~km} / \mathrm{h}$, com demanda $35 \%$ reduzida & 0 & 0.4 & 47 & 51 & 7 \\
\hline Defasagens geradas em 2 etapas por Sband, bandas iguais, a $40 \mathrm{~km} / \mathrm{h}$, com demanda $35 \%$ reduzida & 0 & 0 & 47 & 43 & 87 \\
\hline Defasagens geradas pelo INTEGRATION com semáforo 5 como mestre, com demanda $35 \%$ reduzida & 84 & 79 & 1 & 58 & 0 \\
\hline Defasagens simultâneas, com demanda 45\% reduzida & 0 & 0 & 0 & 0 & 0 \\
\hline Defasagens da operação vigente, com demanda $45 \%$ reduzida & 0 & 0 & 74 & 61 & 43 \\
\hline Defasagens geradas por Sband, para bandas iguais, a $35 \mathrm{~km} / \mathrm{h}$, com demanda $45 \%$ reduzida & 0 & 0 & 47 & 51 & 7 \\
\hline Defasagens geradas por Sband, para bandas iguais, a 40km $/ \mathrm{h}$, com demanda $45 \%$ reduzida & 0 & 0 & 47 & 51 & 7 \\
\hline Defasagens geradas por Sband, para bandas diferentes, a $35 \mathrm{~km} / \mathrm{h}$, com demanda $45 \%$ reduzida & 0 & 0 & 47 & 51.5 & 7 \\
\hline Defasagens geradas por Sband, para bandas diferentes, a $40 \mathrm{~km} / \mathrm{h}$, com demanda $45 \%$ reduzida & 0 & 0.4 & 47 & 51 & 7 \\
\hline Defasagens geradas em 2 etapas por Sband, bandas iguais, a $40 \mathrm{~km} / \mathrm{h}$, com demanda $45 \%$ reduzida & 0 & 0 & 47 & 43 & 87 \\
\hline Defasagens geradas pelo INTEGRATION com semáforo 5 como mestre, com demanda $45 \%$ reduzida & 73 & 69 & 44 & 41 & 0 \\
\hline Defasagens simultâneas, com demanda 55\% reduzida & 0 & 0 & 0 & 0 & 0 \\
\hline Defasagens da operação vigente, com demanda $55 \%$ reduzida & 0 & 0 & 74 & 61 & 43 \\
\hline Defasagens geradas por Sband, para bandas iguais, a $35 \mathrm{~km} / \mathrm{h}$, com demanda $55 \%$ reduzida & 0 & 0 & 47 & 51 & 7 \\
\hline Defasagens geradas por Sband, para bandas iguais, a $40 \mathrm{~km} / \mathrm{h}$, com demanda $55 \%$ reduzida & 0 & 0 & 47 & 51 & 7 \\
\hline Defasagens geradas por Sband, para bandas diferentes, a $35 \mathrm{~km} / \mathrm{h}$, com demanda $55 \%$ reduzida & 0 & 0 & 47 & 51.5 & 7 \\
\hline Defasagens geradas por Sband, para bandas diferentes, a $40 \mathrm{~km} / \mathrm{h}$, com demanda $55 \%$ reduzida & 0 & 0.4 & 47 & 51 & 7 \\
\hline Defasagens geradas em 2 etapas por Sband, bandas iguais, a $40 \mathrm{~km} / \mathrm{h}$, com demanda $55 \%$ reduzida & 0 & 0 & 47 & 43 & 87 \\
\hline Defasagens geradas pelo INTEGRATION com semáforo 5 como mestre, com demanda $55 \%$ reduzida & 73 & 70 & 85 & 33 & 0 \\
\hline Defasagens simultâneas, com demanda 65\% reduzida & 0 & 0 & 0 & 0 & 0 \\
\hline Defasagens da operação vigente, com demanda $65 \%$ reduzida & 0 & 0 & 74 & 61 & 43 \\
\hline Defasagens geradas por Sband, para bandas iguais, a $35 \mathrm{~km} / \mathrm{h}$, com demanda $65 \%$ reduzida & 0 & 0 & 47 & 51 & 7 \\
\hline Defasagens geradas por Sband, para bandas iguais, a $40 \mathrm{~km} / \mathrm{h}$, com demanda $65 \%$ reduzida & 0 & 0 & 47 & 51 & 7 \\
\hline Defasagens geradas por Sband, para bandas diferentes, a $35 \mathrm{~km} / \mathrm{h}$, com demanda $65 \%$ reduzida & 0 & 0 & 47 & 51.5 & 7 \\
\hline Defasagens geradas por Sband, para bandas diferentes, a $40 \mathrm{~km} / \mathrm{h}$, com demanda $65 \%$ reduzida & 0 & 0.4 & 47 & 51 & 7 \\
\hline Defasagens geradas em 2 etapas por Sband, bandas iguais, a $40 \mathrm{~km} / \mathrm{h}$, com demanda $65 \%$ reduzida & 0 & 0 & 47 & 43 & 87 \\
\hline Defasagens geradas pelo INTEGRATION com semáforo 5 como mestre, com demanda $65 \%$ reduzida & 79 & 79 & 58 & 61 & 0 \\
\hline Defasagens simultâneas, com demanda 75\% reduzida & 0 & 0 & 0 & 0 & 0 \\
\hline Defasagens da operação vigente, com demanda $75 \%$ reduzida & 0 & 0 & 74 & 61 & 43 \\
\hline Defasagens geradas por Sband, para bandas iguais, a $35 \mathrm{~km} / \mathrm{h}$, com demanda $75 \%$ reduzida & 0 & 0 & 47 & 51 & 7 \\
\hline Defasagens geradas por Sband, para bandas iguais, a $40 \mathrm{~km} / \mathrm{h}$, com demanda $75 \%$ reduzida & 0 & 0 & 47 & 51 & 7 \\
\hline Defasagens geradas por Sband, para bandas diferentes, a $35 \mathrm{~km} / \mathrm{h}$, com demanda $75 \%$ reduzida & 0 & 0 & 47 & 51.5 & 7 \\
\hline Defasagens geradas por Sband, para bandas diferentes, a $40 \mathrm{~km} / \mathrm{h}$, com demanda $75 \%$ reduzida & 0 & 0.4 & 47 & 51 & 7 \\
\hline Defasagens geradas em 2 etapas por Sband, bandas iguais, a $40 \mathrm{~km} / \mathrm{h}$, com demanda $75 \%$ reduzida & 0 & 0 & 47 & 43 & 87 \\
\hline Defasagens geradas pelo INTEGRATION com semáforo 5 como mestre, com demanda $75 \%$ reduzida & 58 & 50 & 13 & 34 & 0 \\
\hline Defasagens simultâneas, com demanda 85\% reduzida & 0 & 0 & 0 & 0 & 0 \\
\hline Defasagens da operação vigente, com demanda $85 \%$ reduzida & 0 & 0 & 74 & 61 & 43 \\
\hline Defasagens geradas por Sband, para bandas iguais, a $35 \mathrm{~km} / \mathrm{h}$, com demanda $85 \%$ reduzida & 0 & 0 & 47 & 51 & 7 \\
\hline Defasagens geradas por Sband, para bandas iguais, a $40 \mathrm{~km} / \mathrm{h}$, com demanda $85 \%$ reduzida & 0 & 0 & 47 & 51 & 7 \\
\hline Defasagens geradas por Sband, para bandas diferentes, a $35 \mathrm{~km} / \mathrm{h}$, com demanda $85 \%$ reduzida & 0 & 0 & 47 & 51.5 & 7 \\
\hline Defasagens geradas por Sband, para bandas diferentes, a $40 \mathrm{~km} / \mathrm{h}$, com demanda $85 \%$ reduzida & 0 & 0.4 & 47 & 51 & 7 \\
\hline Defasagens geradas em 2 etapas por Sband, bandas iguais, a $40 \mathrm{~km} / \mathrm{h}$, com demanda $85 \%$ reduzida & 0 & 0 & 47 & 43 & 87 \\
\hline Defasagens geradas pelo INTEGRATION com semáforo 5 como mestre, com demanda $85 \%$ reduzid & 0 & 1 & 46 & 61 & 0 \\
\hline
\end{tabular}




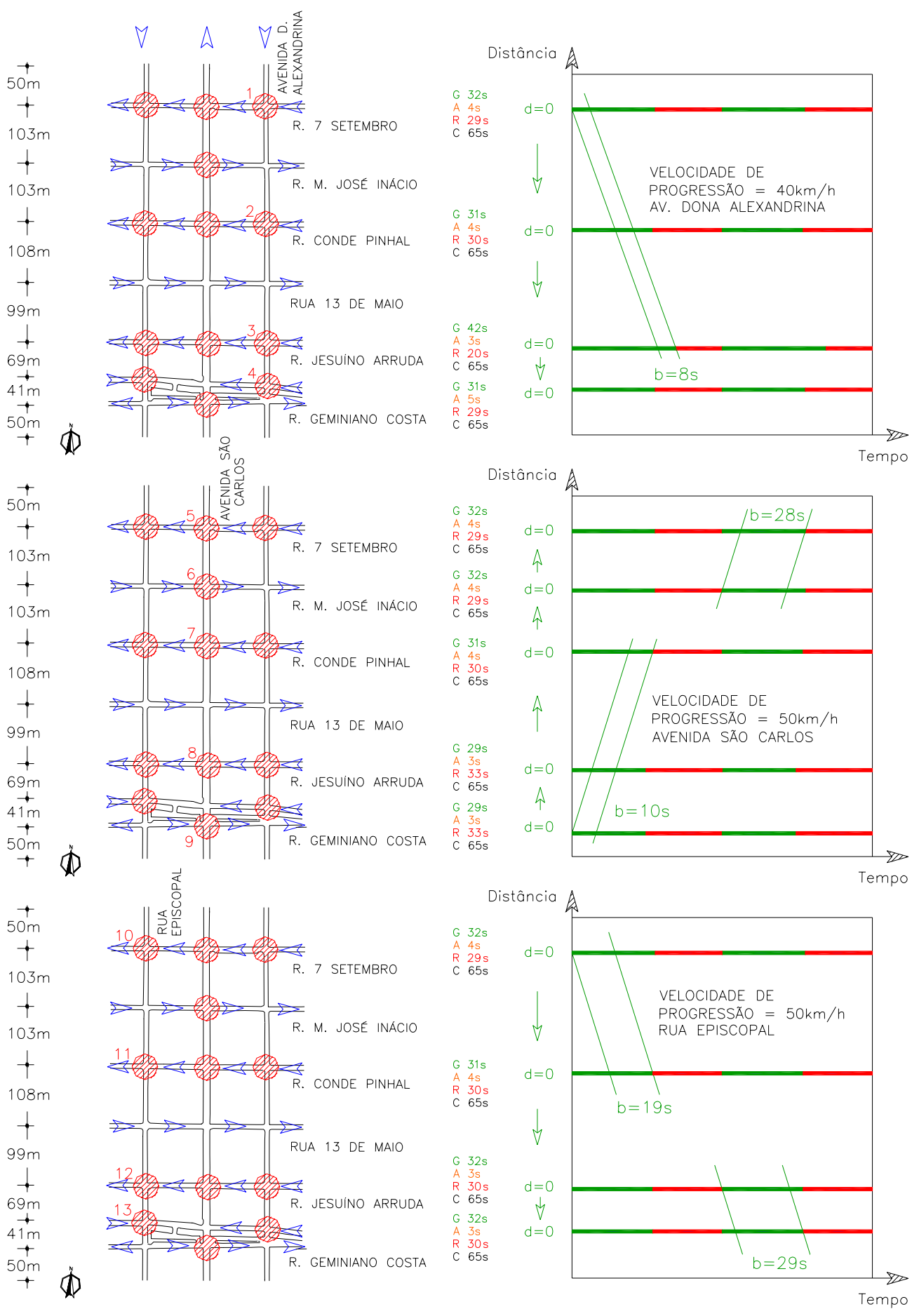

Figura 6-32: Diagramas Espaço-Tempo simultâneos da rede de São Carlos

- Cenário 2 - operação vigente: os diagramas Espaço-Tempo da Figura 6-33 ilustram os trechos de bandas formados pela operação semafórica vigente nos três corredores da rede de São Carlos, onde praticamente inexiste coordenação, considerando também como velocidade de progressão aquela máxima regulamentada em cada via. 


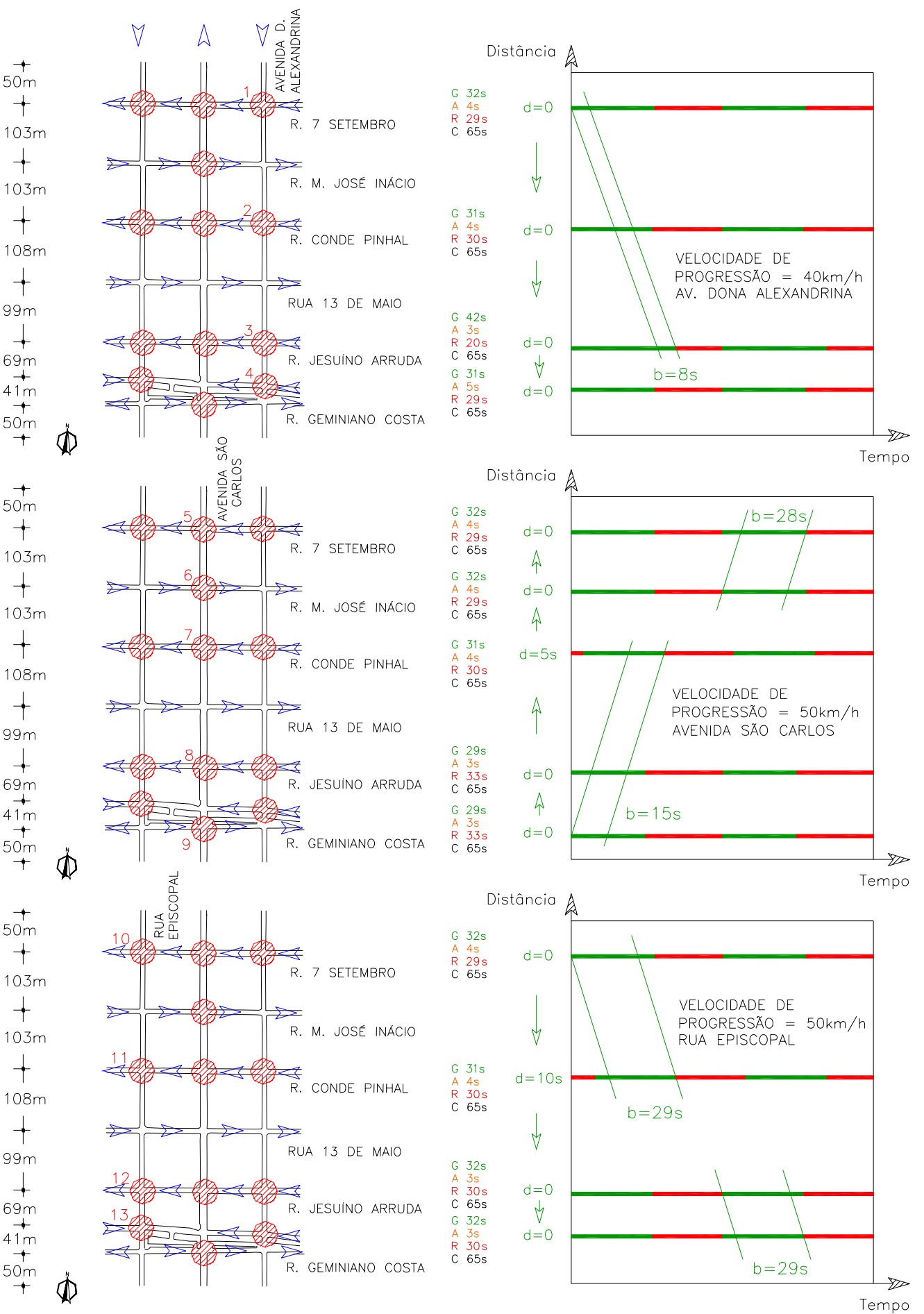

Figura 6-33: Diagramas Espaço-Tempo vigentes da rede de São Carlos

- Cenários 3 - coordenações geradas pelo programa SBAND, considerando como velocidades de progressão aquelas regulamentadas nas vias: as defasagens e os diagramas Espaço-Tempo obtidos estão representados na Figura 6-34, gerando soluções com bandas de larguras iguais ao menor tempo de verde em cada corredor. 


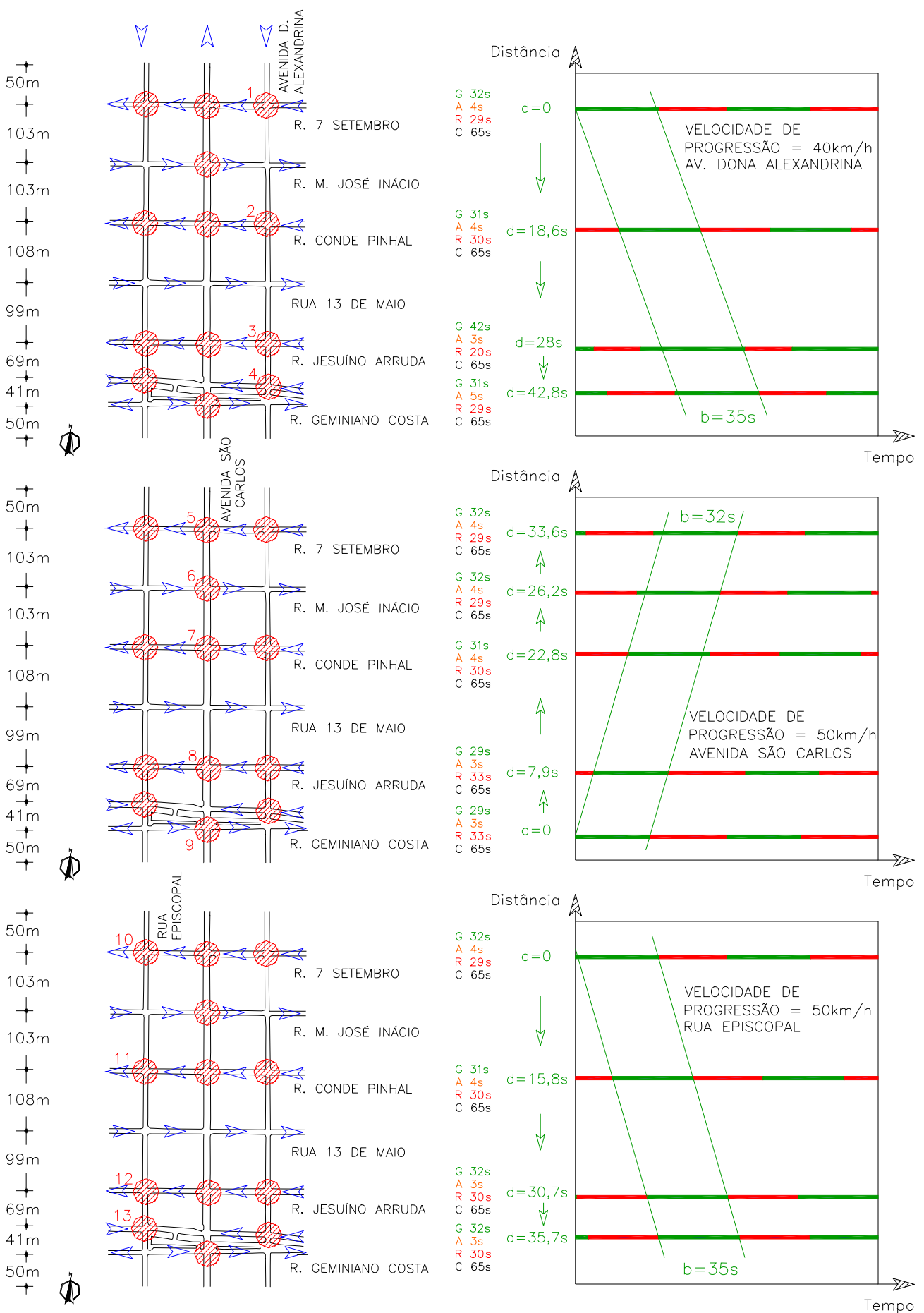

Figura 6-34: Diagramas Espaço-Tempo gerados pelo SBAND para a rede de São Carlos, com velocidades de 40-50-50 km/h

- Cenário 4 - coordenações geradas pelo programa SBAND, com velocidades de progressão $10 \mathrm{~km} / \mathrm{h}$ mais baixas do que aquelas regulamentadas nas vias: a Figura 6-35 ilustra as defasagens e os diagramas Espaço-Tempo gerados pelo SBAND, que também resultam em soluções com bandas de larguras iguais ao menor tempo 
de verde em cada corredor.

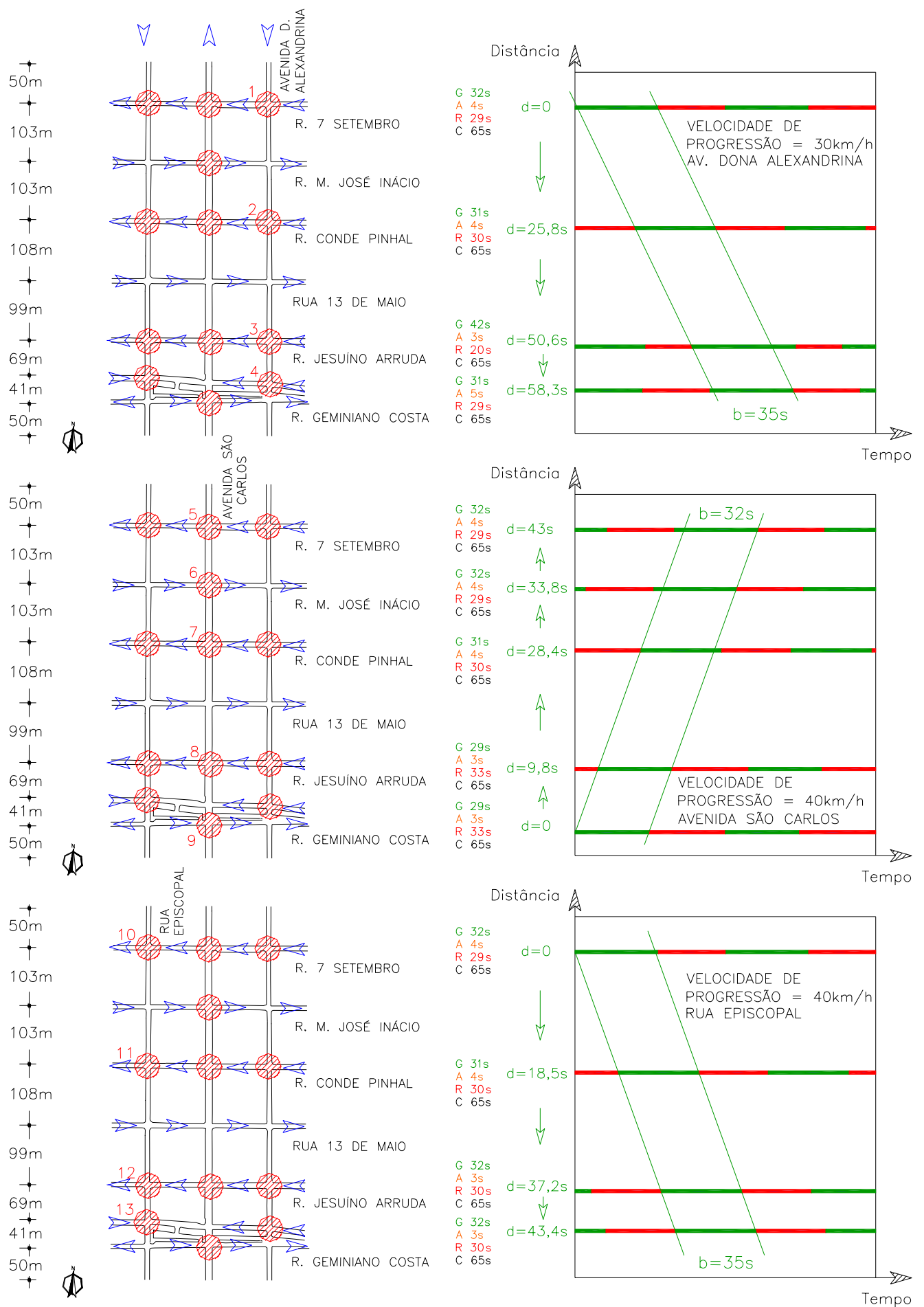

Figura 6-35: Diagramas Espaço-Tempo gerados pelo SBAND para a rede de São Carlos, com velocidades de 30-40-40 km/h

- Cenário 5 - coordenado através do INTEGRATION: a opção de coordenação existente na rotina do simulador INTEGRATION foi utilizada para gerar as 
defasagens ótimas, mas sem otimização do ciclo ou das fases. A Figura 6-36 apresenta as defasagens obtidas e as bandas formadas em cada um dos três corredores da rede de São Carlos.

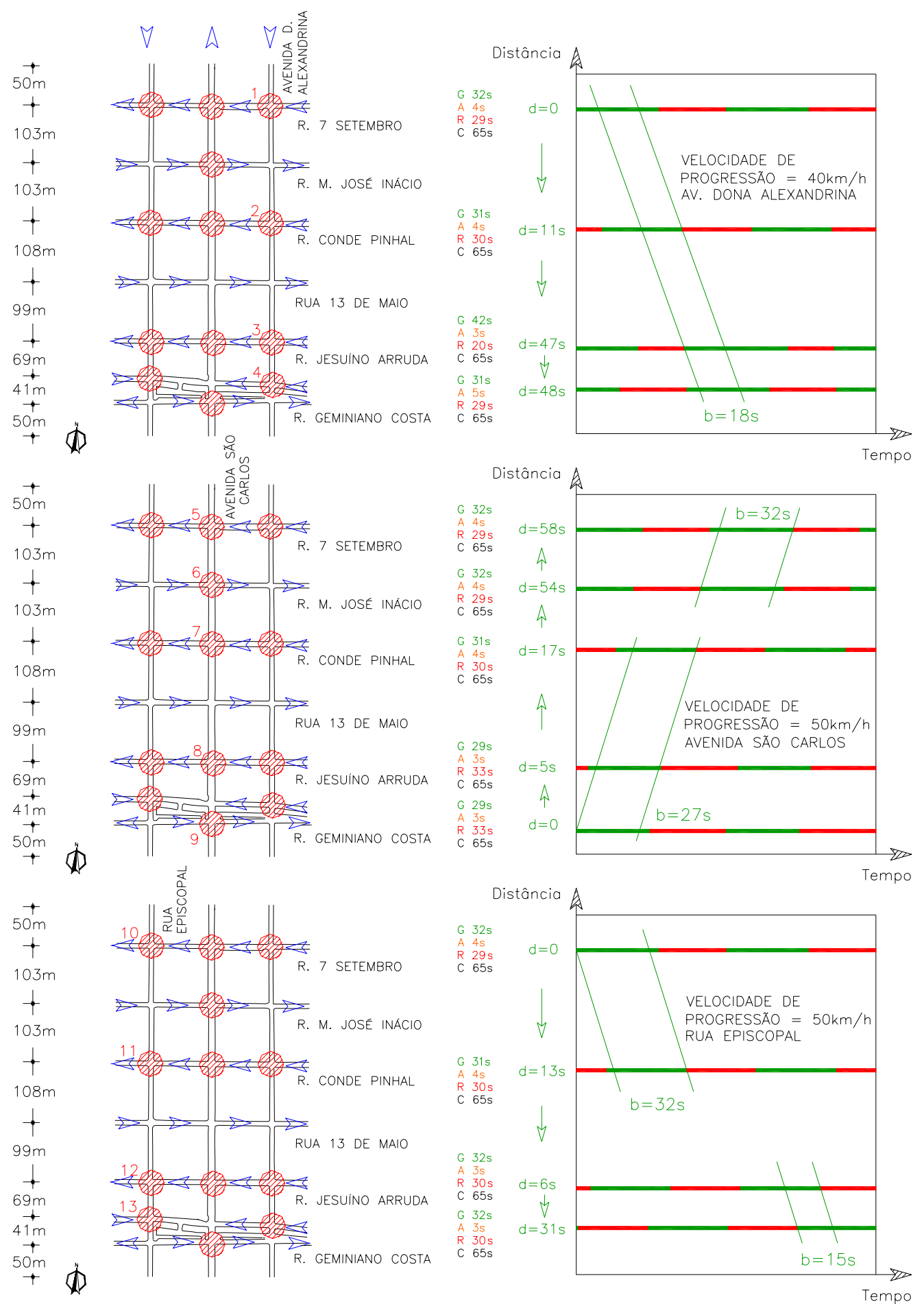

Figura 6-36: Diagramas Espaço-Tempo gerados pelo INTEGRATION para a rede de São Carlos

A Tabela 6-12 apresenta o resumo dos cinco cenários avaliados para a rede da 
cidade de São Carlos, com as respectivas defasagens em cada um dos três corredores:

Tabela 6-12: Cenários simulados para a rede de São Carlos

\begin{tabular}{lccccccccccccc}
\hline \multicolumn{1}{c}{ Cenários da rede de São Carlos } & \multicolumn{1}{c}{ Defasagens entre semáforos (segundos) } \\
& 1 & 2 & 3 & 4 & 5 & 6 & 7 & 8 & 9 & 10 & 11 & 12 & 13 \\
\hline Defasagens simultâneas & 0 & 0 & 0 & 0 & 0 & 0 & 0 & 0 & 0 & 0 & 0 & 0 & 0 \\
Defasagens da operação vigente & 0 & 0 & 0 & 0 & 0 & 0 & 5 & 0 & 0 & 0 & 10 & 0 & 0 \\
$\begin{array}{l}\text { Defasagens geradas pelo método Sband, com } \\
\quad \text { velocidades vigentes (40-50-50km/h) }\end{array}$ & 0 & 18.6 & 28.0 & 42.8 & 33.6 & 26.2 & 22.8 & 7.9 & 0 & 0 & 15.8 & 30.7 & 35.7 \\
$\begin{array}{l}\text { Defasagens geradas pelo método Sband, com } \\
\quad \text { velocidades reduzidas (30-40-40km/h) }\end{array}$ & 0 & 25.8 & 50.6 & 58.3 & 43.0 & 33.8 & 28.4 & 9.8 & 0 & 0 & 18.5 & 37.2 & 43.4 \\
Defasagens geradas pelo INTEGRATION & 0 & 11 & 47 & 48 & 58 & 54 & 17 & 5 & 0 & 0 & 13 & 6 & 31 \\
\hline
\end{tabular}

Todos estes diagramas Espaço-Tempo, representados para os cenários simulados das três avenidas da cidade de Londrina e da rede da cidade de São Carlos, servirão de subsídio para a análise dos resultados de cada medida operacional de eficiência, que foram obtidos através do simulador INTEGRATION, e que são apresentados no capítulo a seguir. 


\section{ANÁLISE DOS RESULTADOS OBTIDOS NAS SIMULAÇÕES}

A utilização do programa de simulação de tráfego INTEGRATION permitiu avaliar a eficiência do método de maximização da banda verde, implementado no programa SBAND, testando cenários distintos no perímetro urbano das cidades de Londrina e São Carlos, com várias configurações de vias e características de controle semafórico. A partir das simulações para diferentes níveis de demanda, também foi possível realizar uma análise de sensibilidade da eficiência dos métodos de coordenação em função do volume de tráfego na rede, indicando assim quando é possível utilizar métodos baseados no critério de maximização de banda verde, como o método baseado no algoritmo de Morgan e Little, ou quando é mais recomendado utilizar métodos de coordenação baseados no critério de minimização de atrasos e paradas, como o existente no simulador INTEGRATION.

Três medidas operacionais de eficiência foram selecionadas para avaliação dos cenários simulados pelo programa INTEGRATION (Rakha, 2004) nas redes de Londrina e São Carlos, descritas a seguir:

- Tempo médio de percurso [segundos]: o tempo de viagem de um veículo é determinado a partir da comparação entre o momento de entrada e de saída do veículo nos segmentos de via, sendo que a diferença entre estes momentos fornece diretamente o tempo médio de percurso (ou tempo gasto) de cada veículo em cada trecho da rede;

- Atraso médio total [segundos]: o programa estima o atraso total $(D)$ através do atraso do veículo a cada intervalo de tempo $\Delta t$ (no caso, 1 décimo de segundo), como a diferença de tempo entre a viagem na velocidade instantânea $\left(v_{i}\right)$ do veículo e a viagem na velocidade de fluxo livre $\left(v_{f}\right)$, como indicado na Equação (7-1):

$$
D=\Delta t\left(1-\frac{v_{i}}{v_{f}}\right)
$$

- Número médio de paradas: a estimativa de paradas $(S)$ é contabilizada através da soma das paradas completas (redução desde a velocidade de fluxo livre até $0 \mathrm{~km} / \mathrm{h}$ ) e parciais (quando ocorre redução de velocidade menor que o intervalo de $v_{f}$ a 0 $\mathrm{km} / \mathrm{h}$, por exemplo, da velocidade de fluxo livre até $v f / 2$ ou de $v f / 2$ até $0 \mathrm{~km} / \mathrm{h}$ ) por veículo em cada segmento de via, como demonstrado na Equação (7-2): 


$$
S\left(t_{i}\right)=\frac{v\left(t_{i}\right)-v\left(t_{i-1}\right)}{v_{f}}
$$

onde $S\left(t_{i}\right)$ é a parada parcial instantânea estimada no instante de tempo $t_{i}$.

Os resultados destas medidas de desempenho em cada corredor selecionado e cenário simulado servem como subsídio para avaliação da eficiência dos programas de coordenação em análise - SBAND e INTEGRATION. Para isto, as medidas de desempenho das situações em que todos os semáforos abrem simultaneamente foram escolhidas como referência para a comparação de eventuais melhorias das demais formas de coordenação, considerando a progressão simultânea como a condição mais simples a ser adotada pelas prefeituras na operação semafórica de vias arteriais ou redes.

Os próximos itens abordam a análise dos resultados obtidos nas simulações de cada um dos três corredores escolhidos na cidade de Londrina e da rede selecionada na cidade de São Carlos, de forma a possibilitar as conclusões gerais apresentadas no último capítulo desta dissertação. Inicialmente, no item 7.1, a avaliação é feita através da comparação entre os resultados obtidos com os diferentes cenários e coordenações propostas para as vias arteriais, considerando a demanda real de cada cenário. No item 7.2, são analisados os valores das medidas de desempenho dos cenários da cidade de Londrina em condições com 15 a 85\% de redução na demanda real. Por fim, utilizando a característica de eqüidistância entre interseções semaforizadas da Avenida Higienópolis, a análise da interferência do espaçamento dos semáforos pode ser realizada para comparação da eficiência dos métodos de coordenação (item 7.3).

\subsection{Simulações dos Cenários com Demanda Real}

Os resultados das medidas de desempenho operacional dos cenários simulados para os três corredores de Londrina e para a rede de São Carlos com as propostas de programação vigente, coordenações geradas pelo programa SBAND para diferentes velocidades de progressão, e com coordenação obtida através da rotina interna do programa INTEGRATION, são comparados entre si e principalmente em relação à situação de referência com abertura simultânea dos semáforos consecutivos.

\subsubsection{Avenida Higienópolis}

A programação vigente na Avenida Higienópolis já havia sido avaliada diversas vezes pelo técnico do poder público municipal, que considerando o tráfego elevado na via 
principal e também nas transversais e o espaçamento praticamente eqüidistante entre as interseções semaforizadas, estabeleceu o sistema de coordenação alternada de indicações contrárias nos semáforos consecutivos (conforme benefícios deste procedimento já citados no capítulo 4). Posteriormente, através de repetidas observações do tráfego local, foram realizados ajustes nas defasagens e a cada alteração as filas formadas nas aproximações dos semáforos foram observadas, permitindo assim novas modificações.

Os resultados médios das medidas de desempenho obtidas para a Avenida Higienópolis estão representados nos gráficos da Figura 7-1, para os oito cenários de coordenação semafórica simulados: simultânea, vigente, gerada pelo programa SBAND para velocidades de 40 e de $50 \mathrm{~km} / \mathrm{h}$ com bandas bidirecionais iguais e direcionais diferentes, obtida pelo programa SBAND em duas etapas separadas com velocidade de $50 \mathrm{~km} / \mathrm{h}$, e por fim com coordenação gerada pela rotina do programa INTEGRATION.
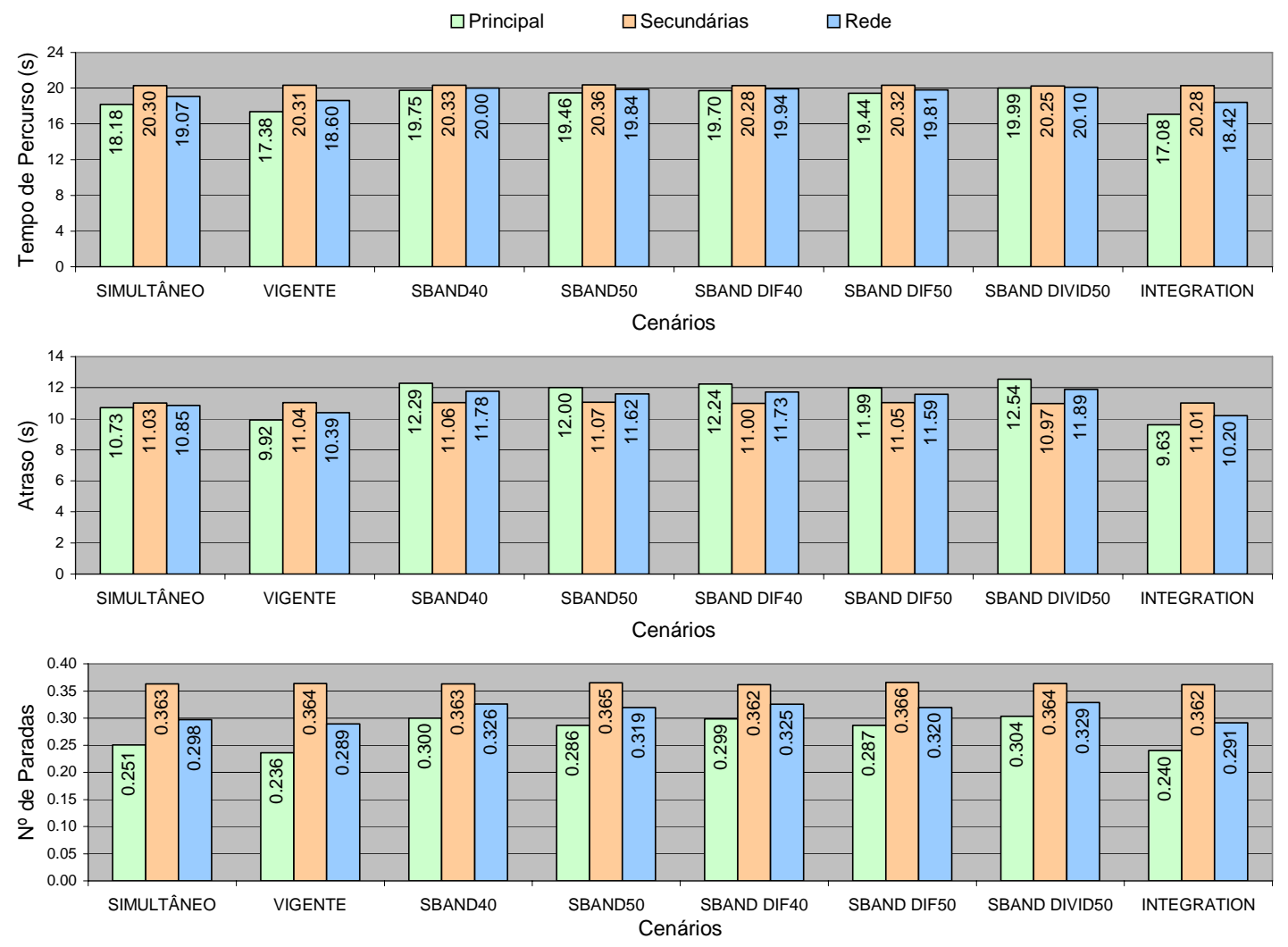

Figura 7-1: Médias das medidas de desempenho para a Avenida Higienópolis

A Tabela 7-1 apresenta as porcentagens comparativas das medidas de desempenho obtidas para a Avenida Higienópolis, e demonstram que em relação à situação de referência com progressão simultânea, as defasagens do cenário vigente proporcionam redução de 4,4\% no tempo médio de percurso por veículo que circula na 
via principal e 2,4\% para todos os veículos da rede, 7,5\% de redução no atraso médio por veículo na via principal e 4,3\% na rede, e 5,8\% menos paradas na via principal e 2,7\% em toda a rede. Vale ressaltar que a comparação entre as medidas de desempenho aponta que nenhuma situação simulada promoveu benefícios ou prejuízos superiores a 1\% nas vias transversais à Avenida Higienópolis, em relação ao cenário de referência, o que também pode ser observado na Tabela 7-1.

Tabela 7-1: Quadro comparativo entre as medidas de desempenho para a Avenida Higienópolis

\begin{tabular}{|c|c|c|c|c|c|c|c|c|c|c|c|c|c|c|c|}
\hline \multirow[t]{2}{*}{ Cenário } & \multirow{2}{*}{$\frac{\text { Simultâneo* }}{\text { média/veic }}$} & \multicolumn{2}{|c|}{ Vigente } & \multicolumn{2}{|c|}{ Sband $40 \mathrm{~km} / \mathrm{h}$} & \multicolumn{2}{|c|}{ Sband $50 \mathrm{~km} / \mathrm{h}$} & \multicolumn{2}{|c|}{ Sband Dif40km/h } & \multicolumn{2}{|c|}{ Sband Dif50km/h } & \multicolumn{2}{|c|}{ Sband Divid50km $/ \mathrm{h}$} & \multicolumn{2}{|c|}{ Integration } \\
\hline & & média/veic & $\%$ & média/veic & $\%$ & média/veic & $\%$ & média/veic & $\%$ & média/veic & $\%$ & média/veic & $\%$ & média/veic & $\%$ \\
\hline \multicolumn{16}{|l|}{$\begin{array}{l}\text { Tempo de } \\
\text { Percurso (s) }\end{array}$} \\
\hline principal & 18.18 & 17.38 & -4.4 & 19.75 & 8.7 & 19.46 & 7.1 & 19.70 & 8.4 & 19.44 & 7.0 & 19.99 & 10.0 & 17.08 & -6.0 \\
\hline secundárias & 20.30 & 20.31 & 0.1 & 20.33 & 0.1 & 20.36 & 0.3 & 20.28 & -0.1 & 20.32 & 0.1 & 20.25 & -0.3 & 20.28 & -0.1 \\
\hline rede & 19.07 & 18.60 & -2.4 & 20.00 & 4.9 & 19.84 & 4.0 & 19.94 & 4.6 & 19.81 & 3.9 & 20.10 & 5.4 & 18.42 & -3.4 \\
\hline \multicolumn{16}{|l|}{ Atraso (s) } \\
\hline principal & 10.73 & 9.92 & -7.5 & 12.29 & 14.6 & 12.00 & 11.9 & 12.24 & 14.1 & 11.99 & 11.7 & 12.54 & 16.9 & 9.63 & -10.3 \\
\hline secundárias & 11.03 & 11.04 & 0.1 & 11.06 & 0.2 & 11.07 & 0.4 & 11.00 & -0.2 & 11.05 & 0.2 & 10.97 & -0.5 & 11.01 & -0.2 \\
\hline rede & 10.85 & 10.39 & -4.3 & 11.78 & 8.5 & 11.62 & 7.0 & 11.73 & 8.0 & 11.59 & 6.8 & 11.89 & 9.5 & 10.20 & -6.0 \\
\hline \multicolumn{16}{|l|}{$\mathrm{N}^{\circ}$ de Paradas } \\
\hline principal & 0.251 & 0.236 & -5.8 & 0.300 & 19.7 & 0.286 & 14.3 & 0.299 & 19.3 & 0.287 & 14.4 & 0.304 & 21.2 & 0.240 & -4.1 \\
\hline secundárias & 0.363 & 0.364 & 0.2 & 0.363 & 0.0 & 0.365 & 0.6 & 0.362 & -0.4 & 0.366 & 0.7 & 0.364 & 0.1 & 0.362 & -0.4 \\
\hline rede & 0.298 & 0.289 & -2.7 & 0.326 & 9.6 & 0.319 & 7.3 & 0.325 & 9.3 & 0.320 & 7.5 & 0.329 & 10.4 & 0.291 & -2.2 \\
\hline
\end{tabular}

De certa forma, por tentativa e erro, a programação vigente estabelecida na Avenida Higienópolis pelo técnico da cidade já contempla a minimização do atraso e paradas principalmente na via principal, portanto dificilmente os demais cenários propostos com diferentes defasagens poderiam proporcionar melhorias significativas em suas medidas operacionais de desempenho. Sendo assim, os resultados obtidos na simulação deste cenário também podem representar um parâmetro de comparação com os resultados dos planos de coordenação gerados pelo programa SBAND e pelo próprio INTEGRATION. Porém, é necessário considerar que os procedimentos de ajustes realizados in loco pelo técnico do município afetam diretamente o tráfego da via, podendo causar distúrbios e prejuízos aos usuários, e ainda requer tempo demasiado em tentativas e observações. Esta situação pode ser evitada através da análise da coordenação com a utilização de programas computacionais simples como o SBAND, ou sofisticados com maior quantidade de dados de entrada como o INTEGRATION.

As reduções nas medidas de eficiência resultantes do cenário vigente são superadas no cenário de coordenação gerada pela rotina interna do simulador INTEGRATION, atingindo $6 \%$ de redução no tempo médio de percurso gasto por veículo na via principal e 3,4\% na rede, e com redução de 10,3\% no atraso médio por veículo na via principal e 6\% na rede. Porém, o número de paradas é ligeiramente maior do que no cenário vigente, embora as defasagens obtidas pelo programa INTEGRATION para a Avenida Higienópolis também proporcionem redução de 4,1\% das paradas na via 
principal e 2,2\% na rede em relação ao cenário simultâneo.

Para os resultados gerados pelo programa proposto SBAND, nenhuma redução nas medidas operacionais foi obtida na via principal ou para a rede. Ao contrário do que seria desejado, os valores médios de tempo de percurso são até $10 \%$ maiores do que aqueles resultantes do cenário com progressão simultânea na via principal e até 5,4\% maior quando toda a rede é considerada. O atraso médio por veículo na Avenida Higienópolis aumentou de 11,7 a 16,9\% na via principal e 6,8 a 9,5\% para toda a rede, e o número de paradas variou entre 14,3 e 21,2\% a mais na via principal e 7,3 e 10,4\% superior para média de toda a rede. Estas constatações vêm ao encontro das citações de autores como Rogness e Messer (1983) e Gartner et al. (1990), que mencionam que o método de maximização de banda verde não garante a minimização de atrasos e paradas, embora promova a redução em relação à falta de coordenação semafórica.

A ausência de benefícios gerados na rede da Avenida Higienópolis pela coordenação do programa SBAND, que é baseado no conceito de maximização da banda verde, pode ser explicada em função das larguras máximas de banda que foram obtidas para os casos de velocidades de progressão de 40 e $50 \mathrm{~km} / \mathrm{h}$, que não ultrapassaram 13,2 e 11,1 segundos, respectivamente. Observando visualmente a simulação desta avenida, é possível registrar a média de 18 veículos nas aproximações dos semáforos por ciclo, sendo que somente 12 a 15 veículos conseguem passar por estas larguras de banda, considerando a capacidade da Avenida Higienópolis de 4130 veículos por hora de verde (para suas duas faixas de rolamento). Portanto, para esta situação, as bandas contínuas geradas pelo SBAND não têm largura suficiente para acomodar a passagem do tráfego real da avenida, ficando aproximadamente 5 veículos retidos no vermelho por ciclo, ainda sem levar em consideração as possíveis filas formadas nestas quadras também pelos veículos oriundos das vias transversais, devido aos seus volumes de tráfego elevados.

A comparação das médias das medidas de desempenho a cada tramo da rede da Avenida Higienópolis (tempo de percurso, atraso e número de paradas) confirma que a maior variação de valores ocorre ao longo da via principal (tramos 1 a 8 no sentido Norte-Sul e 9 a 17 no sentido Sul-Norte), ficando os valores das vias secundárias (tramos 18 a 33) praticamente constantes em qualquer uma das propostas de coordenação simuladas, conforme demonstram os gráficos da Figura 7-2. As menores medidas de desempenho ilustradas nos gráficos da Figura 7-2 são relativas aos tramos 8 e 17 da via principal e 19, 21, 23, 25, 27, 29, 31 e 33 das vias secundárias, e refletem o fato de que a saída dos veículos em tais segmentos não é controlada por semáforo. 

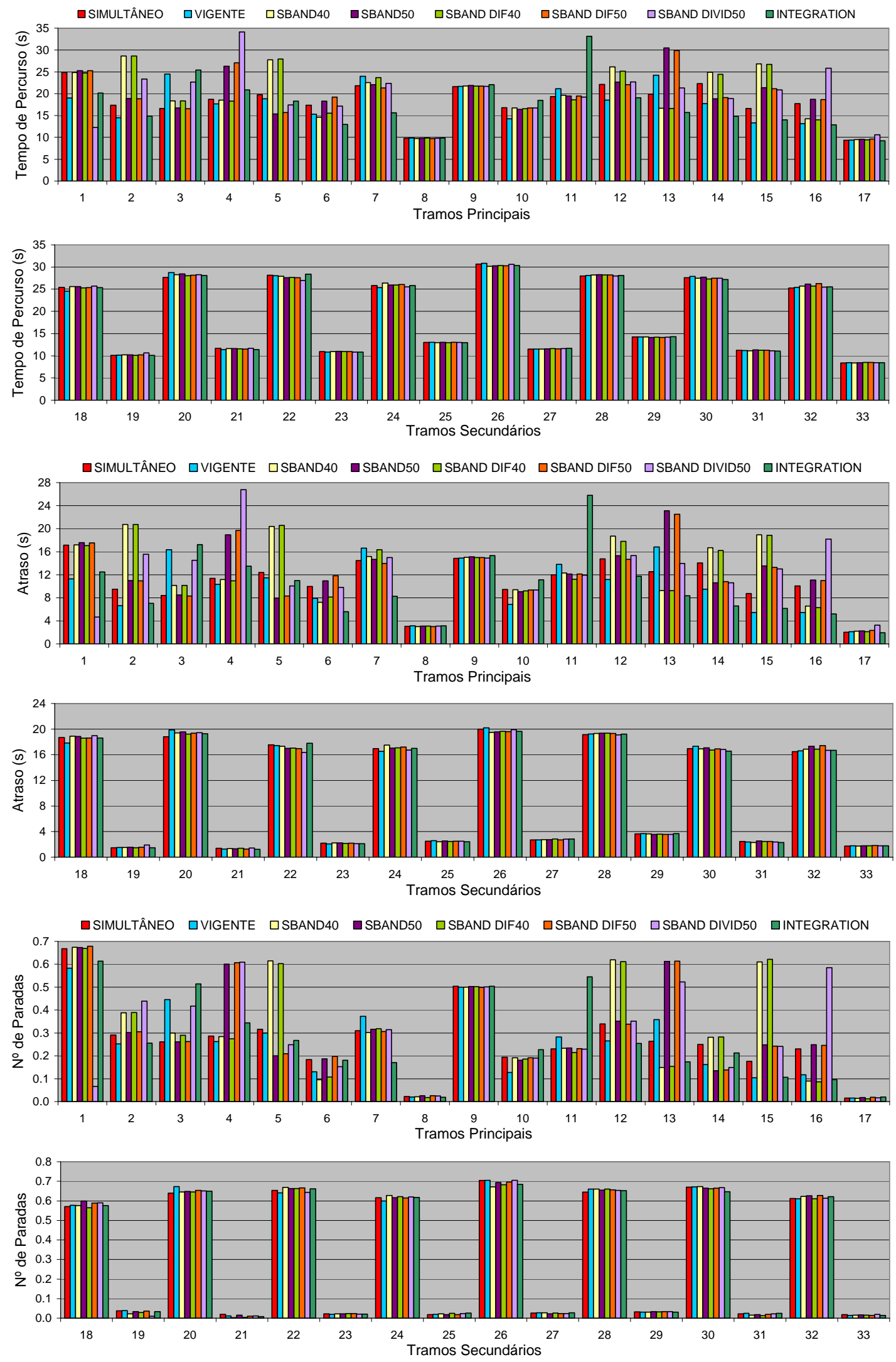

Figura 7-2: Medidas operacionais de eficiência por tramo da Avenida Higienópolis 


\subsubsection{Avenida Juscelino Kubitscheck}

Da mesma forma que ocorre para a situação encontrada na Avenida Higienópolis, também o cenário vigente da Avenida Juscelino Kubitscheck é resultado de um plano de coordenação semafórica gerado inicialmente através do Diagrama Espaço-Tempo e posteriormente adaptado por ajustes nas defasagens. Estas modificações foram realizadas pelo técnico responsável pelo gerenciamento do sistema semafórico na cidade de Londrina, através de sucessivas observações do tráfego e das filas formadas nas aproximações das interseções, introduzindo na programação vigente a minimização do atraso e paradas na via principal.

Os espaçamentos entre as interseções semaforizadas da Avenida Juscelino Kubitscheck não são eqüidistantes, e as defasagens vigentes promovem uma banda contínua no sentido Sul-Norte com 26 segundos de largura, e quatro trechos de banda interrompidas no sentido Norte-Sul. Esta largura de banda contínua não foi superada por nenhum outro cenário analisado, embora a programação vigente priorize um único sentido de tráfego.

Os valores médios das medidas operacionais de eficiência obtidas para os cenários de coordenação semafórica simulados na Avenida Juscelino Kubitscheck (simultâneo, vigente, gerado pelo programa SBAND para velocidades de 55 e $50 \mathrm{~km} / \mathrm{h}$ com bandas bidirecionais iguais e direcionais diferentes, obtido pelo programa SBAND em duas etapas separadas com velocidade de $55 \mathrm{~km} / \mathrm{h}$, e com coordenação gerada através da rotina interna do programa INTEGRATION), estão representados nos gráficos da Figura 7-3.

As porcentagens de acréscimo ou redução das medidas de desempenho obtidas para a Avenida Juscelino Kubitscheck estão resumidas na Tabela 7-2, e demonstram que em relação à situação de referência com progressão simultânea, as defasagens do cenário vigente geram uma pequena redução de 1,2\% no tempo médio de percurso gasto por veículo da via principal e um pequeno acréscimo de 1,7\% para todos os veículos da rede. Por outro lado, causam aumento de 11,5\% no tempo de percurso nas vias secundárias. O atraso médio por veículo na via principal é reduzido em 1,8\%, mas considerando o atraso médio para toda a rede, o cenário vigente resulta em 2,5\% de acréscimo e ainda 23,2\% de aumento nas vias secundárias. A melhor situação para os resultados do cenário vigente quando comparado ao cenário simultâneo pode ser observada na quantidade de paradas, com redução de 3,3\% para a via principal e 2,2\% para a rede, porém também com aumento de 1,4\% nas paradas sofridas pelos veículos 
das vias secundárias.
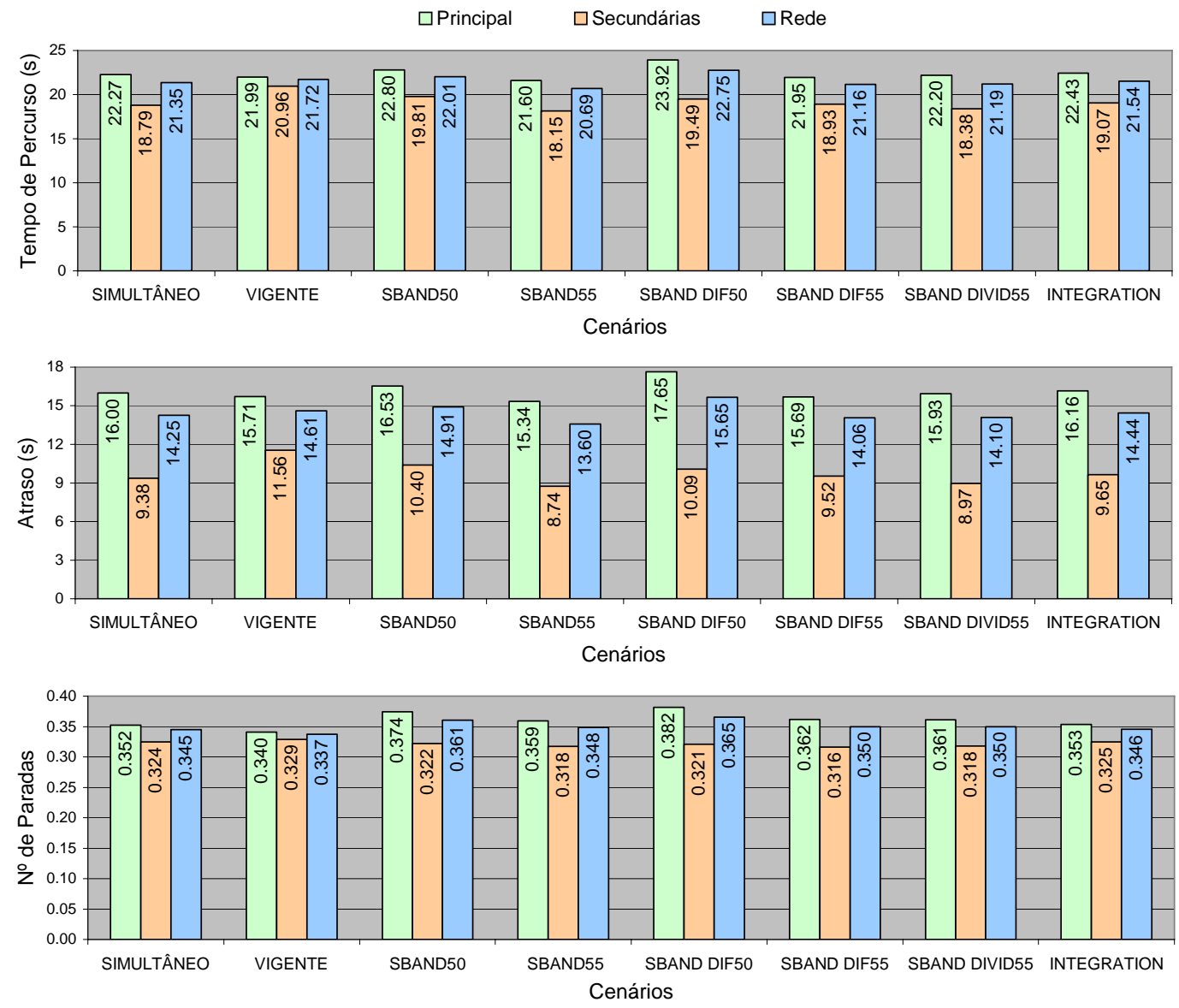

Figura 7-3: Médias das medidas de desempenho para a Avenida Juscelino Kubitscheck

As medidas de eficiência resultantes do cenário de coordenação gerada pelo simulador INTEGRATION para a Avenida Juscelino Kubitscheck são todas piores do que aquelas obtidas no cenário vigente, e praticamente iguais às medidas resultantes do cenário simultâneo.

Tabela 7-2: Quadro comparativo entre as medidas de desempenho para a Avenida Juscelino Kubitscheck

\begin{tabular}{|c|c|c|c|c|c|c|c|c|c|c|c|c|c|c|c|}
\hline \multirow[t]{2}{*}{ Cenário } & \multirow{2}{*}{$\frac{\text { Simultâneo* }}{\text { média/veic }}$} & \multicolumn{2}{|c|}{ Vigente } & \multicolumn{2}{|c|}{ Sband $55 \mathrm{~km} / \mathrm{h}$} & \multicolumn{2}{|c|}{ Sband $50 \mathrm{~km} / \mathrm{h}$} & \multicolumn{2}{|c|}{ Sband Dif55km/h } & \multicolumn{2}{|c|}{ Sband Dif50km/h } & \multicolumn{2}{|c|}{ Sband Divid55km/h } & \multicolumn{2}{|c|}{ Integration } \\
\hline & & média/veic & $\%$ & média/veic & $\%$ & média/veic & $\%$ & média/veic & $\%$ & média/veic & $\%$ & média/veic & $\%$ & média/veic & $\%$ \\
\hline \multicolumn{16}{|l|}{$\begin{array}{c}\text { Tempo de } \\
\text { Percurso (s) }\end{array}$} \\
\hline principal & 22.27 & 21.99 & -1.2 & 21.60 & -3.0 & 22.80 & 2.4 & 21.95 & -1.4 & 23.92 & 7.4 & 22.20 & -0.3 & 22.43 & 0.7 \\
\hline secundárias & 18.79 & 20.96 & 11.5 & 18.15 & -3.4 & 19.81 & 5.4 & 18.93 & 0.8 & 19.49 & 3.7 & 18.38 & -2.2 & 19.07 & 1.5 \\
\hline rede & 21.35 & 21.72 & 1.7 & 20.69 & -3.1 & 22.01 & 3.1 & 21.16 & -0.9 & 22.75 & 6.6 & 21.19 & -0.7 & 21.54 & 0.9 \\
\hline \multicolumn{16}{|l|}{ Atraso (s) } \\
\hline & 16.00 & 15.71 & -1.8 & 15.34 & -4.1 & 16.53 & 3.3 & 15.69 & -2.0 & 17.65 & 10.3 & 15.93 & -0.4 & 16.16 & 1.0 \\
\hline secundárias & 9.38 & 11.56 & 23.2 & 8.74 & -6.8 & 10.40 & 10.9 & 9.52 & 1.5 & 10.09 & 7.6 & 8.97 & -4.4 & 9.65 & 2.9 \\
\hline rede & 14.25 & 14.61 & 2.5 & 13.60 & -4.6 & 14.91 & 4.6 & 14.06 & -1.4 & 15.65 & 9.8 & 14.10 & -1.1 & 14.44 & 1.3 \\
\hline \multicolumn{16}{|l|}{$\mathrm{N}^{\circ}$ de Paradas } \\
\hline principal & 0.352 & 0.340 & -3.3 & 0.359 & 2.0 & 0.374 & 6.3 & 0.362 & 2.7 & 0.382 & 8.3 & 0.361 & 2.5 & 0.353 & 0.3 \\
\hline secundárias & 0.324 & 0.329 & 1.4 & 0.318 & -2.1 & 0.322 & -0.7 & 0.316 & -2.5 & 0.321 & -1.1 & 0.318 & -2.0 & 0.325 & 0.1 \\
\hline rede & 0.345 & 0.337 & -2.2 & 0.348 & 1.0 & 0.361 & 4.6 & 0.350 & 1.4 & 0.365 & 6.0 & 0.350 & 1.4 & 0.346 & 0.3 \\
\hline
\end{tabular}

* os percentuais de redução e acréscimo das medidas de desempenho foram calculados em relação ao cenário simultâneo. 
Os melhores resultados gerados pelo programa SBAND para a Avenida Juscelino Kubitscheck foram obtidos com velocidade de progressão de $55 \mathrm{~km} / \mathrm{h}$ e bandas iguais nos dois sentidos (gerando larguras de 11 segundos), onde os resultados apontam 3\% de redução no tempo de percurso na via principal, 3,4\% nas vias secundárias e 3,1\% para toda a rede, quando comparados ao cenário com abertura simultânea dos semáforos. Neste mesmo cenário gerado pelo programa SBAND, o atraso médio por veículo diminuiu 4,1\% na via principal, 6,8\% nas vias secundárias e 4,6\% na rede. As soluções geradas pelo SBAND não proporcionaram melhorias nas quantidades de paradas na via principal e na rede, mas somente no número de paradas causadas nas vias secundárias, com pequena redução de 2,1\%.

Entretanto, estes bons resultados obtidos pela coordenação gerada através do programa SBAND com velocidade de progressão de $55 \mathrm{~km} / \mathrm{h}$ devem ser cuidadosamente analisados, uma vez que esta proposta considera velocidade superior à velocidade regulamentada na via (50 km/h). Desta forma, seria necessário inicialmente a alteração da sinalização de regulamentação, para não estabelecer uma programação que incentivasse os motoristas a desrespeitar a sinalização para se beneficiarem da progressão em “onda verde”. Porém, por questões de segurança, os técnicos devem avaliar se a nova velocidade (60 km/h) é compatível com as demais características da via, como geometria e principalmente uso do solo.

Os gráficos da Figura 7-4 ilustram os resultados médios das medidas de desempenho em cada tramo da rede da Avenida Juscelino Kubitscheck (tempo de percurso, atraso e número de paradas), e demonstram que a maior variação de valores ocorre na via principal (tramos 1 a 14 no sentido Norte-Sul e 15 a 28 no sentido SulNorte), ficando os valores das vias secundárias (tramos 29 a 49) praticamente constantes em qualquer uma das propostas de coordenação simuladas. Observando a Figura 7-4, somente os tramos 30 e 36, que possuem tempos de verde muito pequenos em relação à via principal, apresentaram alterações significativas nas medidas de desempenho relativas às vias secundárias.

Também é possível observar nos gráficos da Figura 7-4 que as menores medidas de desempenho são relativas aos tramos extremos da rede (14 e 28 da via principal e 29, 31, 33, 34, 37, 38, 39, 41, 42, 44, 46, 48 e 49 das vias secundárias), especialmente para o número médio de paradas, uma vez que a saída destes segmentos não é controlada por semáforo. 

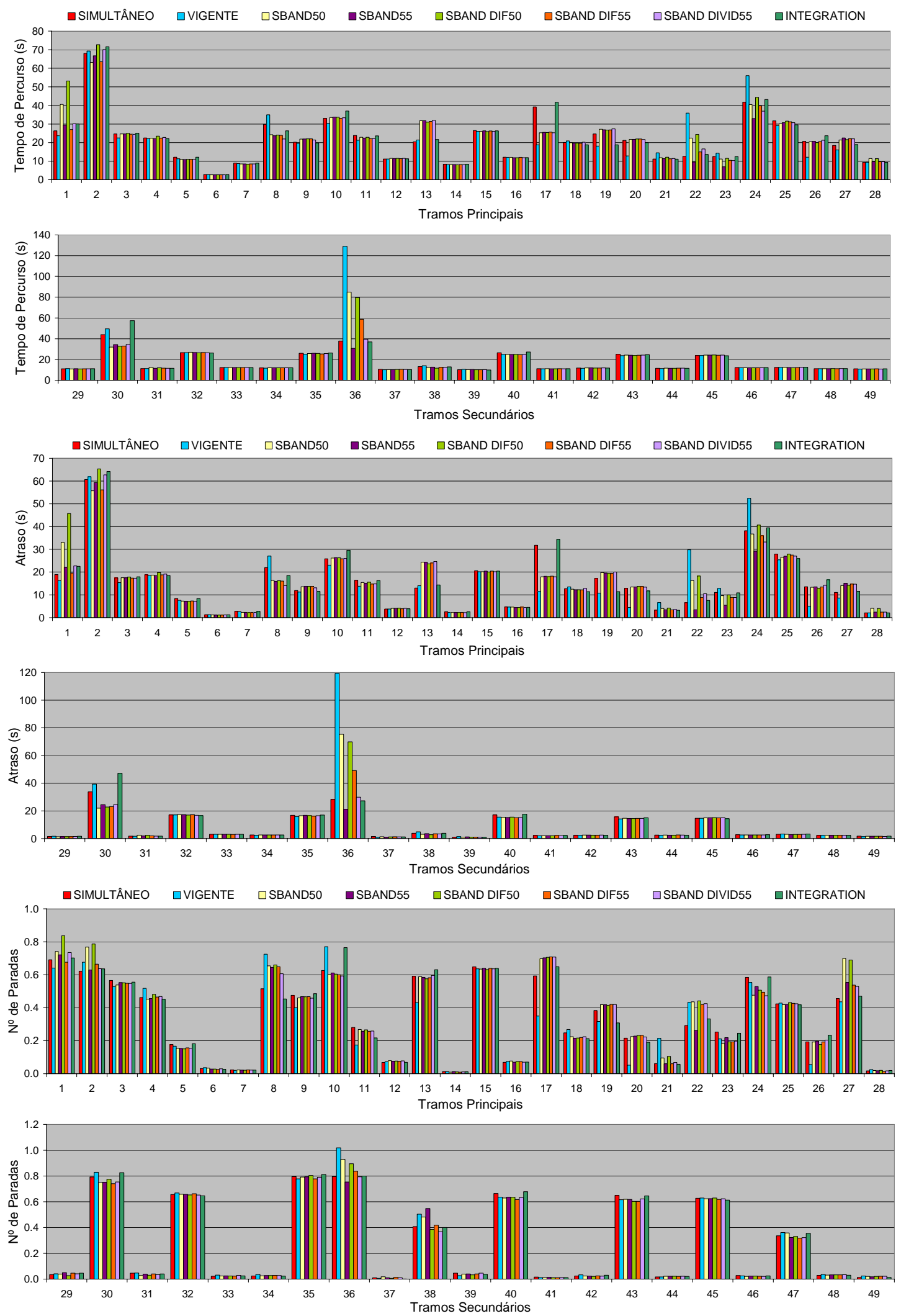

Figura 7-4: Medidas operacionais de eficiência por tramo da Avenida Juscelino Kubitscheck 


\subsubsection{Avenida Maringá}

Das três avenidas selecionadas em Londrina para avaliação, a Avenida Maringá é a única que não foi ajustada pelo técnico responsável pela programação semafórica da cidade, e que apresenta no sistema operacional vigente problemas com excesso de paradas e atraso na hora de pico registrada (17:45 - 18:45). De maneira geral, os benefícios dos cenários propostos com coordenações obtidas através dos programas SBAND e INTEGRATION para a demanda real, são mais significativos quando comparados à condição de simples progressão simultânea e também ao cenário vigente.

Os gráficos da Figura 7-5 apresentam os resultados das medidas operacionais médias de eficiência obtidas nos oito cenários de coordenação semafórica simulados na Avenida Maringá: simultâneo, vigente, gerado pelo programa SBAND para velocidades de 35 e $40 \mathrm{~km} / \mathrm{h}$ com bandas bidirecionais iguais e direcionais diferentes, obtido pelo programa SBAND em duas etapas separadas com velocidade de $40 \mathrm{~km} / \mathrm{h}$, e coordenado através do programa INTEGRATION.
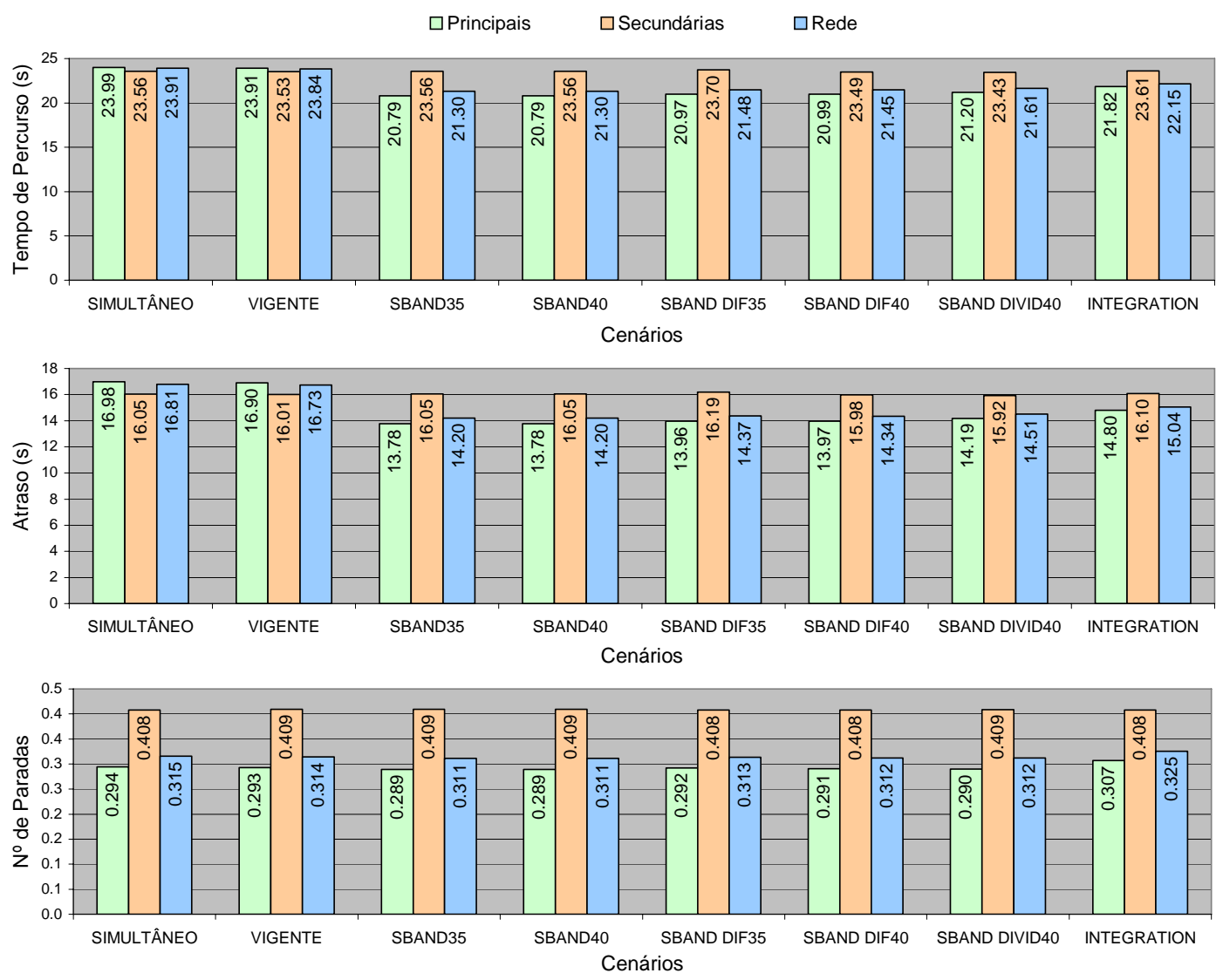

Figura 7-5: Médias das medidas de desempenho para a Avenida Maringá

Considerando que a programação semafórica da Avenida Maringá não foi adequada por nenhum método para prover coordenação entre seus cinco semáforos com 
espaçamentos distintos, os resultados obtidos com o cenário vigente são praticamente idênticos às medidas de eficiência observadas com a abertura simultânea dos semáforos, mesmo com 21 segundos de banda gerados no sentido Norte-Sul com o cenário vigente. Estes valores podem ser confirmados pelas porcentagens comparativas das medidas operacionais de eficiência obtidas para a Avenida Maringá, resumidas na Tabela 7-3.

Tabela 7-3: Quadro comparativo entre as medidas de desempenho para a Avenida Maringá

\begin{tabular}{|c|c|c|c|c|c|c|c|c|c|c|c|c|c|c|c|}
\hline \multirow[t]{2}{*}{ Cenário } & \multirow{2}{*}{$\frac{\text { Simultâneo* }^{*}}{\text { média/veic }}$} & \multicolumn{2}{|c|}{ Vigente } & \multicolumn{2}{|c|}{ Sband $35 \mathrm{~km} / \mathrm{h}$} & \multicolumn{2}{|c|}{ Sband $40 \mathrm{~km} / \mathrm{h}$} & \multicolumn{2}{|c|}{ Sband Dif $35 \mathrm{~km} / \mathrm{h}$} & \multicolumn{2}{|c|}{ Sband Dif $40 \mathrm{~km} / \mathrm{h}$} & \multicolumn{2}{|c|}{ Sband Divid $40 \mathrm{~km} / \mathrm{h}$} & \multicolumn{2}{|c|}{ Integration } \\
\hline & & média/veic & $\%$ & média/veic & $\%$ & média/veic & $\%$ & média/veic & $\%$ & média/veic & $\%$ & média/veic & $\%$ & média/veic & $\%$ \\
\hline \multicolumn{16}{|l|}{$\begin{array}{l}\text { Tempo de } \\
\text { Percurso (s) }\end{array}$} \\
\hline principal & 23.99 & 23.91 & -0.4 & 20.79 & -13.3 & 20.79 & -13.3 & 20.97 & -12.6 & 20.99 & -12.5 & 21.20 & -11.6 & 21.82 & -9.1 \\
\hline secundárias & 23.56 & 23.53 & -0.1 & 23.56 & 0.0 & 23.56 & 0.0 & 23.70 & 0.6 & 23.49 & -0.3 & 23.43 & -0.6 & 23.61 & 0.2 \\
\hline rede & 23.91 & 23.84 & -0.3 & 21.30 & -10.9 & 21.30 & -10.9 & 21.48 & -10.2 & 21.45 & -10.3 & 21.61 & -9.6 & 22.15 & -7.4 \\
\hline \multicolumn{16}{|l|}{ Atraso (s) } \\
\hline $\begin{array}{l}\text { principal } \\
\text { secundárias }\end{array}$ & $\begin{array}{l}16.98 \\
16.05\end{array}$ & 16.01 & -0.2 & $\begin{array}{l}10.10 \\
16.05\end{array}$ & 0.0 & 16.05 & 0.0 & 16.19 & 0.9 & 15.98 & -0.4 & 15.92 & -0.8 & 16.10 & 0.3 \\
\hline rede & 16.81 & 16.73 & -0.4 & 14.20 & -15.5 & 14.20 & -15.5 & 14.37 & -14.5 & 14.34 & -14.7 & 14.51 & -13.7 & 15.04 & -10.5 \\
\hline \multicolumn{16}{|l|}{$\mathrm{N}^{\circ}$ de Paradas } \\
\hline principal & 0.294 & 0.293 & -0.5 & 0.289 & -1.7 & 0.289 & -1.7 & 0.292 & -0.8 & 0.291 & -1.3 & 0.290 & -1.5 & 0.307 & 4.2 \\
\hline secundárias & 0.408 & 0.409 & 0.3 & 0.409 & 0.2 & 0.409 & 0.2 & 0.408 & 0.0 & 0.408 & -0.1 & 0.409 & 0.1 & 0.408 & -0.1 \\
\hline $\begin{array}{l}\text { rede } \\
\text { res }\end{array}$ & 0.315 & 0.314 & -0.3 & 0.311 & -1.2 & 0.311 & -1.2 & 0.313 & -0.6 & 0.312 & -1.0 & 0.312 & -1.1 & 0.325 & 3.2 \\
\hline
\end{tabular}

Os cinco cenários de coordenação geradas pelo programa SBAND, quando comparados ao cenário simultâneo de referência, apresentaram melhorias semelhantes e significativas principalmente no tempo médio de percurso gasto por veículo (aproximadamente $13 \%$ de redução para a via principal e $10 \%$ para toda a rede) e no atraso médio por veículo (cerca de 18\% menor na via principal e $15 \%$ na rede). O número de paradas também diminuiu em todos os cenários propostos pelo programa SBAND, em porcentagens pequenas de 0,8 a 1,7\% na via principal, e 0,6 e 1,2\% de redução para toda a rede.

A Tabela 7-3 também apresenta os valores obtidos pelo cenário com coordenação gerada pelo programa INTEGRATION, que proporcionou redução de 9,1\% no tempo médio de percurso gasto por veículo na via principal e 7,4\% para todos os veículos da rede, e diminuiu 12,8\% o atraso médio por veículo na via principal e 10,5\% na rede. Mesmo com estas medidas de eficiência significativamente menores do que no cenário simultâneo da Avenida Maringá, o número médio de paradas sofridas pelos veículos foi 4,2\% maior na via principal e 3,2\% maior para toda a rede.

A comparação das médias das medidas de eficiência a cada tramo da rede da Avenida Maringá (tempo de percurso, atraso e número de paradas) confirma que a maior variação de valores ocorre na via principal (tramos 1 a 11 no sentido Norte-Sul e 12 a 22 no sentido Sul-Norte), e os valores das vias secundárias (tramos 23 a 41) ficam 
praticamente constantes em qualquer uma das propostas de coordenação simuladas, conforme ilustram os gráficos da Figura 7-6. As menores medidas de desempenho observadas nos gráficos da Figura 7-6 são relativas aos tramos 24, 26, 27, 31, 33, 34, 37, 38 e 40 das vias secundárias, principalmente para o número de paradas nestes segmentos que não têm a saída controlada por semáforo.

\subsubsection{Rede da Cidade de São Carlos}

Embora as vias que compõem a rede selecionada na cidade de São Carlos tenham sentido único de circulação, facilitando a definição de programações coordenadas, os planos vigentes nos corredores principais da rede foram estabelecidos praticamente com abertura simultânea dos tempos de verde dos semáforos. Uma defasagem foi incluída em cada semáforo central do trecho analisado da Avenida São Carlos e da Rua Episcopal, porém sem que o técnico do poder público municipal tivesse avaliado uma programação coordenada entre as interseções semaforizadas de cada corredor. Desta forma, os cenários simultâneo e vigente apresentam todos os resultados das medidas operacionais de eficiência bastante semelhantes, enquanto os cenários simulados com coordenações obtidas pelos programas SBAND e INTEGRATION resultam, de maneira geral, em menores valores das medidas de desempenho quando comparados ao cenário simultâneo.

Os resultados médios das medidas de desempenho obtidas para a rede da cidade de São Carlos são apresentados nos gráficos da Figura 7-7, para os cinco cenários de coordenação semafórica simulados: simultânea, vigente, gerada pelo programa SBAND para velocidades iguais às regulamentadas nos três corredores e também 10\% superiores a elas, e com coordenação gerada pela rotina interna do programa INTEGRATION.

A Tabela 7-4 apresenta o resumo das porcentagens comparativas das medidas operacionais de eficiência obtidas para as vias da rede de São Carlos, demonstrando que os piores resultados são obtidos pela programação vigente, mesmo quando comparados com a situação de referência com simples progressão simultânea. As defasagens do cenário vigente proporcionam aumento de 1,2\% no tempo médio de percurso gasto pelos veículos que circulam nas vias principais e 0,4\% para todos os veículos da rede, $2,1 \%$ de aumento no atraso médio por veículo na via principal e $0,7 \%$ na rede, e promovem $1,1 \%$ mais paradas na via principal e $0,4 \%$ em toda a rede. As medidas de eficiência do cenário vigente relativas às vias secundárias demonstram melhorias em relação ao cenário simultâneo, mas que não chegam a reduzir 1\% de seus resultados. 

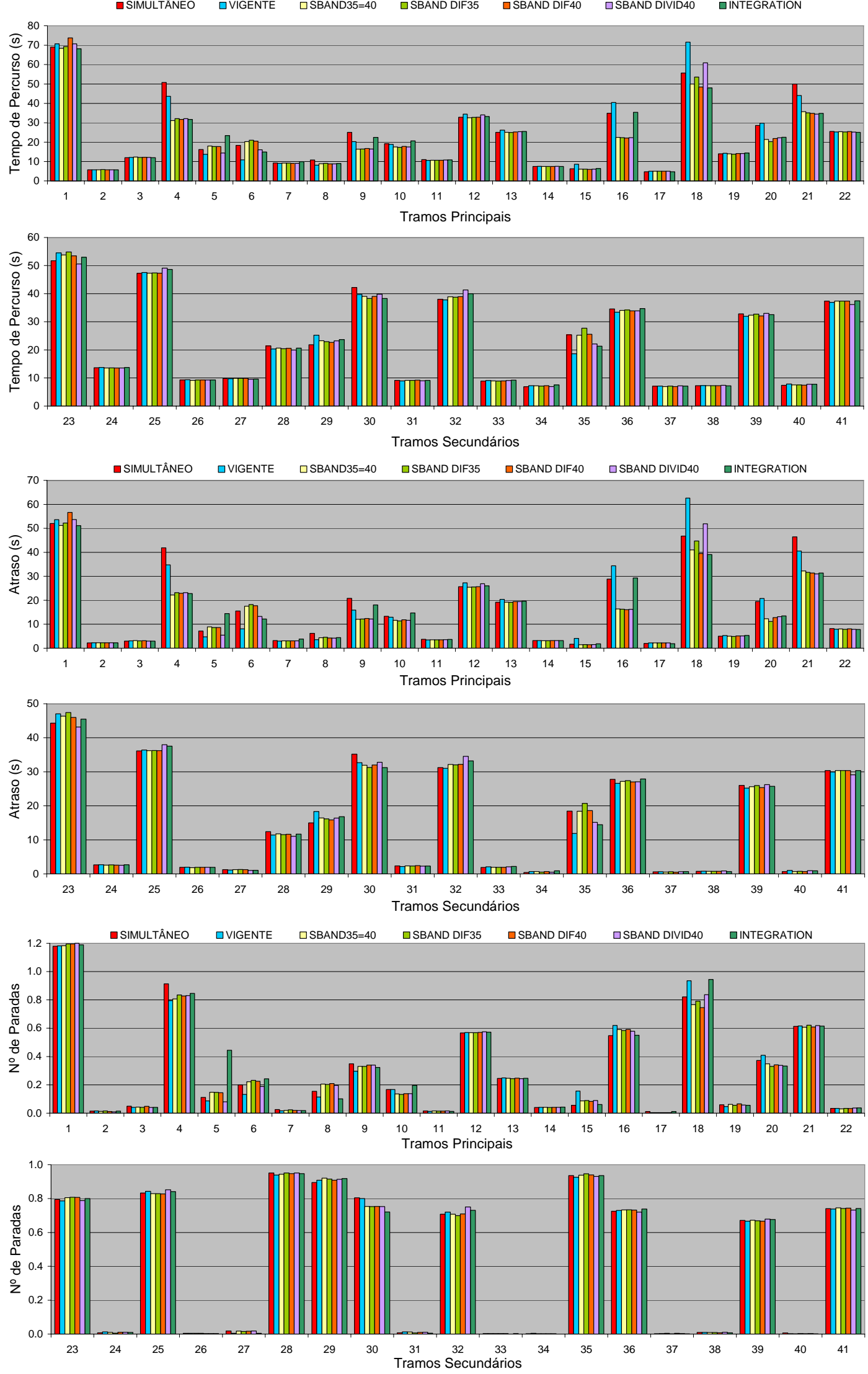

Figura 7-6: Medidas operacionais de eficiência por tramo da Avenida Maringá 
As medidas de eficiência resultantes da coordenação gerada pela rotina interna do simulador INTEGRATION proporcionam em média 6,5\% de redução no tempo de percurso gasto pelos veículos nos corredores principais e 6,3\% na rede em relação ao cenário simultâneo, 11,9\% de redução média no atraso dos veículos nas vias principais e $10,9 \%$ na rede, e ainda $4,8 \%$ a menos no número de paradas nas três vias principais e 4,5\% na rede. Para as vias secundárias, os resultados representam 5,2\% a menos no tempo de percurso, 8,4\% de redução no atraso e 3,6\% menos paradas.
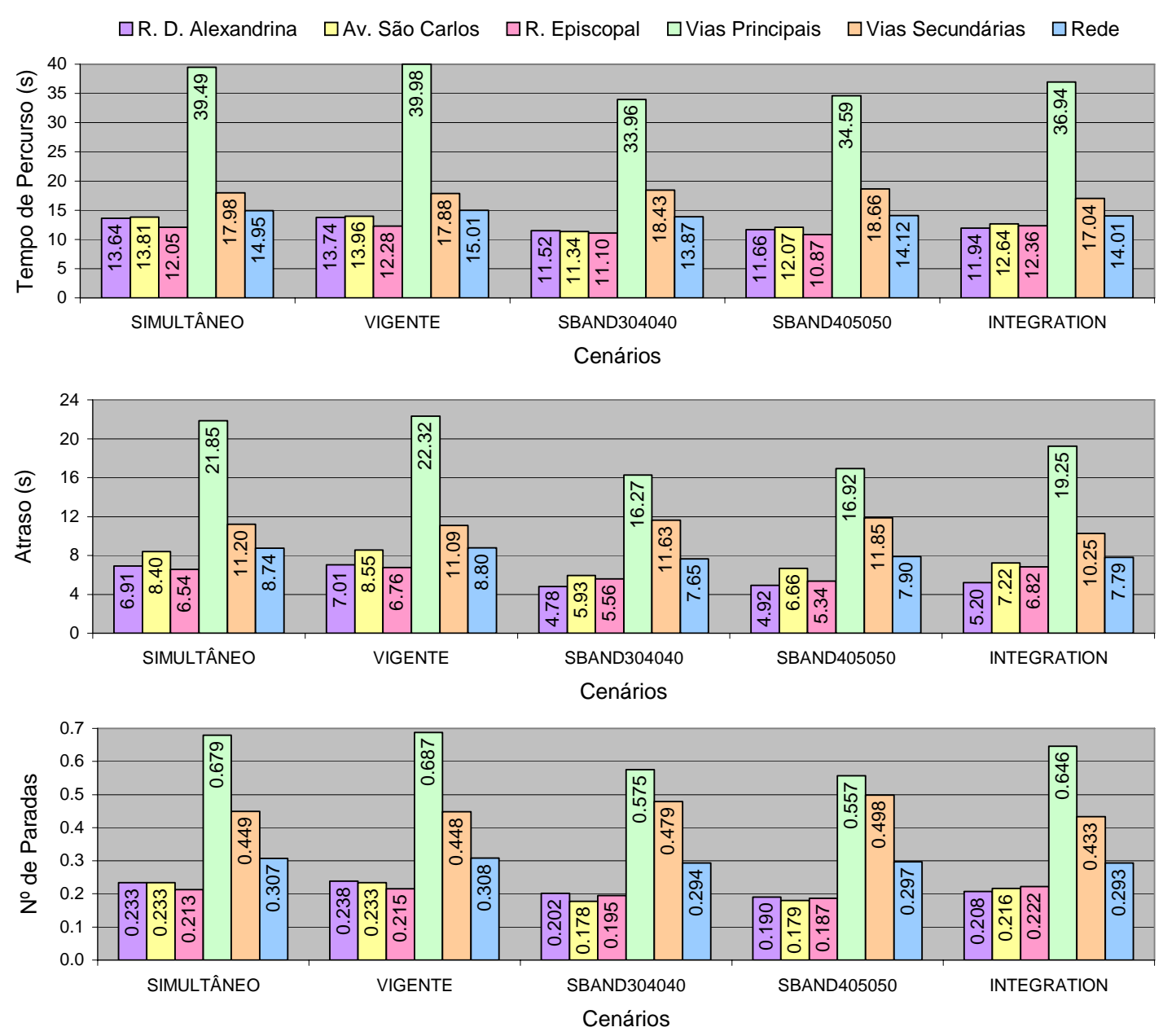

Figura 7-7: Médias das medidas de desempenho para a rede de São Carlos

Porém, são os resultados gerados pelo programa proposto SBAND que promovem os maiores benefícios especialmente para os corredores principais da rede simulada da cidade de São Carlos. Os valores médios de tempo de percurso gasto pelos veículos, quando comparados com o cenário simultâneo, são 14\% menores nas vias principais e 7,2\% menores para toda a rede. Também o atraso por veículo é 25,5\% menor em média para os três corredores e 12,5\% para a rede, com 15,3\% menos paradas nas vias principais e 4,2\% na rede. Em conseqüência, as vias secundárias tiveram 
aumento de $2,5 \%$ no tempo de percurso, 3,8\% no atraso médio e 6,5\% no número de paradas.

Tabela 7-4: Quadro comparativo entre as medidas de desempenho para a rede da cidade de São Carlos

\begin{tabular}{|c|c|c|c|c|c|c|c|c|c|}
\hline \multirow[t]{2}{*}{ Cenário } & \multirow{2}{*}{$\frac{\text { Simultâneo* }}{\text { média/veic }}$} & \multicolumn{2}{|c|}{ Vigente } & \multicolumn{2}{|c|}{ Sband $40-50-50 \mathrm{~km} / \mathrm{h}$} & \multicolumn{2}{|c|}{ Sband $30-40-40 \mathrm{~km} / \mathrm{h}$} & \multicolumn{2}{|c|}{ Integration } \\
\hline & & média/veic & $\%$ & média/veic & $\%$ & média/veic & $\%$ & média/veic & $\%$ \\
\hline \multicolumn{10}{|l|}{$\begin{array}{c}\text { Tempo de } \\
\text { Percurso (s) }\end{array}$} \\
\hline R. D. Alexandrina & 13.64 & 13.74 & 0.7 & 11.66 & -14.5 & 11.52 & -15.5 & 11.94 & -12.5 \\
\hline Av. São Carlos & 13.81 & 13.96 & 1.1 & 12.07 & -12.6 & 11.34 & -17.8 & 12.64 & -8.5 \\
\hline R. Episcopal & 12.05 & 12.28 & 1.9 & 10.87 & -9.8 & 11.10 & -7.9 & 12.36 & 2.6 \\
\hline Vias Principais & 39.49 & 39.98 & 1.2 & 34.59 & -12.4 & 33.96 & -14.0 & 36.94 & -6.5 \\
\hline Vias Secundárias & 17.98 & 17.88 & -0.6 & 18.66 & 3.7 & 18.43 & 2.5 & 17.04 & -5.2 \\
\hline Rede & 14.95 & 15.01 & 0.4 & 14.12 & -5.5 & 13.87 & -7.2 & 14.01 & -6.3 \\
\hline \multicolumn{10}{|l|}{ Atraso (s) } \\
\hline R. D. Alexandrina & 6.91 & 7.01 & 1.5 & 4.92 & -28.8 & 4.78 & -30.8 & 5.20 & -24.7 \\
\hline Av. São Carlos & 8.40 & 8.55 & 1.7 & 6.66 & -20.8 & 5.93 & -29.5 & 7.22 & -14.0 \\
\hline R. Episcopal & 6.54 & 6.76 & 3.3 & 5.34 & -18.3 & 5.56 & -14.9 & 6.82 & 4.3 \\
\hline Vias Principais & 21.85 & 22.32 & 2.1 & 16.92 & -22.6 & 16.27 & -25.5 & 19.25 & -11.9 \\
\hline Vias Secundárias & 11.20 & 11.09 & -1.0 & 11.85 & 5.8 & 11.63 & 3.8 & 10.25 & -8.4 \\
\hline Rede & 8.74 & 8.80 & 0.7 & 7.90 & -9.6 & 7.65 & -12.5 & 7.79 & -10.9 \\
\hline \multicolumn{10}{|l|}{$N^{\circ}$ de Paradas } \\
\hline R. D. Alexandrina & 0.233 & 0.238 & 2.1 & 0.190 & -18.4 & 0.202 & -13.6 & 0.208 & -11.0 \\
\hline Av. São Carlos & 0.233 & 0.233 & 0.0 & 0.179 & -23.0 & 0.178 & -23.6 & 0.216 & -7.2 \\
\hline R. Episcopal & 0.213 & 0.215 & 1.3 & 0.187 & -12.2 & 0.195 & -8.1 & 0.222 & 4.6 \\
\hline Vias Principais & 0.679 & 0.687 & 1.1 & 0.557 & -18.1 & 0.575 & -15.3 & 0.646 & -4.8 \\
\hline Vias Secundárias & 0.449 & 0.448 & -0.3 & 0.498 & 10.9 & 0.479 & 6.5 & 0.433 & -3.6 \\
\hline Rede & 0.307 & 0.308 & 0.4 & 0.297 & -3.1 & 0.294 & -4.2 & 0.293 & -4.5 \\
\hline
\end{tabular}

* os percentuais de redução e acréscimo das medidas de desempenho foram calculados em relação ao cenário simultâneo.

A Figura 7-8 ilustra os resultados médios das medidas de desempenho em cada tramo da rede de São Carlos (tempo de percurso, atraso e número de paradas), onde é possível verificar que as maiores alterações oriundas das diferentes propostas de coordenação ocorrem nos tramos dos corredores arteriais: tramos 1 a 8 referentes à Rua D. Alexandrina, tramos 9 a 16 da Avenida São Carlos, e tramos 17 a 24 para a Rua Episcopal. Os valores das medidas operacionais de eficiência resultantes dos tramos das vias secundárias da rede da cidade de São Carlos (25 a 51) não sofrem alterações tão significativas.

É possível perceber que as menores medidas de desempenho ilustradas nos gráficos da Figura 7-8 são relativas aos tramos extremos da rede selecionada na cidade de São Carlos (8, 9 e 24 da via principal e 25, 32, 33, 40, 41, 48 e 51 das vias secundárias), apresentado até valores nulos, uma vez que a saída destes segmentos não é controlada por semáforo. 

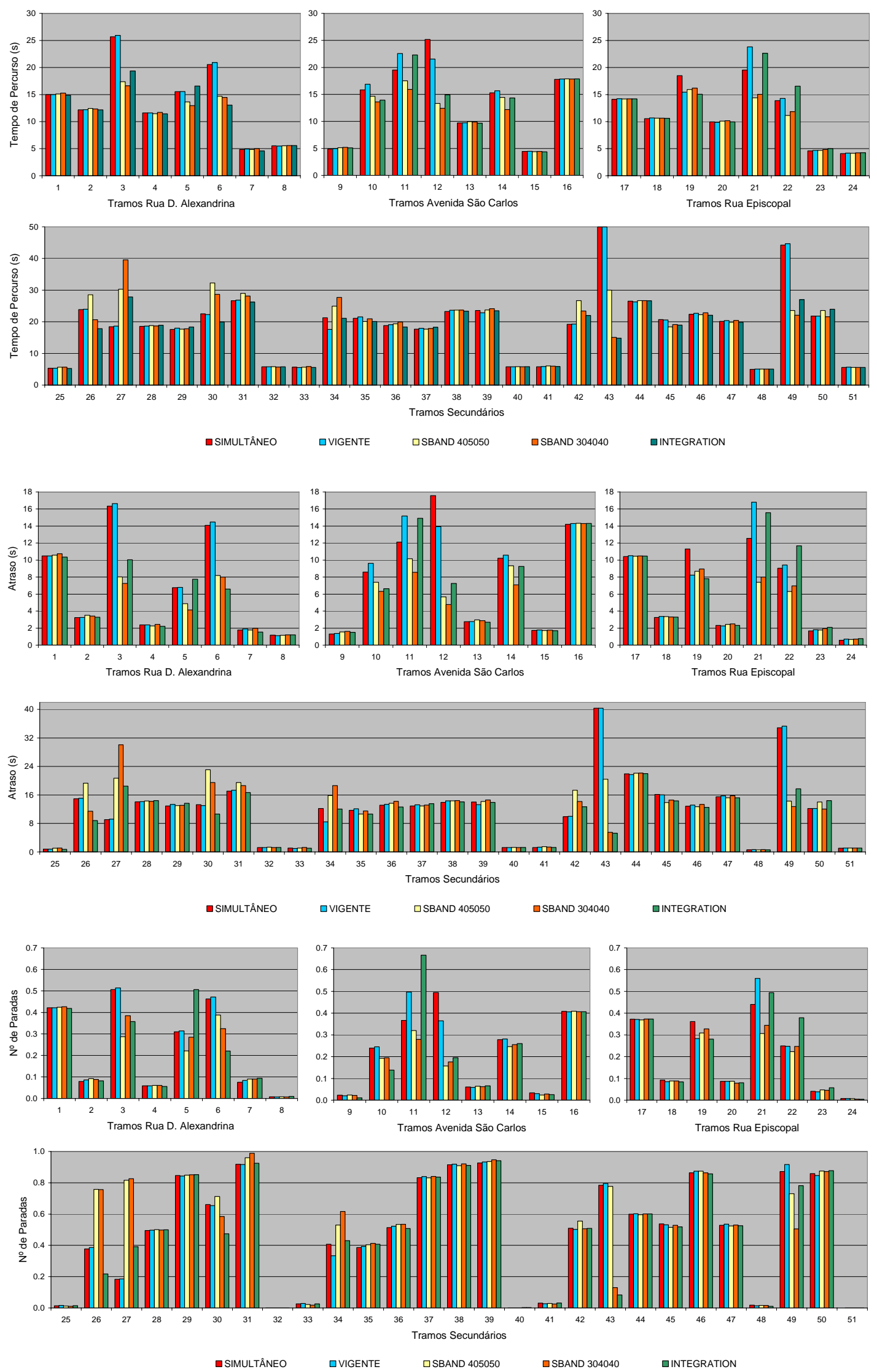

Figura 7-8: Medidas operacionais de eficiência por tramo da rede de São Carlos 


\subsection{Simulações dos Cenários com Demandas Reduzidas}

Para realizar a análise de sensibilidade do desempenho do programa proposto SBAND e do simulador INTEGRATION em relação às variações de volume de tráfego, e considerando que as Avenidas Higienópolis, Juscelino Kubitscheck e Maringá apresentam volumetria elevada ou que se aproxima da saturação, todos os pares da matriz origem-destino destes corredores foram alterados na mesma porcentagem, em variações de redução entre $15 \%$ a $85 \%$ da demanda real. Com a utilização das novas matrizes reduzidas, todos os cenários foram simulados novamente, sem nenhuma mudança na duração do ciclo ou nas divisões do tempo de verde, para comparação isolada das medidas de eficiência em cada porcentagem de demanda.

\subsubsection{Avenida Higienópolis}

A Figura 7-9 apresenta separadamente em forma de gráfico, os resultados de tempo de percurso médio gasto por veículo na via principal, nas vias secundárias e para a rede, obtidos em cada cenário avaliado da Avenida Higienópolis com as demandas reduzidas entre $15 \%$ e $85 \%$ da demanda real.
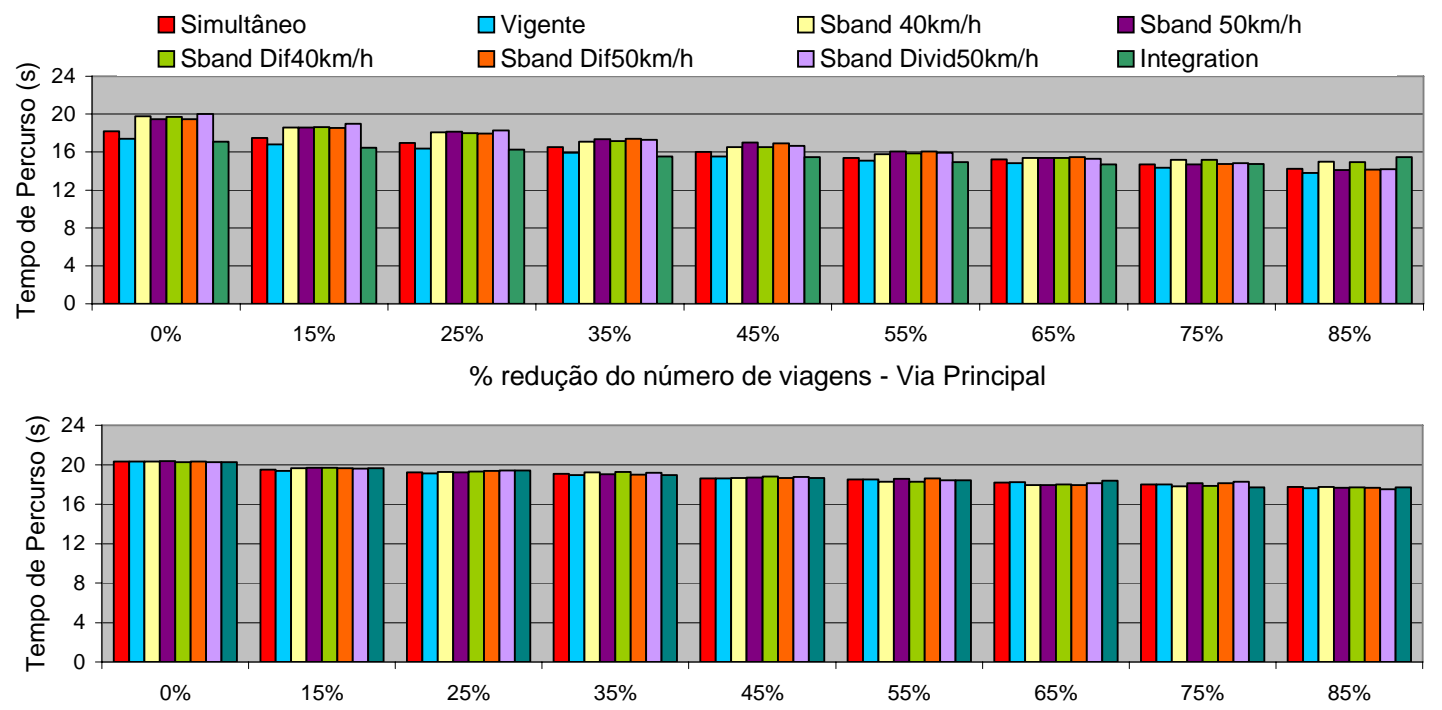

\% redução do número de viagens - Vias Secundárias

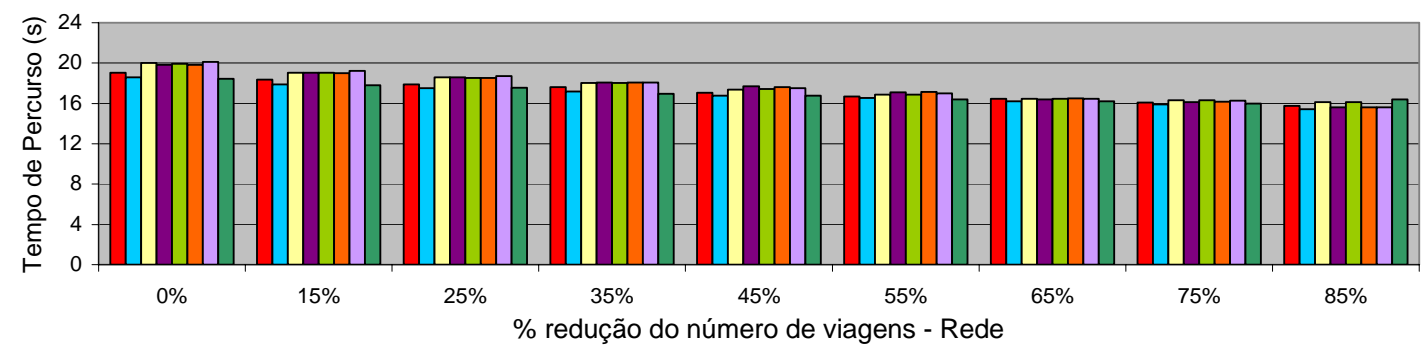

Figura 7-9: Valores de tempo médio de percurso obtidos para cada porcentagem de viagens na Avenida Higienópolis 
No resumo da Tabela 7-5, é possível verificar que para praticamente todas as demandas simuladas com redução, o cenário vigente com coordenação alternada e o cenário de coordenação gerada pelo INTEGRATION resultam em menores valores de tempo de percurso, tanto para a via principal como para a rede, em relação ao cenário de progressão simultânea, embora as porcentagens de redução no tempo de percurso sejam menos expressivas à medida que a demanda diminui.

Tabela 7-5: Percentuais de redução ou acréscimo nos tempos médios de percurso obtidos na Avenida Higienópolis

\begin{tabular}{|c|c|c|c|c|c|c|c|c|}
\hline Cenário & Simultâneo* & Vigente & $\begin{array}{l}\text { Sband Igual } \\
40 \mathrm{~km} / \mathrm{h}\end{array}$ & $\begin{array}{l}\text { Sband Igual } \\
50 \mathrm{~km} / \mathrm{h}\end{array}$ & $\begin{array}{l}\text { Sband Diferente } \\
40 \mathrm{~km} / \mathrm{h}\end{array}$ & $\begin{array}{c}\text { Sband Diferente } \\
50 \mathrm{~km} / \mathrm{h}\end{array}$ & $\begin{array}{c}\text { Sband Dividido } \\
50 \mathrm{~km} / \mathrm{h}\end{array}$ & Integration \\
\hline & média/veic & $\%$ & $\%$ & $\%$ & $\%$ & $\%$ & $\%$ & $\%$ \\
\hline \multicolumn{9}{|l|}{ Redução 15\% } \\
\hline principal & 17.49 & -3.8 & 6.3 & 6.4 & 6.5 & 5.9 & 8.4 & -5.7 \\
\hline secundárias & 19.51 & -0.7 & 0.6 & 0.8 & 0.8 & 0.8 & 0.5 & 0.6 \\
\hline rede & 18.33 & -2.4 & 3.8 & 3.9 & 4.0 & 3.6 & 4.9 & -2.9 \\
\hline \multicolumn{9}{|l|}{ Redução 25\% } \\
\hline principal & 16.94 & -3.4 & 6.7 & 7.0 & 6.1 & 5.8 & 7.8 & -4.1 \\
\hline secundárias & 19.22 & -0.5 & 0.3 & 0.1 & 0.4 & 0.6 & 0.9 & 1.0 \\
\hline rede & 17.90 & -2.1 & 3.8 & 3.9 & 3.5 & 3.5 & 4.7 & -1.8 \\
\hline \multicolumn{9}{|l|}{ Redução 35\% } \\
\hline principal & 16.52 & -3.7 & 3.6 & 5.0 & 3.8 & 5.2 & 4.7 & -6.0 \\
\hline secundárias & 19.07 & -0.6 & 0.8 & -0.1 & 0.9 & -0.4 & 0.5 & -0.7 \\
\hline rede & 17.59 & -2.3 & 2.3 & 2.7 & 2.5 & 2.6 & 2.8 & -3.6 \\
\hline \multicolumn{9}{|l|}{ Redução 45\% } \\
\hline principal & 16.00 & -2.9 & 3.2 & 6.1 & 3.1 & 5.7 & 4.2 & -3.3 \\
\hline secundárias & 18.59 & 0.1 & 0.2 & 0.6 & 1.0 & 0.3 & 0.7 & 0.4 \\
\hline rede & 17.06 & -1.6 & 1.9 & 3.7 & 2.2 & 3.3 & 2.6 & -1.6 \\
\hline \multicolumn{9}{|l|}{ Redução 55\% } \\
\hline principal & 15.35 & -1.7 & 2.8 & 4.5 & 3.2 & 4.6 & 3.8 & -2.7 \\
\hline secundárias & 18.49 & 0.0 & -1.1 & 0.5 & -1.2 & 0.5 & -0.4 & -0.5 \\
\hline rede & 16.68 & -0.9 & 1.0 & 2.6 & 1.1 & 2.6 & 1.8 & -1.7 \\
\hline \multicolumn{9}{|l|}{ Redução 65\% } \\
\hline principal & 15.25 & -2.8 & 1.0 & 0.7 & 0.8 & 1.4 & 0.2 & -3.6 \\
\hline secundárias & 18.20 & 0.2 & -1.4 & -1.5 & -1.3 & -1.4 & -0.3 & 1.0 \\
\hline rede & 16.47 & -1.4 & -0.1 & -0.3 & -0.2 & 0.1 & 0.0 & -1.6 \\
\hline \multicolumn{9}{|l|}{ Redução 75\% } \\
\hline principal & 14.70 & -2.5 & 3.2 & -0.3 & 3.4 & 0.0 & 0.8 & 0.2 \\
\hline secundárias & 17.97 & 0.2 & -0.9 & 1.0 & -0.7 & 0.9 & 1.7 & -1.4 \\
\hline rede & 16.08 & -1.3 & 1.3 & 0.3 & 1.5 & 0.4 & 1.2 & -0.5 \\
\hline \multicolumn{9}{|l|}{ Redução 85\% } \\
\hline principal & 14.25 & -3.1 & 5.1 & -1.1 & 4.9 & -0.7 & -0.4 & 8.5 \\
\hline secundárias & 17.76 & -0.8 & -0.2 & -0.7 & -0.4 & -0.6 & -1.3 & -0.4 \\
\hline rede & 15.74 & -2.0 & 2.6 & -0.9 & 2.4 & -0.7 & -0.8 & 4.2 \\
\hline
\end{tabular}

* os percentuais de redução e acréscimo das medidas de desempenho foram calculados em relação ao respectivo cenário simultâneo com demanda reduzida.

No caso da menor demanda simulada (somente $15 \%$ da demanda real), a coordenação gerada pelo programa INTEGRATION resultou em acréscimo de 8,5\% no tempo médio de percurso gasto por veículo na via principal e 4,2\% a mais na rede, quando comparado com o cenário simultâneo. Este fato provavelmente reflete a falta de distribuição dos tempos de verde e otimização dos ciclos para diferentes níveis de demanda, que se tornam especialmente necessários para baixos volumes de tráfego, visto que todas as simulações utilizaram o ciclo e os tempos de verde do cenário vigente, independente do fluxo de veículos na rede. 
Já nos cenários com coordenação obtida pelo programa SBAND, nota-se melhorias nos valores de tempo de percurso em função do decréscimo da demanda em comparação com a condição de defasagens simultâneas, mas sem superar as medidas deste cenário. Principalmente para as defasagens obtidas com velocidade de progressão semelhante à regulamentada na Avenida Higienópolis $(50 \mathrm{~km} / \mathrm{h})$, os resultados do tempo de percurso praticamente se igualam àqueles obtidos pelo cenário simultâneo, porém somente para baixas demandas (com reduções de 65\% a 85\% da demanda real), e ainda sem atingir as reduções geradas especialmente pelo cenário vigente.

Os resultados de atraso médio por veículo na via principal, nas vias secundárias e para a rede, obtidos em cada cenário avaliado da Avenida Higienópolis com as demandas reduzidas entre $15 \%$ e $85 \%$ da demanda real, estão representados separadamente em forma de gráfico na Figura 7-10.
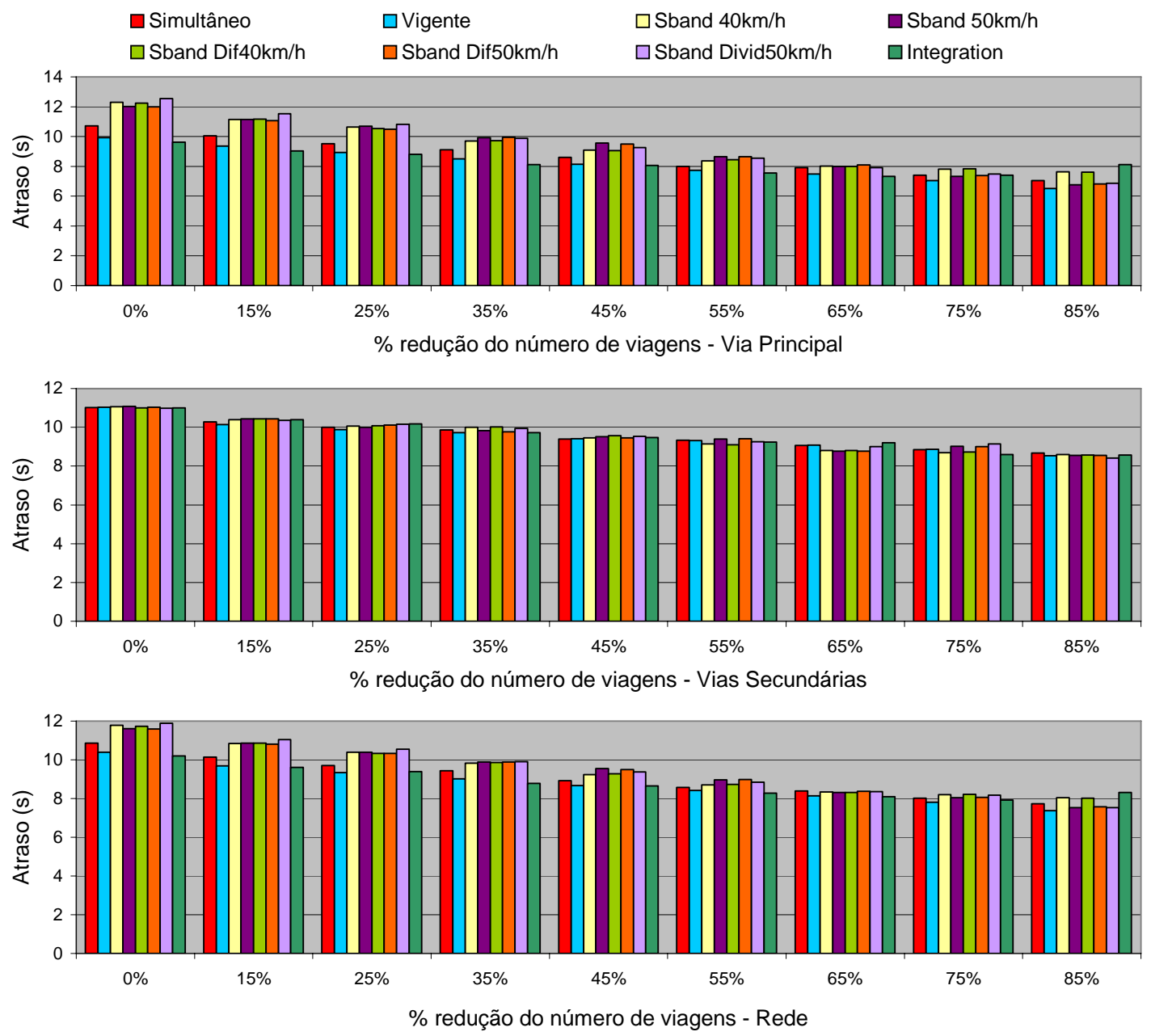

Figura 7-10: Valores de atraso médio obtidos para cada porcentagem de viagens na Avenida Higienópolis 
Assim como ocorre para o tempo de percurso, os resultados observados no cenário vigente e no cenário obtido pelo INTEGRATION, quando comparados com o cenário simultâneo, proporcionam reduções no atraso médio por veículo na via principal e na rede, e estas reduções também ficam menos significativas à medida que a demanda fica menor. Somente para a simulação com apenas 15\% da demanda real, a coordenação gerada pelo programa INTEGRATION resultou no acréscimo de 15,3\% no atraso médio por veículo na via principal e 7,5\% na rede, em comparação com o cenário simultâneo. Os valores de atraso resultantes das demandas reduzidas em cada cenário da Avenida Higienópolis estão resumidos na Tabela 7-6.

Tabela 7-6: Percentuais de redução ou acréscimo nos atrasos médios obtidos na Avenida Higienópolis

\begin{tabular}{|c|c|c|c|c|c|c|c|c|}
\hline Cenário & Simultâneo* & Vigente & $\begin{array}{c}\text { Sband Igual } \\
40 \mathrm{~km} / \mathrm{h}\end{array}$ & $\begin{array}{c}\text { Sband Igual } \\
50 \mathrm{~km} / \mathrm{h}\end{array}$ & $\begin{array}{c}\text { Sband Diferente } \\
40 \mathrm{~km} / \mathrm{h}\end{array}$ & $\begin{array}{c}\text { Sband Diferente } \\
50 \mathrm{~km} / \mathrm{h}\end{array}$ & $\begin{array}{c}\text { Sband Dividido } \\
50 \mathrm{~km} / \mathrm{h}\end{array}$ & Integration \\
\hline & média/veic & $\%$ & $\%$ & $\%$ & $\%$ & $\%$ & $\%$ & $\%$ \\
\hline \multicolumn{9}{|l|}{ Redução 15\% } \\
\hline principal & 10.04 & -6.6 & 11.0 & 11.1 & 11.3 & 10.1 & 14.7 & -10.0 \\
\hline secundárias & 10.28 & -1.4 & 1.2 & 1.5 & 1.5 & 1.5 & 0.8 & 1.1 \\
\hline rede & 10.14 & -4.4 & 6.8 & 7.0 & 7.1 & 6.5 & 8.8 & -5.3 \\
\hline \multicolumn{9}{|l|}{ Redução 25\% } \\
\hline principal & 9.51 & -6.2 & 11.8 & 12.3 & 10.7 & 10.3 & 13.8 & -7.3 \\
\hline secundárias & 10.00 & -1.1 & 0.6 & 0.1 & 0.8 & 1.2 & 1.7 & 1.9 \\
\hline rede & 9.71 & -4.0 & 7.0 & 7.1 & 6.4 & 6.4 & 8.6 & -3.3 \\
\hline \multicolumn{9}{|l|}{ Redução 35\% } \\
\hline principal & 9.12 & -6.7 & 6.3 & 8.8 & 6.7 & 9.1 & 8.4 & -10.9 \\
\hline secundárias & 9.86 & -1.4 & 1.5 & -0.3 & 1.7 & -0.9 & 0.8 & -1.4 \\
\hline rede & 9.43 & -4.4 & 4.2 & 4.8 & 4.5 & 4.7 & 5.1 & -6.8 \\
\hline \multicolumn{9}{|l|}{ Redução 45\% } \\
\hline principal & 8.60 & -5.4 & 5.7 & 11.2 & 5.4 & 10.4 & 7.6 & -6.3 \\
\hline secundárias & 9.39 & 0.3 & 0.6 & 1.2 & 1.9 & 0.6 & 1.5 & 0.8 \\
\hline rede & 8.93 & -3.0 & 3.5 & 6.9 & 3.9 & 6.2 & 4.9 & -3.2 \\
\hline \multicolumn{9}{|l|}{ Redução 55\% } \\
\hline principal & 8.00 & -3.4 & 4.8 & 8.1 & 5.4 & 8.2 & 6.7 & -5.5 \\
\hline secundárias & 9.33 & -0.1 & -2.0 & 0.8 & -2.4 & 0.9 & -0.7 & -1.0 \\
\hline rede & 8.57 & -1.9 & 1.6 & 4.7 & 1.8 & 4.8 & 3.3 & -3.4 \\
\hline \multicolumn{9}{|l|}{ Redução 65\% } \\
\hline principal & 7.92 & -5.4 & 1.2 & 0.9 & 0.8 & 2.2 & -0.1 & -7.3 \\
\hline secundárias & 9.06 & 0.3 & -2.8 & -3.2 & -2.8 & -3.1 & -0.6 & 1.5 \\
\hline rede & 8.39 & -2.9 & -0.6 & -0.9 & -0.8 & -0.2 & -0.3 & -3.4 \\
\hline \multicolumn{9}{|l|}{ Redução 75\% } \\
\hline principal & 7.42 & -5.0 & 5.4 & -1.1 & 5.6 & -0.5 & 1.0 & 0.0 \\
\hline secundárias & 8.84 & 0.3 & -1.7 & 2.0 & -1.3 & 1.9 & 3.4 & -2.8 \\
\hline rede & 8.02 & -2.6 & 2.1 & 0.3 & 2.4 & 0.6 & 2.1 & -1.3 \\
\hline \multicolumn{9}{|l|}{ Redução 85\% } \\
\hline principal & 7.04 & -7.3 & 8.5 & -3.7 & 8.2 & -3.0 & -2.3 & 15.3 \\
\hline secundárias & 8.66 & -1.6 & -0.8 & -1.3 & -1.1 & -1.3 & -3.0 & -1.1 \\
\hline rede & 7.73 & -4.6 & 4.0 & -2.6 & 3.7 & -2.2 & -2.6 & 7.5 \\
\hline
\end{tabular}

* os percentuais de redução e acréscimo das medidas de desempenho foram calculados em relação ao respectivo cenário simultâneo com demanda reduzida.

Para os cenários com defasagens geradas pelo programa SBAND, os valores de atraso médio na Avenida Higienópolis somente são menores do que os resultados obtidos pelo cenário com abertura simultânea dos semáforos para o caso da velocidade de progressão de $50 \mathrm{~km} / \mathrm{h}$, nas simulações com baixas demandas (reduções de 65\% a $85 \%$ da demanda real). 
A Figura 7-11 ilustra separadamente em forma de gráfico, os resultados do número de paradas na via principal, nas vias secundárias e para a rede, obtidos em cada cenário avaliado da Avenida Higienópolis com as demandas reduzidas entre 15\% e 85\% da demanda real.
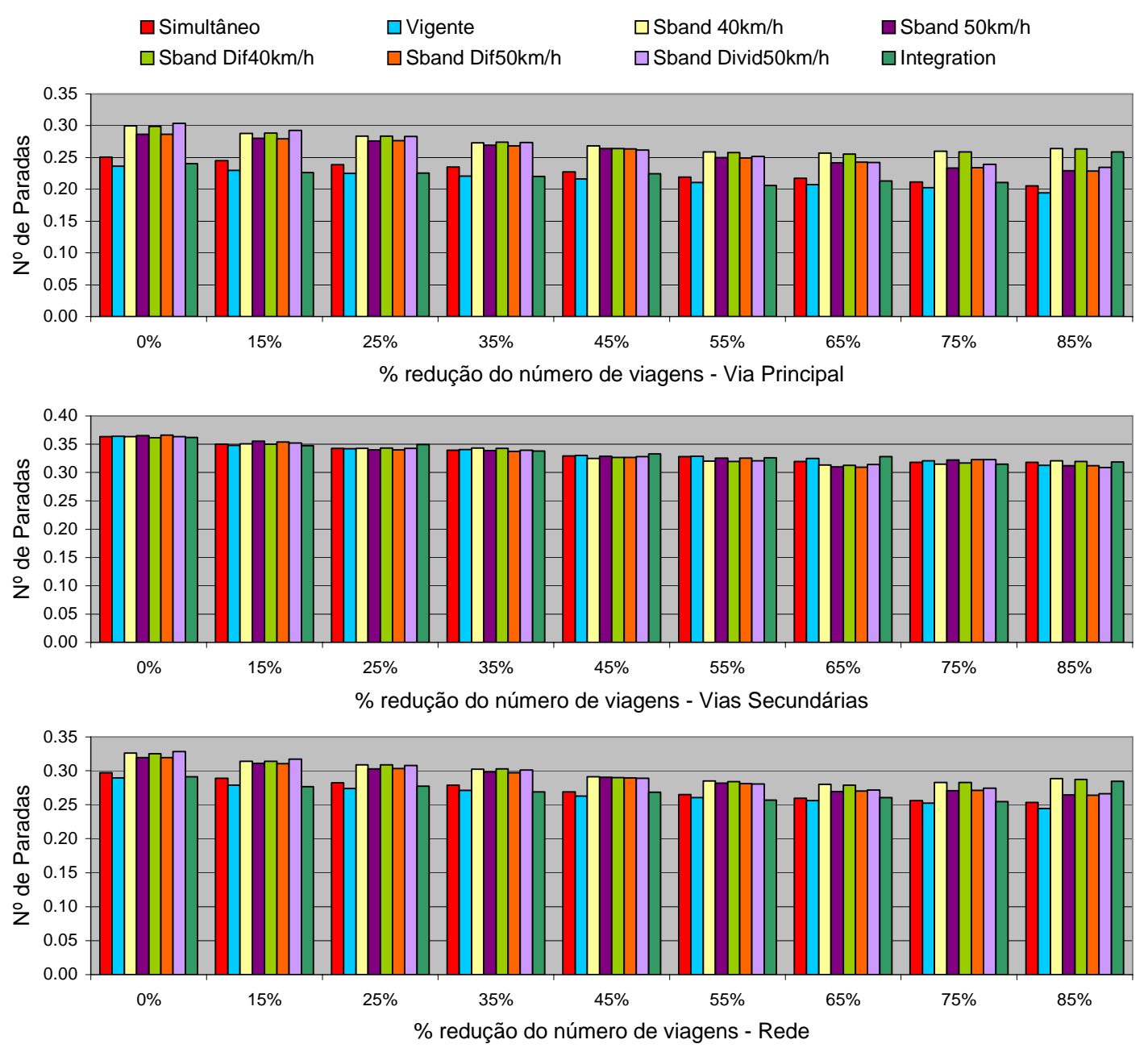

Figura 7-11: Valores de número de paradas obtidos para cada porcentagem de viagens na Avenida Higienópolis

A quantidade de paradas sofridas em média pelos veículos que circulam pela via principal e também para a rede com o cenário vigente demonstram redução em todas as demandas avaliadas, quando comparadas ao cenário simultâneo utilizado como referência, conforme porcentagens resumidas na Tabela 7-7. Isto também ocorre na comparação entre o cenário simultâneo e o cenário com defasagens definidas pelo simulador INTEGRATION, com exceção da simulação com redução de 85\% na demanda real, onde a coordenação gerada pelo programa INTEGRATION resultou em 25,8\% de acréscimo no número de paradas, provavelmente em função da duração fixa 
do ciclo e dos tempos de verde.

Tabela 7-7: Percentuais de redução ou acréscimo nos números médios de paradas obtidos na Avenida Higienópolis

\begin{tabular}{|c|c|c|c|c|c|c|c|c|}
\hline Cenário & Simultâneo* & Vigente & $\begin{array}{l}\text { Sband Igual } \\
40 \mathrm{~km} / \mathrm{h}\end{array}$ & $\begin{array}{l}\text { Sband Igual } \\
50 \mathrm{~km} / \mathrm{h}\end{array}$ & $\begin{array}{c}\text { Sband Diferente } \\
40 \mathrm{~km} / \mathrm{h}\end{array}$ & $\begin{array}{l}\text { Sband Diferente } \\
50 \mathrm{~km} / \mathrm{h}\end{array}$ & $\begin{array}{l}\text { Sband Dividido } \\
50 \mathrm{~km} / \mathrm{h}\end{array}$ & Integration \\
\hline & média/veic & $\%$ & $\%$ & $\%$ & $\%$ & $\%$ & $\%$ & $\%$ \\
\hline \multicolumn{9}{|l|}{ Redução 15\% } \\
\hline principal & 0.245 & -6.3 & 17.6 & 14.3 & 17.7 & 14.1 & 19.3 & -7.7 \\
\hline secundárias & 0.350 & -0.6 & 0.1 & 1.4 & -0.1 & 1.1 & 0.4 & -0.9 \\
\hline rede & 0.289 & -3.4 & 8.7 & 7.7 & 8.7 & 7.5 & 9.7 & -4.3 \\
\hline \multicolumn{9}{|l|}{ Redução 25\% } \\
\hline principal & 0.239 & -5.7 & 18.9 & 15.5 & 18.7 & 15.8 & 18.5 & -5.5 \\
\hline secundárias & 0.343 & -0.3 & 0.0 & -0.8 & 0.2 & -0.8 & -0.1 & 1.8 \\
\hline rede & 0.283 & -3.0 & 9.2 & 7.2 & 9.3 & 7.3 & 9.0 & -1.8 \\
\hline \multicolumn{9}{|l|}{ Redução 35\% } \\
\hline principal & 0.235 & -6.0 & 16.2 & 14.6 & 16.7 & 14.1 & 16.2 & -6.4 \\
\hline secundárias & 0.340 & 0.3 & 1.1 & -0.2 & 0.9 & -0.6 & 0.0 & -0.5 \\
\hline rede & 0.279 & -2.8 & 8.5 & 7.0 & 8.6 & 6.6 & 7.9 & -3.5 \\
\hline \multicolumn{9}{|l|}{ Redução 45\% } \\
\hline principal & 0.227 & -4.9 & 17.9 & 16.3 & 16.2 & 15.9 & 15.2 & -1.4 \\
\hline secundárias & 0.329 & 0.2 & -1.4 & -0.2 & -0.7 & -0.8 & -0.3 & 1.1 \\
\hline rede & 0.269 & -2.3 & 8.3 & 8.0 & 7.8 & 7.5 & 7.4 & -0.1 \\
\hline \multicolumn{9}{|l|}{ Redução 55\% } \\
\hline principal & 0.219 & -3.7 & 18.2 & 14.1 & 17.7 & 13.8 & 14.8 & -5.8 \\
\hline secundárias & 0.328 & 0.1 & -2.5 & -0.8 & -2.8 & -0.9 & -2.4 & -0.7 \\
\hline rede & 0.265 & -1.7 & 7.4 & 6.3 & 7.0 & 6.1 & 5.8 & -3.1 \\
\hline \multicolumn{9}{|l|}{ Redução 65\% } \\
\hline principal & 0.217 & -4.6 & 18.2 & 11.2 & 17.5 & 11.8 & 11.5 & -1.8 \\
\hline secundárias & 0.320 & 1.7 & -2.0 & -3.0 & -2.3 & -3.2 & -1.9 & 2.6 \\
\hline rede & 0.260 & -1.4 & 7.9 & 3.9 & 7.4 & 4.1 & 4.7 & 0.4 \\
\hline \multicolumn{9}{|l|}{ Redução 75\% } \\
\hline principal & 0.211 & -4.1 & 23.1 & 10.6 & 22.5 & 10.8 & 13.3 & -0.3 \\
\hline secundárias & 0.318 & 0.9 & -0.9 & 1.3 & -0.4 & 1.5 & 1.5 & -0.9 \\
\hline rede & 0.256 & -1.5 & 10.6 & 5.7 & 10.5 & 5.9 & 7.1 & -0.6 \\
\hline \multicolumn{9}{|l|}{ Redução 85\% } \\
\hline principal & 0.206 & -5.6 & 28.5 & 11.4 & 28.2 & 11.2 & 14.2 & 25.9 \\
\hline secundárias & 0.318 & -1.8 & 0.8 & -2.0 & 0.3 & -2.0 & -3.0 & 0.2 \\
\hline rede & 0.254 & -3.6 & 13.7 & 4.3 & 13.3 & 4.2 & 5.0 & 12.2 \\
\hline
\end{tabular}

* os percentuais de redução e acréscimo das medidas de desempenho foram calculados em relação ao respectivo cenário simultâneo com demanda reduzida.

Nenhuma das propostas geradas pelo programa SBAND resultou em reduções no número de paradas na via principal ou na rede, independentemente das demandas simuladas, sendo que reduções de até 3\% foram promovidas na quantidade de paradas das vias secundárias, quando comparadas ao cenário com abertura simultânea dos semáforos.

\subsubsection{Avenida Juscelino Kubitscheck}

Todos os pares da matriz origem-destino da Avenida Juscelino Kubitscheck também foram alterados na mesma porcentagem, em variações de redução entre $15 \%$ a $85 \%$ da demanda real, de forma a possibilitar a análise de sensibilidade da eficiência dos programas SBAND e INTEGRATION em relação aos diferentes volumes. A Figura 7-12 ilustra separadamente os resultados de tempo médio de percurso por veículo na via principal, nas vias secundárias e para toda a rede. 

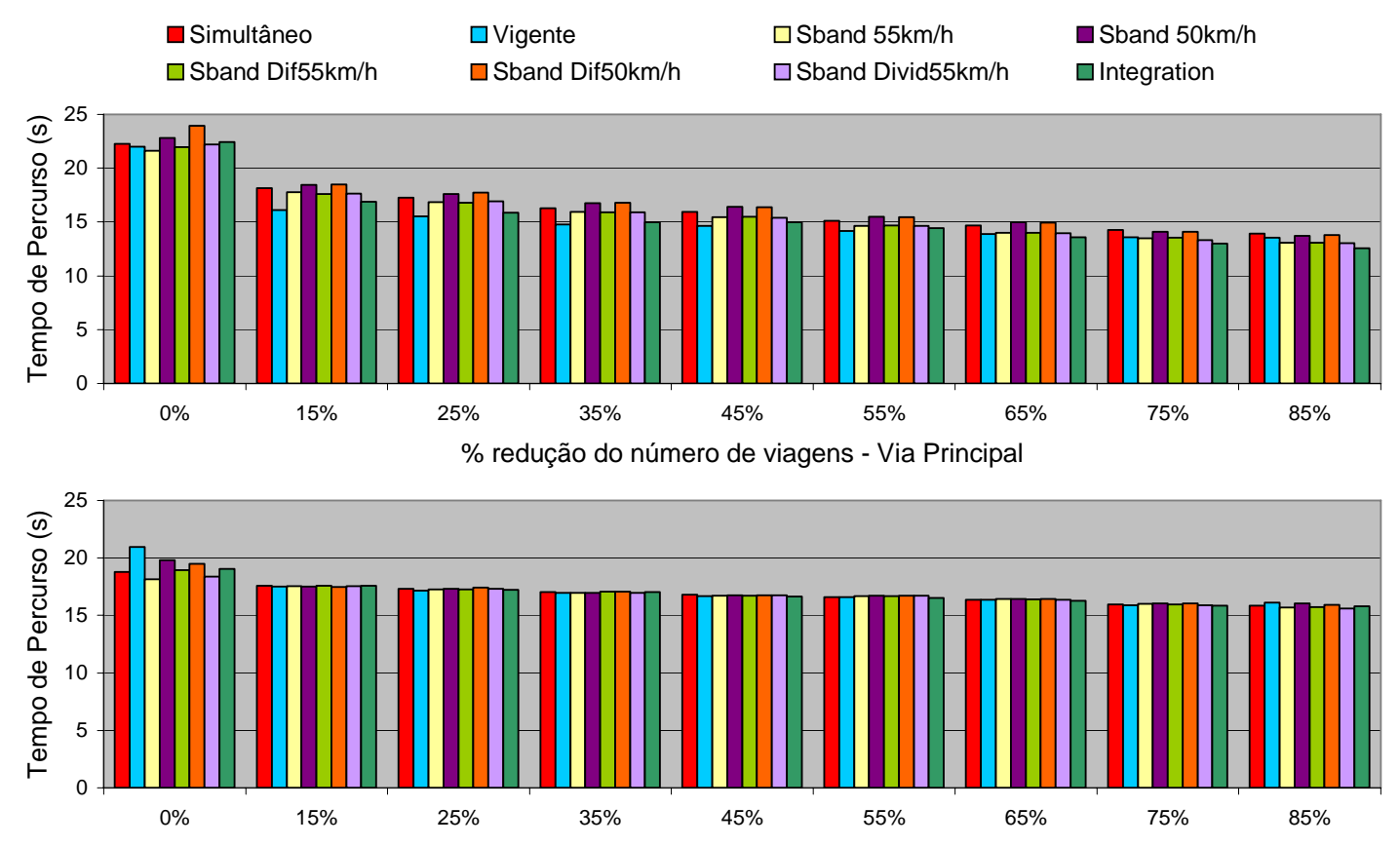

\% redução do número de viagens - Vias Secundárias

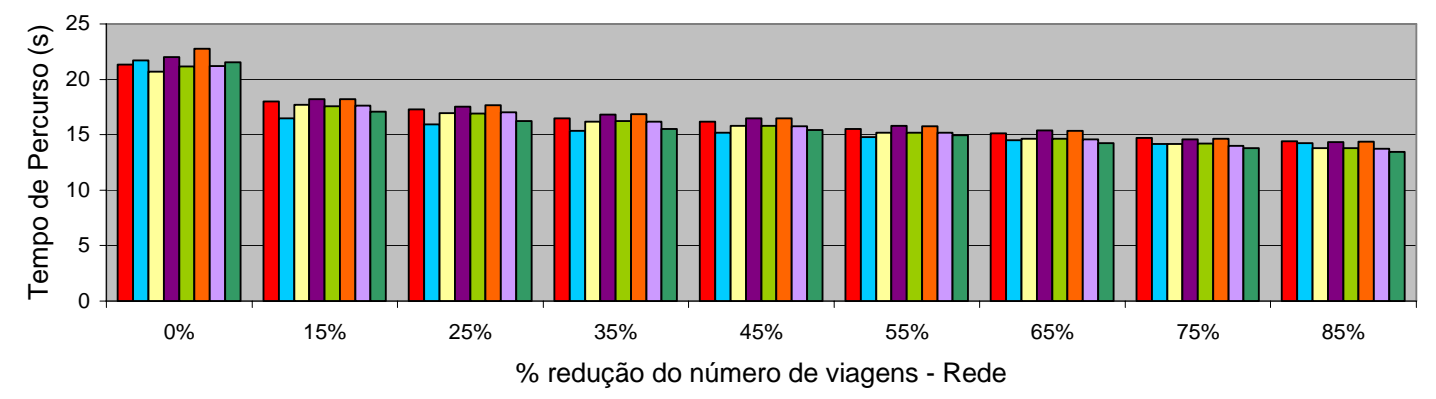

Figura 7-12: Valores de tempo médio de percurso obtidos para cada porcentagem de viagens na Avenida Juscelino Kubitscheck

Observando os valores resumidos na Tabela 7-8, especialmente para as situações com demandas entre $15 \%$ e $55 \%$ da demanda real observada na Avenida Juscelino Kubitscheck, é possível verificar que o cenário vigente resulta nos menores valores de tempo de percurso, tanto para a via principal como para a rede, em relação ao cenário de progressão simultânea, embora as porcentagens de redução sejam menos expressivas à medida que a demanda diminui. As propostas de coordenação geradas pelo programa INTEGRATION também proporcionaram diminuição no tempo de percurso para todas as demandas simuladas, principalmente para as condições simuladas com baixa demanda.

Das coordenações obtidas pelo programa proposto SBAND, os menores valores de tempo de percurso foram observados nos cenários com velocidade de progressão de $55 \mathrm{~km} / \mathrm{h}$, tanto para bandas bidirecionais iguais quanto para bandas 
proporcionais aos volumes direcionais. Para as reduções de demanda na Avenida Juscelino Kubitscheck de $75 \%$ e $85 \%$, o cenário gerado pelo programa SBAND em duas etapas com velocidade de $55 \mathrm{~km} / \mathrm{h}$ proporcionou significativas melhorias no tempo de percurso, superiores àquelas geradas pelo cenário vigente.

Tabela 7-8: Percentuais de redução ou acréscimo nos tempos médios de percurso obtidos na Avenida Juscelino Kubitscheck

\begin{tabular}{|c|c|c|c|c|c|c|c|c|}
\hline \multirow{2}{*}{ Cenário } & Simultâneo* & Vigente & Sband $55 \mathrm{~km} / \mathrm{h}$ & Sband $50 \mathrm{~km} / \mathrm{h}$ & Sband Dif55km/h & Sband Dif50km/h & Sband Divid55km/h & Integration \\
\hline & média/veic & $\%$ & $\%$ & $\%$ & $\%$ & $\%$ & $\%$ & $\%$ \\
\hline \multicolumn{9}{|l|}{$\begin{array}{l}\text { Redução 15\% } \\
\text { principal }\end{array}$} \\
\hline principal & 18.15 & -11.2 & -2.0 & 1.7 & -3.0 & 1.8 & -2.8 & -7.0 \\
\hline secundárias & 17.61 & -0.5 & -0.3 & -0.5 & -0.1 & -0.7 & -0.3 & -0.1 \\
\hline & 18.01 & -8.5 & -1.6 & 1.1 & -2.3 & 1.1 & -2.2 & -5.2 \\
\hline \multicolumn{9}{|l|}{ Redução 25\% } \\
\hline principal & 17.28 & -10.2 & -2.5 & 2.0 & -2.9 & 2.6 & -2.1 & -8.2 \\
\hline secundárias & 17.30 & -0.9 & -0.2 & 0.1 & -0.2 & 0.7 & 0.0 & -0.3 \\
\hline rede & 17.29 & -7.7 & -1.9 & 1.5 & -2.2 & 2.1 & -1.6 & -6.1 \\
\hline \multicolumn{9}{|l|}{ Redução 35\% } \\
\hline principal & 16.27 & -9.2 & -2.1 & 2.9 & -2.2 & 3.2 & -2.3 & -7.9 \\
\hline secundárias & 17.04 & -0.5 & -0.5 & -0.4 & 0.2 & 0.1 & -0.4 & -0.1 \\
\hline rede & 16.47 & -6.8 & -1.7 & 2.0 & -1.5 & 2.4 & -1.8 & -5.8 \\
\hline \multicolumn{9}{|l|}{ Redução 45\% } \\
\hline principal & 15.95 & -8.3 & -3.1 & 2.8 & -2.8 & 2.6 & -3.4 & -6.1 \\
\hline secundárias & 16.79 & -0.6 & -0.3 & -0.1 & -0.4 & -0.1 & -0.2 & -0.8 \\
\hline rede & 16.17 & -6.2 & -2.3 & 2.0 & -2.1 & 1.9 & -2.5 & -4.6 \\
\hline \multicolumn{9}{|l|}{ Redução 55\% } \\
\hline principal & 15.10 & -6.2 & -3.0 & 2.4 & -2.9 & 2.3 & -3.2 & -4.6 \\
\hline secundárias & 16.61 & 0.0 & 0.3 & 0.5 & 0.4 & 0.8 & 0.6 & -0.5 \\
\hline rede & 15.50 & -4.5 & -2.0 & 1.9 & -2.0 & 1.8 & -2.1 & -3.4 \\
\hline \multicolumn{9}{|l|}{ Redução 65\% } \\
\hline principal & 14.69 & -5.7 & -4.7 & 2.1 & -4.7 & 1.7 & -5.0 & -7.7 \\
\hline secundárias & 16.37 & 0.0 & 0.5 & 0.3 & 0.2 & 0.3 & -0.2 & -0.6 \\
\hline rede & 15.13 & -4.1 & -3.3 & 1.6 & -3.3 & 1.3 & -3.6 & -5.7 \\
\hline \multicolumn{9}{|l|}{ Redução 75\% } \\
\hline principal & 14.28 & -5.0 & -5.5 & -1.4 & -5.1 & -1.3 & -6.8 & -8.9 \\
\hline secundárias & 15.97 & -0.5 & 0.2 & 0.4 & 0.1 & 0.5 & -0.6 & -0.7 \\
\hline rede & 14.73 & -3.7 & -3.9 & -0.8 & -3.6 & -0.7 & -5.0 & -6.5 \\
\hline \multicolumn{9}{|l|}{ Redução 85\% } \\
\hline principal & 13.91 & -2.5 & -5.9 & -1.5 & -5.9 & -0.8 & -6.3 & -9.5 \\
\hline secundárias & 15.8 & 1.7 & -0.9 & 1.2 & -0.8 & 0.6 & -1.5 & -0.3 \\
\hline rede & 14.43 & -1.3 & -4.4 & -0.7 & -4.4 & -0.4 & -4.9 & -6.7 \\
\hline
\end{tabular}

* os percentuais de redução e acréscimo das medidas de desempenho foram calculados em relação ao respectivo cenário simultâneo com demanda reduzida.

Os resultados de atraso médio por veículo com as demandas reduzidas entre $15 \%$ e $85 \%$ da demanda real, separados para a via principal, vias secundárias e para a rede, obtidos em cada cenário avaliado da Avenida Juscelino Kubitscheck, estão representados em forma de gráfico na Figura 7-13.

Melhorias semelhantes às obtidas com o tempo de percurso resultaram em medidas de atraso médio por veículo com reduções significativas para o cenário vigente, quando comparado com o cenário simultâneo utilizado como referência, porém com os benefícios também ficando menores à medida que a demanda diminui. Todas as coordenações geradas pelo programa INTEGRATION com demandas reduzidas resultaram em diminuição no atraso médio por veículo, tendendo a serem melhores à medida que o volume simulado diminui. Os valores de atraso resultantes das demandas 
reduzidas em cada cenário da Avenida Juscelino Kubitscheck estão esquematizados na Tabela 7-9.
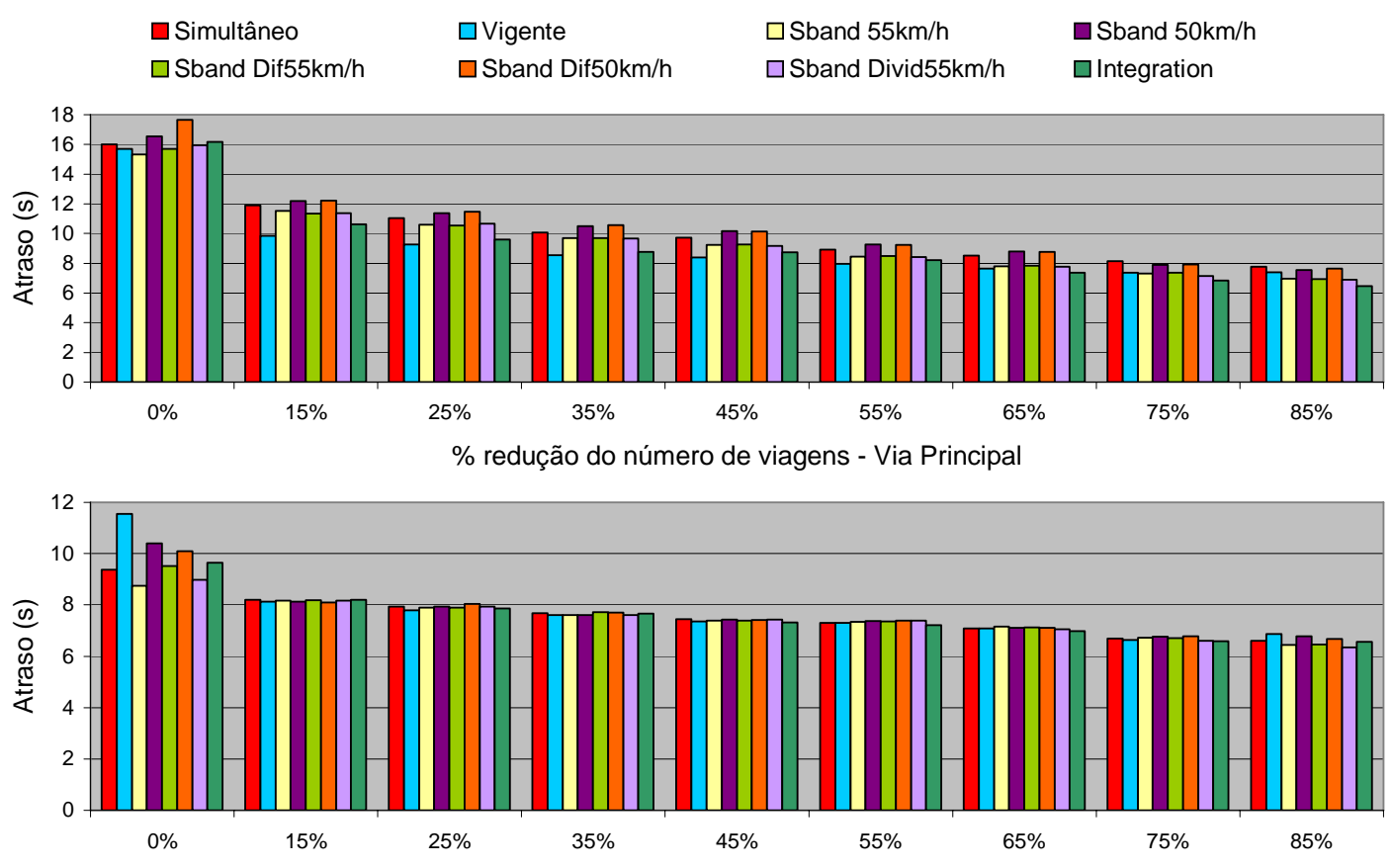

\% redução do número de viagens - Vias Secundárias

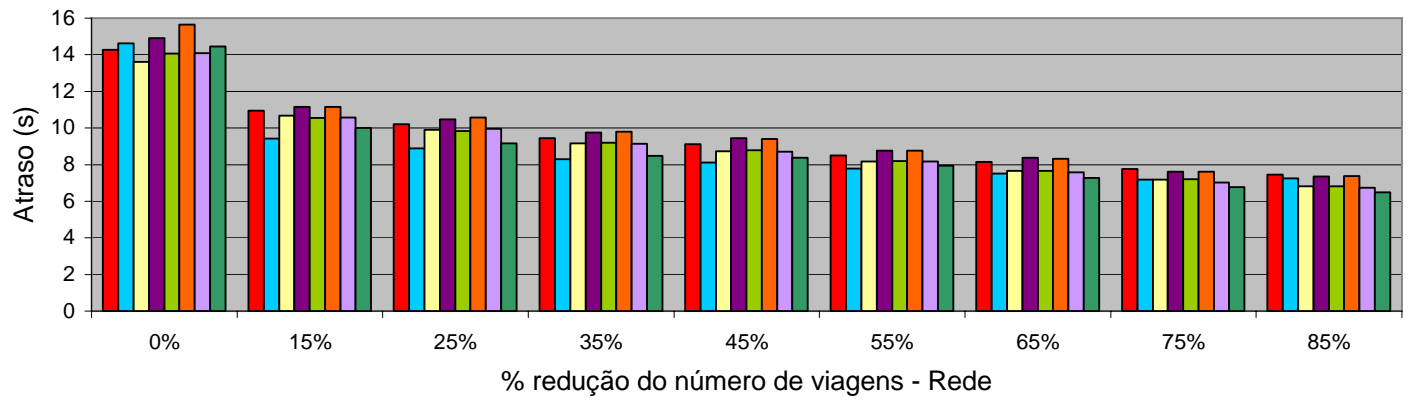

Figura 7-13: Valores de atraso médio obtidos para cada porcentagem de viagens na Avenida Juscelino Kubitscheck

Para os cenários com coordenação gerada pelo programa SBAND considerando velocidade de progressão de $55 \mathrm{~km} / \mathrm{h}$, todos os valores de atraso médio na Avenida Juscelino Kubitscheck são menores do que os resultados obtidos com o cenário simultâneo, e estas reduções ficam ainda mais significativas à medida que o volume diminui. 
Tabela 7-9: Percentuais de redução ou acréscimo nos atrasos médios obtidos na Avenida Juscelino Kubitscheck

\begin{tabular}{|c|c|c|c|c|c|c|c|c|}
\hline \multirow[t]{2}{*}{ Cenário } & Simultâneo* & Vigente & Sband $55 \mathrm{~km} / \mathrm{h}$ & Sband $50 \mathrm{~km} / \mathrm{h}$ & Sband Dif55km/h & Sband Dif50km/h & Sband Divid55km/h & Integration \\
\hline & média/veic & $\%$ & $\%$ & $\%$ & $\%$ & $\%$ & $\%$ & $\%$ \\
\hline \multicolumn{9}{|l|}{ Redução 15\% } \\
\hline principal & 11.90 & -17.1 & -3.1 & 2.5 & -4.6 & 2.7 & -4.3 & -10.7 \\
\hline secundárias & 8.21 & -0.9 & -0.6 & -1.0 & -0.3 & -1.5 & -0.5 & -0.1 \\
\hline rede & 10.94 & -13.9 & -2.6 & 1.8 & -3.8 & 1.8 & -3.5 & -8.6 \\
\hline \multicolumn{9}{|l|}{ Redução 25\% } \\
\hline principal & 11.04 & -16.0 & -3.9 & 3.0 & -4.5 & 4.0 & -3.3 & -12.9 \\
\hline secundárias & 7.93 & -1.6 & -0.3 & 0.1 & -0.5 & 1.4 & 0.1 & -0.7 \\
\hline rede & 10.21 & -13.0 & -3.2 & 2.4 & -3.7 & 3.5 & -2.6 & -10.4 \\
\hline \multicolumn{9}{|l|}{ Redução 35\% } \\
\hline principal & 10.06 & -15.0 & -3.5 & 4.6 & -3.6 & 5.1 & -3.8 & -12.8 \\
\hline secundárias & 7.69 & -1.1 & -1.1 & -0.9 & 0.5 & 0.1 & -0.9 & -0.2 \\
\hline rede & 9.43 & -12.0 & -2.9 & 3.4 & -2.7 & 4.0 & -3.2 & -10.1 \\
\hline \multicolumn{9}{|l|}{ Redução 45\% } \\
\hline principal & 9.72 & -13.8 & -5.1 & 4.5 & -4.6 & 4.2 & -5.6 & -10.0 \\
\hline secundárias & 7.46 & -1.3 & -0.9 & -0.4 & -0.9 & -0.6 & -0.4 & -1.9 \\
\hline rede & 9.12 & -11.0 & -4.2 & 3.4 & -3.8 & 3.1 & -4.4 & -8.3 \\
\hline \multicolumn{9}{|l|}{ Redução 55\% } \\
\hline principal & 8.91 & -10.8 & -5.1 & 3.9 & -4.9 & 3.7 & -5.4 & -7.9 \\
\hline secundárias & 7.30 & 0.0 & 0.6 & 1.0 & 0.7 & 1.4 & 1.3 & -1.2 \\
\hline rede & 8.49 & -8.4 & -3.8 & 3.3 & -3.7 & 3.1 & -3.9 & -6.4 \\
\hline \multicolumn{9}{|l|}{ Redução 65\% } \\
\hline principal & 8.51 & -10.0 & -8.1 & 3.5 & -8.0 & 2.9 & -8.5 & -13.2 \\
\hline secundárias & 7.09 & -0.1 & 1.2 & 0.4 & 0.7 & 0.4 & -0.6 & -1.6 \\
\hline rede & 8.14 & -7.8 & -6.0 & 2.8 & -6.0 & 2.3 & -6.7 & -10.6 \\
\hline \multicolumn{9}{|l|}{ Redução 75\% } \\
\hline principal & 8.14 & -9.3 & -10.1 & -2.9 & -9.3 & -2.7 & -12.1 & -16.0 \\
\hline secundárias & 6.70 & -0.9 & 0.4 & 0.9 & 0.0 & 1.1 & -1.5 & -1.7 \\
\hline rede & 7.75 & -7.4 & -7.7 & -2.0 & -7.1 & -1.8 & -9.6 & -12.7 \\
\hline \multicolumn{9}{|l|}{ Redução 85\% } \\
\hline principal & 7.76 & -4.8 & -10.5 & -2.6 & -10.5 & -1.5 & -11.2 & -16.8 \\
\hline secundárias & 6.59 & 4.2 & -2.2 & 2.8 & -2.0 & 1.3 & -3.8 & -0.4 \\
\hline rede & 7.44 & -2.6 & -8.5 & -1.3 & -8.5 & -0.8 & -9.4 & -12.8 \\
\hline
\end{tabular}

* os percentuais de redução e acréscimo das medidas de desempenho foram calculados em relação ao respectivo cenário simultâneo com demanda reduzida.

A quantidade de paradas sofridas pelos veículos na Avenida Juscelino Kubitscheck estão ilustradas na Figura 7-14, com os resultados divididos por gráficos da via principal, das vias secundárias e da rede, obtidos em cada cenário avaliado com as demandas reduzidas entre $15 \%$ e $85 \%$ da demanda real.

Os cenários simulados com a programação vigente em todas as porcentagens de demanda (de $15 \%$ a $85 \%$ da demanda real) apresentaram menor número de paradas para a via principal e para a rede, quando comparados com a programação simultânea, assim como os cenários com coordenações obtidas com o programa INTEGRATION. Os benefícios da coordenação vigente da Avenida Juscelino Kubitscheck são maiores para os volumes maiores, e as melhorias no número de paradas tendem a ser mais expressivas na coordenação gerada pelo INTEGRATION à medida que o volume diminui, conforme valores esquematizados na Tabela 7-10. 

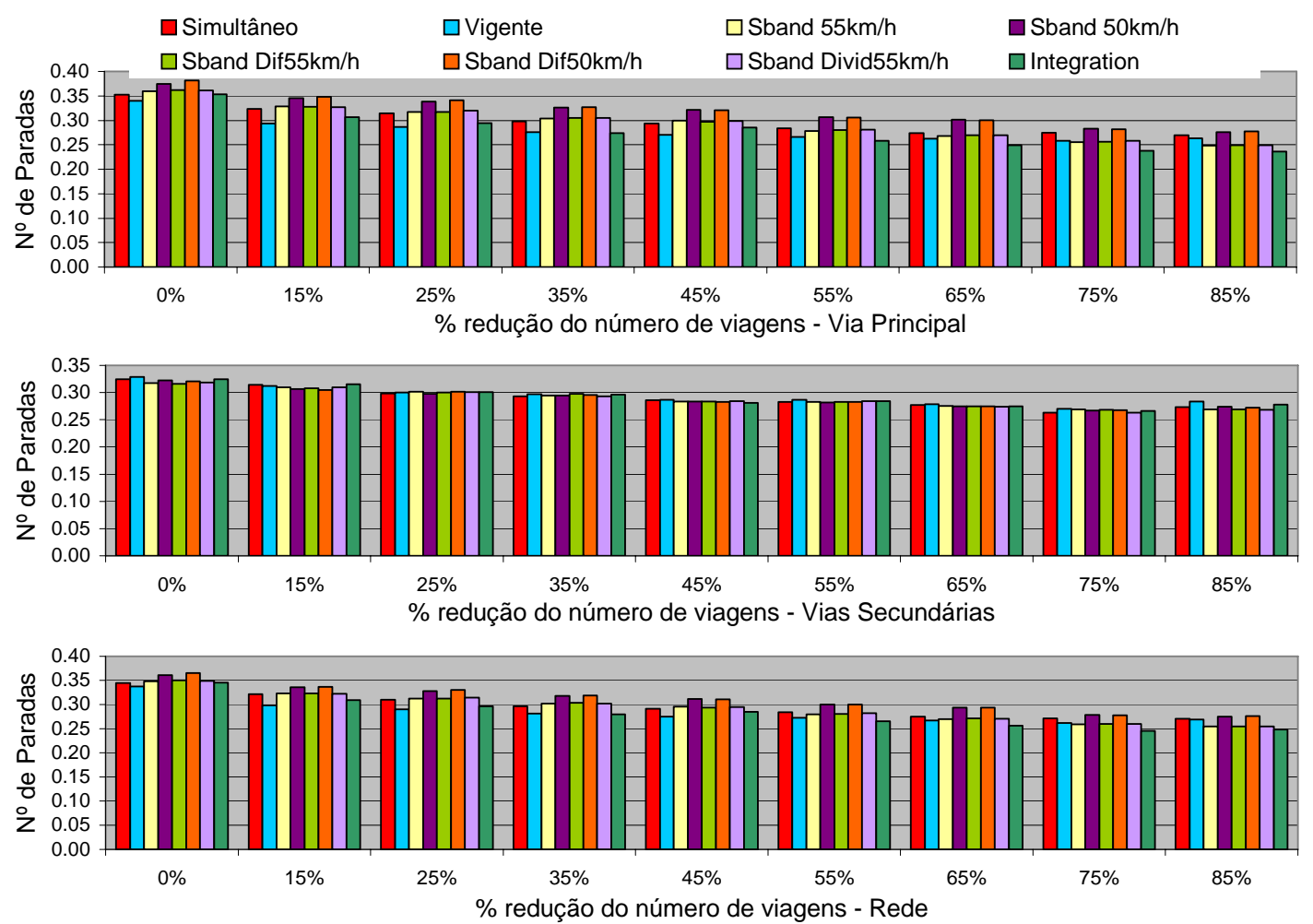

Figura 7-14: Valores de número de paradas obtidos para cada porcentagem de viagens na Avenida Juscelino Kubitscheck

Tabela 7-10: Percentuais de redução ou acréscimo nos números médios de paradas obtidos na Avenida Juscelino Kubitscheck

\begin{tabular}{|c|c|c|c|c|c|c|c|c|}
\hline Cenário & Simultâneo* & Vigente & Sband $55 \mathrm{~km} / \mathrm{h}$ & Sband $50 \mathrm{~km} / \mathrm{h}$ & Sband Dif55km/h & Sband Dif50km/h & Sband Divid55km/h & Integration \\
\hline & média/veic & $\%$ & $\%$ & $\%$ & $\%$ & $\%$ & $\%$ & $\%$ \\
\hline \multicolumn{9}{|l|}{ Redução 15\% } \\
\hline principal & 0.323 & -9.3 & 1.5 & 6.9 & 1.5 & 7.5 & 1.1 & -5.2 \\
\hline secundárias & 0.314 & -0.7 & -1.5 & -2.4 & -1.9 & -3.0 & -1.5 & 0.4 \\
\hline rede & 0.321 & -7.1 & 0.8 & 4.5 & 0.6 & 4.8 & 0.4 & -3.8 \\
\hline \multicolumn{9}{|l|}{ Redução 25\% } \\
\hline principal & 0.314 & -8.9 & 0.8 & 7.5 & 0.9 & 8.4 & 1.6 & -6.4 \\
\hline secundárias & 0.298 & 0.5 & 1.2 & -0.3 & 0.6 & 1.0 & 0.8 & 0.9 \\
\hline rede & 0.310 & -6.5 & 0.9 & 5.5 & 0.8 & 6.5 & 1.4 & -4.6 \\
\hline \multicolumn{9}{|l|}{ Redução 35\% } \\
\hline principal & 0.298 & -7.5 & 2.2 & 9.4 & 2.5 & 9.7 & 2.4 & -8.0 \\
\hline secundárias & 0.293 & 1.3 & 0.5 & 0.5 & 1.5 & 0.8 & -0.1 & 0.9 \\
\hline rede & 0.297 & -5.2 & 1.7 & 7.1 & 2.2 & 7.4 & 1.8 & -5.7 \\
\hline \multicolumn{9}{|l|}{ Redução 45\% } \\
\hline principal & 0.294 & -7.8 & 2.0 & 9.5 & 1.3 & 9.4 & 1.8 & -2.6 \\
\hline secundárias & 0.286 & 0.3 & -0.7 & -0.8 & -0.8 & -1.0 & -0.3 & -1.7 \\
\hline rede & 0.291 & -5.7 & 1.3 & 6.8 & 0.7 & 6.7 & 1.3 & -2.4 \\
\hline \multicolumn{9}{|l|}{ Redução 55\% } \\
\hline principal & 0.284 & -6.2 & -1.9 & 7.8 & -1.4 & 7.8 & -0.9 & -9.0 \\
\hline secundárias & 0.282 & 1.7 & 0.2 & 0.0 & 0.0 & 0.2 & 0.8 & 0.8 \\
\hline rede & 0.284 & -4.1 & -1.3 & 5.7 & -1.0 & 5.8 & -0.5 & -6.4 \\
\hline \multicolumn{9}{|l|}{ Redução 65\% } \\
\hline principal & 0.274 & -4.1 & -2.2 & 9.9 & -1.5 & 9.7 & -1.5 & -8.8 \\
\hline secundárias & 0.278 & 0.3 & -0.6 & -1.1 & -1.0 & -1.1 & -1.4 & -1.0 \\
\hline rede & 0.275 & -2.9 & -1.8 & 7.0 & -1.4 & 6.8 & -1.5 & -6.7 \\
\hline \multicolumn{9}{|l|}{ Redução $75 \%$} \\
\hline principal & 0.274 & -5.9 & -7.0 & 2.9 & -6.5 & 2.8 & -5.9 & -13.3 \\
\hline secundárias & 0.263 & 2.8 & 2.5 & 1.6 & 2.1 & 1.7 & 0.1 & 1.3 \\
\hline rede & 0.271 & -3.6 & -4.5 & 2.6 & -4.3 & 2.5 & -4.3 & -9.5 \\
\hline \multicolumn{9}{|l|}{ Redução 85\% } \\
\hline principal & 0.270 & -2.2 & -7.8 & 2.2 & -7.7 & 2.8 & -7.5 & -12.3 \\
\hline secundárias & 0.273 & 3.8 & -1.5 & 0.4 & -1.3 & -0.3 & -1.7 & 1.7 \\
\hline rede & 0.271 & -0.5 & -6.0 & 1.7 & -5.9 & 1.9 & -5.9 & -8.4 \\
\hline
\end{tabular}

* os percentuais de redução e acréscimo das medidas de desempenho foram calculados em relação ao respectivo cenário simultâneo com demanda reduzida. 
Somente para volumes entre 55\% e $85 \%$ da demanda real é que a coordenação gerada pelo programa SBAND, com velocidade de $55 \mathrm{~km} / \mathrm{h}$, proporciona redução no número de paradas comparada ao cenário simultâneo.

\subsubsection{Avenida Maringá}

A análise da eficiência dos programas SBAND e INTEGRATION em relação às variações de volume também foi realizada através da redução de todos os pares da matriz origem-destino da Avenida Maringá, em porcentagens de 15\% a 85\% da demanda real. Os resultados de tempo médio de percurso por veículo separados para a via principal, vias secundárias e para a rede, obtidos em cada cenário avaliado da Avenida Maringá com as demandas reduzidas entre 15\% e 85\% da demanda real, estão demonstrados nos gráficos da Figura 7-15.
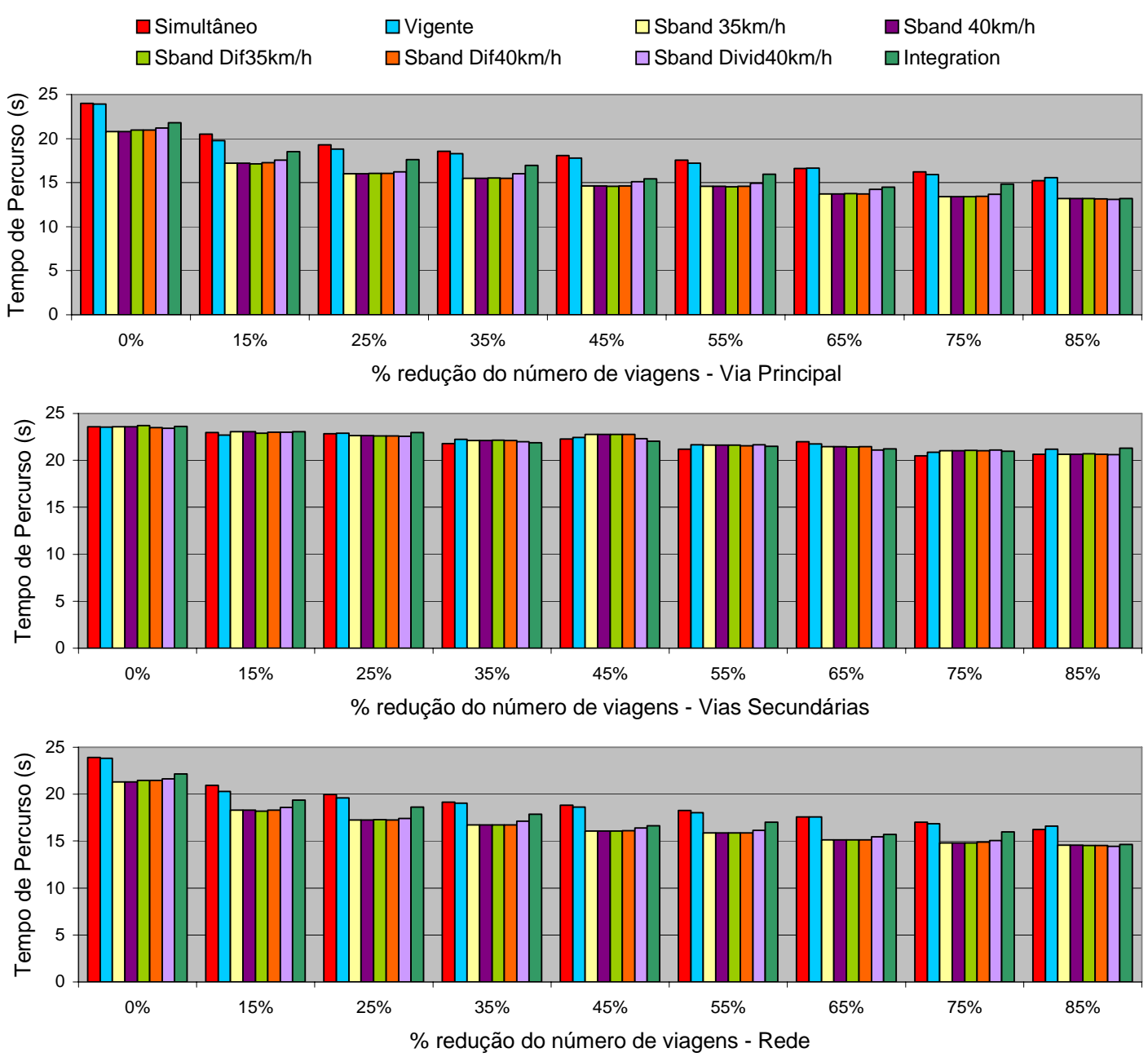

Figura 7-15: Valores de tempo médio de percurso obtidos para cada porcentagem de viagens na Avenida Maringá 
A Tabela 7-11 apresenta resumidamente os valores de tempo médio de percurso obtidos com as demandas reduzidas, em cada um dos cenários avaliados da Avenida Maringá. Praticamente todos os resultados de tempo de percurso obtidos pela simulação do cenário vigente são menores do que os resultados gerados pelo cenário simultâneo, porém com benefícios muito pequenos e ainda menos expressivos à medida que o volume de tráfego diminui. Já os cenários com coordenações geradas pelo programa INTEGRATION resultam sempre em menores valores de tempo de percurso, tanto para a via principal como para a rede, com alterações insignificantes nos resultados das vias secundárias.

Tabela 7-11: Percentuais de redução ou acréscimo nos tempos médios de percurso obtidos na Avenida Maringá

\begin{tabular}{|c|c|c|c|c|c|c|c|c|}
\hline \multirow[t]{2}{*}{ Cenário } & Simultâneo* & Vigente & Sband $35 \mathrm{~km} / \mathrm{h}$ & Sband $40 \mathrm{~km} / \mathrm{h}$ & Sband Dif35km/h & Sband Dif40km/h & Sband Divid $40 \mathrm{~km} / \mathrm{h}$ & Integration \\
\hline & média/veic & $\%$ & $\%$ & $\%$ & $\%$ & $\%$ & $\%$ & $\%$ \\
\hline \multicolumn{9}{|l|}{ Redução 15\% } \\
\hline principal & 20.49 & -3.5 & -16.0 & -16.0 & -16.5 & -15.9 & -14.3 & -9.6 \\
\hline secundárias & 22.96 & -1.3 & 0.4 & 0.4 & -0.3 & 0.3 & 0.3 & 0.5 \\
\hline rede & 20.95 & -3.1 & -12.7 & -12.7 & -13.2 & -12.6 & -11.3 & -7.5 \\
\hline \multicolumn{9}{|l|}{ Redução 25\% } \\
\hline principal & 19.31 & -2.4 & -17.1 & -17.1 & -16.9 & -17.0 & -16.1 & -8.7 \\
\hline secundárias & 22.84 & 0.3 & -0.9 & -0.9 & -1.0 & -1.0 & -1.2 & 0.6 \\
\hline rede & 19.97 & -1.9 & -13.6 & -13.6 & -13.5 & -13.5 & -12.9 & -6.7 \\
\hline \multicolumn{9}{|l|}{ Redução 35\% } \\
\hline principal & 18.56 & -1.3 & -16.6 & -16.6 & -16.4 & -16.5 & -13.8 & -8.8 \\
\hline secundárias & 21.79 & 2.1 & 1.4 & 1.4 & 1.6 & 1.4 & 0.9 & 0.4 \\
\hline rede & 19.16 & -0.6 & -12.8 & -12.8 & -12.6 & -12.7 & -10.7 & -6.8 \\
\hline \multicolumn{9}{|l|}{ Redução 45\% } \\
\hline principal & 18.09 & -1.7 & -19.2 & -19.2 & -19.4 & -19.1 & -16.5 & -14.6 \\
\hline secundárias & 22.29 & 0.6 & 2.2 & 2.2 & 2.1 & 2.1 & 0.1 & -1.1 \\
\hline rede & 18.85 & -1.2 & -14.6 & -14.6 & -14.8 & -14.6 & -13.0 & -11.7 \\
\hline \multicolumn{9}{|l|}{ Redução 55\% } \\
\hline principal & 17.58 & -2.1 & -17.1 & -17.1 & -17.3 & -17.2 & -15.1 & -9.1 \\
\hline secundárias & 21.18 & 2.2 & 2.1 & 2.1 & 2.2 & 1.8 & 2.3 & 1.6 \\
\hline rede & 18.25 & -1.1 & -13.0 & -13.0 & -13.1 & -13.1 & -11.4 & -6.8 \\
\hline \multicolumn{9}{|l|}{ Redução 65\% } \\
\hline principal & 16.61 & 0.2 & -17.4 & -17.4 & -17.2 & -17.4 & -14.4 & -12.9 \\
\hline secundárias & 21.99 & -1.1 & -2.4 & -2.4 & -2.6 & -2.3 & -4.0 & -3.4 \\
\hline rede & 17.59 & 0.0 & -14.0 & -14.0 & -13.9 & -14.0 & -12.1 & -10.7 \\
\hline \multicolumn{9}{|l|}{ Redução 75\% } \\
\hline principal & 16.21 & -1.8 & -17.2 & -17.2 & -17.4 & -16.9 & -15.7 & -8.4 \\
\hline secundárias & 20.49 & 1.8 & 2.6 & 2.6 & 2.8 & 2.7 & 3.0 & 2.3 \\
\hline rede & 17.01 & -1.0 & -12.8 & -12.8 & -12.9 & -12.5 & -11.5 & -6.0 \\
\hline \multicolumn{9}{|l|}{ Redução 85\% } \\
\hline principal & 15.24 & 2.2 & -13.4 & -13.4 & -13.5 & -13.7 & -14.1 & -13.5 \\
\hline secundárias & 20.64 & 2.7 & 0.1 & 0.1 & 0.3 & 0.2 & -0.2 & 3.3 \\
\hline rede & 16.22 & 2.3 & -10.3 & -10.3 & -10.3 & -10.5 & -10.9 & -9.6 \\
\hline
\end{tabular}

* os percentuais de redução e acréscimo das medidas de desempenho foram calculados em relação ao respectivo cenário simultâneo com demanda reduzida.

Todos os cenários simulados com coordenações obtidas pelo programa SBAND para a Avenida Maringá resultaram em redução significativa no tempo de percurso na via principal (entre 13,4 e 19,4\%) e também em toda a rede (de 10,3 a 14,8\%), promovendo ora diminuição no tempo de percurso para as vias secundárias (mínimo de 4\%) e ora aumento (máximo de 3\%). O cenário com coordenação definida em duas etapas apresentou reduções no tempo de percurso, mas que não foram melhores 
do que nas demais situações simuladas com coordenação do SBAND, provavelmente em função da reduzida quantidade de semáforos no corredor (somente 5 interseções). Para todos os volumes (de 15\% a $85 \%$ da demanda real), os valores de tempo de percurso das simulações com coordenações definidas pelo programa SBAND foram menores do que aqueles resultantes da coordenação simultânea, da condição vigente e ainda da programação gerada pela rotina interna do programa INTEGRATION, o que pode ser constatado nos valores da Tabela 7-11.

Os valores de atraso resultantes das demandas reduzidas da Avenida Maringá estão ilustrados na Figura 7-16, divididos em gráficos da via principal, das vias secundárias e da rede, obtidos em cada cenário avaliado com as demandas reduzidas entre $15 \%$ e $85 \%$ da demanda real.
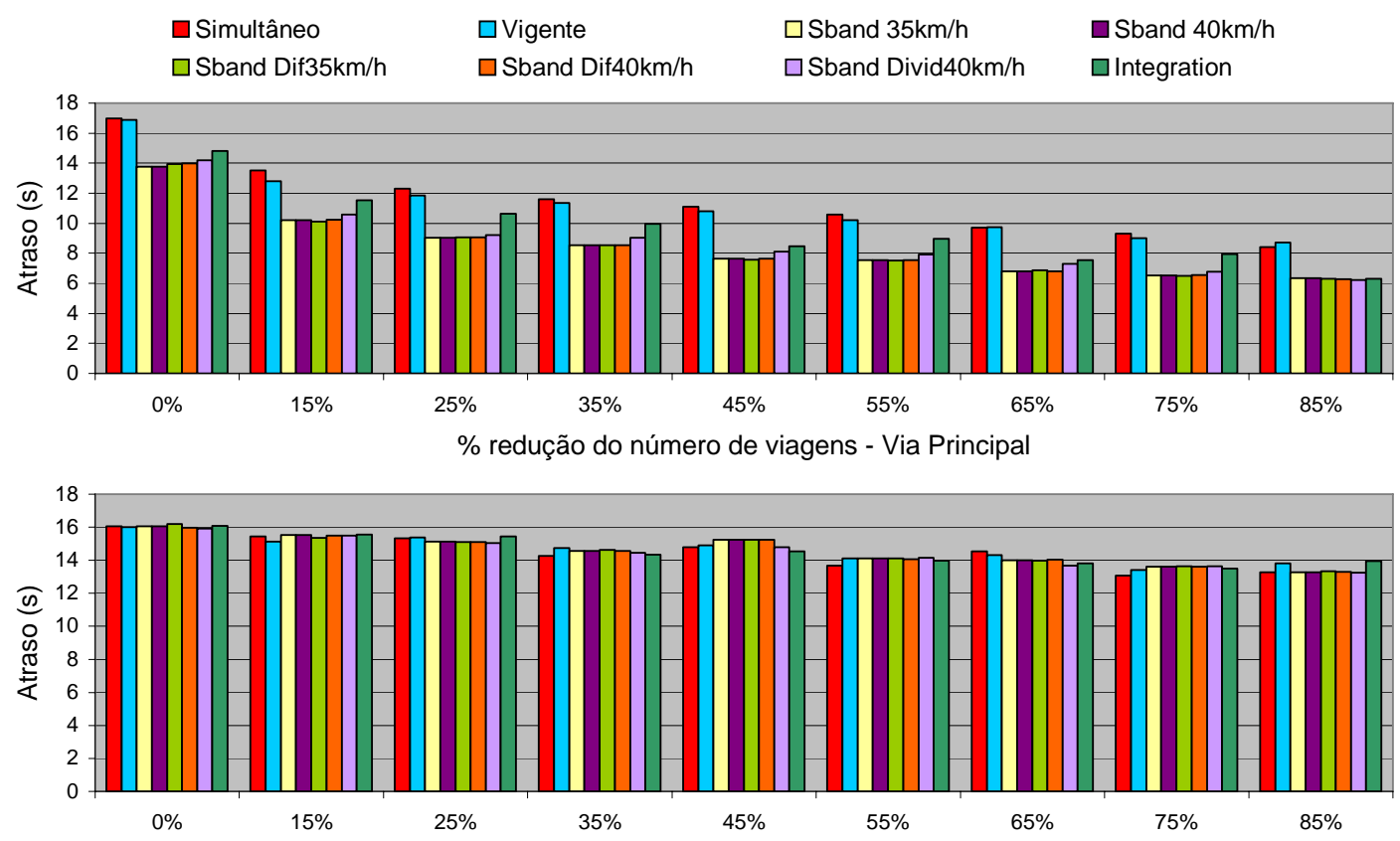

\% redução do número de viagens - Vias Secundárias

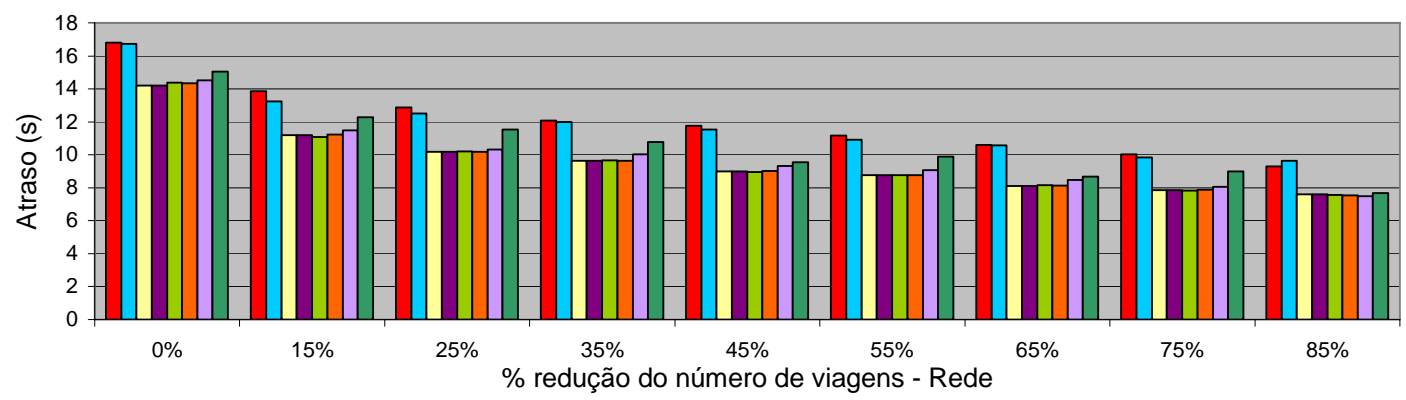

Figura 7-16: Valores de atraso médio obtidos para cada porcentagem de viagens na Avenida Maringá 
Os dados resumidos na Tabela 7-12 demonstram que as simulações do cenário vigente proporcionam resultados menores do que o atraso médio gerado pelo cenário simultâneo. Todas as coordenações geradas pelo programa INTEGRATION com demandas reduzidas resultaram em diminuição no atraso médio por veículo, variando entre 13,6 e $25 \%$ na via principal e 10,4 e 18,8\% na rede.

Para os cenários simulados com coordenações obtidas pelo programa SBAND, o atraso médio na via principal atingiu 31,7\% de redução em relação ao cenário simultâneo, e 23,9\% para toda a rede, superando em todos os volumes (de 15\% a 85\% da demanda real) os resultados obtidos na condição vigente e também para a coordenação gerada pelo programa INTEGRATION.

Tabela 7-12: Percentuais de redução ou acréscimo nos atrasos médios obtidos na Avenida Maringá

\begin{tabular}{|c|c|c|c|c|c|c|c|c|}
\hline \multirow[t]{2}{*}{ Cenário } & Simultâneo* $^{\star}$ & Vigente & Sband $35 \mathrm{~km} / \mathrm{h}$ & Sband $40 \mathrm{~km} / \mathrm{h}$ & Sband Dif35km/h & Sband Dif40km/h & Sband Divid $40 \mathrm{~km} / \mathrm{h}$ & Integration \\
\hline & média/veic & $\%$ & $\%$ & $\%$ & $\%$ & $\%$ & $\%$ & $\%$ \\
\hline \multicolumn{9}{|l|}{ Redução 15\% } \\
\hline principal & 13.51 & -5.3 & -24.4 & -24.4 & -25.0 & -24.1 & -21.7 & -14.5 \\
\hline secundárias & 15.43 & -1.9 & 0.6 & 0.6 & -0.4 & 0.4 & 0.4 & 0.7 \\
\hline rede & 13.86 & -4.6 & -19.2 & -19.2 & -20.0 & -19.0 & -17.1 & -11.4 \\
\hline \multicolumn{9}{|l|}{ Redução 25\% } \\
\hline principal & 12.32 & -3.8 & -26.8 & -26.8 & -26.4 & -26.6 & -25.2 & -13.6 \\
\hline secundárias & 15.33 & 0.4 & -1.3 & -1.3 & -1.5 & -1.5 & -1.9 & 0.8 \\
\hline rede & 12.88 & -2.9 & -21.1 & -21.1 & -20.9 & -21.0 & -20.0 & -10.4 \\
\hline \multicolumn{9}{|l|}{ Redução 35\% } \\
\hline principal & 11.59 & -2.1 & -26.5 & -26.5 & -26.3 & -26.4 & -22.1 & -14.0 \\
\hline secundárias & 14.27 & 3.2 & 2.1 & 2.1 & 2.4 & 2.1 & 1.3 & 0.5 \\
\hline rede & 12.09 & -0.9 & -20.2 & -20.2 & -20.0 & -20.2 & -16.9 & -10.8 \\
\hline \multicolumn{9}{|l|}{ Redução 45\% } \\
\hline principal & 11.11 & -2.9 & -31.4 & -31.4 & -31.7 & -31.3 & -27.0 & -23.8 \\
\hline secundárias & 14.79 & 0.9 & 3.2 & 3.2 & 3.1 & 3.1 & 0.1 & -1.6 \\
\hline rede & 11.77 & -2.0 & -23.6 & -23.6 & -23.9 & -23.5 & -20.9 & -18.8 \\
\hline \multicolumn{9}{|l|}{ Redução 55\% } \\
\hline principal & 10.58 & -3.6 & -28.6 & -28.6 & -28.9 & -28.7 & -25.3 & -15.2 \\
\hline secundárias & 13.67 & 3.3 & 3.2 & 3.2 & 3.3 & 2.8 & 3.5 & 2.3 \\
\hline rede & 11.16 & -2.1 & -21.4 & -21.4 & -21.6 & -21.6 & -18.8 & -11.2 \\
\hline \multicolumn{9}{|l|}{ Redução 65\% } \\
\hline principal & 9.72 & 0.2 & -30.0 & -30.0 & -29.5 & -29.9 & -24.8 & -22.4 \\
\hline secundárias & 14.55 & -1.7 & -3.7 & -3.7 & -4.0 & -3.5 & -6.1 & -5.2 \\
\hline rede & 10.60 & -0.2 & -23.4 & -23.4 & -23.1 & -23.4 & -20.2 & -18.1 \\
\hline \multicolumn{9}{|l|}{ Redução 75\% } \\
\hline principal & 9.32 & -3.4 & -30.1 & -30.1 & -30.4 & -29.5 & -27.4 & -14.8 \\
\hline secundárias & 13.07 & 2.7 & 4.0 & 4.0 & 4.4 & 4.2 & 4.4 & 3.3 \\
\hline rede & 10.02 & -1.9 & -21.8 & -21.8 & -21.9 & -21.3 & -19.7 & -10.4 \\
\hline \multicolumn{9}{|l|}{ Redução 85\% } \\
\hline principal & 8.41 & 3.6 & -24.7 & -24.7 & -25.0 & -25.4 & -26.2 & -25.0 \\
\hline secundárias & 13.27 & 4.1 & 0.1 & 0.1 & 0.4 & 0.2 & -0.2 & 5.0 \\
\hline rede & 9.29 & 3.7 & -18.3 & -18.3 & -18.4 & -18.8 & -19.4 & -17.2 \\
\hline
\end{tabular}

* os percentuais de redução e acréscimo das medidas de desempenho foram calculados em relação ao respectivo cenário simultâneo com demanda reduzida.

A Figura 7-17 ilustra a quantidade de paradas sofridas pelos veículos na Avenida Maringá, em gráficos que dividem os resultados da via principal, das vias secundárias e da rede, obtidos em cada cenário avaliado com as demandas reduzidas entre 15 e $85 \%$ da demanda real. 

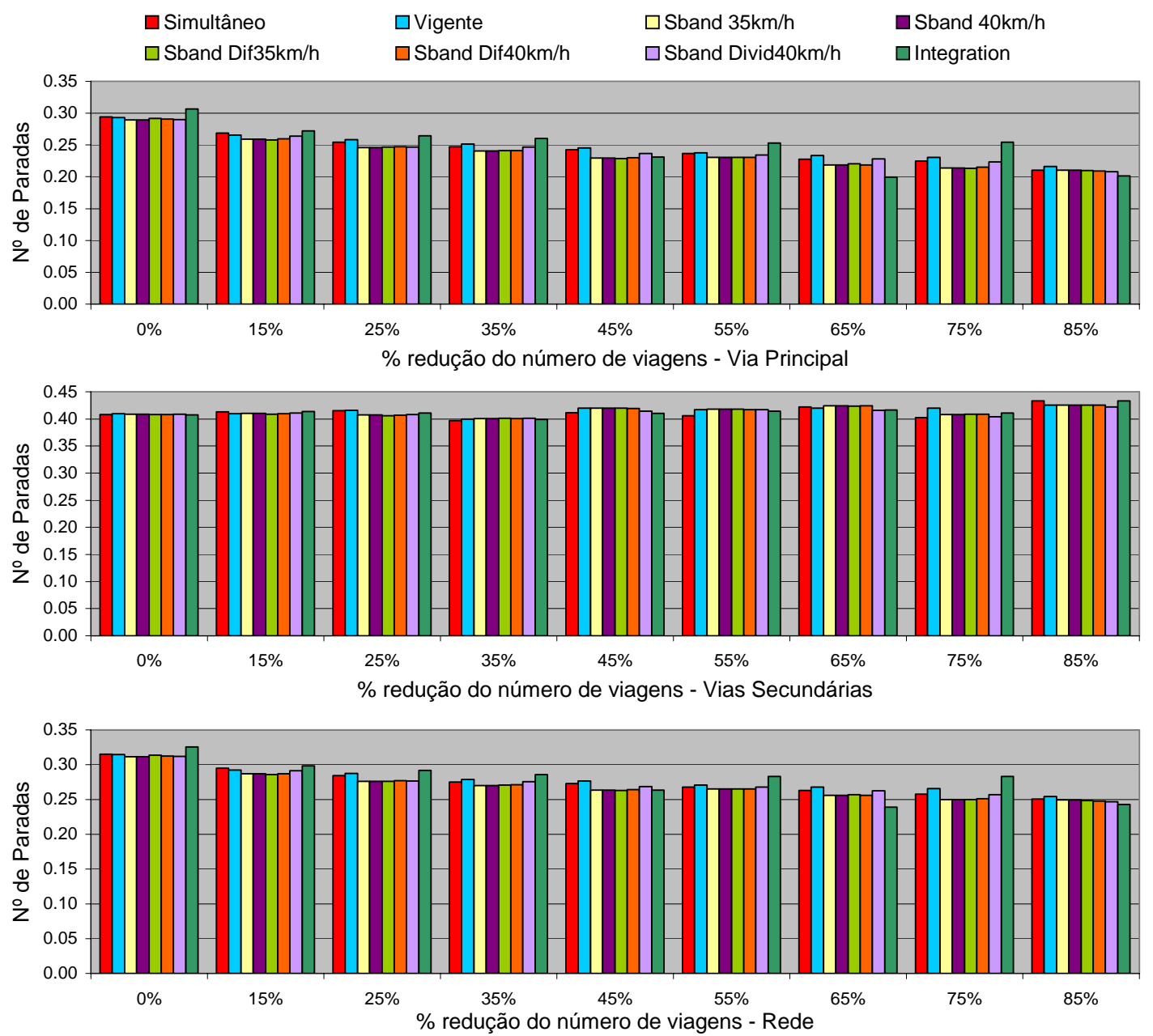

Figura 7-17: Valores de número de paradas obtidos para cada porcentagem de viagens na Avenida Maringá

Praticamente todos os cenários simulados com a coordenação vigente na Avenida Maringá e com diferentes porcentagens de demanda apresentaram maior número de paradas para a via principal, vias secundárias e para a rede, quando comparados com a programação simultânea, conforme pode ser observado nos valores esquematizados na Tabela 7-13. Também a maioria dos cenários com demandas reduzidas e coordenações geradas pelo programa INTEGRATION produziu maior número de paradas do que a situação com abertura simultânea dos semáforos.

Somente nas simulações com coordenações geradas pelo programa SBAND é que o número de paradas foi reduzido em todas as situações com demandas reduzidas (de 15 a 85\% da demanda real da Avenida Maringá), atingindo 5,8\% a menos de paradas na via principal e 3,7\% de redução para a rede. 
Tabela 7-13: Percentuais de redução ou acréscimo nos números médios de paradas obtidos na Avenida Maringá

\begin{tabular}{|c|c|c|c|c|c|c|c|c|}
\hline Cenário & Simultâneo* & Vigente & Sband $35 \mathrm{~km} / \mathrm{h}$ & Sband $40 \mathrm{~km} / \mathrm{h}$ & Sband Dif35km/h & Sband Dif40km/h & Sband Divid $40 \mathrm{~km} / \mathrm{h}$ & Integration \\
\hline & média/veic & $\%$ & $\%$ & $\%$ & $\%$ & $\%$ & $\%$ & $\%$ \\
\hline \multicolumn{9}{|l|}{ Redução 15\% } \\
\hline principal & 0.269 & -1.2 & -3.6 & -3.6 & -4.1 & -3.4 & -1.7 & 1.3 \\
\hline secundárias & 0.413 & -0.8 & -0.7 & -0.7 & -1.0 & -0.9 & -0.5 & 0.2 \\
\hline rede & 0.295 & -1.1 & -2.9 & -2.9 & -3.3 & -2.8 & -1.4 & 1.0 \\
\hline \multicolumn{9}{|l|}{ Redução 25\% } \\
\hline principal & 0.254 & 1.6 & -3.2 & -3.2 & -3.1 & -2.8 & -3.1 & 3.9 \\
\hline secundárias & 0.415 & 0.2 & -1.9 & -1.9 & -2.1 & -2.0 & -1.6 & -1.0 \\
\hline rede & 0.284 & 1.2 & -2.8 & -2.8 & -2.8 & -2.6 & -2.6 & 2.6 \\
\hline \multicolumn{9}{|l|}{ Redução 35\% } \\
\hline principal & 0.247 & 1.7 & -2.7 & -2.7 & -2.5 & -2.3 & -0.2 & 5.3 \\
\hline secundárias & 0.397 & 0.7 & 0.9 & 0.9 & 1.0 & 0.9 & 0.9 & 0.4 \\
\hline rede & 0.275 & 1.5 & -1.7 & -1.7 & -1.6 & -1.5 & 0.1 & 4.0 \\
\hline \multicolumn{9}{|l|}{ Redução 45\% } \\
\hline principal & 0.243 & 1.2 & -5.5 & -5.5 & -5.8 & -5.2 & -2.5 & -4.7 \\
\hline secundárias & 0.412 & 2.0 & 1.9 & 1.9 & 2.0 & 1.8 & 0.6 & -0.3 \\
\hline rede & 0.273 & 1.4 & -3.5 & -3.5 & -3.7 & -3.3 & -1.7 & -3.5 \\
\hline \multicolumn{9}{|l|}{ Redução 55\% } \\
\hline principal & 0.237 & 0.4 & -2.6 & -2.6 & -2.6 & -2.6 & -1.0 & 7.1 \\
\hline secundárias & 0.406 & 2.7 & 3.0 & 3.0 & 3.0 & 2.8 & 2.8 & 2.1 \\
\hline rede & 0.268 & 1.0 & -1.0 & -1.0 & -1.0 & -1.1 & 0.1 & 5.7 \\
\hline \multicolumn{9}{|l|}{ Redução 65\% } \\
\hline principal & 0.227 & 2.8 & -4.0 & -4.0 & -3.2 & -3.9 & 0.3 & -12.1 \\
\hline \multirow{2}{*}{$\begin{array}{l}\text { secundárias } \\
\text { rede }\end{array}$} & 0.422 & -0.5 & 0.5 & 0.5 & 0.4 & 0.6 & -1.5 & -1.3 \\
\hline & 0.263 & 1.9 & -2.7 & -2.7 & -2.2 & -2.6 & -0.2 & -8.9 \\
\hline \multicolumn{9}{|l|}{ Redução 75\% } \\
\hline principal & 0.225 & 2.6 & -4.7 & -4.7 & -5.0 & -4.3 & -0.6 & 13.2 \\
\hline secundárias & 0.402 & 4.4 & 1.5 & 1.5 & 1.6 & 1.5 & 0.4 & 2.1 \\
\hline rede & 0.258 & 3.1 & -2.9 & -2.9 & -3.1 & -2.6 & -0.3 & 10.0 \\
\hline \multicolumn{9}{|l|}{ Redução 85\% } \\
\hline principal & 0.210 & 2.9 & 0.0 & 0.0 & -0.4 & -0.6 & -1.2 & -4.3 \\
\hline \multirow{2}{*}{$\begin{array}{l}\text { secundárias } \\
\text { rede }\end{array}$} & 0.433 & -1.7 & -1.8 & -1.8 & -1.8 & -1.8 & -2.6 & 0.0 \\
\hline & 0.251 & 1.4 & -0.5 & -0.5 & -0.8 & -1.0 & -1.6 & -3.0 \\
\hline
\end{tabular}

* os percentuais de redução e acréscimo das medidas de desempenho foram calculados em relação ao respectivo cenário simultâneo com demanda reduzida.

\subsection{Simulações dos Cenários com Diferentes Espaçamentos entre Semáforos}

A rede utilizada para esta análise é similar ao trecho selecionado da Avenida Higienópolis, que conta com oito interseções semaforizadas com distâncias praticamente eqüidistantes entre elas. Mantendo as mesmas condições de programação (ciclo e divisão dos tempos de verde) e alterando o distanciamento entre semáforos, é possível avaliar a influência desta característica geométrica na eficiência do método de coordenação por maximização de banda verde, existente no programa SBAND. Quatro alternativas de espaçamentos foram testadas (220, 320, 420 e 520 metros) com a demanda real, tanto para simulações com progressão simultânea quanto com coordenação gerada pelo programa proposto SBAND, além da situação real dos semáforos da Avenida Higienópolis com aproximadamente 120 metros de distância simulada anteriormente e comentada no item 7.1.1.

Os resultados das medidas operacionais de eficiência obtidas para os supostos cenários com diferentes espaçamentos entre as interseções semaforizadas estão resumidos na Tabela 7-14, e comprovam a teoria utilizada no programa SBAND, 
baseado no método de Morgan e Little (1964), em que a banda máxima para os dois sentidos de tráfego ocorre quando a distância entre os semáforos é tal que os veículos percorram a quadra na metade da duração do ciclo, circulando na velocidade de progressão.

Considerando a velocidade regulamentada na Avenida Higienópolis de $50 \mathrm{~km} / \mathrm{h}$, o programa SBAND gerou bandas bidirecionais contínuas próximas de 10 segundos para os espaçamentos de 120, 220, 320 e 420 metros, e banda com largura de 40 segundos para a situação que supõe interseções semaforizadas a 520 metros. Esta condição com bandas bidirecionais com 40 segundos de largura é a melhor progressão contínua possível para a velocidade de progressão de $50 \mathrm{~km} / \mathrm{h}$ e ciclo de 75 segundos, utilizando na íntegra o menor tempo de verde/amarelo (37 + 3 segundos) entre os oito semáforos do corredor arterial. Sendo assim, este cenário resultou na maior redução do número de paradas já obtida, com 39,8\% a menos de paradas na via principal e $28 \%$ na rede, além da redução de 18,5\% no tempo de percurso para a via principal e 15,1\% para a rede, e 38,5\% de redução dos atrasos sofridos na via principal e 30,5\% na rede, todos comparados aos respectivos cenários simultâneos.

Tabela 7-14: Quadro comparativo entre as medidas de desempenho para diferentes espaçamentos entre semáforos

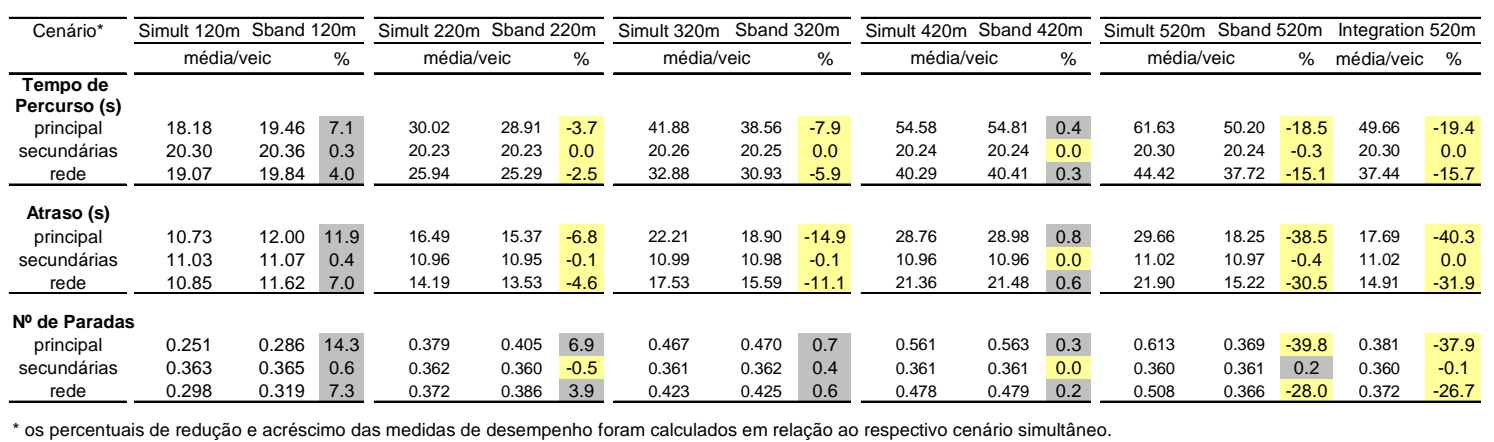

O plano de coordenação gerado pelo programa INTEGRATION para avaliação da situação ideal com espaçamentos de 520 metros também foi testado, proporcionando dois trechos de banda com larguras de 31 e 35 segundos, e resultando nas maiores reduções no tempo de percurso (19,4\% na via principal e $15,7 \%$ na rede) e no atraso (40,3\% na via principal e 31,9\% na rede), e ainda com 37,9\% a menos no número de paradas na via principal e $26,7 \%$ na rede. 


\subsection{Considerações Finais}

Todas as redes selecionadas foram simuladas com progressão simultânea dos semáforos, supondo a abertura dos tempos de verde para via arterial ou para os principais corredores da rede ao mesmo tempo, sendo considerado a forma mais simplificada de operação que servisse de referência na análise de eficiência das demais situações. Também o plano de coordenação vigente em cada rede foi simulado, para representar a maneira que estão operando na prática, de acordo com as programações definidas pelo técnico da prefeitura local, seja pela elaboração do Diagrama EspaçoTempo do corredor ou através de ajustes promovidos em campo pela observação do tráfego.

O programa proposto SBAND foi testado através da simulação de duas possibilidades de velocidade de progressão - a velocidade regulamentada na via e outra velocidade próxima desta que gere maior largura de banda. No caso de avenidas com duplo sentido de circulação, as duas condições de velocidade foram avaliadas tanto para a situação de bandas iguais nos dois sentidos como para bandas proporcionais aos volumes direcionais. Também os corredores arteriais de duplo sentido foram divididos em dois trechos, para que separadamente tivessem as defasagens definidas pelo programa SBAND, a fim de avaliar a eficiência para as vias que excedem 1.000 metros em dois blocos de coordenação.

O programa INTEGRATION foi codificado e calibrado para todos os cenários citados, de forma a simular o fluxo de tráfego para as diferentes possibilidades de coordenação, inclusive da programação coordenada gerada para cada rede pelo próprio simulador, e desta maneira gerar medidas de desempenho para a comparação das propostas.

Estes cenários foram avaliados em redes com condições diferentes de geometria, circulação e volumetria de tráfego, de acordo com o resumo demonstrado na Tabela 7-15, caracterizando quatro situações distintas para análise da eficiência dos programas SBAND e INTEGRATION. A classificação das vias segue a divisão entre três níveis médios de volumetria de tráfego por sentido da via, sendo considerado baixo para fluxo de até 500 veículos/hora, moderado para volumes entre 501 e 900 veículos/hora, e fluxo elevado para os casos com volume superior a 900 veículos/hora, relativos a cada aproximação das interseções semafóricas, independente do número de faixas de rolamento. 
Tabela 7-15: Características das redes simuladas em Londrina e São Carlos

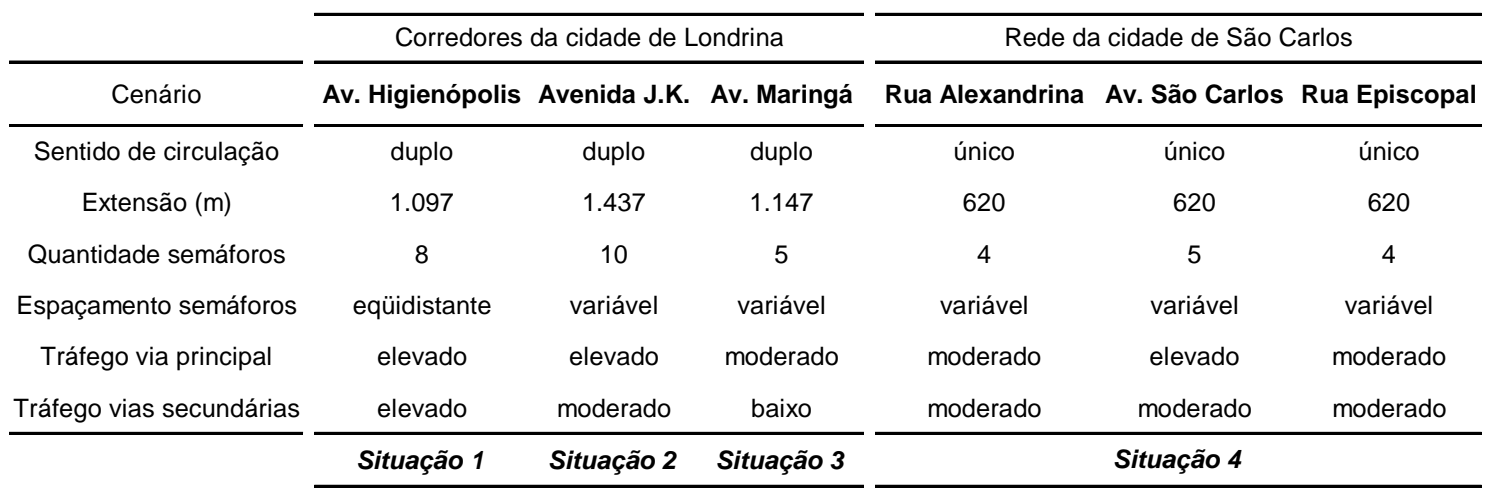

A Tabela 7-16 apresenta os percentuais aproximados obtidos para cada uma das quatro situações simuladas com demandas reais, em comparação com os respectivos cenários que supõem simplesmente a abertura simultânea dos semáforos.

Tabela 7-16: Resumo dos percentuais de redução ou acréscimo nas medidas de desempenho para as demandas reais

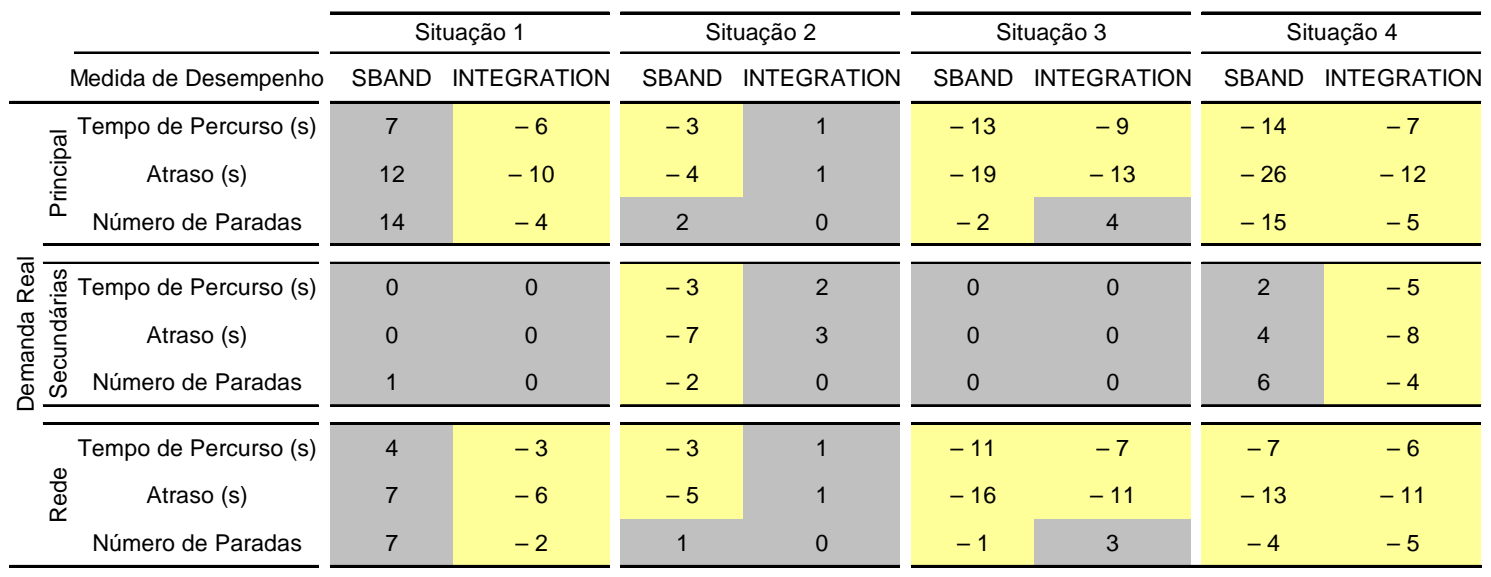

Os percentuais de redução e acréscimo nas medidas de desempenho em cada situação com característica específica de tráfego e de geometria sugerem as seguintes conclusões, baseadas nos melhores resultados obtidos pelos programas SBAND ou INTEGRATION:

- Situação 1 (via principal com duplo sentido e elevado volume de tráfego, assim como nas vias secundárias, contendo várias interseções semaforizadas eqüidistantes): o plano de coordenação semafórica gerado pelo programa INTEGRATION resultou em pequenas reduções nas medidas de desempenho da via principal e da rede, sem proporcionar nenhum benefício ou prejuízo para as vias 
secundárias, enquanto os resultados gerados pelo programa SBAND produziram aumento nas três medidas de desempenho avaliadas, praticamente sem alterações nos resultados das vias secundárias;

- Situação 2 (via principal com duplo sentido e elevado volume de tráfego, contendo várias interseções semaforizadas com distanciamentos distintos, e vias transversais com fluxo moderado): a coordenação proposta pelo programa SBAND apresentou pequenas reduções para as medidas de desempenho da via principal, vias secundárias e para a rede, enquanto o plano de coordenação gerado pelo programa INTEGRATION resultou em pequenos aumentos em todas as medidas de desempenho avaliadas;

- Situação 3 (via principal com duplo sentido e moderado volume de tráfego, contendo poucas interseções semaforizadas com distanciamentos distintos, e vias transversais com fluxo baixo): ambos programas resultaram em reduções nas medidas de desempenho da via principal e para toda a rede, sem proporcionar nenhum benefício ou prejuízo para as vias secundárias, sendo que para a coordenação gerada pelo programa SBAND as reduções foram mais significativas;

- Situação 4 (via principal e vias secundárias com sentido único e moderado volume de tráfego, contendo poucas interseções semaforizadas com distanciamentos distintos): o plano de coordenação gerado pelo programa SBAND apresentou porcentagens significativas de redução nas medidas de desempenho da via principal e da rede, porém promovendo pequenos acréscimos nos valores das medidas das vias secundárias, enquanto a coordenação gerada pelo programa INTEGRATION apresentou menores benefícios para a via principal e rede, mas ainda proporcionou reduções nas medidas de desempenho das vias secundárias.

Além dos volumes de veículos constatados pelas contagens de tráfego realizadas, também reduções de $15 \%$ a $85 \%$ destas quantidades foram simuladas para as avenidas da cidade de Londrina, a fim de avaliar a interferência do fluxo na eficiência de cada forma de coordenação, para o caso de corredores com duplo sentido de circulação. A Tabela 7-17 resume os percentuais aproximados resultantes das simulações dos corredores de Londrina, também em comparação com os respectivos cenários de referência com abertura simultânea dos semáforos. 
Tabela 7-17: Resumo dos percentuais de redução ou acréscimo nas medidas de desempenho para demandas reduzidas

\begin{tabular}{|c|c|c|c|c|c|c|c|}
\hline \multirow{2}{*}{\multicolumn{2}{|c|}{ Medida de Desempenho }} & \multicolumn{2}{|c|}{ Situação 1a } & \multicolumn{2}{|c|}{ Situação 2a } & \multicolumn{2}{|c|}{ Situação 3a } \\
\hline & & SBAND & INTEGRATION & SBAND & INTEGRATION & SBAND & INTEGRATION \\
\hline \multirow{6}{*}{ 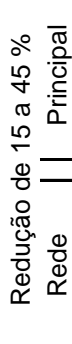 } & Tempo de Percurso (s) & 5 & -6 & -3 & -8 & -19 & -15 \\
\hline & Atraso (s) & 8 & -11 & -5 & -13 & -31 & -24 \\
\hline & Número de Paradas & 15 & -8 & 1 & -8 & -6 & -5 \\
\hline & Tempo de Percurso (s) & 3 & -4 & -2 & -6 & -15 & -12 \\
\hline & Atraso (s) & 5 & -7 & -4 & -10 & -24 & -19 \\
\hline & Número de Paradas & 7 & -4 & 1 & -6 & -4 & -4 \\
\hline & & & ação 1b & Sitl & ação 2b & Sitc & ação 3b \\
\hline ○ $\overline{\widetilde{\sigma}}$ & Tempo de Percurso (s) & -1 & -4 & -6 & -10 & -17 & -14 \\
\hline$\infty \bar{\Phi}$ & Atraso (s) & -4 & -7 & -11 & -17 & -30 & -25 \\
\hline & Número de Paradas & 11 & -6 & -9 & -13 & -5 & -12 \\
\hline & Tempo de Percurso (s) & -1 & -2 & -4 & -7 & -14 & -10 \\
\hline 굼 वृ & Atraso (s) & -3 & -3 & -9 & -13 & -23 & -17 \\
\hline & Número de Paradas & 4 & -3 & -6 & -10 & -3 & -9 \\
\hline
\end{tabular}

Nas condições de demandas reduzidas, os percentuais de redução ou acréscimo nas medidas de desempenho das vias secundárias não são significativos em nenhuma das situações analisadas (inferiores a 5\%). Observando os demais valores obtidos pelos programas SBAND ou INTEGRATION, as seguintes conclusões podem ser constatadas:

- Situação 1a (via principal com duplo sentido e moderado volume de tráfego, assim como nas vias secundárias, contendo várias interseções semaforizadas eqüidistantes): os planos de coordenação semafórica gerados pelo programa INTEGRATION resultam em reduções nas medidas de desempenho da via principal e da rede, enquanto os resultados gerados pelo programa SBAND produziram aumento nas três medidas de desempenho avaliadas;

- Situação 1b (via principal com duplo sentido e baixo volume de tráfego, assim como nas vias secundárias, contendo várias interseções semaforizadas eqüidistantes): os planos de coordenação semafórica gerados pelos dois programas resultam em reduções no tempo de percurso e no atraso da via principal e da rede, mas somente o programa INTEGRATION proporciona reduções no número de paradas;

- Situação 2a (via principal com duplo sentido e moderado volume de tráfego, contendo várias interseções semaforizadas com distanciamentos distintos, e vias 
transversais com fluxo baixo): as coordenações geradas pelo programa INTEGRATION apresentaram reduções significativas nas medidas de desempenho da via principal e da rede, enquanto as defasagens propostas pelo programa SBAND resultaram em pequenas reduções no tempo de percurso e no atraso, mas ocasionando aumento no número de paradas;

- Situação 2b (via principal com duplo sentido e baixo volume de tráfego, contendo várias interseções semaforizadas com distanciamentos distintos, e vias transversais com fluxo baixo): as coordenações geradas pelos dois programas testados apresentaram reduções nas medidas de desempenho da via principal e da rede, sendo mais significativas as reduções obtidas pelos planos do programa INTEGRATION;

- Situações 3a e 3b (via principal com duplo sentido e baixo volume de tráfego, contendo poucas interseções semaforizadas com distanciamentos distintos, e vias transversais com fluxo baixo): ambos programas resultaram em porcentagens significativas de redução nas medidas de desempenho da via principal e para toda a rede, com melhores valores gerados para a coordenação definida pelo programa SBAND.

Por fim, com base no trecho da Avenida Higienópolis (situação 1) que apresenta oito interseções semaforizadas praticamente eqüidistantes com elevado fluxo na via principal e nas transversais, e supondo a situação em que este distanciamento seja tal que os veículos percorram cada quadra na metade da duração do ciclo, as defasagens geradas tanto pelo programa INTEGRATION quanto com o programa SBAND proporcionam melhorias significativas nas medidas de desempenho avaliadas.

Os resultados das simulações demonstram quantitativamente o potencial dos sistemas de progressão pela máxima largura da banda, que apropriadamente coordenados podem reduzir o número de paradas, o tempo de percurso e principalmente o atraso nas interseções semaforizadas. Conforme já havia sido mencionado por Rogness e Messer (1983) e Gartner et al. (1990), os maiores benefícios dos métodos de maximização da banda verde podem ser observados quando a via principal tem predominantemente tráfego de passagem e o número de veículos entrando nesta via é pequeno, ou nos casos de volumes moderados ou baixos, enquanto a coordenação baseada na minimização dos atrasos e paradas demonstra-se mais apropriada para ser utilizada nas situações com elevados volumes de tráfego. Estas limitações corroboram com as constatações sobre a importância de considerar os aspectos dinâmicos do fluxo e sua natureza dependente do tempo nas situações com elevadas demandas. 


\section{CONCLUSÕES E RECOMENDAÇÕES}

Os planos de coordenação semafórica são reconhecidamente eficientes para promover a fluidez das correntes de tráfego e melhorar a qualidade operacional do sistema viário, reduzindo tempos de percurso, atrasos e repetidas paradas, além de prevenir a formação de filas, o desgaste aos veículos e também o consumo excessivo de combustível, preservando o meio ambiente através da mínima poluição atmosférica.

Sendo assim, estabelecer adequadamente estratégias de coordenação semafórica torna-se muitas vezes mais importante do que algumas intervenções físicas, pois sua qualidade pode melhorar o nível de serviço oferecido nas vias, evitando que sejam necessários investimentos significativos das prefeituras, principalmente em obras de adequações de geometria e ampliações das vias. Os técnicos responsáveis pelo gerenciamento semafórico dos municípios devem adotar portanto, métodos para a definição das defasagens adequadas entre interseções consecutivas dos principais corredores arteriais da cidade ou mesmo de uma rede de semáforos, utilizando ferramentas que auxiliem e facilitem nas decisões destas operações coordenadas.

Esta dissertação apresentou definições, benefícios e características das técnicas de coordenação semafórica, através de diversas etapas de pesquisa sobre os métodos existentes e formas de utilização, incluindo ainda o desenvolvimento de uma opção alternativa para obtenção de coordenação. Basicamente o trabalho foi dividido em quatro etapas, as quais possibilitaram um conjunto amplo de conclusões, e que são apresentadas seqüencialmente a seguir, de acordo com a ordem em que foram obtidas:

- Identificação dos métodos e programas de coordenação utilizados pelas prefeituras brasileiras;

- Revisão dos métodos de coordenação semafórica mais conhecidos e citados na bibliografia;

- Desenvolvimento de um aplicativo computacional de coordenação em vias semaforizadas de áreas urbanas, baseado no critério de maximização da banda verde;

- Avaliação da eficiência dos resultados obtidos pelo método de coordenação proposto e pelo método de coordenação baseado no critério de minimização de atrasos e paradas incorporado ao simulador INTEGRATION, quanto às situações 
recomendadas de aplicação, eficiência e facilidade de utilização.

\subsection{Métodos e Programas de Coordenação Utilizados pelas Prefeituras Brasileiras}

Buscando conhecer os métodos de coordenação utilizados pelas prefeituras brasileiras, uma pesquisa foi realizada em 30 cidades das regiões Sul e Sudeste do país (regiões estas que englobam quase $60 \%$ da população brasileira, $77 \%$ da frota registrada no país e ainda contam com cinco das dez mais populosas cidades do Brasil), a respeito das formas de controle e estratégias de gerenciamento do tráfego empregadas. As entrevistas foram feitas por telefone entre os meses de agosto de 2003 e janeiro de 2004, sempre incluindo a capital do estado e pelo menos uma cidade com frota superior a 30.000 veículos, dentre as possibilidades identificadas no site oficial do Departamento Nacional de Trânsito - DENATRAN. Os setores ou órgãos de trânsito dos municípios e seus respectivos contatos foram identificados através de pesquisa dos sites na Internet, e então o técnico responsável pela operação semafórica das cidade era questionado sobre as condições de operação semafórica e os métodos de coordenação adotados.

As sete capitais entrevistadas possuem controle computadorizado de tráfego em área (CTA), com aproximadamente 50\% do total de seus cruzamentos semaforizados controlados por uma ou mais centrais, onde praticamente todas utilizaram o programa TRANSYT pelo menos para a implantação da programação inicial de seus sistemas. Técnicos destas capitais realizam ajustes das programações através de novas simulações ou principalmente por observação das condições do tráfego, pois nem todas as equipes dispõem de dados de contagem volumétrica atualizados para realizar simulações mais próximas à realidade, deixando de fazer uso de todo o potencial disponível do software adquirido. O Diagrama Espaço-Tempo ainda é utilizado por quatro destas capitais para prover coordenação nos corredores semaforizados que não estão nas centrais.

Dos municípios de médio porte selecionados nas regiões Sul e Sudeste, praticamente $40 \%$ têm central semafórica computadorizada, porém somente 30\% destes utilizam software para prover planos de coordenação, ou seja, 13\% das prefeituras das cidades médias entrevistadas. Para os demais corredores semaforizados não monitorados por centrais, os resultados das informações relativas às estratégias semafóricas adotadas demonstram que 27\% dos municípios de porte médio entrevistados utilizam o procedimento manual do Diagrama Espaço-Tempo para definição dos planos de coordenação, 36\% realizam repetidos ajustes locais através da 
observação do tráfego vigente, 14\% utilizam veículos-teste na busca do melhor esquema de operação, enquanto que o restante das cidades entrevistadas (23\%) não adota nenhum esquema de coordenação.

A identificação deste panorama representativo das condições nas prefeituras brasileiras alerta sobre o fato de que apesar de vários softwares estarem disponíveis no mercado, grande parte das cidades de médio porte não fazem uso de programas computacionais para estabelecer formas de coordenação semafórica, tanto no controle das centrais quanto principalmente nos corredores semaforizados em que a coordenação poderia representar melhorias significativas na operação do sistema. As informações obtidas principalmente nas entrevistas com os técnicos responsáveis pelo controle de tráfego dos municípios de médio porte, aparentemente sugerem alguns fatores como causas prováveis da não utilização dos esquemas de coordenação semafórica:

- falta de profissional capacitado para trabalhar somente com a avaliação das questões semafóricas, como a análise da implantação dos equipamentos, suas programações e os possíveis planos de coordenação;

- inexistência de programas específicos para definição dos planos de coordenação semafórica;

- falta de conhecimento mais aprofundado sobre o funcionamento dos programas de coordenação adquiridos, restringindo sua utilização e dificultando a avaliação da eficácia dos planos estabelecidos;

- falta de dados de campo atualizados, principalmente contagens volumétricas, inviabilizando a realização de novas simulações e programações mais condizentes com o tráfego vigente.

\subsection{Revisão Bibliográfica dos Métodos de Coordenação Semafórica}

O diagnóstico sobre a utilização de coordenação semafórica nas prefeituras brasileiras remete à necessidade de aplicativos mais acessíveis, que possam auxiliar na definição dos esquemas de coordenação de uma forma simples e eficiente, impulsionando este trabalho no desenvolvimento de um procedimento computacional que exija relativamente poucos dados de entrada, voltado principalmente à realidade dos municípios de médio porte. Sendo assim, uma revisão bibliográfica detalhada sobre os métodos de coordenação mais conhecidos foi realizada, para identificar as principais técnicas e programas de coordenação existentes, e servindo posteriormente de subsídio na elaboração de um programa próprio de coordenação em vias semaforizadas de áreas 
urbanas.

De forma geral, os programas que geram as defasagens entre semáforos de vias arteriais ou redes mais citados na bibliografia nos últimos 40 anos, seguem três abordagens distintas:

- Maximização da largura da banda verde de progressão: estes métodos consistem em definir as defasagens entre os semáforos consecutivos, de forma a criar um efeito de “onda verde” ao longo do corredor, e são baseados principalmente no algoritmo proposto por Little, no desenvolvimento das programações Half-Integer Synchronization e Mixed-Integer Linear;

- Minimização dos atrasos e paradas: estes métodos consistem em definir os instantes de abertura dos semáforos de forma a minimizar uma combinação entre o número de paradas e atrasos sofridos pelos veículos, e são baseados na avaliação do índice de performance $P I$;

- Combinação de maximização da banda verde e minimização de atrasos e paradas: os métodos combinados reúnem de maneira seqüencial ou simultânea, as vantagens de ambos os métodos citados, através de implementações computacionais que utilizam as características dos métodos baseados no algoritmo de Little e no índice $P I$.

Dentre os métodos mencionados, a maximização da banda verde é normalmente preferida pelos engenheiros de tráfego, pois possibilita a visualização prévia da largura da banda obtida através de diagramas Espaço-Tempo, e a qualidade desta progressão também é facilmente percebida pelos motoristas. Os métodos analíticos de maximização da banda verde mais conhecidos foram desenvolvidos praticamente como uma extensão dos métodos manuais, inicialmente com o programa Half-Integer Synchronization descrito por Morgan e Little em 1964 para a obtenção das defasagens que geram as maiores bandas bidirecionais possíveis entre semáforos de duas fases, e posteriormente com o programa Mixed-Integer Linear para coordenação de redes semaforizadas apresentado por Little em 1966.

As referências existentes descrevem implementações computacionais dos métodos mencionados (Half-Integer Synchronization e Mixed-Integer Linear, no caso da maximização de banda verde, ou minimização da função de atrasos e paradas, no caso do método homônimo). Porém, devido à falta de acesso aos programas disponíveis, não foi possível testá-los diretamente em situações reais como os corredores selecionados nas cidades de Londrina e São Carlos. Sendo assim, este trabalho 
apresenta uma revisão bibliográfica sobre coordenação semafórica, que pode subsidiar a elaboração de novas pesquisas sobre o assunto, bem como o desenvolvimento de aplicativos computacionais para definição de planos coordenados.

\subsection{Desenvolvimento de um Aplicativo Computacional de Coordenação Semafórica}

Considerando a dificuldade de acesso a programas de coordenação, um procedimento computacional denominado SBAND foi criado por Demarchi (2004) e descrito por Demarchi e Dutra (2004a e 2004b), para definir o conjunto de defasagens ótimas baseado no método de maximização da largura de banda verde originalmente desenvolvido por Morgan e Little (1964), como uma opção alternativa à não disponibilidade de um programa similar.

O programa SBAND não apresenta complexidade de utilização nem requer grande esforço de aprendizado por parte de analistas e operadores, necessitando somente do espaçamento entre os semáforos, as velocidades de progressão do tráfego, o ciclo e as proporções dos tempos de verde/vermelho, para gerar através de interações computacionais as defasagens apropriadas para a operação coordenada de corredores com duplo sentido de tráfego. Também pode ser aplicado em vias com sentido único de circulação, considerando nesse caso que toda a banda disponível deve ser alocada em um sentido. A velocidade de progressão pode ser diferente em cada sentido, assim como uma porcentagem maior da largura da banda verde pode ser atribuída para privilegiar o sentido com maior volume de tráfego.

\subsection{Avaliação da Eficiência dos Programas SBAND e INTEGRATION}

No intuito de testar a eficiência dos programas SBAND (baseado no critério de maximização da banda verde) e INTEGRATION (baseado na minimização de atrasos e paradas), e verificar os limites de aplicação efetiva de cada método, o programa INTEGRATION foi utilizado para simular diversas condições de tráfego e geometria viária, a fim de gerar as medidas de desempenho para comparação das soluções obtidas. Para isto, três avenidas com duplo sentido de circulação e diferentes características foram selecionadas na cidade de Londrina, e uma rede composta por três corredores com sentido único de circulação foi escolhida na cidade de São Carlos.

Diversos cenários foram simulados para estas quatro situações, considerando inicialmente a suposição de abertura simultânea dos tempos de verde dos semáforos, assim como a programação semafórica vigente identificada in loco e várias 
possibilidades de coordenação geradas pelos programa INTEGRATION e SBAND. A avaliação dos resultados gerados em cada situação selecionada e cenários simulados foi realizada através da comparação de três medidas operacionais de eficiência - tempo de percurso, atraso e número de paradas - considerando os valores médios por veículo para as vias principais, secundárias e para toda a rede, de forma que os benefícios ou prejuízos provocados por cada programação pudesse ser observado separadamente. Todas as situações foram comparadas ao respectivo cenário simultâneo, considerado como a forma mais simples de coordenação semafórica a ser adotada.

Para coordenação de avenidas com duplo sentido e tráfego preferencial na via principal, o programa de coordenação SBAND apresentou reduções entre 3\% e 5\% no tempo de percurso e atrasos para os corredores contendo elevado volume e várias interseções semaforizadas (acima de 5 semáforos) com distanciamentos distintos, e 11\% a 19\% para corredores com tráfego moderado e até 5 cruzamentos semaforizados. Porém estes benefícios não foram observados no caso de volume de tráfego elevado ou moderado nas vias principal e secundárias, onde a coordenação obtida através do programa SBAND gerou acréscimos de 5\% a 15\% nas medidas de desempenho da via principal e $3 \%$ a $7 \%$ na rede.

O programa INTEGRATION proporcionou para o caso de avenidas com duplo sentido e elevado volume de tráfego, tanto na via principal como nas vias secundárias, reduções entre $2 \%$ e $10 \%$ nas medidas de desempenho da via principal e da rede, e reduções entre $4 \%$ e $11 \%$ nos casos com fluxo de tráfego moderado na rede e mais de 5 cruzamentos semaforizados ao longo da via principal. Mas para a situação em que a via principal apresenta várias interseções semaforizadas e elevado tráfego de passagem, o plano coordenado gerado pelo programa INTEGRATION resultou em pequenos acréscimos de $1 \%$ nas medidas de desempenho da via principal e da rede, além de $2 \%$ a 3\% para as vias secundárias.

Em condições de volume baixo e até 5 semáforos ao longo da via principal com duplo sentido de tráfego, o programa SBAND apresentou reduções de até 19\% no tempo de percurso, $31 \%$ no atraso e $6 \%$ no número de paradas, enquanto com o programa INTEGRATION as reduções atingem 10\% no tempo de percurso, $17 \%$ no atraso e $13 \%$ no número de paradas para os casos com volume baixo e mais de 5 semáforos na avenida principal.

Em vias com sentido único de circulação, o programa INTEGRATION gerou reduções entre $5 \%$ e $12 \%$ nas medidas de desempenho da via principal e da rede, 
proporcionando ainda de $4 \%$ a $8 \%$ de redução para as vias secundárias. Caso o tráfego da via principal precise ser privilegiado, o programa SBAND pode ser utilizado para prover o plano de coordenação, pois os resultados das simulações indicaram 14\% a 26\% de redução nas medidas de desempenho para o corredor principal e $4 \%$ a $13 \%$ para a rede, mas com acréscimo de $2 \%$ a $6 \%$ para as vias transversais.

A análise destes resultados sugere as condições para as quais recomenda-se a utilização do programa SBAND ou do programa INTEGRATION para definição do plano de coordenação a ser adotado, em função das características das vias, conforme esquematizado na Tabela 8-1.

Tabela 8-1: Programa de coordenação recomendado de acordo com as características das vias

\begin{tabular}{|c|c|c|c|}
\hline \multicolumn{2}{|c|}{ Condição do Tráfego } & \multicolumn{2}{|c|}{ Programa sugerido para o Corredor Principal } \\
\hline Via Principal & Vias Secundárias & Via de duplo sentido & Via de sentido único* \\
\hline elevado & elevado & INTEGRATION** & - \\
\hline elevado & moderado & SBAND & - \\
\hline moderado & moderado & INTEGRATION** & INTEGRATION \\
\hline moderado & baixo & $\begin{array}{l}\text { SBAND (até } 5 \text { semáforos) } \\
\text { INTEGRATION (acima } 5 \text { semáforos) }\end{array}$ & SBAND \\
\hline baixo & baixo & $\begin{array}{l}\text { SBAND (até } 5 \text { semáforos) } \\
\text { INTEGRATION (acima } 5 \text { semáforos) }\end{array}$ & - \\
\hline
\end{tabular}

* as situações sem sugestão correspondem aos cenários não testados.

** o programa SBAND também é recomendado para o caso de distância entre os semáforos percorrida na metade do ciclo.

Considerando os resultados das 230 simulações realizadas para cenários distintos em vias com duplo sentido ou mão única de circulação, os valores das medidas de desempenho avaliadas (tempo de percurso, atraso e número de paradas) indicam maiores benefícios com a utilização do programa INTEGRATION - baseado na minimização de atrasos e paradas - para situações em que o volume de tráfego na via principal e nas vias secundárias é semelhante, principalmente para os casos com mais de 5 semáforos ao longo do corredor principal.

Os planos de coordenação gerados pelo programa SBAND - baseado na maximização de banda verde - são recomendados para as situações em que o tráfego de passagem na via principal é maior do que os volumes das vias secundárias, ou para redes com baixo fluxo de veículos e até 5 interseções semaforizadas. O programa SBAND pode ser utilizado ainda nas situações com elevado volume de tráfego tanto na via principal quanto nas secundárias, onde haja espaçamento praticamente eqüidistante 
entre as interseções, especialmente no caso em que a distância entre elas seja percorrida na metade da duração do ciclo. A dificuldade de coordenação é maior à medida que o espaçamento entre interseções diminui, se afastando da situação ideal de distância percorrida na metade da duração do ciclo.

Vale salientar que o programa SBAND apresenta a vantagem de proporcionar em pouco tempo, especialmente para as situações com tráfego preferencial de passagem nos corredores arteriais, propostas de planos similares ou mais eficientes do que aqueles obtidos por tentativa e erro, evitando sucessivos ajustes nas programações semafóricas e interferências diretas no tráfego.

\subsection{Recomendações}

A característica básica dos métodos de maximização da banda verde é que oferecem controle de tráfego provendo movimento agrupado e contínuo dos veículos através de semáforos sucessivos, considerando pelotão uniforme. Porém, os volumes de tráfego variam ao longo das vias devido ao tráfego de entrada e saída em cada interseção, assim como o tamanho do pelotão, portanto a largura da banda definida somente através do volume médio do movimento direto pode causar desperdício em interseções com baixo volume direto ou ser deficiente em interseções com alto volume.

Embora o programa SBAND também seja baseado no critério de banda de progressão, que não depende do fluxo atual nos tramos das vias analisadas, sendo insensível às suas variações dos fluxos, seus resultados de coordenação semafórica já demonstram melhorias significativas nas medidas de desempenho em vias arteriais, para condições específicas de tráfego e de características geométricas.

Estes resultados indicam que, mesmo que o programa SBAND não possa no estágio atual de desenvolvimento, ser utilizado para determinar bandas com largura variável e proporcional ao volume de tráfego nos diferentes segmentos de via, ele representa o ponto de partida para o desenvolvimento de uma rotina mais sofisticada que seja comparável aos programas de coordenação existentes no exterior. Novas rotinas podem ser elaboradas no futuro para automatizar o processo de escolha dos parâmetros utilizados no programa SBAND, tais como velocidade e ciclo (dentro de limites pré-estabelecidos em função dos volumes), além da aplicação em operações com múltiplas fases, na busca da solução com maiores larguras de banda.

Seria recomendável também, como continuidade das pesquisas sobre a eficiência dos programas SBAND e INTEGRATION, realizar simulações que 
comparassem estes programas em diferentes condições de ciclo e divisões dos tempos de verde e vermelho, visto que por motivo de simplificação os cenários avaliados com reduções de volumes de tráfego foram simulados sem otimização de suas programações.

Vale ressaltar também que, em razão da limitação de recursos e de tempo, não foi possível realizar coletas de dados para uma calibração mais efetiva do simulador INTEGRATION, em especial no que se refere aos parâmetros da relação fluxovelocidade, a composição da frota e as características dos veículos. Seria desejável a obtenção in loco de dados para calibração destes parâmetros, de tal forma a garantir uma maior precisão aos resultados desta pesquisa. Também a utilização de veículos equivalentes nas matrizes origem-destino das redes simuladas, ao invés da consideração de veículos desagregados por categorias (automóvel, ônibus e caminhões) pode ter interferido nos resultados. Esta questão pode ser verificada através da realização das simulações utilizando matrizes O-D desagregadas por tipo de veículo.

O programa de coordenação SBAND pode ser considerado como uma maneira alternativa e simplificada para obtenção da estratégia de coordenação semafórica offline, principalmente para municípios de pequeno e médio porte, podendo nestes casos substituir os métodos manuais de tentativa e erro ou os procedimentos de ajustes locais que demandam tempo e esforços repetitivos, ainda amplamente utilizados pelas prefeituras. Devido à sua facilidade de utilização e eficiência de aplicação em algumas condições específicas, os planos de coordenação gerados pelo programa SBAND poderão contribuir com o trabalho de analistas e operadores de tráfego da cidade de Londrina, sobretudo para os benefícios já identificados nos resultados dos cenários simulados, assim como para outros técnicos envolvidos com a busca da melhoria na qualidade operacional das vias urbanas nas cidades brasileiras. 


\section{REFERÊNCIAS BIBLIOGRÁFICAS}

Abu-Lebdeh, G.; Benekohal, R.F. (1997) Development of Traffic Control and Queue Management Procedures for Oversaturated Arterials. Transportation Research Record, 160, p.119-127.

Bavarez, E.; Newell, G.F. (1967) Traffic Signal Synchronization on a One-Way Street. Transportation Science, v.1, n.2, p.55-73.

Bleyl, R.L.; (1967) A Practical Computer Program for Designing Traffic-Signal-System Timing Plans. Highway Research Record, 211, p.19-33.

Chang, E.C.P.; Messer, C.J. (1985) Minimum Delay Optimization of a Maximum Bandwidth Solution to Arterial Signal Timing. Transportation Research Record, 1005, p.89-95.

Chang, E.C.P.; Messer, C.J.; Cohen, S.L. (1986) Directional Weighting for Maximal Bandwidth Arterial Signal Optimization Programs. Transportation Research Record, 1057, p.10-19.

Cohen, S.L. (1983) Concurrent Use of MAXBAND and TRANSYT Signal Timing Programs for Arterial Signal Optimization. Transportation Research Record, 906, p.81-84.

Cohen, S.L.; Liu, C.C. (1986) The Bandwidth-Constrained TRANSYT Signal - Optimization Program. Transportation Research Record, 1057, p.1-9.

Colella, D.A.T. (2004) Calibração e Validação da Relação Fluxo-Velocidade para Vias Urbanas Utilizando Comparação de Tempos de Viagem. Monografia de conclusão de curso, Departamento de Engenharia Civil, Universidade Estadual de Maringá - DEC - UEM, 59 p.

Colella, D.A.T; Lima, E.P.; Demarchi, S.H. (2004) Calibração e Validação do Modelo Fluxo-Velocidade do INTEGRATION para Vias Urbanas Semaforizadas. Anais do XVIII Congresso de Pesquisa e Ensino em Transportes, Associação Nacional de Pesquisa e Ensino em Transportes, Florianópolis, SC, v.1, p.453-464.

Demarchi, S.H. (2000) Influência dos Veículos Pesados na Capacidade e Nível de Serviço de Rodovias de Pista Dupla. Tese (Doutorado), Escola de Engenharia de São Carlos, USP. São Carlos, SP, 166 p.

Demarchi, S.H. (2004) SBAND - Programa para Coordenação Semafórica de Vias Arteriais.

Demarchi, S.H.; Bertoncini, B.V. (2004) Determinação de Matrizes O-D Sintéticas a Partir de Contagens Volumétricas. Anais do XVIII Congresso de Pesquisa e Ensino em Transportes. Associação Nacional de Pesquisa e Ensino em Transportes, Florianópolis, SC, v.2, p.832-843.

Demarchi, S.H.; Bertoncini, B.V.; Lima, E.P. (2004) Estimativa de uma Matriz O-D Sintética para a Região Central de Maringá Utilizando o QUEENSOD. Anais do XVIII Congresso de Pesquisa e Ensino em Transportes, Associação Nacional de Pesquisa e Ensino em Transportes, Florianópolis, SC, v.2, 
p.844-855.

Demarchi, S.H.; Colella, D.A.T.; Bertoncini, B.V. (2003) Determinação da Densidade de Congestionamento em Filas de Interseções Semaforizadas. Anais do XVII Congresso de Pesquisa e Ensino em Transportes. Associação Nacional de Pesquisa e Ensino em Transportes, Rio de Janeiro, RJ, v.1, p.476-488.

Demarchi, S.H.; Dutra, C.B. (2004a) Coordenação Semafórica Através do Método de Maximização da Banda Verde. Anais do XVIII Congresso de Pesquisa e Ensino em Transportes, Associação Nacional de Pesquisa e Ensino em Transportes, Florianópolis, SC, v.1, p.503-514.

Demarchi, S.H.; Dutra, C.B. (2004b) SBAND: Implementação em Planilha Eletrônica de um Método para Maximização da Banda Verde em Vias Semaforizadas. Anais do XVIII Congresso de Pesquisa e Ensino em Transportes, Associação Nacional de Pesquisa e Ensino em Transportes, Florianópolis, SC. (meio digital).

DENATRAN (1984) Manual de Semáforos. Coleção Serviços de Engenharia, 2ª Edição. Brasília.

DENATRAN (2003) Frota de veículos por estado em junho de 2003. Disponível em http://www.denatran.gov.br. Acessado em 25/08/2003.

Ferraz, A.C.P.; Fortes, F.Q.; Simões, F.A. (1999) Engenharia de Tráfego Urbano - Fundamentos Práticos. São Carlos, EESC.

Gartner, N.H.; Assmann, S.F.; Lasaga, F.; Hou, D.L. (1990) MULTIBAND: A Variable - Bandwidth Arterial Progression Scheme. Transportation Research Record, 1287, p.212-222.

Gartner, N.H.; Little, J.D.C.; Gabbay, H. (1975) Optimization of Traffic Signal Settings by MixedInterger Linear Programming. Transportation Science, v.9, n.4, parte I, p.321-343 e parte II, p.344-363.

Green, F.B.; Robertson, D.I. (1974) Traffic Signal Control Using Cableless Linking - the A4 Experiment. Traffic Engineering and Control, v.9, p.547-551.

Hale, D.K. (2005) McTrans Center - University of Florida. Comunicação Pessoal.

Homburger, W.S.; Kell, J.H.; Perkins, D.D. (1992) Fundamentals of Traffic Engineering. Institute of Transportation Studies. University of California at Berkeley. $13^{\text {th }}$ Edition.

ITE - Institute of Transportation Engineers (1992) Traffic Engineering Handbook, $4^{\text {th }}$ Edition.

Lan, C.J.; Messer, C.J.; Chaudhary, N.A.; Chang, E.C.P. (1992) Compromise Approach to Optimize Traffic Signal Coordination Problems During Unsaturated Conditions. Transportation Research Record, 1360, p.112-119.

Lieberman, E.B.; Woo, J.L. (1976) SIGOP II: A New Computer Program for Calculating Optimal Signal Timing Patterns. Transportation Research Record, 596, p.16-21.

Little, J.D.C. (1966) The Synchronization of Traffic Signals by Mixed - Integer Linear Programming. 
Operations Research, v.14, n.4, p.568-593.

Little, J.D.C.; Kelson, M.D.; Gartner, N.H. (1981) MAXBAND: A Program for Setting Signals on Arteries and Triangular Networks. Transportation Research Record, 795, p.40-46.

Little, J.D.C.; Martin, B.V.; Morgan, J.T. (1966) Synchronizing Traffic Signals for Maximal Bandwidth. Highway Research Record, 1340, n.118, p.21-47.

Loureiro et al. (2005) Avaliação da Adequabilidade do HCM2000 na Análise de Capacidade e Nivel de Serviço de Vias Arteriais Urbanas Brasileiras. Relatório final de atividades, RedeTráfego.

Loureiro, C.F.G.; Paiva Neto, P.M.; Castro Neto, M.M. (2003b) Progressão em Tempo Real Versus Tempo Fixo por Banda de Passagem em Períodos de Baixa Demanda - Estudo de Caso. Anais do XVII Congresso de Pesquisa e Ensino em Transportes, ANPET, Rio de Janeiro, RJ (meio magnético).

Loureiro, C.F.G.; Pereira Neto, W.A.; Oliveira Neto, F.M. (2003a) Avaliação do Desempenho Operacional em Períodos de Pico do Controle Semafórico em Tempo Real nos Corredores Arteriais de Fortaleza. Anais do XVII Congresso de Pesquisa e Ensino em Transportes, ANPET, Rio de Janeiro, RJ (meio magnético).

Magalhães, D.J.A.V. (1981) Sincronização de Semáforos em um Corredor Urbano: Desenvolvimento de um Modelo Simplificado. Dissertação (Mestrado), Instituto Militar de Engenharia, Rio de Janeiro, 223 p.

Messer, C.J.; Whitson, R.H.; Dudek, C.L.; Romano, E.J. (1973) A Variable - Sequence Multiphase Progression Optimization Program. Highway Research Record, 445, p.24-33.

Morgan, J.T.; Little, J.D.C. (1964) Synchronizing Traffic Signals for Maximal Bandwidth. Operations Research, v.12, n.6, p.896-912.

PlanetaGeo (2003) Mapa da população do Brasil. Disponível em http://planetageo.sites.uol.com.br/ brpopula.htm. Acessado em 12/08/2003.

Rakha, H. (2004) INTEGRATION Release 2.30 for Windows: User's Guide. Vol. I e II. Michel Van Aerde and Associates, Ltd. Kingston, Ontario, Canada.

Rakha, H.; Van Aerde, M. (1996) Comparison of Simulation Modules of TRANSYT and INTEGRATION Models. Transportation Research Record, 1566, p.1-7.

Robertson, D.I. (1997) The TRANSYT Method of Co-ordinating Traffic Signals. Traffic Engineering and Control, p.76-77.

Robertson, D.I.; Lucas, C.F.; Baker, R.T. (1980) Coordinating Traffic Signals to Reduce Fuel Consumption. Transport and Road Research Laboratory, 934.

Roess, R.P.; Mc Shane, W.R.; Prassas, E.S. (1998) Traffic Engineering. Second Edition. Prentice Hall. New Jersey.

Rogness, R.O.; Messer, C.J. (1983) Heuristic Programming Approach to Arterial Signal Timing. 
Transportation Research Record, 906, p.67-75.

Site da Prefeitura de Fortaleza (2004) Disponível em http://www.fortaleza.ce.gov.br. Acessado em 25/02/2004.

Site da Prefeitura de Londrina (2005) Disponível em http://www.londrina.pr.gov.br. Acessado em 02/05/2005.

Site da Prefeitura de São Carlos (2005) Disponível em http://www.saocarlos.sp.gov.br. Acessado em 02/05/2005.

Skabardonis, A.; Bertini, R.L.; Gallagher, B.R. (1998) Development and Application of Control Strategies for Signalized Intersections in Coordinated Systems. Transportation Research Record, 1634, p.110-117.

Sripathi, H.K.; Gartner, N.H.; Stamatiadis, C. (1995) Uniform and Variable Bandwidth Arterial Progression Schemes. Transportation Research Record, 1494, p.135-145.

Stamatiadis, C.; Gartner, N.H. (1996) MULTIBAND - 96: A Program for Variable - Bandwidth Progression Optimization of Multiarterial Traffic Networks. Transportation Research Record, 1554, p.917.

TRL Software Bureau (2005) Disponível em http://www.trlsoftware.co.uk. Acessado em 12/02/2005.

Tsay, H.S.; Lin, L.T. (1988) New Algorithm for Solving the Maximum Progression Bandwidth. Transportation Research Record, 1194, p.15-30.

Van Aerde, M. (1998) QUEENSOD Release 2.10 - User's Guide: Estimating Origin Destination Traffic Demands from Link Flow Counts. Michel Van Aerde and Associates, Blacksburg, VA.

Wallace, C.E.; Courage, K.G. (1982) Arterial Progression - New Design Approach. Transportation Research Record, 881, p.53-59.

Webster, F.V.; Cobbe, B.M. (1966) Traffic Signals. Road Research Technical Paper n.56. Road Research Laboratory - Ministry of Transport, London, England. 